\title{
Conspiracy and the Logic of Capital
}

\author{
by
}

Ian Nagy

B.A. [Hons.] Simon Fraser University (1993)

M.A. Simon Fraser University (1997)

\author{
A thesis submitted to \\ the Faculty of Graduate Studies and Research \\ in partial fulfilment of \\ the requirements for the degree of
}

Doctor of Philosophy

School of Journalism and Communication

Faculty of Public Affairs and Management

\author{
Carleton University \\ Ottawa, Ontario \\ January 31, 2006 \\ (C) Ian Nagy 2006
}




$\begin{array}{ll}\begin{array}{l}\text { Library and } \\ \text { Archives Canada }\end{array} & \begin{array}{l}\text { Bibliothèque et } \\ \text { Archives Canada }\end{array} \\ \begin{array}{l}\text { Published Heritage } \\ \text { Branch }\end{array} & \begin{array}{l}\text { Direction du } \\ \text { Patrimoine de l'édition }\end{array} \\ \begin{array}{l}\text { 395 Wellington Street } \\ \text { Ottawa ON K1A 0N4 } \\ \text { Canada }\end{array} & \begin{array}{l}\text { 395, rue Wellington } \\ \text { Ottawa ON K1A ON4 } \\ \text { Canada }\end{array}\end{array}$

Your file Votre référence ISBN: 978-0-494-18227-7 Our file Notre référence ISBN: 978-0-494-18227-7

NOTICE:

The author has granted a nonexclusive license allowing Library and Archives Canada to reproduce, publish, archive, preserve, conserve, communicate to the public by telecommunication or on the Internet, loan, distribute and sell theses worldwide, for commercial or noncommercial purposes, in microform, paper, electronic and/or any other formats.

The author retains copyright ownership and moral rights in this thesis. Neither the thesis nor substantial extracts from it may be printed or otherwise reproduced without the author's permission.
AVIS:

L'auteur a accordé une licence non exclusive permettant à la Bibliothèque et Archives Canada de reproduire, publier, archiver, sauvegarder, conserver, transmettre au public par télécommunication ou par l'Internet, prêter, distribuer et vendre des thèses partout dans le monde, à des fins commerciales ou autres, sur support microforme, papier, électronique et/ou autres formats.

L'auteur conserve la propriété du droit d'auteur et des droits moraux qui protège cette thèse. $\mathrm{Ni}$ la thèse ni des extraits substantiels de celle-ci ne doivent être imprimés ou autrement reproduits sans son autorisation.
In compliance with the Canadian

Privacy Act some supporting forms may have been removed from this thesis.

While these forms may be included in the document page count, their removal does not represent any loss of content from the thesis.
Conformément à la loi canadienne sur la protection de la vie privée, quelques formulaires secondaires ont été enlevés de cette thèse.

Bien que ces formulaires aient inclus dans la pagination, il n'y aura aucun contenu manquant.

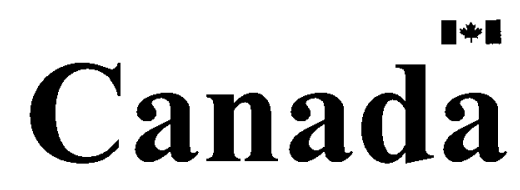




\begin{abstract}
This thesis draws on Mikhail Bakhtin's description of the carnival in order to frame conspiracy theory as an epistemological category. It positions conspiracy theories as a carnivalesque form of discourse, and demonstrates how to understand them as ideological optics on the dialectics of representation and reality. It does so, in part, by tracing the mainstream news coverage of the invasion of Iraq around the notion of conspiracy theory, as deployed by the Bush Administration, and follows this development as it happened. It shows that not only was the charge of 'conspiracy theory' a major element in the unfolding of the current conflict in Iraq, but also, that it is effectively impossible to understand this conflict without reference to many competing conspiracy theories. These include the belief in a Western/Zionist conspiracy against Islam, the perceived role of Saddam Hussein in the affairs of global terror, and the widely held feeling that the invasion was 'all about oil'.
\end{abstract}

One of the main themes is that the study of conspiracy theories has been largely relegated to conspiracy theorists. With a few notable exceptions, this has precluded serious academic study of the topic as a general representational practice. One of the objectives is to reflect on the role of conspiracy thinking in the aftermath of the $9 / 11$ attacks. While not fashioning conspiracy theories as causal explanations for world affairs, the belief in them can nonetheless become a material force in historical events. In this way they act as a 'mediating plane of appearances' in the face of geopolitical, economic, and religious frictions.

The thesis approaches conspiracy theories not so much as a marginal form of discourse, but as quasi-oral histories, and as such a medium of communication. As with other media, conspiracy theories convey certain aspects of experience quite well, while shielding or completely missing others. The carnival focus gets behind conspiracy/theory in order to draw on many different areas as a basis for a new synthesis. The thesis concludes by demonstrating how useful and effective a focus on conspiracy theories can be as an analytical tool, especially in the topsy-turvy wake of 9/11. 


\section{Acknowledgments}

As is always the case in circumstances like this, there are so many people to thank. Going back to the beginning, Gary McCarron, Lynne Hissey, and Richard Gruneau at Simon Fraser University were all indispensable to my critical awakening so-to-speak. I owe special thanks to Chris Dornan at Carleton University whose unwavering support from the very start of this project helped to sustain it, and to Paul Attallah and Michael Dorland for coming on board so relatively late in the process to help make it a success. Carole Craswell was always there on the other end of my sometimes frantic emails, and came through time and time again with exactly what I needed to know.

I would also like to thank John B. Thompson, Naomi Wolf, Mark Kingwell, Alasdair Spark, Terry Eagleton, and Jack Bratich, all of whom provided advice, assistance, and/or support which proved to be invaluable to the completion of this thesis. I individually thank all of you in different (but mostly unspoken) ways in the following pages.

I owe a debt of gratitude to Vincent Mosco for generously reading and commenting on draft chapters. The perspective I gained as a result was very important to my understanding of the questions I was asking in the first place. On top of this, I owe my consideration of conspiracy theories as a medium of communication directly to a comment during my second comprehensive exam from Professor Mosco. That, together with a suggestion from Professor Dornan that I "might be able to do something with Guy Fawkes Day", - combined to form the bicameral spark of the carnival focus I would bring to my studies in the School of Journalism and Communication.

No thesis gets written without collaborative interaction with one's colleagues. Chris Bodnar and Enda Brophy were but two of the many indefatigably loyal friends I would not have wanted to have gone though this without. Thanks. Omar Khan gave me informed feedback on chapter 4 , over and above countless digressions among and between the cubicles of office space. From Omar I learned that there will always be more to understand about history, and I tried to remember that as I wrote any of the forward-looking passages here, not to mention those which look back. Erin Reid and Lorraine Bruce schooled me many a time on the mitigating contingencies of philosophy, and it all started 'that night in Toronto'.

I thank my family for all the support and encouragement that only the long walk of family can ever provide. And my special thanks to Leigh. Easter in New York will forever have meaning. I cherish the photo.

Of course, and despite the heartfelt thanks, I claim and acknowledge any and all errors or omissions as my own. 


\section{Table of Contents}

\section{Introduction}

Background to the Project $\quad$ ix

Dissertation Overview $\quad$ xx

Conspiracy Theory as a Communicational Concept $\quad$ xxv

Chapter One - 'By Wicked and Artful Men': Faith and Suspicion in an Age of Empire

1

Conspiracy Theory and the Politics of Conservatism 6

'Bring 'em On': George W. Bush and the Paranoid Style 11

Conspiracy Theory and Anti-Catholicism $\quad 14$

The Paranoid Style and the Religious Right $\quad 17$

Bedouin Trade and the Rise of Islam $\quad 22$

Globalism and the British Empire $\quad 24$

Labor, Liberty, and the Pursuit of Happiness $\quad 27$

Protestant Patriotism and the Politics of Paranoia 31

Evangelical Imperialism and the Old World Order 38

Out of Africa on the Orient Express 44

Faith and Suspicion in and Age of Empire 53

Chapter Two - Conspiracy Theory and the Politics of Carnival 59

From Carnival to Transgression $\quad 64$

Bakhtin and the 'Carnivalization' of Experience 66

Carnival, Conspiracy Theory, and Communication $\quad 74$

Conspiracy Theory and the Body Politic 79

In the Beginning: Symbolic Inversion in Religion and Classical Thought 85

Turning the World Upside Down $\quad 88$

Inversion and Conspiracy Theory in the Reformation 91

Chapter Three - Conspiracy Theory and the Political Economy of Meaning 95

Conspiracy Theory and the Dialectical Imagination $\quad 98$

Ideology 104

Language, Meaning, and Ideology 117

Hegemony 126

$\begin{array}{ll}\text { Structuration } & 131\end{array}$ 
Conspiracy Theory in Hollywood Film 134

The Cold War and the International Communist Conspiracy 135

The Post-Vietnam, Post-Watergate Era 137

The Contemporary Period $\quad 140$

Conspiracy Theory 145

Conspiracy Theory in Popular Culture $\quad 147$

Conspiracy Theory, Hegemony, and Ideology? 157

Chapter Four - The Paranoid Style in Middle East Politics 162

The Zionists, the Oil Companies, and Washington 176

Israel $\quad 184$

Iran 184

From Vietnam to the Middle East Oil Embargo 185

The Carter Doctrine $\quad 188$

Marx and Engels on Islam $\quad 191$

Osama bin Laden and the Paranoid Style 192

The Paranoid Style, the Protestant Ethic, and the Spirit of Capitalism 198

Onward Christian Soldiers $\quad 206$

$\begin{array}{ll}\text { George W. Christ? } & 221\end{array}$

$\begin{array}{lr}\text { Chapter Five - Sixteen Little Words } & 227\end{array}$

Parsing Paranoia $\quad 237$

Conspiracy Theory, 9/11, and the Global War on Terrorism 240

Blood and Oil: Iraq and Petro-Politics 246

Saudi Arabia and the Path to 9/11 252

9/11 Conspiracy Theories $\quad 257$

Conspiracy Theory and Collective Memory $\quad 267$

$\begin{array}{ll}\text { Conspiracy Theory as Conceptual Tool } & 274\end{array}$

Chapter Six - Smoking Guns and Mushroom Clouds 276

$\begin{array}{ll}\text { Conspiracy/Theory } & 312\end{array}$

Chapter Seven - Legitimating the Looney Left 327

Conspiracy Theory and Capitalist Crises $\quad 335$

Euro vs. U.S. Dollar $\quad 347$

'Things Related and Not' $\quad 350$ 
Chapter Eight - Conclusion: 'Remember, remember the fifth of November' 358

$\begin{array}{ll}\text { Conspiracy Theory and the Materiality of Meaning } & 370\end{array}$

Philosophy in a Time of Terror $\quad 376$

9/11 and the Neoconservative Agenda $\quad 380$

Leo Strauss and the Religious Right $\quad 388$

Conspiracy and the Logic of Capital 392

$\begin{array}{ll}\text { Bibliography } & 407\end{array}$ 
"We must speak the truth about terror. Let us never tolerate outrageous conspiracy theories concerning the attacks of September the $11^{\text {th }}$; malicious lies that attempt to shift the blame away from the terrorists, themselves, away from the guilty."

-George W. Bush-

United Nations General Assembly, November 10, 2001

"I conclude, therefore, that a prince should not be too concerned with conspiracies when the people are well disposed towards him; but when the populace is hostile and regards him with hatred, he must fear everything and everyone."

-Niccolò Machiavelli-

The Prince, 1513

vii 
For Lynne Hissey 
Even into my early-20s, I wanted to believe in anti-gravity flying machines. Though I had already long abandoned the belief in UFOs to childhood, and had never believed in aliens, I remained convinced that there was a secret which would one day be revealed. After all, I had been assured by a number of the programs I had watched on the subject that there were many previously secret U.S. military programs - such as the SR-71 Blackbird and the Stealth Fighter - whose existence had been strenuously denied by the military. Furthermore, I had a childhood recollection of another television program I had seen. It had involved what I remember to be some sort of talking head scientist, and he made a comment that continued to haunt my thinking on the subject of flying saucers into adulthood. "Everyone already knows," he said, "that two counter-rotating spheres counteract the force of gravity." For me, especially with the sharpened critical faculties of a twelve year-old, this was the evidence I had been waiting for. Moreover, this revelation followed and built upon something kids of my generation were already familiar with from science class. Anyone who had seen a spinning gyroscope cling to the edge of a table, or weave along a tightly held string, was already intuitively prepared to accept such a possibility. On top of this, we were told that a spinning gyroscope falls slightly slower than a non-spinning one did. It was all adding up. And so, armed with this new bit of information, I eagerly awaited the press conference I was certain would follow at some point, announcing this staggering development of anti-gravity to the rest of the world. 
But the press conference never came. I never heard anything more about counter-rotating spheres and their erstwhile effects on the law of gravity. Oddly, however, this did very little to quash my belief in the possibility of gravity-free travel. I began to wonder about the fate of that messenger. Had he been silenced? Why could I not remember his name? How could I even begin to find out more about what he was saying? I thought about him every time I saw new video of UFOs on television specials. Sure, the pictures were always grainy and inconclusive, but surely this was just an effect of the gravitational field created and thrown off by the crafts themselves. I became convinced I had been privy to a bit of information I was not supposed to know. But I did know, and I was on the lookout for more.

I don't believe in anti-gravity flying machines anymore. And now, as I exchange nervous parting glances with my $30 \mathrm{~s}$, the significance of this anecdote is clearer to me than it was then. It is a significance which lies in the awareness of how powerful the desire to believe can become in shaping the world I saw, and in affecting the ways I understood it. In my youthful pursuit of evidence for a novel form of transportation, I now see a willingness to override and change the parameters of experience in order to uphold a singular idea. Maybe UFOs didn't come from outer space after all, for how could I believe in that when I didn't even believe in the beings that were supposed to be inside them. That had to mean they were man-made. But if they were man-made, why could no one prove they existed? That had to mean that they were part of a secret government program to cover them up. But if they were being covered up, how was it that so many people were capturing them on video cameras? Well, that obviously meant 
there needed to be a cover story to de-legitimate their sightings, for which alien crafts served as the perfect foil.

The origins of this project, however, have very little to do with UFOs or the belief in them. Instead, it grows directly out of the course of study for my master's thesis on situation comedy. In that work, I came to be very interested in the ways that certain entertainment forms, such as the sitcom, seemed to be able to accommodate disruption and resolution at the very same time. The underlying narrative structures of the 'situation' needed to remain constant, while the threats to that situation were also necessary in order to generate the 'comedy'. It was this duality which led to the suggestion that perhaps the sitcom might be an interesting way to map out and see how various social tensions were addressed and represented within the sitcom form. Given the fact that the overall structure of situation comedies would remain constant - this is to say, some kind of stable situation is threatened by some kind of event - then they might be a handy way to compare different historical eras on some common theme.

For my study, I was interested in the ways that women were represented at three different points in American history: one before the feminist movement, one during, and one after. For this kind of approach, 'I Love Lucy', 'The Mary Tyler Moore Show', and 'Murphy Brown' were examined along a consistent set of parameters. The specifics of the findings do not matter here, except to point out that the sitcom itself was shown to be a remarkably effective means of collecting historically resonant themes around the 
ideology of gender. Each television show dealt with this same underlying theme in its own unique ways, ways which were broadly indicative of real historical tensions.

It was this study which led me to the work of Mikhail Bakhtin, and his notion of 'carnival laughter'. The work of Bakhtin and the significance of the carnival to the current project will be developed more fully in the following pages, beginning in chapter two, but the key thing about carnival laughter was the spirit of irreverence it always represented. It was a laughter which was directed outwards, to everything which was ordered, valued, and complete. It was directed at all forms of power, and at the fear which kept ordinary people from challenging it. It was emblematic of a power which pre-exists priests and kings, and which did not even exclude itself as an object of ridicule. It was the laughter of liberation, albeit a form of liberation which was temporary. As such, it was a form of transgression. But it was a transgression which was as fleeting as it was liberating, and so was said to serve an important political role in the maintenance of the very systems of power it was directed at. The paradox that such a situation represents became a means of attempting to look at other forms of expression which effectively did the same thing.

It was during a late 1996 reading of Mark Kingwell's Dreams of Millennium, ${ }^{1}$ as I was about to start writing the conclusions for my master's, that I began to think about the conspiracy theory as one of these forms of expression. This was because within the conspiracy theory, very serious charges could be made about any number of complex

\footnotetext{
${ }^{1}$ Mark Kingwell, Dreams of Millennium: Report from a Culture on the Brink, Viking Books, 1996.
} 
social and political issues, but in a manner which did not seem to threaten the institutions they were directed at. In short, since they were just conspiracy theories, they weren't taken very seriously (if at all) and so were thought to be very similar to the various carnival forms I had already been thinking about. In some cases, it could even be said that the charge itself, quite apart from threatening the dominant arrangements they were directed at, also seemed to be strengthening them in some ways. At the same time though, the threats they collectively represented to these dominant forms never really disappeared. As such, they became an area of study I wanted to learn more about.

Despite protesting to the contrary, I was quickly convinced that the M.A. could and should not branch out into conspiracy theories in the conclusions, and that investigation of these questions would be saved for a potential project in a Ph.D. program somewhere. That program would be at Carleton, in a new program that, unknown to me at the time, was gearing up to admit its first doctoral students in the fall of 1997 . While preparing my application package in early 2000 , I was very aware of how a proposal for a project like this might be received. My feelings at the time that my proposal would either be accepted or laughed off the table makes what has transpired since somewhat difficult to reconcile with the euphoria of completing it.

I will leave any elaboration on the connections between carnival and conspiracy theories to the chapters which follow. Instead, I will briefly look over some of the recent academic writing on the topic of conspiracy theories as a way of indicating what it is that makes the current approach unique. The work of Richard Hofstadter, in his famous essay 
"The Paranoid Style in American Politics", is a necessary starting point. However, since much of the opening chapter onward elaborates on the value of his contribution, a focus on more contemporary pre-9/11 writing on the subject helps provide an indication of the academic climate on the subject before the attacks occurred. This thesis is intended, in part, to chart a possible course for the study of conspiracy theories in a post $9 / 11$ world, while building on these newer contributions. It is also intended to reflect on the ways the notion of conspiracy theory evolved around, and was deployed by, the administration of George W. Bush in the lead up to the invasion of Iraq. And, it does so while noting the refraction of reality which took place in the process.

This study is expressly not intended to uncover some sort of conspiracy involving the administration of George W. Bush. On the contrary, it is an attempt to understand the symbolic and historical significance of the charge itself when employed by the president of the most powerful country and economy in the world. The repercussions of decisions taken by the president of the United States often have global repercussions. Considering this sort of clout, it is worth considering the consistencies which emerge in the ways the charge was utilized by the White House in the wake of $9 / 11$ up to and through the invasion of Iraq. The themes which are assembled here in this fashion do display rather consistent constellations of symbolic meaning, and so deserve extended critical analysis. 
Mark Fenster ${ }^{2}$ grapples with the 'duality' at play within conspiracy theories in his own way. He writes that on the one hand, conspiracy theories are often regarded as illegitimate or pathological, not to mention being a threat to political stability. On the other hand, though, he notes the 'play' element of conspiracy theories. Conspiracy theories, in this regard, are an "entertaining narrative form, a populist expression of a democratic culture, that circulates deep skepticism about the truth of the current political order throughout contemporary culture." ${ }^{33}$ Fenster goes on to describe his book as an attempt to reconcile this tension. He describes it as an "extended argument about the partiality of the first characterization" with an attempt to comprehend "the issues related to the second." He insists that understanding the contemporary role of conspiracy thinking in political culture requires more than simply dismissing it as "pathological Other or mere ideology." He continues that conspiracy theories draw on "the most simplistic, disabling, and dangerous interpretations of political order, including fascism, totalitarianism, racism, and anti-Semitism - yet it also represents a populist possibility, a resistance to power that implicitly imagines a better, collective future." ${ }^{4}$

My own path to Bakhtin has already been established above, and the significance of Bakhtin's thought to the current project will be fully developed in the following pages. But given Fenster's just-cited description of the paradoxical nature of conspiracy theory

\footnotetext{
${ }^{2}$ Mark Fenster, Conspiracy Theories: Secrecy and Power in American Culture, University of Minnesota Press, 1999.

${ }^{3}$ ibid., p. xiii.

${ }^{4}$ ibid.
} 
as a subject of study, it is highly significant that Bakhtin also receives a mention in Fenster's book. What is striking about it, though, is that he does so almost in passing. It comes by as little more than an after-thought, and even then, only at the very end of his book. After building out of his own discussion of laughter, Fenster mentions the fact that the play and laughter within forms like the conspiracy theory represent "some degree of carnivalesque disruption of political order." He goes on to say that

As Mikhail Bakhtin argued, the Rabelaisian carnival has historically worked as a significant cultural and political transgression of the ordered distinctions between categories such as high and low, and popular and dominant, and serves as a source of social renewal, a practice that could be used to challenge and destroy older orders. As such, the analogy between the transgressions of the carnivalesque and the "play" of conspiracy theory is important. 5

Had Fenster begun where he leaves off, it may have rendered the present study redundant before it began.

Peter $\mathrm{Knight}^{6}$ also picks up on and develops the significance of conspiracy theories for academic study. He opens his introduction by saying that at the turn of the millennium in America, it was already beginning to seem as though conspiracy theories were everywhere. "From $J F K$ to The X-Files, from the Oklahoma bombing to TWA flight 800 , and from rumors about the CIA distributing crack in the ghetto to suspicions about the origins of HIV/AIDS in a government laboratory, the language of conspiracy has become a familiar feature of the political and cultural landscape in the last couple of decades." He goes on to draw attention to the then-recent and now infamous interview

\footnotetext{
${ }^{5}$ ibid., pp. 217-218.

${ }^{6}$ Peter Knight, Conspiracy Culture: From Kennedy to the X Files, Routledge, 2000.
}

xvi 
with Hillary Rodham Clinton on NBC's Today show. It was in this interview where she claimed that her husband, then President Bill Clinton, had become the victim of a "vast right-wing conspiracy that has been conspiring against my husband since the day he announced for president."?

Knight goes on to point out that Rodham Clinton had taken much more than her fair share of ridicule for the comment, especially on conservative radio talk shows. Though this particular incident will receive no further attention other than to simply recall it here, ${ }^{8}$ it does stand as a good example of how the charge of 'conspiracy' can have a tangible influence in the formation of popular political meanings and understandings. Writing before the $9 / 11$ attacks, Knight says that given the pervasive nature of the charge, it was already cascading into meaninglessness, taking whatever it tarred with 'conspiracy theory' right along with it. "Conspiracy culture, in short, provides an everyday epistemological quick-fix to often intractably large and complex problems", Knight says. "The task is therefore not to condemn but to understand why the logic of conspiracy has become attractive in so many different areas of American culture, and how it is reshaping how people think about questions of causality, agency, responsibility, and identity."

\footnotetext{
${ }^{7}$ ibid., p. 1.

${ }^{8}$ It should also be noted that Jodi Dean provides an extended development of this particular example in her chapter 'Declarations of Independence' for her edited volume Cultural Studies and Political Theory (Cornell University Press, 2000).
} 
Knight goes on to cite a couple of other recent authors who would agree that conspiracism in the contemporary U.S. has ceased to be harmful. He shows how these authors (Daniel Pipes, Robert Robins, and Jerrold Post) argue that, since the paranoid style has now devolved into a mere cultural phenomenon, it has become insignificant. Knight continues, somewhat prophetically in retrospect, that "unless there is a body count that can be measured in the thousands if not millions, outbursts of populist paranoia hardly register on their scales." In contrast to positions like these, however, Knight suggests that this sort of patent dismissal of conspiracy theory is a mistake, and writes that his study argues that "conspiracy thinking is becoming increasingly important in spite of - and perhaps even because of - its cultural turn."9

Knight's perspective helps to enhance an academic study of conspiracy theory, not only because of his insistence on taking the subject seriously, but precisely because it is accepted so uncritically as a marginalized form of discourse. This is not to forget for one moment how often this is absolutely the right thing to do. It is merely meant to highlight how easy it is to dismiss the entire subject itself as a productive avenue of inquiry. In other words, the various preoccupations of given conspiracy theories, such as those regarding 'aliens' or 'Area 51 ' for example, may be rightfully dispensed with in many regards. But, the study of the conspiratorial reflex in response to the existential and scientific complexities they actually 'represent', should very much remain a viable and productive area of scholarly study.

\footnotetext{
${ }^{9}$ ibid., pp. 8-9; emphasis added.
} 
Robert Alan Goldberg, ${ }^{10}$ as another example just before the $9 / 11$ attacks, writes of the modern-day continuities which conspiracy theories share with the past. As we shall see in more detail in chapter one, the history of the United States is rife with perceived threats to religion, race, and nation. "Salem witches, British ministers, Catholic priests, slaveholders, Wall Street bankers, Jews, Bolsheviks, and black militants, all in their turn and among many other suspects, have been cast in the plotter's role. The enemy appears chameleon-like, pervasive, and opportunistic" Goldberg writes. In a theme that will be picked up and developed in chapters three and five, he continues that the "legal definition of conspiracy, which is straightforward if not rigorous, is conducive to such diverse and perceptions of plots and plotters." He explains that this is because the crime of conspiracy requires an agreement between two or more persons who engage in either an unlawful act, or a lawful act by unlawful means. The reality of illegal conspiracy, however, becomes an impetus for the formation of conspiracy theories which are out of all proportion to any ability to practically exist in the material world. In other words, it acts as a form of inspiration. On this point, Goldberg foreshadows a discussion on 'paranoid literature' we pick up again in chapter five as he refers to those

activists and entrepreneurs who spin theories that are strenuously logical and crammed with facts, find foundation here and then move to a more expansive view of crimes and misdemeanors. Secret dealings of all sorts are within their range, from presidential murder to threats against American institutions to the cover-up of classified information. Intensity of belief and knowledge of plot details are greatest in this core. With increasing emotional and intellectual distance from the nucleus, suspiciousness lessens along with the commitment to the specifics of the plot. ${ }^{11}$

${ }^{10}$ Robert Alan Goldberg, Enemies Within: The Culture of Conspiracy in Modern America, Yale University Press, 2001.

${ }^{11}$ ibid., pp. X-xi. 


\section{Dissertation Overview}

It needs to be noted that each of these authors write quite extensively on the contributions of many others, material which is important to round out a general background to academic work in the area, but which will not be developed here. One common theme in the above cited authors' work, however, is a fairly consistent descriptive approach which highlights the centralities of conspiracy theory to 'religion, race, and nation.' One of the intentions of the present study is to build off of that body of work in order to construct a theoretical model grounded in a more conventional approach to social and political analysis and critique. To do this, it is necessary to 'get behind' conspiracy/theory in order to approach all of it from some common vantage point. That vantage point is Bakhtin's carnival, especially but not exclusively as developed and described by Peter Stallybrass and Allon White in The Politics and Poetics of Transgression. ${ }^{12}$ What makes this latter contribution so useful, is the extent to which their application of the notion of carnival to a study of social hierarchies within English Literature, provides a template for a similar attempt to understand and study the genesis and pervasive presence of conspiracy theories about $9 / 11$ and the invasion of Iraq.

To this end, I begin in chapter one, 'By Wicked and Artful Men': Faith and Suspicion in an Age of Empire', by citing an instance of conspiratorial fear around the Jesuits as being indicative of the general charge of 'conspiracy' itself. This is used as a way to introduce the essential work of Richard Hofstadter, and serves as a point of entry in to a general

\footnotetext{
${ }^{12}$ Peter Stallybrass and Allon White, The Politics and Poetics of Transgression, Cornell University Press, 1986.
} 
look at the centrality of conspiratorial suspicion backwards across U.S. history. The chapter points to the central political roles that conspiracy theories played, not only to the formation of the United States itself, but also to the very reasons given for, and religious frictions behind, the 'Puritanical exodus' from Europe in the first place.

Taking Hofstadter's cue that the paranoid style should not be considered a uniquely American phenomenon, a look at some of the same tensions as they came to be expressed and mobilized during the British colonial experiences in Africa and India provide useful points of comparison. They demonstrate that, not only is the paranoid style truly not limited to American experience, it consistently embodies some of the same compositional features in these other countries. The chapter ends by considering the curious but hard to miss dialectic between faith and suspicion as they relate to religion and conspiracy theory respectively.

In chapter two, 'Conspiracy Theory and the Politics of Carnival', a Catholic plot to blow up the British Houses of Parliament four centuries ago is used as a handy but essential way to bring together the threat of political conspiracy with a long-standing carnival tradition which has commemorated that foiled attempt ever since. This is taken as an opportunity to explore the comparative symbolic politics of the carnival generally, and extends into the more broad history of symbolic inversion and the World Upside Down thesis. Both are developed so as to draw attention to the ways in which the study of conspiracy theories might be modeled upon them. This is because at the center of all 
three, lies the 'dialectics of social classification as such', and provides a jumping off point for the next chapter.

Chapter three, 'Conspiracy Theory and the Political Economy of Meaning', takes up the dialectic as a complicated but invaluable concept in exploring connections to a wellestablished critical tradition in the form of Marxian conceptions of dialectics, ideology, and hegemony. These are posited as useful and inherently inter-related conceptual tools, and quite apart from their presence within political economy, work well as a way of framing the conspiracy theory as a productive epistemological orientation for social and political analysis. After an important digression into the role of language itself as the symbolic common denominator of human understanding, through which all of these larger forces necessarily act, the focus is extended to include an illustrative historical look at the Hollywood film as means of bringing all of these ideas together.

'The Paranoid Style in Middle East Politics' in chapter four establishes some context for the competing paranoid visions which exist between the three major monotheistic religions. It provides some historical background for unpacking some of the many different factors in the long-standing unrest in that region. It also works to highlight its emergence as an important element in, and on-going importance to, the global political economy. Though Middle East politics is a very complex topic, it is perhaps not surprising in some ways that it has also been a fertile breeding ground for many of the most pervasive and influential conspiracy theories of our modern era. Not the least of these, is the belief in a western-Zionist conspiracy against Islam. Feeding into a more xxii 
detailed look at the major conspiracy theories as they relate to the $9 / 11$ attacks in the following chapter, the work of Max Weber underlines the fusion of capitalist success and godly favor in some interesting ways. The post-9/11 spike in evangelical Christian apocalyticism by the religious right in the United States, is tied to the various conspiracy theories and end-times prophecy involving the Middle East. The guiding thread in this endeavor is an aspect of the paranoid style which Hofstadter identified, but did not elaborate on. It is the propensity for paranoid rhetoric and conspiracy theory to become self-fulfilling prophecy in certain circumstances.

In chapter five, 'Sixteen Little Words', President George W. Bush's claim that Iraq had sought to purchase significant quantities of uranium from Africa is credited to a longstanding and widely held conspiracy theory about the perceived role of Saddam Hussein in the affairs of global terrorism. The chief proponents of this theory are described, and their contributions are assessed in terms of Hofstadter's description of paranoid literature. This leads into a suggestion from intelligence historian Christopher Andrew that conspiracy theories themselves could and should become an accepted means of understanding modern geopolitical crises.

This moves the dissertation further along the path towards $9 / 11$ by addressing the role of religious tension and conspiracy theories about the continued presence of U.S. military forces in Saudi Arabia after the end of the first Gulf War. bin Laden's former relationship with Saudi Prince Turki al-Faisal is discussed as a factor in the eventual turn towards an increasingly hostile stance by bin Laden towards U.S. political and economic 
aims. His suspicions in this regard were communicated in the form of conspiracy theories about the Zionist influence in world affairs. This leads into a comparative look at a number of $9 / 11$ conspiracy theories from different parts of the world. The chapter concludes with a consideration of conspiracy theories as a component feature of collective memory, and positions them as a useful analytical and conceptual tool.

The case study portion of the dissertation follows in chapter six, 'Smoking Guns and Mushroom Clouds'. It is a general examination of how the notion of conspiracy theory was a formative element in the mainstream news coverage of the lead up to war in Iraq, with specific attention to how it was actively deployed by the Bush administration. Considering the heavy emphasis at the time placed on the threat posed by Saddam Hussein and his allegedly active nuclear weapons program, the chapter attends to the circumstances surrounding the first public rebuke of the Bush administration's case for war. It concludes by pointing to a number of popular critics of Bush administration policies in the mainstream press, and how they reacted to or labored under the dismissive charge of 'conspiracy theory'.

Chapter seven, 'Legitimating the Looney Left' shifts the focus to some of the large-scale economic crises presently unfolding within globalized capital markets. Building off of the work of Marxist geographer David Harvey in a 20 year old essay from the Reagan years, it is counterposed with mainstream economic policy advisors, investment houses, currency speculators, and global financial institutions. The chapter demonstrates that, under the current circumstances, there is effectively no difference between these 
traditionally antagonistic perspectives. The irony of this situation is taken to be a stark indication of the severity of the various crises described in this chapter. The staggering financial costs of the occupation of Iraq, along with the collective threat posed by the euro to the 'individualistic ethos' of the American dollar, are shown to only exacerbate these originating crises. It is noted, and should not be forgotten, that bin Laden and alQaeda understand all of this as to be going according to script. It was a script largely set into motion by the only real conspiracy behind the attacks of September 11, 2001 .

The eighth and final chapter is the conclusion, 'Conspiracy and the Logic of Capital'. In this chapter, the major themes are summarized and drawn together around a question of what role is to be played by 'philosophy in a time of terror'. The relational flirtation between conspiracy and capital interests is accepted as being as natural as it is necessary to suspend. The foundational importance of political philosopher Leo Strauss and his advocacy of the religious right in the United States is shown to be a significant factor in the rise of the modern neo-conservative movement.

\section{Conspiracy Theory as a Communicational Concept}

The Latin root of the word conspiracy is conspirare, which means 'to breathe together.' The root origin of the word itself already suggests intrigue, secrecy, and danger. But it also harkens life, trust, and cooperation. As such, it is an inherently communicational concept. A conspiracy, even when noting Goldberg's definition of the legal term noted earlier, only comes into being as the result of communication between two or more parties. It cannot even exist as a true 'conspiracy' otherwise. Communication brings a 
conspiracy into being, and in so doing, transforms the very nature of that communication. The language of conspiracy theory, then, needs to be understood as its own form of communication. This is because by their very nature, conspiracy theories mediate experience with the physical world in terms of a previously established set of beliefs or practices. As is the case with any other medium of communication, conspiracy theories communicate certain aspects of meaning very well, while completely missing or even shielding others. It is this approach to the study of conspiracy theories about the $9 / 11$ attacks and the war in Iraq that informs the rest of the study.

The dissertation addresses the three fields of concentration in the doctoral program of Communication at Carleton University. These are i) the history of communication; ii) the political economy of communication; and iii) the socio-cultural analysis of communication. First, the dissertation explores the subject of conspiracy theories from the point of view of history, showing that not only do they reflect and refract historical frictions as a necessary part of their expression as such, but also, are themselves seen to act as material forces in the unfolding of history in different ways. Second, the dissertation traverses the terrain of political economy in the sense that conspiracy theories comprise a form of ideological discourse which grow out of and sustain the systems which help to produce them. This is done while necessarily being concerned with the ways that the meanings mobilized within conspiracy theories are sometimes active components of those same systems. Thirdly, the dissertation conducts a specific study of the conspiracy theories sparked by the $9 / 11$ attacks from different parts of the world, while at the same time attending to the specific ways the Bush administration 
drew on the rhetoric of conspiracy theory in order to disparage criticism of its policies and actions.

xxvii 


\section{Chapter One - 'By Wicked and Artful Men': Faith and Suspicion in an Age of Empire}

In an 1879 interview in London by the Chicago Tribune, Karl Marx was asked an interesting question. Already well known for his epic Capital, and as the founder of The International Society, his ideas as well as the activities of the Society had evidently been generating some attention. The first Chancellor of his native Germany, Chancellor Bismarck, had suggested that Marx was somehow the mastermind of global insurrection, and the general rules of The International Society provide an indication as to why. Published a few years earlier in 1871, the rules stated that "the emancipation of the working classes must be conquered by the working classes themselves, that the struggle for the emancipation of the working classes means not a struggle for class privileges and monopolies, but for equal rights and duties, and the abolition of all class rule...”. Efforts to create the conditions for the universal emancipation of the working classes had, it continued, "hitherto failed from want of solidarity between the manifold divisions of labor in each country". The Association was formed in London "to afford a central medium of communication and cooperation between the workingmen's societies in the different countries". The clearly stated aim of the Society was "the protection, advancement, and complete emancipation of the working classes." The German Chancellor, a media owner himself, had used his North German Gazette to accuse Marx of being in league with the Jesuits. "It is said that you are the head and front of socialism, Doctor," the journalist said, "and from your villa here pull the wires of all the associations, revolutions, etc., now going on. What do you say about it?"

"I know it," Marx smiled in reply. "It is very absurd yet it has a comic side." 
What Marx found funny might be lost on us today. As a Catholic Order founded by Ignatius of Loyola in 1540, the Society of Jesus served as a prominent and controversial force in the CounterReformation. Its tumultuous history need not be recounted here, but after being successively driven out of various European locales, it was officially disbanded in 1774 by Pope Clement XIV. It clung on however in various places, most notably under Catherine the Great of Russia. By 1814, Pope Pius VII had re-established the Society of Jesus, and over the next few decades it was able to regain some of its previous influence. But key to the pejorative charge against Marx by the Chancellor of Germany were the widely held suspicions of the power that the Order was believed to hold, suspicions that came from both within and outside of the Catholic Church. And this is what Marx found so funny: The Chancellor had placed him at the center of a conspiracy theory.

This chapter will explore the tensions which exist between capital expansion, religious rationalization, and the suspicions created by both in the evolution of history. The origins of tensions like these are eternally complicated, and may even be impossible to ever fully understand. As such, there will be no overly strenuous effort to try and explain them here. Whatever the difficulties in contemplating these origins, however, their echoes linger still in many different ways. One of these is the conspiracy theory. No doubt a holdover of sorts from the oral traditions of pre-literate societies, conspiracy theories are a form of communication which offer a latter-day connection to a mysterious and mythical past. In being so, they can also inform and help mobilize visions of the future. But as explanations of lived historical reality, they fail miserably. Still though, the relative simplicity of conspiracy theories render them as compelling as they are illusory, and so merit serious attention. As much as they attempt to explain circumstances that are far too difficult to comprehend 
all at once, they do nonetheless hit upon a surprisingly consistent set of frictions.

Not surprisingly, there is already a well-documented history of American political suspicion described by Richard Hofstadter in the 1960s as the "paranoid style". It provides a handy way into an analysis of the ways that religious faith was always been tied up with the expansion of capital interests in what would become the United States of America. Though Hofstadter's work is not exclusively focused on connections like these, it does provide a worthwhile look at some of the American inflections on this otherwise global theme. As a means of establishing a pretext for an understanding of the American variety, as well as an examination of its role in the formation of the United States itself, it is useful to first look towards some of the more celebrated instances of conspiratorial thinking as they emerged out of the European Enlightenment. As we shall see by doing so, the opening anecdote does more than show that Marx had a sense of humor. It highlights a rather interesting and more general tension between the 'right' and 'left' of the political spectrum, and how readily the charge of conspiracy can be thrown about in these circumstances.

Conservative viewpoints often regard alternative positions with skepticism, and so too of liberal ideas and causes that come into conflict with 'the way things have always been'. The dictionary defines conservatism as "the inclination, especially in politics, to maintain the existing or traditional order. A political philosophy or attitude emphasizing respect for traditional institutions, distrust of government activism, and opposition to sudden change in the established order." This is contrasted

\footnotetext{
${ }^{1}$ Mark Fenster [op. cit., pp. 3-21] provides an important and extended critique of Hofstadter which need not be described here in detail.
} 
with a definition of liberalism generally understood to represent a political theory "founded on the natural goodness of humans and the autonomy of the individual and favoring civil and political liberties, government by law with consent of the governed, and protection from arbitrary authority." Interestingly, it also refers to "an economic theory in favor of laissez-faire, the free market, and the gold standard."

Even in these generic terms, it isn't difficult to understand how these competing viewpoints, when conceived of through the operation of macro-systems of such as government, religion, the economy, or even the mass media, sometimes come to be expressed as conspiracy theories. When confronting the inertia of established standards and practices, or responding to well coordinated attempts at some form of widespread change, conspiracy theories serve, in part, to fill gaps in understanding on the part of the people constructing them. The conspiratorial frame neither characterizes right vs. leftwing clashes any more than conspiracy theories are limited to them. Still, as a way to delimit a study of conspiracy theories, a focus on right-wing vs. left-wing tensions quickly becomes a handy way of discussing a whole range of different discourses. To the extent that conspiracy theories can also be understood as expressions of perceived threats to (or from) various forms of power, they become even more interesting. Religious beliefs, political ideologies, economic systems, class structures, military factions, imperialism, historical trends, gender issues, racial inequalities, all of these can and have been explored and discussed in terms of the right-left dynamic. Even within each of these groupings lie yet other sub-groupings and gradations which, in and of themselves, can be further discriminated along this simple binary opposition. Ultra-conservative religious minorities, as only one example, might be compared to or contrasted with less conservative or even other very 
liberal ones, but this is still only a small part of the picture.

Though an admittedly convenient analytical distinction for now, a concentration on right-left tensions doesn't mean such an approach has to be limiting or short-sighted. Even among the few categories noted above, lie any number of overlapping possibilities through their interactions with other spheres of experience. For example, a fundamentalist Christian religious faith may work very well in tandem with a conservative political ideology. Even that simple pairing would not necessarily represent a region or country's power-bloc, but taken together, could significantly influence the workings of either micro- or macro-political, economic, or cultural systems.

Macro-decisions taken in circumstances like these regularly alter the course of history. The ways those events are symbolized and represented in mainstream commercial news media may be an interesting way to track and study them. 'Conspiracy theory', in this regard, may be useful as an analytic device to help point out where some of the more complicated frictions lie. While one of the least significant things about conspiracy theories is their explanatory potential, they are a unique form of communication that nonetheless expresses some very interesting consistencies. Of these, concerns about various forms of power stand out as singularly consistent. When coupled with a deliberate attempt to understand the wider conflicts that give rise to conspiracy thinking across an array of different political and cultural practices, a focus on conspiracy theories may become a handy way of exploring many of these wider conflicts at the very same time. Though the focus of this study is on conspiracy theories about the U.S. invasion of Iraq after the attacks on the World Trade Centers and the Pentagon, the conclusions drawn will be directly applicable to many different kinds 
of conspiracy theory. For example, theories about the role of the C.I.A. in the crack epidemic in the U.S., or about the global spread of AIDS, corporate influence in big government, mass media control of information, secret societies like 'Skull and Bones', or fears about a 'New World Order': All of these express different groups' fears about a system which has forsaken them. And these examples hardly begin to exhaust the seemingly limitless ways that conspiracy theories are configured. They do, however, help to narrow the focus to a more specific investigation of what a case study on the 9/11 attacks and the U.S. invasion of Iraq can teach us about how conspiracy theories circulate and function within global capitalism. It is one of the contentions of my thesis that this case study is particularly well-suited to this purpose.

\section{Conspiracy Theory and the Politics of Conservatism}

One of the many interesting things about a focus on conspiracy theories is how central conservatism is to their genesis and sustainability. It is difficult to imagine a conspiracy theory without some preexisting set of practices or ideals which either threaten, or are threatened by, some or another of the same. Geoffrey Cubitt offers a useful definition of conspiracy theory which helps to unpack some of these complicated inter-relationships. At their most schematic level, "a conspiracy theory does three things: it attributes the events of history or current affairs to conscious human volition; it sharply distinguish[es] between the human forces of good and of evil; [and,] it implies a hidden reality beneath and at odds with the superficial appearances of the political and social world $\left[\ldots . . .{ }^{2}\right.$ He goes on to point out that as theories go, the historian is much less likely to encounter them as fully elaborated and researched points of view, but more as interpretive habits in the meandering

\footnotetext{
${ }^{2}$ Geoffrey Cubitt, The Jesuit Myth, Clarendon Press, Oxford; 1993, p. 2.
} 
streams of experience, few of which have any analytical purpose. As a caveat, Cubitt reminds us how important it is not to essentialize the structure or function of conspiracy theories. "It follows that, while reflections on the common structures of conspiracy theory can be illuminating, the temptation to pare the paranoid style down to a central set of immutable theoretical elements needs to be resisted". He continues that by their "rhetorical emphases, by their choice of imagery and selection of themes, writers and polemicists ensure that the balance between the three basic dimensions of the conspiracy theorists message is different in different cases and at different times". ${ }^{3}$

Heeding Cubitt's worthwhile caution, he is correct to point out how illuminating a look at some of the similarities and common themes can be. Even a quick overview of some of the more notable groups targeted by conspiracy theories over the past few hundred years reveals some consistent features. Not the least of these are the fears they consistently generated with previously well established orders. For example, Hofstadter points out that the Bavarian Illuminati's teachings, today, read very much like Enlightenment rationalism. ${ }^{4}$ At the time, however, they were received quite a bit differently. Illuminism had been founded in 1776 by Adam Weishaupt, a law professor at the University of Ingolstadt. Hofstadter describes it as a somewhat naïve and utopian movement that aspired to improve the human race through the rules of reason, albeit with an anti-clerical bent. It attracted many converts including dukes and princes of various German states, as well as writers and philosophers including Johann Gottfriedd von Herder, Goethe, and Johann Heinrich Pestolozzi.

\footnotetext{
3 ibid.

${ }^{4}$ Richard Hofstadter, The Paranoid Style in American Politics and Other Essays, Knopf, New York; 1966 , p. 10.
} 
By the end of the eighteenth century, it was at the centre of a moral panic over the alleged subversive activities of the group, which included instigating the French Revolution according to some authors. John Robison, a well-known Scottish scientist at the time, introduced the Illuminati to America in a 1797 book titled Proofs of a Conspiracy Against All the Religions and Governments of Europe, carried on in the Secret Meetings of Free Masons, Illuminati, and Reading Societies. Robison felt that the groups were formed "for the express purpose of ROOTING OUT ALL THE RELIGIOUS ESTABLISHMENTS, AND OVERTURNING ALL THE EXISTING GOVERNMENTS OF EUROPE". 5

Freemasonry is another central player in the history of conspiracy thinking, and it is in this period where its long history reaches the North American conspiratorial imagination. Theories on the origins of Freemasonry need not be outlined in any great detail. However, one theory holds that the origins of the Masonic fraternity date to biblical times and to the construction of the Temple of King Solomon. The undertaking was so vast that it required a new form of organizing the stonemasons and architects into various grades and classes, each with particular responsibilities and highly specialized knowledge. The generally accepted theory on the origin of Freemasonry, though, has been in the stonemason's guilds of the Middle Ages. The term "free" refers to the fact that the mason was not bound to the land as a serf, but was free to travel about the country as required by construction projects. Examples of these sorts of projects were the many great Cathedrals built during the period. Their construction required that masons had considerable education in the principles of geometry, arithmetic, and engineering. This is significant because the guild of

\footnotetext{
${ }^{5}$ ibid., p. 11; emphasis in original.
} 
stonemasons became one of the few repositories of learning outside the clergy. It is assumed that after the wave of cathedral building ebbed and the Renaissance began, that membership was extended to other members of the upper classes who were not stone workers. The purpose was to maintain their organizations for the discussion of philosophical questions and the pursuit of knowledge. These organizations are then supposed to have evolved into the modern Lodges.

Following in the footsteps of anti-illuminism and the considerable suspicion that order attracted, a wave of anti-Mason activity began with the disappearance of an ex-Mason who was writing a book exposing the order. The Masons were suspected in the case. As Hofstadter writes, "Masonry was considered to be a standing conspiracy against republican government [...] Masonry was also accused of constituting a separate system of loyalty, a separate imperium within the framework of American and state governments, inconsistent with loyalty to them." ${ }^{16}$ Since Masons pledged to come to each other's assistance, serious questions were raised about the exercise of law. Masonic judges, police constables, news editors and the like, could all work together to suppress Masonic wrong doing. In other words, Masonry was "held to be a fraternity of the privileged classes, closing business opportunities and nearly monopolizing political offices, thus shutting out hardy common citizens of the type the anti-Masonic movement like to claim for its own."

All of this, however, is Hofstadter's preamble to his famous discussion of the "paranoid style in American politics". A lot more will be said about this in the coming pages. For now it is enough

\footnotetext{
${ }^{6}$ ibid., p. 16.

${ }^{7}$ ibid., p. 17.
} 
to cite a couple of direct examples from his text. In beginning to abstract the dimensions of the paranoid style, he writes that the "central image is that of a vast and sinister conspiracy, a gigantic and yet subtle machinery of influence set in motion to undermine and destroy a way of life." Hofstadter makes clear that he is not talking about a group that sees plots and conspiracies here and there. On the contrary, "they regard a 'vast' or 'gigantic' conspiracy as the motive force in historical events. History is a conspiracy, set in motion by demonic forces of almost transcendent power, and what is felt to be needed to defeat it is not the usual methods of political give-and-take, but an all-out crusade." $\quad$ Even more chilling is his very next sentence where he continues that the

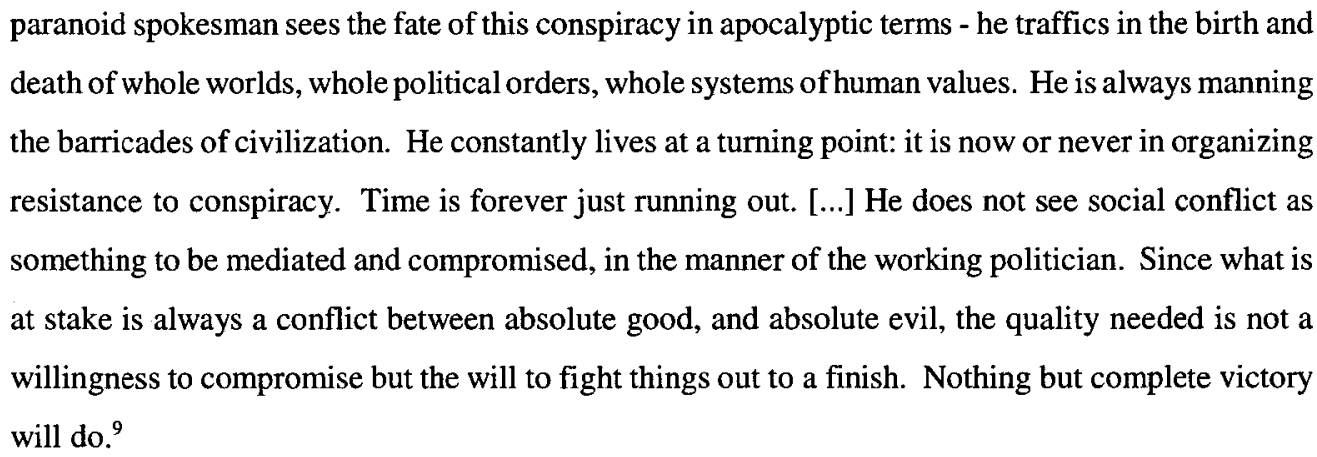

Hofstadter allows that there is nothing which requires that this paranoid mind set manifest itself all the time, but may exist somewhere in a considerable minority of the population and comes in episodic waves. This suggests that it can be mobilized as a result of social conflict, especially those which involve "ultimate schemes of values and that bring fundamental fears and hatreds, rather than negotiable interests, into political action. Catastrophe or fear of catastrophe is most likely to elicit the syndrome of paranoid rhetoric." 10

\footnotetext{
${ }^{8}$ ibid., p. 29; emphasis in original.

${ }^{9}$ ibid., p. 29-31.

${ }^{10}$ ibid., p. 39.
} 


\section{'Bring 'em On': George W. Bush and the Paranoid Style}

Hofstadter's work is interesting for many reasons, but key among these is the way it connects a study of an identifiable political style to a study of the political system from which it springs. The 'paranoid style' is much more than a simple aberration in American political history; it is a reflection of one of its more consistent and transformative characteristics. In order to better understand present day circumstances as a manifestation of the paranoid style, as well as what they both contribute to a more broadly-based study of the $9 / 11$ attacks, a brief overview of some earlier examples will help to provide some context for the current Bush Administration. It is only from within this context that the post-9/11 rhetoric of the Administration is seen to be historically consistent with some other notable cases where the 'American Way' was said to be under attack. Though Hofstadter is careful to point out that the paranoid style is by no means unique to American experience, ${ }^{11}$ he is nonetheless very interested in trying to delineate the forms and functions of the paranoid style backwards across the American historical landscape.

Perhaps the most recently famous of these earlier instances of American exceptionalism was the McCarthy era. But Hofstadter touches on McCarthy only briefly as he skips back in roughly 50 year increments to make his larger point that this sort of thing is anything but exceptional. "How can we account for our present situation," McCarthy began in 1951, "unless we believe that men high in this government are concerting to deliver us to disaster. This must be the product of a great conspiracy, a conspiracy on a scale so immense as to dwarf any previous such venture in the history of man." 12

\footnotetext{
11 ibid., p. 6-7.

${ }^{12}$ Congressional Record, $82^{\text {nd }}$ Cong., $1^{\text {st }}$ Sess. [June 14, 1951], p. 6602; cited in Hofstadter, ibid.; p. 7.
} 
Going back to 1895 , a manifesto signed by many leaders of the Populist party declared that as early as 1865-66 "a conspiracy was entered into between the gold gamblers of Europe and America...For nearly thirty years these conspirators have kept the people quarreling over less important matters, while they have pursued with unrelenting zeal their one central purpose...". ${ }^{13}$ A Texas newspaper in 1855 loudly proclaimed that it was "a notorious fact that the Monarchs of Europe and the Pope of Rome are at this very moment plotting our destruction and threatening our political, civil, and religious institutions [...] These minions of the Pope are boldly insulting our Senators; reprimanding our Statesmen; propagating the adulterous union of the Church and state; $[\ldots]$ and spewing out the bitterest execrations on all Protestantism."14 Finally, a sermon delivered in Massachusetts in 1798 exhorted that " [s]ecret and systematic means have been adopted and pursued, with zeal and activity, by wicked and artful men, in foreign countries, to undermine the foundations of this Religion (Christianity), [...] These impious conspirators and philosophists have completely effected their purposes in a large portion of Europe, and boast of their means of accomplishing their plans in all parts of Christendom." 15

Even within these few examples, some clear consistencies emerge. In sketching out the parameters of the paranoid style in American politics, it would be difficult not to hit upon the trifecta of suspicions which both characterize the style and which fuel it at the same time. For the proponents of the paranoid style in the United States, the conspiratorial frame is readily applied to those who in

\footnotetext{
${ }^{13}$ Frank McVey, "The Populist Movement," Economic Studies, I [August 1896], pp. 201-2; cited in Hofstadter, ibid.; p. 8.

${ }^{14}$ Texas State Times, September 15, 1855; cited in Hofstadter, ibid., pp. 8-9.

${ }^{15}$ Jedidiah Morse, A Sermon Preached at Charlestown, November 29, 1798; cited in Hofstadter, ibid.; p. 9.
} 
anyway threaten the tenets of conservative protestant religious teachings, the sanctity of American individualism in whatever form one might imagine, or who subject either to critical appraisal. In short, it is a political orientation which is patently fundamentalist, xenophobic, and anti-intellectual. Some attention to some of the less mainstream targets of this sort of thinking will help to lay a broader groundwork for a consideration of the ways that George W. Bush embodies these traits as he simultaneously pandered to them in the wake of $9 / 11$.

One of Hofstadter's motivations in writing about the paranoid style was his keen interest in what he called the extreme right-wing, or what he called "pseudo-conservatives." 16 Though he concedes that the style itself also exists with key modulations and differences on the left, it is the overarching tendency to see the world in terms of a secularized religious world-view and to frame political questions in terms of Christian imagery that is most interesting to consider. The tendency to see and understand the world as a terrain of battle between 'Good' and 'Evil' feeds very quickly into apocalyptic thinking. If the warning signs aren't heeded soon enough, the argument runs, the consequences will be dire. Setting aside for the moment the immense potential for extreme right wing religious beliefs to become self-fulfilling prophecy [something Hofstadter noted in his own time $\left.{ }^{17}\right]$, it is worth flagging the central importance of the Book of Revelation to the evangelical Christian movement as a virtual 'roadmap' of human destiny, especially in a post-9/11 world.

So clearly, the capacity for conservative religious beliefs to mobilize the rhetoric of the paranoid

\footnotetext{
${ }^{16}$ ibid., p. xi. It should be noted this is analogous to the term "neo-conservative" today.

${ }^{17}$ ibid., p. xii.
} 
style has a history that extends well beyond September 11,2001. Whatever history of anti-masonic sentiment can be pointed to, what characterized it most clearly was the apocalyptic fervor with which Freemasonry was denounced. The order was considered to be nothing less than satanic in origin and was deemed to be foretold by the apostle John for its role in amassing the armies of the world against God, only to be defeated at the battle of Armageddon. Of particular concern were Masonic oaths, which were said to be blasphemous and ran contrary to the civil order. The loyalties they required could only work to the detriment of healthy Christian societies. Barbarous penalties were imagined for those who broke with the sanctities of the order, and in turn this only worked to further demonize those who held to them. ${ }^{18}$

\section{Conspiracy Theory and Anti-Catholicism}

The Catholic church only vivified these sorts of widely held suspicions, and was itself seen as a plot against American values. These passions were inflamed by a desire to maintain a society which was both ethnically and religiously homogenous. This more general tendency in American experience helped the anti-Catholic movement gain ground even among moderates for whom the paranoid style in its more forceful expressions held no appeal. An 1835 book by none other than Samuel Morse, the inventor of Morse Code, elevated fears of a society being unraveled from within, unseen, in a "vulnerable quarter which cannot be defended by our ships, our forts, or our armies."19 The not-sothinly-veiled xenophobia of anti-Catholicism [considering that many immigrants came from largely Catholic countries like Italy and Ireland] ran rampant in an age of increased European immigration.

\footnotetext{
${ }^{18}$ ibid., pp. 17-18.

${ }^{19}$ ibid., p. 19.
} 
Interestingly, at the same time, the spectre of the carnival can be heard in the conspiratorial imaginings of anti-Catholic rhetoric. It was a fact, wrote one Protestant militant, "that Jesuits are prowling about all parts of the United States in every possible disguise, expressly to ascertain the advantageous situations and modes to disseminate Popery [...] the western country swarms with them under the names of puppet show men, dancing masters, music teachers, peddlers of images and ornaments, barrel organ players, and similar practitioners." ${ }^{20}$ The ranks of the lower classes were swelling with those who, quite apart from posing a mortal threat to Protestantism itself, were spreading violence, filling jails, raising taxes, and corrupting the electoral process through their concentrated populations. ${ }^{21}$

Where the Masons were said to hold suspect loyalties which were maintained through subversive oaths, the Catholics were charged with all manner of sexual indiscretion. Hofstadter suggests wilful projection as he writes that "anti-Catholicism has always been the pornography of the Puritan."22 Whether it be the seductive lore of the confessional, licentious monasteries and convents, or the carnal semiotics of a young woman kneeling before an ardent young priest, these and other variations on the temptation theme filled the imaginations of anti-Catholic polemicists. The displacement of forbidden desire in this way worked to uphold Puritan values at the same time it gave voice to baser longings.

\footnotetext{
${ }^{20}$ Billington [1938], The Protestant Crusade, p. 120; cited in Hofstadter, ibid.; p. 20.

${ }^{21}$ ibid., p. 21.

22 ibid.
} 
One of the surest indications that it was indeed Puritan longing which was the real issue, was the vicious demonization of Catholics which attempted to rob them of any redeeming attributes whatsoever. They were made repugnant and perverse with accusations of incest and brutal sadism. Catholics were said to cut unborn infants from the wombs of their mothers and throw them to dogs while their parents watched in horror. Mormons, whose polygamy set them apart for special censure, lashed and raped unruly women, and seared their offending mouths with red-hot irons. These and many other examples stood as signs of wider threats against Protestant values and the American way. As such, they were subjected to the meandering rationalities of the paranoid style in defense of social and political order. It is worthwhile to point out here that the alleged secret conspiracies that inhered in the actions of groups such as Masons, Mormons, and Catholics, worked to strengthen the resolve of those opposed to them, while legitimating the established order in the process. ${ }^{23}$

Intellectuals were also targeted in various ways for being somehow involved in undermining older established practices. Hofstadter draws attention to a perceived shift in right-wing sensibilities from the nineteenth-century, writing that at the time, there was still a sense among those on the right that the country belonged to them and that they were defending a well-established way of life. Citing Daniel Bell, Hofstadter claims that the modern right wing felt "dispossessed" from the America they once knew and defended. At the same time, however, they were determined to repossess it and prevent this subversion from undermining them completely. For the 'new right', it was felt that the old American virtues had already been weakened by intellectuals and their cosmopolitan pretensions.

\footnotetext{
${ }^{23}$ David Brion Davis, The Fear of Conspiracy: Images of Un-American Subversion from the Revolution to the Present, Cornell University Press, London; 1971; pp. 18-22.
} 
Socialist and communist ideas had begun to take hold, supplanting the older competitive capitalist model. National security and the cherished American independence were being destroyed from within by agents no longer hailing from foreign lands, but by major statesmen at the controls of the American political machine. The rise of mass media was said to move the conspirators out of the shadowy recesses of Masonic Lodges and the Vatican, for example, and place them squarely in the public eye. Hofstadter writes that "we may now substitute eminent public figures like Presidents Roosevelt, Truman, and Eisenhower, Secretaries of State like Marshall, Acheson and Dulles, justices of the Supreme Court like Frankfurter and Warren, and the whole battery of lesser but still famous and vivid conspirators headed by Alger Hiss." ${ }^{24}$ The fears of the 'new right' in other words, were largely predicated on what was felt to be the creeping leftist sensibilities embodied in the twin bogeymen of 'communism' and 'socialism'.

\section{The Paranoid Style and the Religious Right}

The Bush Administration, and more so its ultra-conservative right-wing base, could arguably be said to represent a version of the paranoid style for the new millennium on many of these counts. As will be seen later in much more detail, the Administration is steeped within a tradition of evangelical Christian conservatism. During the 2000 Election campaign for example, the soon-to-be President responded to a question about who his favorite political philosopher was. "Christ," came his earnest reply, "because he changed my heart." While doing research for his book Plan of Attack, author Bob Woodward relates Bush's answer to a question about whether he had consulted his father, Bush Senior, for advice about the invasion of Iraq, a decision he had just taken. "I asked the president

\footnotetext{
${ }^{24}$ Hofstadter, op. cit., pp. 23-24.
} 
about this. And President Bush said, 'Well, no,' and then he got defensive about it," Woodward recalled. "Then he said something that really struck me. He said of his father, 'He is the wrong father to appeal to for advice. The wrong father to go to, to appeal to in terms of strength.' And then he said, 'There's a higher Father that I appeal to'". ${ }^{25}$ His repeated invocations of the mission in Iraq, and against terrorism in general, as a front in the battle between 'good' and 'evil' are simply too numerous to mention.

Leaving aside Bush's references to the war on terror as a "crusade" for the time being, not to mention the resonance this carries for those in the Muslim world, this sort of rhetoric has been by no means limited to the president. In another famous demonstration of this pervasive religiosity, Deputy Undersecretary of Defense for Intelligence Lieutenant-General William G. Boykin, while in full uniform, told Christian audiences that the enemy in the battle against terrorism was "Satan", and related a story from his time in Somalia. He had encountered a Muslim fighter who said he had the protection of Allah against US forces. Boykin remarked, "Well you know what I knew, that my God was bigger than his, I knew that my God was a real God, and his was an idol". ${ }^{26}$ Moral Majority leader Jerry Falwell, drawing his own inspired conclusions about the attacks, suggested that $9 / 11$ happened because God was mad at abortionists, feminists, lesbians and gays. ${ }^{27}$ Such appropriation

\footnotetext{
${ }^{25} 60$ Minutes, 'Woodward Shares War Secrets', CBS.com, April 18, 2004. Accessed on December 2, 2004.

${ }^{26}$ Author Unknown, 'US is “battling Satan" says general', BBC.com, October 17, 2003. Accessed on December 2, 2004.

${ }^{27}$ On a broadcast of "The 700 Club" immediately following the 9/11 attacks, Falwell made the following statement: "I really believe that the pagans, and the abortionists, and the feminists, and the gays and the lesbians who are actively trying to make that an alternative lifestyle, the ACLU, People For the American Way, all of them who have tried to secularize America. I point the finger in their face and say 'you helped this happen."' (Author
} 
of divine will to world or even local events has a history as long as monotheistic religion itself. ${ }^{28}$ Taken in isolation, comments such as these and the many more like them are inane, predictable, and maybe even harmless. However, when taken in the context of a broader American history of entitlement, exceptionalism, and evangelical exegesis, they become something more.

Were it not already the case that the paranoid style in American politics was so deeply entwined with a fundamentalist evangelical Christian ethos, such a case would have to be made today. But the connections between the idea of 'one God', globalization in its many forms, and the belief in certain forms of conspiracy theory, are a lot closer than one might first imagine. In fact, it becomes increasingly difficult to consider the three as truly separate from each other. There is no question that religious beliefs have broad and diverse histories which precede the existence of capital markets, and, that there is no necessary relationship between the two. Interestingly, however, the very idea of one 'true' God is closely tied to the development and expansion of early capitalism. Karen Armstrong points to what she refers to as the 'Axial Age' between $800-200$ Before the Christian Era (BCE) where, in the main regions of the civilized world, new ideologies and religious systems emerged which reflected the changing economic and social conditions. During this period, a new prosperity began to emerge which saw the rise of a merchant class, along with new forms of exploitation and inequality. She suggests that different regions developed distinct ideologies to address these problems and concerns, such as Taoism and Confucianism in China, Hinduism and

Unknown, 'Falwell Apologizes to gays, feminists, lesbians', CNN, September 14, 2001. Accessed online January 3, 2006).

${ }^{28}$ Karen Armstrong, A History of God, Ballantine Books, New York, 1993. 
Buddhism in India, and philosophical rationalism in Europe. "Strange as it may seem," she writes, "the idea of 'God', like the other great religious insights of the period, developed in a market economy in a spirit of aggressive capitalism."29 Biblical accounts being what they are (or perhaps more accurately, what they are not), there are nonetheless a few rather interesting thematic consistencies which merit some attention.

While obviously not intended as a historical record, Armstrong suggests that the Jewish myth of the Exodus, though itself important to all three monotheistic religions, has been pointed to by some modern scholars as a "mythical rendering of a peasants' revolt against the suzerainty of Egypt and its allies in Canaan." 30 She points out that the "God' which may have inspired the first successful peasants' uprising in history, is a God of revolution that espoused an ideal of social justice, notwithstanding later transformations within each religion to a God of the status quo. The idea that God was on the side of the weak and oppressed itself had roots in the social ideals of the prophets. In line with ideals like these, 'compassion' was to become one of the hallmarks of each of the major religions formed in the Axial Age. But the true test of its authenticity was to come in the real world, outside of the confines of the temple and the world of myth. After enlightenment, these teachings held, "a man or woman must return to the marketplace and practice compassion for all living beings." ${ }^{31}$ In the spirit of this sentiment, Armstrong goes on to show how in the earliest of the four Gospels, the Gospel of Mark, Jesus is presented as a perfectly normal man who may have even been

\footnotetext{
${ }^{29}$ ibid., p. 27.

${ }^{30}$ ibid., p. 19

${ }^{31}$ ibid., p. 45.
} 
a disciple of John the Baptist. "John," she writes, "had regarded the Jerusalem establishment as hopelessly corrupt and preached excoriating sermons against it." ${ }^{32}$ The biblical tale of an infuriated Jesus chasing merchants out of the temple and overturning the tables of the money-changers would be, at the very least, consistent with such teaching.

Later Christian teachings would echo some of these same themes. Though Judaism attracted many converts in the first century, after $70 \mathrm{AD}$ when Jews came into conflict with the Roman Empire and their position began to decline, they were more reluctant to seek converts and even became suspicious of them. Pagans, who may have formerly been attracted to Judaism, turned to Christianity instead. Initially, their new membership was composed primarily of slaves and those in the lower classes. It was not until the end of the second century that more highly educated pagans would become Christians and explain the new religion to an equally suspicious pagan world.

Armstrong writes that, to the Roman Empire, Christianity was first regarded as an offshoot of Judaism. It wasn't until Christians made it clear that they were no longer attending the synagogue, that the Romans began to think of them as fanatics, and became, in their turn, suspicious of Christianity. Ironically for a group that institutionalized social and political change throughout the ancient world, the Roman ethos was conservative and regarded those who threw off ancestral custom as dangerous and subversive. Against a Roman tradition of pantheism, Christianity posed a particular threat by claiming that their God was the only God and that other gods were delusions.

\footnotetext{
${ }^{32}$ ibid., p. 80.
} 
Educated pagans had looked to the philosophers of antiquity such as Plato for enlightenment, with Plato himself sometimes regarded as the son of the Greek god Apollo. To this older way of thinking, the Christian son of God seemed an unlikely one indeed. "It was one thing to suggest that men of the caliber of Plato or Alexander the Great had been sons of a god," Armstrong continues, "but a Jew who had died a disgraceful death in an obscure corner of the Roman empire was quite another matter." 33

\section{Bedouin Trade and the Rise of Islam}

Islam, not surprisingly, finds its origins colored in much the same way. In the early $7^{\text {th }}$ century, an Arab merchant who had never read the Bible was about to have his life changed forever. Traveling with his family to make the traditional spiritual retreat during the month of Ramadan, Muhammad ibn Abdallah would have spent this time praying and giving alms to the poor. A member of the Meccan tribe of Quraysh, he was becoming increasingly aware of a growing malaise in Mecca. Only two generations earlier, his tribe had been living a difficult nomadic life in the Arabian steppes not unlike many other Bedouin tribes. But in the late sixth century they had become extremely successful in trade, and Mecca had become the most important Arabian settlement. They were, in Armstrong's words, "rich beyond their wildest dreams. Yet their drastically altered lifestyle meant that the old tribal values had been superceded by a rampant and ruthless capitalism. People felt obscurely disoriented and lost." ${ }^{, 34}$ Most political solutions at the time tended towards being religious

\footnotetext{
${ }^{33}$ ibid., pp. 90-92.

${ }^{34}$ ibid., p. 132.
} 
in nature, and Muhammad was aware that the new conditions would require a corresponding ideological shift.

The Quraysh were beginning to make a new religion out of money, which makes a great deal of sense considering how it had brought them out of starvation, and from the threat of extinction that all Bedouin tribes faced. But Muhammad worried that this new cult of self-sufficiency would threaten the survival of the tribe. Previously, the tribe had always taken precedence over the individual. Personal fortunes were beginning to be built, supplanting the older communal ideal, and giving rise to a new norm of competition. Some of the least successful of family groups (or clans) within these tribes, such as Muhammad's Hashim clan, worried about their very survival. Muhammad thought that without some transcendent value at the center of the tribe other than money, tribes would tear themselves apart amid moral and political strife. Though there is much more detail to the story of Muhammad and the rise of Islam, it will suffice to point out for now that the early moral message of the Koran is that it is wrong to stockpile personal wealth, and good to share the wealth of society by giving a portion to the poor. Like the Hebrew prophets before him, Muhammad "preached an ethic that we might call socialist as a consequence of his worship of the one God." 35

It is easy to make sweeping generalizations about the practices of early capitalism and the rise of organized religions. This becomes even more problematic when one considers that these 'histories', with the possible exception of Islam, are based on little more than stories which were passed down

\footnotetext{
${ }^{35}$ ibid., p. 143.
} 
through the ages. Even the first written Christian gospel was not recorded until some 40 years after Jesus (whoever he was) had already died. It is more reasonable to assume that whatever the stories which survived, and whatever the consistencies which might be said to exist, they probably speak more broadly to collective experiences in the face of real historical change. Even when read as mere symbols of moral and ethical challenges, this need not diminish their significance. On the contrary, it is precisely at the level of symbolism and ideology that they retain a utility for trying to understand any number of later historical events carried out in the name of God. The spread of modern empire and the rise of global trade is an era in human history which also unfolded in tandem with the wilful spread of Christianity. In turning attention to more recent history, conspiratorial thinking remains a companion or component feature of this expansion.

\section{Globalism and the British Empire}

Niall Ferguson ${ }^{36}$ writes that though economic historians often refer to England as the first industrial nation, in the European quest for empire they were late-comers to the game. Following in the mold of both the Spanish and Portugese before them, they had sought the wealth attained by the Spanish with the discoveries of gold and silver in the Americas since the time of Henry VII (1485-1509). With an empire that stretched from Madrid to Manila and which included the wealthy and populous territories of Peru and Mexico, the Spanish were the envy of the world. With English dreams of finding their own 'El Dorado' going unrealized, the best they could do was to employ their skill on the seas and steal gold from Spanish settlements and ships. This envy on the part of the English only

\footnotetext{
${ }^{36}$ Niall Ferguson, Empire: The Rise And Demise Of The British World Order And The Lessons For Global Power, Basic Books, New York; 2004.
} 
grew more acute after the Reformation, Ferguson writes, "when proponents of war against Catholic Spain began to argue that England had a religious duty to build a Protestant empire to match the 'Popish' empires of the Spanish and the Portugese [...] The English conception of empire was thus formed in reaction to that of her Spanish rival." ${ }^{37}$

Ferguson spends a great deal of time detailing the growth and spread of British trade, influence, and military might around the world. It is in his description of the complicated and precarious economics of British America that he raises the central importance of religious fundamentalism to the later success of British colonies there. In addition to the profit motive, the untrammeled wilderness of the New World appealed to the Puritan desire to create a godly society from scratch. Having left England in the wake of their dissatisfaction with the 'moderate Protestantism' of Queen Elizabeth I, which was later to be upheld by James I, they arrived in 1620 on the 'New England' shores of the appropriately named Cape Cod.

Ferguson writes that it is interesting to speculate what New England might have been like if all of the people on the Mayflower had been Pilgrims. "After all, they were not just fundamentalists; they were also in a literal sense communists, who intended to own their property and distribute their produce equally." In fact, he continues, only about a third of the 149 aboard were Pilgrims, with most having responded to company ads promising rewards of a more material nature. In addition to a depression in the textile industry at home, the others were attracted by "not so much the absence

${ }^{37}$ ibid., p. 3. 
of bishops and other relics of Popery, but the presence, in large quantities, of fish." 38 As he puts it elsewhere: it was not God, but cod, that these others found appealing.

Slaughter in the name of imperialist ambitions was nothing new even then. With vastly superior weaponry and the fringe benefits of infectious disease, indigenous populations tumbled by over half in the two centuries after 1500 . What makes this noteworthy here, however, is the religious justification offered for what was otherwise a clearly commercial exercise. There was to be no peace between the Christians and the Native American "devils". The devastating impact of the smallpox epidemic that ravaged Native populations was offered as proof that God was on the side of the colonists. In fact, one of the things the Pilgrims gave thanks for in 1621 was that 90 percent of the indigenous population of New England had died in the decade before their arrival. In the words of a Carolina Governor some decades later in the 1690's 'the Hand of God [has been] eminently seen in thinning the Indians, to make room for the English." 39

In another manifestation of the twin towers of capital expansion and a belief in one God, Charles II granted William Penn the deed to what would become Pennsylvania, making him the largest individual landowner in British history overnight. Ferguson points out that this also gave him the opportunity to demonstrate "what the combination of religious fervor and the profit motive could achieve." As a Quaker, another radical religious sect, he had even been imprisoned for a time in the

\footnotetext{
${ }^{38}$ ibid., p. 52.

${ }^{39}$ ibid., p. 56; emphasis in original.
} 
Tower of London for his beliefs. Unlike the Pilgrims however, Penn sought to create a "tolerance settlement" not only for Quakers, but for any religious sect as long as it was monotheistic. With a keen understanding of the importance of profit to the success of his colony, he was to remark that "[t]hough I desire to extend religious freedom yet I want some recompense for my trouble." To this end he sold vast tracts of land at remarkably good prices, and extended his appeals for emigration beyond the British Isles into continental Europe. His plan worked, with over one million Europeans moving to the British West Indies and mainland North America. The combination of religious freedom and nearly free land proved to be a successful combination, but Ferguson points out that there was a limit to this freedom. Clearly not everyone could be a landowner. There would have to be workers too. Crops such as sugar, tobacco, and rice were being grown, but they were also very labor intensive. Various methods were needed to fill the chronic labor shortages, and it was here that the British Empire was to discover the "limits of liberty."

\section{Labor, Liberty, and the Pursuit of Happiness}

For those with only their labor to sell, the prospects of emigration to the new world ordinarily meant a conscious decision to suspend if not give up their liberty. A system of indentured servitude ensured a steady stream of cheap labor, and between a half to two-thirds of all Europeans emigrating to North America between 1650 and 1780 did so under contracts such as these. For what was essentially a period of consensual slavery, usually four to five years, immigrants received passage by ship under often deplorable conditions. Like slaves, they too were advertised for sale in local

\footnotetext{
${ }^{40}$ ibid., pp. 56-58.
} 
papers. A typical ad from the Virginia Gazette reflects the class and type of labor that were commonly in need. "Just arrived...139 men, women and boys. Smiths, bricklayers, plasterers, shoemakers...a glazier, a tailor, a printer, a book binder...and several seamstresses..." Nor was their stay very pleasant once they arrived. Approximately two in five of the new workers died within their first couple of years in Virginia, with most succumbing to malaria or intestinal disorders. But even this was vastly preferable to the British West Indies, which is where about 69 percent of them ended up. This is because trade with the Carribean dwarfed that of America, with anywhere between three to five times the revenue for the years 1713 to 1775 . In Virginia, a total immigration of 116000 produced a settlement of around 90 000. In Barbados, for example, it required 150000 to produce a population of about 20000 . Word got out eventually, and by 1700 emigration to the Caribbean dropped off sharply. ${ }^{41}$

Against a backdrop like this, it would seem hardly surprising that rebellion in the colonies was afoot. In what was to become a defining moment in American history, the much vaunted British ideal of liberty began to blowback, and the Empire began to tear itself apart. On April 19, 1775, British soldiers exchanged fire for the first time with armed American colonists. They had been sent to confiscate an arms cache belonging to colonial militias. In a now mythical ride, Paul Revere rode ahead not with a warning that 'The British are coming' - Ferguson points out they were all still British at this point - but 'The regulars are out'. ${ }^{42}$ Though the details add a bit of color to the story,

\footnotetext{
${ }^{41}$ ibid., pp. 59-61.

${ }^{42}$ ibid., p. 69.
} 
the important point is that the American War of Independence had begun. The paradox is why it should have happened where and how it did.

It is highly ironic that Lexington, Massachusetts should be the place where the Revolution started, and not, for example, at the hands of the indentured laborers of Virginia. By the 1770's, the colonists of New England were some of the wealthiest people in the world. Incomes were comparable if not at least equal to those of the U.K., not to mention being more equally distributed. Their farms and families were bigger, their educations better, and they paid a fraction of the taxes to boot. "To say that being British subjects had been good for these people would be an understatement." ${ }^{, 43}$

At the root of the unrest was the right of determination of their own affairs in the way of taxes and the like. It was the imposition of decisions from the outside, no matter how favorable they had been to this point, that cumulatively over time began to wear on the colonists of New England. To choose just one, albeit famous, example, the 'Boston Tea Party' of December 16, 1773, where 342 boxes of tea worth $£ 10000$ were dumped into the Boston harbor from the East India ship Dartmouth, shows how these tensions were not about higher taxes at all as many assume. In fact, the British had just given the East India Company a rebate on the duty on tea upon entering Britain, partly in response to the American colonists' boycott of tea. The tax on tea was exceptionally low, and the price of tea in New England had never been lower. The organizers of the 'Party' were not disgruntled consumers, but the wealthy Boston smugglers who stood to lose out by the reduction of

${ }^{43}$ ibid., p. 70. 
taxes.

On close inspection, then, the taxes that caused so much fuss were not just trifling; by 1773 they had all but gone. In any case, these disputes about taxation were trivial compared with the basic economic reality that membership of the British Empire had been good - very good - for the American colonial economy. The much-maligned Navigation Acts may have given British ships a monopoly over trade with the colonies, but they also guaranteed a market for North American exports of agricultural staples, cattle, pig iron and, indeed, ships. It was the constitutional principle - the right of the British parliament to levy taxes on the American colonists without their consent - that was the true bone of contention. ${ }^{44}$

Amid circumstances like these (including the closing of the port of Boston and the imposition of military rule after the 'Tea Party'), the first Continental Congress was held in the fall of 1774 in Philadelphia, and brought together some of the more rebellious of the colonial assemblies' membership. For the first time, votes were taken and resolutions passed which would withhold all taxes from the British government. But this itself was no statement against being British; on the contrary, it was the expression of an emphatic desire to enjoy the same level of representative clout as their compatriots in Old England. "In other words, they wanted their assemblies to be put on par with the Westminster Parliament, in what would have been a reformed, quasi-federal Empire. As

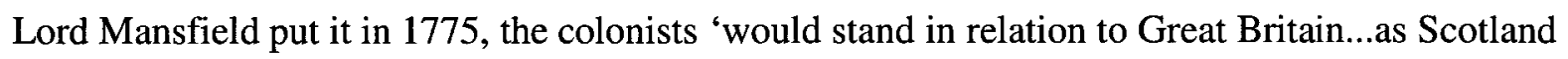
stood towards England, previous to the treaty of Union'." 45 Just over a year after the first shots at Lexington, the Declaration of Independence was adopted at the Second Continental Congress by the representatives of the thirteen secessionist colonies on July 4, 1776. A good deal of the Declaration is a rather long list of wrongs supposedly imposed on the colonists by the King, who the writers of

\footnotetext{
${ }^{44}$ ibid., pp. 72-73.

${ }^{45}$ ibid., p. 74.
} 
the Declaration, including principal author Thomas Jefferson, accused of "trying to erect a 'Tyranny over these States." His preamble captures the flavor of this period of history: "We hold these truths to be self-evident, that all men are created equal, that they are endowed by their Creator with certain inalienable rights, that among these are life, liberty and the pursuit of happiness." ${ }^{, 46}$ Though Ferguson points out that today this sounds about as revolutionary as motherhood and apple pie, at the time it was an explosive challenge not only to Royal authority, but also to the traditional values of hierarchical Christian society ${ }^{47}$.

\section{Protestant Patriotism and the Politics of Paranoia}

It is at this point that the complex of circumstances which would nurture and give rise to the 'paranoid style in American politics' deserves some consideration. While any direct, causal links between the infused religiosity of capital expansion and the origins of the paranoid style in American politics are untenable, the parallels are quite striking nonetheless. As we have already seen, a panic arose in some quarters around this same period, the end of the eighteenth century, over the allegedly subversive activities of the Bavarian Illuminati. This 'panic' was amplified and partly fueled in the West by its own reaction to the French Revolution, a Revolution which many at the time saw as evidence of the insidious successes of Illuminism. This suspicion, or panic, was further heightened in the U.S. by "the response of certain reactionaries, mostly in New England and among the

\footnotetext{
${ }^{46}$ ibid., p. 75 .

${ }^{47}$ Even more ironic is that these words should be written by someone who was himself a Virginian landowner with about 200 slaves, only 7 of whom he ever freed. For a country that won its independence in the name of liberty, slavery would remain firmly entrenched in the southern states for a number of years to come (p. 82).
} 
established clergy, to the rise of Jeffersonian democracy." 48 As an example, Hofstadter shows that in May 1798, Jedidiah Morse of the Massachusetts Congressional establishment in Boston delivered a timely sermon to a young country, a country that was then very much divided between Jeffersonians and Federalists, not to mention between Francophiles and Anglophiles. “After reading Robison," Hofstadter relates, "Morse was convinced that the United States too was the victim of a Jacobinical plot touched off by llluminism, and that the country should be rallied to defend itself against the machinations of the international conspiracy." Hofstadter goes on to say that the warnings were heeded wherever the Federalists stewed over the "rising tide of religious infidelity or Jeffersonian democracy." 4950

In light of the protectionist rhetoric of the Declaration of Independence, it seems rather curious that the rise of 'Jeffersonian democracy' should be received as evidence of a creeping international conspiracy. It begs the question as to why it would be, that in what is otherwise a message consistent with outward-looking fears such as Robison's, that Jefferson himself could become the target of them. Attention to the circumstances around the creation of the Declaration provide some clues as to why Jefferson and his own political style could be viewed this way. For starters, it is interesting that given the stated similarities between Illuminism and Enlightenment rationality, Jefferson's

\footnotetext{
${ }^{48}$ Hofstadter, op. cit., p. 10.

${ }^{49}$ ibid., p. 13.
}

${ }^{50}$ Another author, Abbé Barruel, a Jesuit expelled from France when the order was suppressed in 1773 and who was writing contemporaneously with John Robison, wrote a four-volume work that was translated and published in both England and the United States. In it, he proposed a "triple conspiracy" of anti-Christians, Freemasons, and Illuminati. In Robisonian style, he lays out a fairly predictable diatribe against the usual suspects and their subterfuge which "consisted in plots long hatched and deeply premeditated" (Barruel, pp. ix -x, 1803; cited by Palmer, 1964; in Hofstadter, 1966; p. 12). 
preamble to the Declaration "ensured that the American republic would be fashioned in terms of the Enlightenment, in terms of natural rights - above all the right of every individual 'to judge for himself what will secure his freedom'." ${ }^{51}$ Ferguson continues that it is even hard to believe that all the representatives of the thirteen colonies were able to sign the Declaration. Only twenty years before, such a thing would have seemed impossible with all the different representatives, provinces, interests, and prejudices that existed. It is worthwhile to point to Benjamin Franklin, himself a signatory to the Declaration, who also drew attention to the fact that the colonies had

\begin{abstract}
different forms of government, different laws, different interests, and some of them different religious persuasions and different manners. Their jealousy of each other is so great that however necessary an union of the colonies has long been, for their common defence [sic] and security against their enemies, and how sensible soever each colony has been of that necessity, yet they have ever been able to effect such an union among themselves. ${ }^{52}$
\end{abstract}

While the Declaration was meant to mend these divisions among 'these United States', in practice it had the opposite effect. By the standards of the day, the revolutionary language Jefferson used alienated many conservative colonists. Surprisingly high numbers of colonists fought on the side of the King, and some of the worst violence was between their factions and those of the rebels fighting for independence. It was a war that divided classes, communities, churches, and even families. ${ }^{53}$ It is interesting to note that many of the signatories of the Declaration worshiped in the same congregation at Christ Church in Philadelphia. Even more interesting is that they constituted

\footnotetext{
${ }^{51}$ ibid., p. 76; emphasis added.

${ }^{52}$ ibid.

${ }^{53}$ Benjamin Franklin, as one example, spent over a decade lobbying the colonists' cause in London before returning to the Continental Congress to fight for independence. His son William, who was the governor of New Jersey, remained loyal to the crown and the two never spoke again (ibid., p. 77).
} 
a distinct minority, with about two-thirds of the congregation either neutral or against independence. This is less surprising when one considers that the clergy themselves owed their loyalty to the King as the head of the Church of England. After the Loyalists were defeated, around 100000 left the United States for Canada, England, or the West Indies. "The amazing thing" Ferguson writes in summation, "is that so many people should have voted with their feet against American independence, choosing loyalty to King and Empire over 'life, liberty and the pursuit of happiness'."54

Given the mythical status of the Declaration of Independence today, and its flagship role in charting the early course of the American way, it is difficult to reconcile this with the conspiratorial suspicion surrounding its creation. Davis ${ }^{55}$ helps to shed some light on this otherwise 'dark subversive force,' and how it came to be connected to the very foundations of the United States. Referring to the work of Bernard Bailyn, a former professor of history at Harvard University, Bailyn's Ideological Origins of the American Revolution suggests that Americans may have "inherited a Whig interpretation of British history which largely hinged on the concept of conspiracy." The Glorious Revolution of 1688 was said to have saved British liberty from the supposed plots of the Stuart Royal family and their French and/or Catholic allies. Those triumphs, however, were later said to have been overturned within the British Parliament. By the 1760 s, this bit of history had conditioned the American colonists to the idea that "seemingly innocuous and unrelated acts of legislation might be

\footnotetext{
${ }^{54}$ ibid., p. 81.

${ }^{55}$ Davis (ed.), op. cit.
} 
parts of a systematic plan to subvert traditional liberties and concentrate power in the hands of an aristocratic oligarchy." Davis goes on to write that, at the time, "the idea of political conspiracy was taken with deadly seriousness and played a crucial ideological role in the American Revolution." He points out Bailyn "shows that both Englishmen and Americans were susceptible to suspicions of conspiracy, and that such suspicions were not unreasonable in the light of their fragmentary knowledge and the assumptions of traditional political theory." 56

Bailyn makes the case that, even though it is difficult to know how far back to trace them, the roots of conspiratorial thinking among American Revolutionary leaders were "elaborately embedded in Anglo-American political culture," and were present at least half a century before the Revolution happened. At the first signs of open conflict between the American colonies and the Crown in the early 1760 's, questions about motivations and allegations of secret purposes were openly discussed. He writes that it was as typical for an anti-administration leader to "suppose' for the sake of discussion, 'that no design is formed to enslave them"', as it was for a pro-administration partisan to "refute the charge of design." least inhibited in giving voice to more widely held apprehensions. Importantly, these sorts of debates were not limited at all to the American colonies, but instead enjoyed an almost universal sympathy with the American cause. Even in England, suspicions were rampant that the rule of King George III was such that "the influence of the Crown was being used to staff the administration with new Favourites and 'King's Friends,' who formed a secret Closet party, beyond the control of Parliament

\footnotetext{
${ }^{56}$ ibid., pp. 23-24.

${ }^{57}$ It is worthwhile to note that this parallels a modern dismissive charge of 'conspiracy theory'.
} 
and guided behind the scenes $[\ldots]^{p 58}$

Even the administration itself was not immune from such worries. It is not surprising that members of the British Parliament were as convinced as the leaders of the Revolutionary movement in the American colonies that they, themselves, were "victims of conspiratorial designs." This alleged conspiracy of intriguing men, whose occupations and professions in the New World disguised their true intentions, was thought to be the real problem. There was little doubt at the time that "the root of all the trouble in the colonies was the maneuvering of a secret, power-hungry cabal that professed loyalty to England while assiduously working to destroy the bonds of authority and force a rupture between England and her colonies." Nor did the accusations of conspiratorial wrong-doing wane after the Declaration of Independence and the American successes in battle: "They merely shifted their forms, and began a process of adaptation that has allowed them to survive into our own time."

Just as radical pamphleteers in England, patriot historians in America, and such Whig leaders as the younger Pitt continued after the war to blame the Revolution on the deliberate malevolence of the administrations of the 1760's and 1770's, so loyalists like Galloway and Thomas Jones continued to "expose" the Americans' conspiracy; continued to argue that no error had been committed by the government of George III in not conceding more to America since the colonists had been secretly determined from the start to cast off their dependence upon England; continued to link the rebels with opposition factions in England; and began, in the nadir of military defeat, darkly to suggest that the strangely defeated commander in chief, Sir William Howe, was himself not above suspicion of secret collaboration with the faction that had carried out so successfully the long-planned design of independence. $^{59}$

\footnotetext{
${ }^{58}$ Bailyn, 1967; in Davis (ed.), ibid., pp. 24-25.

${ }^{59}$ Bailyn, 1967; in Davis (ed.), ibid., pp. 26-27.
} 
Quite apart from what one might expect today, and as has been alluded to already, this conspiratorial rhetoric was anything but a fringe sensibility at the time ${ }^{60}$. Bailyn writes that it was "both an end, and a beginning - an end of the main phase of the ideological Revolution and the beginning of its transmutation into historiography." He goes on to list a number of historians on both sides of the American Revolution for whom the "charges of conspiratorial design settled easily into a structure of historical interpretation[.]" They were the histories of participants, or near-participants, each of which he points out are highly personified and highly moral, and in which the conspiratorial rumblings of the Revolution era are proffered as "the essential stuff of explanation." These views, he writes, were to survive almost unaltered for the next two generations until they emerged in a new guise in twentieth-century scholarship. Modern "progressive" historians in the early twentieth century, as well as their successors in the post-World War I era, were quick to adopt, unknowingly, the Tory interpretation of the Revolutionary leaders' expressed fears about 'slavery' and 'ministerial conspiracy" as mere propaganda designed to mobilize otherwise passive colonial populations. "No Tory or administration apologist during the Revolution itself," Bailyn writes, "ever assumed more casually than did such distinguished modern scholars as Philip Davidson and John C. Miller that the fears expressed by the Revolutionary leadership were factitious instruments deliberately devised to manipulate an otherwise inert public opinion." Similarly, no patriot writer ever went to such elaborate lengths to prove that there was in fact a ministerial conspiracy - "a plot of King's friends aimed at victimizing the colonists - than that of Oliver Dickerson in his Navigation Acts and the

\footnotetext{
${ }^{60}$ Even the original ' $W$ ', George Washington, was known to give credence to such theories. Though not a prototypical proponent of the paranoid style, he nonetheless perceived the acts of British Parliament as part of a systematic plan to enslave America. Writing in 1774, he stated that he was "as fully convinced, as I am of my own existence, that there has been a regular, systematic plan formed to enforce [the acts], and nothing but unanimity in the colonies (a stroke they did not expect) and firmness, can prevent it" (cited in Davis (ed.), ibid., p. 34).
} 
American Revolution (1951)." ${ }^{, 61}$ In other words, conspiracy theories from both sides of the American Revolution helped to establish competing templates for subsequent historical recollection.

\section{Evangelical Imperialism and the Old World Order}

There is no need to spend a great deal of time here tracing the history of British imperialism and capitalist expansion. To the extent it was the closest thing to global domination ever achieved, and, to the extent that it contributes to a broader understanding of any interrelationships between that expansion and the rhetoric of conspiracy theory, some attention to these dynamics outside of the American experience is useful. The British experience in both Africa and India demonstrate similar dynamics, albeit with some notable differences. The Victorian era ushered in a new attitude about global domination, one that included dreams of elevating and improving other peoples and races. Gone would be the days when populations were simply exploited. Instead, culture became a new battlefront on the horizons of the British Empire. Where superstitious belief systems and backward societies had ironically been tolerated, and in some cases even admired and studied under Georgian rule, they were now to be eliminated with the British foray into the Dark Continent.

Although Africa was home to a number of states and nations which were in some cases even more economically advanced than pre-colonial North America and Australasia, they were seen as unenlightened by Victorians in some significant ways. With some exceptions in the northern and southern extremities, sub-Saharan Africa was not monotheistic, was home to lethal diseases such as

\footnotetext{
${ }^{61}$ Bailyn, 1967; in Davis (ed.), ibid., pp. 27-28.
} 
malaria and yellow fever, and derived its biggest source of revenue by supplying slaves to European and Arab traders. "The peculiar path of global economic development," Ferguson writes, "led Africans into the business of capturing and selling one another." But the Victorian missionary efforts at the time were like the NGOs of today, and the missionaries believed they knew what was best for the Africans. ${ }^{62}$

In lock-step with a new British moral indignance over slavery, the not-for-profit motive of the missionary experiment in Africa was to be one of the significant differences, though its underlying rationale was still the expansion of British influence. Victorian aid agencies brought a spiritual message along with material assistance to the less developed African continent. With origins in the 1698 Society for the Promotion of the Christian Gospel, and the Society for the Propagation of the Christian Gospel of 1701, aid agencies expanded on their initial concern for the spiritual well being of colonists and overseas soldiers to include the salvation of the heathen. A 1776 editorial in the Evangelical Magazine captures the flavor of this well-intentioned concern. "It was to 'this benighted and oppressed country' that the magazine's editors were 'desirous of sending the Gospel of Christ...that essential blessing which outweighs the evils of the most suffering life'." ${ }^{63}$ Within 20 years, the Baptist Society for Propagating the Gospel among the Heathen, and the London Missionary Society, among others, were formed amid similar aspirations for spiritual enlightenment.

\footnotetext{
${ }^{62}$ Ferguson, op. cit., p. 93-94.

${ }^{63}$ ibid., p. 99.
} 
For those wishing to spread the 'Good News' in Africa, Freetown was the place to start. By 1804 missionary societies had begun work there converting "recaptives", or those slaves freed and brought there by the British Navy. But in other endeavors, the work of converting the heathen took on a dangerous hue for the army of idealistic young men who sought to take on such a charge for the greater good. As always, even the travel necessary to begin work could prove deadly. A typical example is the twenty-three year old William Threlfall, one of the bright lights of the Methodist Mission. On his trip to Cape Town South Africa, a spate of typhus which broke out on board the ship almost killed him, and then he became gravely ill shortly after arriving at his destination. On what he feared was his deathbed, he was recorded to have "seized hold of a friend's hand and, 'with the most impressive earnestness expressed his wish that he was black, that he might go among the natives of the country without being liable to the suspicion of being influenced by sinister or worldly views'. This time Threlfall recovered[,]" Ferguson continues, but "less than a year later he and a companion were hacked to death by bushmen." ${ }^{\prime 4}$

It was the work of another that was to change the nature of the relationship between Africa and Britain forever. Born in 1813, David Livingstone was later to embody the two main intellectual currents of his time, the science of the Enlightenment, and the missionary zeal of Calvinism. One led to the study of medicine, and the other to service with the London Missionary Society. After finishing his medical training, and then being ordained a minister, he seemed to be well suited to the spread of both Christianity and civilization. A hardy individual who survived many a bout with

${ }^{64}$ ibid., pp. 99-100. Threlfall's example is included here not only for the dark irony of his fate, but also as a register of the climate of suspicion that he and thousands like him encountered in their work. 
malaria, not to mention being mauled by a lion, he was quick to become disillusioned by the slow pace of the conversion process, even though he had been posted to the London Society's model mission in Africa. His experiences put the lie to the Missionary Magazine's pious propaganda, and he soon realized that any interest shown in him had much more to do with his medical knowledge than any desire for the Good Word. A British visitor noted that " "the tribe's favourite pas-time' was 'imitating Livingstone reading and singing psalms. This would always be accompanied by howls of derisive laughter' ${ }^{,{ }^{65}}$ Before long, Livingstone was to realize that the superstitions of the African tribes were more impenetrable than he had thought. He came to feel that in order to be successful, the African wilderness itself would have to be converted if it was to become receptive to British civilization. In the spirit of this more earthly revelation, in 1848 he effectively embarked on a career change, unofficially foregoing the missionary calling to become an explorer.

The idea that Africa needed to be explored before it could be converted was not a new one. As early as 1830 , with the foundation of the Royal Geographical Society, many had been saying the same thing. Livingstone was to meet with some very early success too, completing a 600-700 mile journey across the Kalahari desert in 1849 . His report of the trip, after having been passed on to the Geographical Society by the London Mission, won its gold medal and a portion of its annual Royal Prize for geographical discovery. But this was to be only the first of many stories which was to capture the imaginations of his mid-Victorian cohort in the U.K.. In 1853, as an example, he set out on a 300 mile journey along the Zambezi river, then continued up from Linyanti in present-day

\footnotetext{
${ }^{65}$ ibid., pp. 101-104.
} 
Botswana to Luanda on the coast of Portugese Angola. In the words of The Times, it was "one of the greatest geographical explorations of the age." And he wasn't finished either. After resting, he retraced his path back to Linyanti and then embarked on an unprecedented quest to Quilimane in Mozambique, literally becoming the first European to cross the African continent from the Atlantic to the Indian Oceans. He was the quintessential hero of his age, rising from humble origins as a child factory worker, through self-education, to blaze a path for British civilization in what was known to be one of the least habitable continents on earth.

For Livingstone however, in his desire to open up the Dark Continent to Christianity and civilization, what disheartened him the most was the discovery in his travels that the slave trade was still flourishing. This, despite the fact that the trafficking of slaves had supposedly been arrested by British abolition law on the west coast of Africa with the help of the British Navy. The trade had continued, however, with perhaps as many as two million slaves from Central and East Africa being shipped to places like Arabia, Persia, and India. Ferguson puts it well when he writes that "[t]o a man of Livingstone's generation, who had no experience of the far larger slave trade the British themselves had once run in West Africa, the spectacle of slave caravans and the devastation and depopulation they left in their wake was profoundly shocking." He continues that Livingstone was later to write " [ $[\mathrm{t}]$ he strangest disease I have seen in this country [...] seems really to be brokenheartedness, and it attacks free men who have been captured and made slaves... One fine boy of about twelve years...said he had nothing the matter with him, except pain in his heart.' Livingstone was as indignant about the sufferings of slaves as a previous generation had been indifferent to 
them." ${ }^{66}$ This last sentence alone merits an extended quotation:

It is easy to dismiss the Victorian missionaries as cultural chauvinists, unthinkingly dismissive of the African societies they encountered. This charge cannot be levelled at Livingstone. Without the assistance of the indigenous peoples of Central Africa, his journeys would have been impossible. The Makololo may not have accepted Christianity, but they were eager to work for him; and as he came to know them and the other tribes who helped them, his attitudes gradually changed. The Africans, he wrote, were often "wiser than their white neighbours".

To those who portrayed them as murderous, he replied that he had "never entertained any suspicions of foul play while among pure Negroes and was with one or two exceptions always treated politely, indeed so thoroughly civil were the more central tribes [that]... missionary of ordinary prudence and tact would certainly secure respect". He refused to believe, he would later write, "in any incapacity of the African in either mind or heart...In reference to the status of Africans he encountered among the nations of the earth, we have seen nothing to justify the notion that they are of a different 'breed' or 'species' from the most civilized". It was precisely Livingstone's respect for the Africans he encountered that made the slave trade so repugnant to him; for it was this "trade of hell" that was destroying their communities before his very eyes (pp. 106-107).

Up until this point, Livingstone had only encountered subsistence economies and primitive superstition. What he had now come face-to-face with, however, was a very sophisticated economic system on the East African coast that was bolstered by the Arabian and Portugese slave trades. By this time more well known for being an explorer, Livingstone was to set about opening up the center of Africa to both God and civilization. Having been deeply moved by his exposure to the trafficking of his much beloved African people, he became convinced that if a trade route could be found, the natural wealth of the Dark Continent would upend slavery in its tracks.

When he first encountered what he was soon to rename Victoria Falls, he believed he had found the

${ }^{66}$ ibid., pp. 105-106. 
way. Awestruck by their beauty, he was equally moved by his broader vision of a civilizing British settlement in the heart of Africa. As civilization and commerce poured in, he believed, old superstitions would wash away and the God of Christianity would replace them. His written descriptions splashed with opportunity to incorporate the region into the imperial economy. Beside the falls lay the Batoka Plateau, with a landscape he described as "open undulating lawns covered with short herbage such as poets and natives call a pastoral country." It was where "wheat of superior quality and abundant yield" grew alongside "other cereals and excellent roots in great variety." From here, he believed, civilization would radiate outwards until the continent was free from slavery and superstition. It was, in Ferguson's words now, “a bold, messianic vision that linked together not only commerce, civilization and Christianity but also free trade and free labour." ${ }^{\prime 67}$ There in the Zambian Highlands, freedom would reign.

\section{Out of Africa on the Orient Express}

The situation in India was much more complex than that of Africa. Where Africa was comparatively primitive and unexplored, Europeans had been living among the people of India for over a century and a half. With polytheistic and monotheistic belief systems living side be side, Europeans held no intentions to challenge these other faiths. The British, on the contrary, "often took pleasure in being orientalized." ${ }^{68}$ Many of the predominantly male population of soldiers and merchants stationed there learned the languages and took mistresses and brides in the bargain.

\footnotetext{
${ }^{67}$ ibid., pp. 108-109.

${ }^{68}$ ibid., p. 110.
} 
The East India Company had enjoyed many years of prosperity amid religious tolerance and even mutual admiration. Though more like a state-run institution than a business - it maintained its own private army for instance - a steady balance of trade with India remained the primary concern. In what was sometimes even a delicate mixture of Western and Eastern philosophies, commerce was paramount. Movements afoot to either Christianize or in anyway tinker with Anglo-Indian relations in this regard were sternly legislated against. As an example, the East India Company chaplains were expressly forbidden from preaching to Indians, and the company used its leverage to restrict the entry of missionaries into the country. In a letter from the President of the Board of Control in India to the Governor-General in 1808 , he stated that:

\footnotetext{
We are very far from being averse to the introduction of Christianity into India...but nothing could be more unwise than any imprudent or injudicious attempt to induce it by means which should irritate and alarm their religious prejudices...It is desirable that the knowledge of Christianity should be imparted to the native, but the means to be used for that end shall only be such as shall be free from any political danger or alarm...Our paramount power imposes upon us the necessity to protect the native inhabitants in the free and undisturbed possession of their religious opinions.
}

But in 1813 when the company's charter came up for renewal, true to form, the Evangelicals seized the opportunity to try and end the company's control over the role of missionaries in India. The same individuals who were behind the campaign to end the slave trade, and who began the missionary movement in Africa, now had their sights set on India. This time though they were bolstered by an insider, one Charles Grant, who had been a former East India Company director. After a wayward youth spent in India, he experienced a religious conversion and issued a challenge to advocates of toleration, including Thomas Munro, the Governor of Madras at the time. "Is it not necessary, to conclude that...our Asiatic territories...were given to us, not merely that we might draw an annual profit from them, but that we might diffuse among their inhabitants, long sunk in darkness, 
vice and misery, the light and the benign influences of the Truth...??69

Despite the protests of the directors of the East India Company, Evangelicals mobilized 837 petitions all over the country, calling for an end to the restrictions on missionary activity in India. Together, they collected almost a half a million signatures. In a sign of how well coordinated they had been, almost all of the 12 of these petitions that survive today use the same preamble: "The inhabitants of the populous regions in India which form an important portion of the British Empire, being involved in the most deplorable state of moral darkness, and under the influence of the most abominable and degrading superstitions, have a pre-eminent claim on the most compassionate feelings and benevolent services of British Christians." Other versions of this same theme tended to reproduce the assumption of British moral superiority, and the "horrible rites and degrading immorality" of their Indian subjects. Formulaic appeals of this sort were also distributed in Evangelical newspapers at the time. Just as when the issue was the slave trade, appeals like this won out over the vested capital interests. A new East India Act in 1813 opened the door to Evangelical missionaries, with a bishop and three archdeacons appointed to India. Within a number of years, there were some fifty-eight Church Missionary Society preachers operating in India as soldiers of Christ against the forces of darkness. In what would become typical of the rhetoric that accompanied this conversion of the unwilling, British missionaries like George Gogerly were set upon, in one instance, by two "demoniacal" individuals who were "under the influence of some powerful and stimulating drug." After Gogerly and his companion were threatened to remain quiet, the soon-to-be

\footnotetext{
${ }^{69}$ ibid., 112-113.
} 
assailants turned to the crowd and declared that the missionaries were the

paid agents of the Government, who not only had robbed them of their country, but who were determined by force to put down both Hindooism and Mohammedanism and to establish Christianity throughout the land; that their home would be defiled by the killers of the sacred cow, and eaters of her flesh; that their children would be taught in their schools to revile the holy Brahmins and discontinue the worship of the gods. Pointing to [them] they then exclaimed, "These men come to you with honeyed words, but there is poison in their hearts; they intend only to deceive that they may destroy."70

And as crazed and 'demoniacal' as they were described as being, they were, after all, on to something. Liberalism was increasingly popular in mid-nineteenth century India, and part of the Evangelical project was the Anglicization that came with it. Though eighteenth century classical liberals like Adam Smith had been hostile to imperialism, John Stuart Mill took a different view in the Victorian era. Obviously favoring the supremacy of the British order of things, high on his list was the "improvement of the public intelligence; the decay of usages or superstitions which interfere with the effective implementation of industry; and the growth of mental activity, making the people alive to new objects of desire". ${ }^{71}$ Ferguson points out that like Livingstone, Mill also saw that the "cultural transformation of the non-European world [was] inextricably linked to its economic transformation. These twin currents of the Evangelical desire to convert India to Christianity and the Liberal desire to convert it to capitalism flowed into one another, and over the entire British

\footnotetext{
${ }^{70}$ ibid., pp. 114-115.
}

${ }^{71}$ ibid., p 115. The repeated invocations against 'superstitions' in contexts like these begs the observation that they may or may not be, in certain circumstances, synonymous with conspiracy theories. Though not forgetting the very real role that superstition no doubt played in tribal communities in any case, the parallels are worth noting for the time being. It should be pointed out, however, that there is a whole literature on the role of 'rumor' in African American populations in the United States (see Peter Knight, 2000; Ch. 4 'Fear of a Black Planet') which closely echoes conspiracy thinking in that community. 
Empire."72

If the intertwined practices of Christian commercialization created suspicious minds in Indian populations, the same was true of certain Indian customs which struck the British as barbaric. Female infanticide, likely performed to avoid large doweries to high-caste families, had been known to the British since the late 1780 's. Even more dreadful was the Hindu practice of anumarana where the widow of a deceased man was burned along with him, alive, on his funeral pyre. There was no disputing the existence of these customs, nor was there any disputing that the British tried to stamp them out. But it was the existence of one other alleged practice, which was widely reported, that was more difficult to pin down. It was the practice of 'thagi'(often spelled thuggee), and it referred to a cult of assassin priests who were said to strangle and kill unsuspecting travelers on Indian roads. Despite a zealous effort to root it out, its very existence was even doubtful, with some modern scholars suggesting that it was a figment of overactive expatriate imaginations. A key figure in the examination of the alleged practice was William Sleeman, a soldier turned investigator. These "thugs", he was certain, were members of a "complex and sinister secret society" and were "dedicated to the ritual murder of Indian travellers." These thugs

...skilled in the arts of deception...enter into conversation and insinuate themselves, by obsequious attentions, into the confidence of travellers of all descriptions... When [they] determine to attack a traveller, they usually propose to him, under the specious plea of mutual safety or for the sake of society, to travel together and on arriving at a convenient place and a fit opportunity presenting one of the gang puts a rope or sash round the neck of the unfortunate persons, while others assist in depriving him of his life. ${ }^{73}$

\footnotetext{
72 ibid., p. 116.

${ }^{73}$ ibid., pp. 116-117.
} 
Needless to say, conspiracy theories like this were anything but few and far between. And not surprisingly, they took shape on both sides of the imperial fence. One in particular was to play a key role in the Indian Mutiny of 1857.

It needs to be noted that the Indian Army was one of the foundational influences in the establishment of British rule. As a fighting force, the army was composed primarily of the elite sepoys, a traditional warrior caste, and enjoyed a stellar reputation in battle. Quite unlike the traditional British soldier who was drawn from the lower rungs of society, the sepoys considered their warrior status as a calling inseparable from their religious faiths, whether it be Hindu, Muslim, or Sikh. This is significant, because in what Indian schoolbooks refer to as 'The First War of Independence' [notwithstanding the fact that Indians fought on both sides], the unrest began with rumors that the new rifle cartridges had been lubricated with animal fat. The ends of these cartridges had to be bitten off before use, and so this was a problem for either if the fat came from cows or pigs. The risk of defilement-by-cartridge was seen by many sepoys at the time as proof that "the British did indeed have a plan to Christianize India - which, as we have seen, many of them did. The fact that the cartridges had nothing whatever to do with that plan was beside the point." The issues behind the theories were about much more than lard, and had political as well as religious dimensions. It was the cumulative effect of successive efforts on the part of the British to meddle and interfere with Indian culture that, for many, added up to a British plot to Christianize India. The tension in the air was perceptible at the time of the uprising, as one British officer recorded. "I can detect the near approach of the storm, I can hear the moaning of the hurricane, but I can't say how, when or where it will break forth...I don't think they know themselves what they will do, or that they have any plan 
of action except resistence to invasion of their religion, and their faith." In what little testimony survives from that period, a recurring phrase tells the story of the mutiny: It was indeed "a war in the cause of religion." Mutineers were said to cry "brothers, Hindoos and Mussalmans, haste and join us, we are going to a religious war [...] these infidels should not be allowed to remain in India."74

A few of the details surrounding the uprising are worth recounting for how closely they parallel other, more recent events. The infantry divisions who refused the new cartridges were immediately disbanded, and some were jailed for their insubordination. In some cases, after hearing of the imprisonment of their comrades, jails were set upon and thrown open, releasing not only the mutineers, but also "more than a thousand cut-throats and scoundrels of every sort." Their reprisals against their British officers were horrific and bloody. The revolt spread quickly, and it was as if once the decision had been taken to defy the authority of the white officers, the rebels ran amok killing every European they came across, often with the aid of local mobs. Women and children, suffice it to say, were not spared.

In Delhi, the historic capital of the Mughal Empire, a five-point proclamation was issued by the King of Delhi which may be the closest thing produced during the rebellion to a manifesto for national independence. It is notable, not only because it calls on a wide range of social groups (including taxcollectors, merchants, public employees, and priests) to remember that it is a war against the British on account of religion, but also for its list of more secular concerns. Among these are the charge of

\footnotetext{
${ }^{74}$ ibid., pp. 121-122.
} 
excessive tax assessments by the British, excluding Indian merchants from trade, displacement of Indian products with British imports, and maintaining a monopoly on all the best job postings in both the civil and armed services. The tally at the end of the battle for Delhi shows his calls were not heeded as he may have wished. A memorial to those killed on the British side overlooks the city today, and records that one third of officers and over eighty percent of the casualties in the other ranks were 'native'. "When Delhi fell to 'British' forces," Ferguson observes, "those forces were mostly Indian."75 Despite the integrated nature of the forces however, back home in Britain the conflict was cast in terms of black vs. white. Lurid stories of atrocities confirmed in the minds of a credulous population that it was a battle between good and evil, Christian vs. heathen.

Retribution was to be swift and utterly savage. 1857 had been the Evangelical movement's "annus horribilis", having offered the Indians Christian salvation only to have it violently rejected. Calls for revenge filled the Sunday sermons countrywide, replacing what had been petitions for redemption. A sample from a service for 25000 at the Crystal Palace is useful for what it reveals about the mood of the time:

My friends, what crimes they have committed!...The Indian government never ought to have tolerated the religion of the Hindoos at all. If my religion consisted of bestiality, infanticide and murder, I should have no right to it unless I was prepared to be hanged. The religion of the Hindoos is no more than a mass of the rankest filth that imagination ever conceived. The Gods they worship are not entitled to the least atom of respect. Their worship necessitates everything that is evil and morality must put it down. The sword must be taken out of its sheath, to cut off our fellow subjects by the thousands. ${ }^{76}$

\footnotetext{
${ }^{75}$ ibid., pp. 122-125.

${ }^{76}$ ibid., p. 126.
} 
Evangelicals don't mince words. But their actions were to speak louder still. The details are largely irrelevant to the purposes here, except to note that the accounts of the dreadful military executions which followed the containment of the mutiny, were described by a witness as being "read with delight by people who three weeks ago were against all capital punishment." The Times wrote that "every tree and gable-end in the place should have its burden in the shape of a mutineer's carcass." In scores of Indian towns and villages, The Times would have their wish. ${ }^{77}$

It is interesting, and perhaps even counter-intuitive, that in what was to become such an unmitigated and colossal failure, the project to 'modernize and Christianize India' wouldn't weaken the Evangelical cause. In fact the very opposite happened. Despite the commercial viability of the East India Company which was largely possible only through a policy of religious and cultural nonintervention, and, that those who had strongly cautioned against any intervention had been proven right, Evangelicals refused to accept it. To their way of thinking, the Mutiny was the result of Christianization not happening quickly enough. Even while in the throes of the annus horribilus of 1857, one missionary wrote that he felt a blessing was descending upon them. It was a blessing which came as a result, he thought, "in answer to the prayers of our bretheren in England":

Instead of giving way to despondency, well does it become us to brace ourselves anew for our Master's work, in the full assurance that our labour will not be in vain. Satan will again be defeated. He doubtless intended, by this rebellion, to drive the Gospel from India; but he has only prepared the way, as often before in the history of the Church, for its wider diffusion.

${ }^{77}$ ibid., p. 127. 
Only a year later in 1858 , the leaders of the London Missionary society echoed this feeling in a report that read, in part, that

By the deeds of perfidy and blood which have characterized the Sepoy rebellion, the delusion and false security long indulged by multitudes in Britain and in India, have been for ever destroyed and idolatry, in alliance with the principles and spirit of Mahomet, has exhibited its true character, a character only to be understood to be dreaded and abhorred...The labours of the Christian missionary, which were heretofore treated with derision and contempt are now commended as the best and only preservative of property liberty and life.

Even David Livingstone, the 'superhuman' African explorer and sometimes frustrated missionary himself, gave a rousing lecture to Cambridge University's Senate House. In it, the man "who had set out to Christianize Africa made it clear that he also saw the Indian Mutiny as the result of too little missionary work, not too much":

I consider we made a great mistake when we carried commerce into India, in being ashamed of our Christianity...Those two pioneers of civilization - Christianity and commerce - should ever be inseparable; and Englishmen should be warned by the fruits of neglecting that principle in the management of Indian affairs. $^{78}$

\section{Faith and Suspicion in an Age of Empire}

It is at this point that what at first glance appears to be a glaring contradiction needs some extended consideration. It is interesting to consider the paradox which lies at the center of all monotheistic belief systems, and that is the central reliance on faith. Dictionary definitions of the concept suggest variations on the themes of confidence in the belief of some truth, value, or trustworthiness of some

${ }^{78}$ ibid., pp. 128-129. But here, as history shows, even the great Livingstone had overstepped himself. In the reconstruction that was to follow the debacle of the Indian Mutiny, Queen Victoria issued a proclamation on November 1, 1858 that expressly renounced 'the right and the desire to impose Our convictions on any of Our subjects'. 
idea, person, or thing. They go on to add a dimension important to a discussion of religious faith, that being belief in some idea in the absence of any logical proof, or material evidence. Religious dogma is predicated, of course, on faith in the divine wisdom and perfection of God's plan. In fact, it is possible to go even further still, and point out that faith itself is impossible without the complete absence of any tangible evidence to support it. Though the canonical texts of Judaism, Christianity, and Islam are full of stories about divine revelation and Godly intervention, the inescapable reality is that it is the belief in them which makes them work. In other words, one requires faith that they are evidence of God's eternal plan for them to become so. Evidence annihilates faith with time. It is here that the crux of the paradox becomes important because of the way that faith, especially in a religious context, is strengthened in the absence of any proof.

Having just seen this dynamic at work in the failed British efforts to Christianize India, it provides just one handy example of what makes the concept of faith such a powerful force, for in certain circumstances it becomes impossible to refute. Efforts to do so can have precisely the opposite effect. This is not to suggest that, in a rational world, a preponderance of evidence to the contrary can never result in or produce Enlightenment. Rather, it is simply to point out the obvious fact that the dialectical tensions between rationality and religious dogma are still playing themselves out on the world stage today. And furthermore, it raises an interesting parallel. When understood as a narrative form, fundamentalist religious tensions are only spitting distance from conspiracy theory, albeit with one key difference. Where monotheistic religious beliefs are predicated on faith, conspiracy theories are predicated on its dialectical opposite: suspicion. 
There are many interesting similarities between religious rhetoric and conspiracy theory. In fact, it could be said that the only big difference is the agent imagined to be at the controls. Recalling Cubitt's schematic definition of conspiracy theories, he wrote that "a conspiracy theory does three things: it attributes the events of history or current affairs to conscious human volition; it sharply distinguish[es] between the human forces of good and of evil; [and,] it implies a hidden reality beneath and at odds with the superficial appearances of the political and social world [...]"79 Leaving aside for the moment how eerily close this comes to also describing the current foreign policy of the Bush Administration, Evangelical Christianity does attribute the events of history to the will of God, is predicated on the distinctions between good and evil, and requires as an article of faith a belief in the divine wisdom of God's plan, despite the 'superficial appearances of the political and social world'. The colloquial truism that 'God works in mysterious ways' reads more like an after-the-fact rationalization of unforeseen troubles in the ebb and flow of earthly experience. No matter what obstacles one encounters, ones" "faith" is ostensibly enriched by the poverty of circumstance.

The same is true of the opposite. God's 'help to those who help themselves' casts success and prosperity as divine providence, defacto proof of a favored member status with the Almighty. Many examples of this have already been seen. The point here is to highlight the similarities between religious belief systems and those of the conspiracy theorist. The beguiling evil of Satan for the religiously inclined is replaced with a cold-hearted omnipotence and self-serving rationality for the conspiracy theorist. Obstacles to personal enrichment (in whatever form it is imagined) provide

\footnotetext{
${ }^{79}$ Cubitt, op. cit., p. 2.
} 
further evidence of the vastness and on-going success of the conspiracy: 'The Truth is out There' for those unafraid to see it. Presenting evidence to the contrary only reaffirms the scale and scope of what the outsider refuses to acknowledge. In the 'perfect systems world' of the conspiracy theorist, it has all been planned out in advance. Resistance is futile, and exposing the conspiracy the only salvation. Figuratively speaking, the rose-colored glasses of the born again Christian are analogous to the 'Men in Black' shades of the conspiracy theorist.

Admittedly, there is only so much faith one can put in biblical narratives. Still, the consistent presence of what might otherwise be described as 'socialist themes' in the origins of monotheistic religion sets an interesting groundwork for a study of the expansion of commerce, as well as the conspiracy theories which sometimes accompany it. Simply put, there is no missing the consonance between Biblical or Koranic references to the equitable distribution of wealth and prosperity, and later political or economic orientations which, in their own ways, have tried to say more or less the same thing. It may indeed be easier for a camel to pass through the eye of a needle than for a rich man to enter the Kingdom of God, but you wouldn't know it from the rhetoric and practice of global capital.

It is highly ironic that so much of the early history of capitalism and imperial expansion should be cloaked in the language of the pulpit. Considering the many ways that different religions have either embraced or reviled this rhetoric and its practice, the rhetoric of religion remains to be seen in many of the practices which accompany the accumulation of private or corporate wealth. Religion may 
or may not be the opiate of the masses, but it could very well be one key symptom of the excesses of the few. In this regard, a focus on the conspiracy theories related to the ordained exercise of private or corporate wealth may be a productive analytical tool to cut across and help understand the systemic inequalities inherent to the unimaginably vast and complex large-scale successes of global capitalism. This is especially the case in those specific instances where the boundaries between religion, capital expansion, and conspiracy theory spontaneously coalesce and disappear.

There is no intention whatsoever to make the argument that there is no difference between Christianity, capitalism, and conspiracy theories. Jumping into and between Judaism and Islam one encounters compositionally distinct elements that would put the lie to a position like this immediately. Nor is there any attempt to demonstrate that there is a necessary relationship between religion, capital, and conspiracy thinking, because there just simply isn't a necessary relationship. But even the cursory historical overview here demonstrates a number of different instances where each becomes a component of the other two. More specifically, there is no way to think about the 'paranoid style in American politics' without simultaneous reference to a conservative Christian political and economic orientation. Likewise, there is no missing the widespread suspicions against Freemasonry or Illuminism, for example, outside of a faith-based religious orthodoxy, nor the European tensions and puritanical utopianism which accompanied the colonial settlers into the New World. These suspicions also fueled feelings of dissatisfaction and revolutionary sentiment, and simmered their way into the Declaration of Independence. The manifest destiny unleashed along the way in the form of U.S. foreign policy generally (and in the Middle East specifically) has reinforced its own history of conspiracy thinking in the Arab world, something we will see in more detail over 
the coming chapters. Those theories too, have their own religious and economic rationalizations which spin off of or collide with those of the West generally, or in the case of September 11, the U.S. specifically. The military response in Iraq has only exacerbated this already volatile complex of circumstances.

Framing the American-led response to the $9 / 11$ attacks as one of those rare instances where the boundaries between religion, capital interests, and conspiracy theories become more difficult to see, especially but not exclusively in the Arab world, sets the stage for a contextualized analysis along the lines of what has been presented above. In the next chapter, I begin by looking at the role of the Catholic Church in another long-standing ritual of symbolic rebellion, that of the carnival. This will be done in order to establish a rather detailed understanding of the carnival as a basis upon which a study of the conspiracy theory can be modeled. This is because the conspiracy theory, like the carnival, is predicated on social and political frictions which are inseparable from their own expression. 


\section{Chapter Two - Conspiracy Theory and the Politics of Carnival}

If it wasn't for the many barrels of gunpowder in a cellar under the British Houses of Parliament, November 5, 1605 might have started like any other day. It was to have been the culmination of a conspiracy to kill the King of England, James I, along with as many of the British Members of Parliament as possible, over the administration's alleged misdeeds and persecution of English Catholics. In what was to become known as the "Gunpowder Plot", the loyalties of what would eventually become thirteen men were sworn to uphold and carry it out. The oath of the original five conspirators was sanctified by both a mass, and the administering of the sacraments by a Jesuit priest named John Gerard. Under the assumed name of John Johnson, one of the leaders of the conspiracy had been planning the attack since early May of 1604. The original plan had allegedly called for the digging of a tunnel from the basement of a nearby tenement, and while the factual accuracy of this claim is sketchy, it was abandoned in any case when the cellar was secured with the help of coconspirator Thomas Percy.

After gradually filling the cellar with the barrels of gun powder, and covering the tops of them with iron bars and wooden logs so as to maximize the lethality of the explosion, Johnson and his colleagues awaited their opportunity. The significance of November $5^{\text {th }}$ that year was to be the opening session of the British Parliament. It was an event that traditionally included, then as now, the participation of the reigning Monarch. ${ }^{1}$ As the date approached though, what weighed on the

\footnotetext{
${ }^{1}$ It is worth noting that since this time the opening of the British Parliament has included a precautionary and now largely symbolic check of the cellars under the buildings.
} 
minds of some plotters was the likelihood that fellow Catholics in attendance that day might also be killed. On October $26^{\text {th }}$, a now famous but ambiguous letter of warning to William Parker, the $4^{\text {th }}$ Baron Monteagle, caused concern among some of the group that the plot was about to be foiled. The vagueness of the letter, however, was thought to be insufficiently alarming, and the plot continued. By October $30^{\text {th }}$, 'Johnson', apparently unaware of any concern, had by this time again inspected the cellar and determined that nothing had been disturbed.

By November $3^{\text {rd }}$, all but Johnson had made plans to bid a hasty retreat from London. After all, it was he who had agreed to mind the cellar and light the fuse, owing no doubt to previous munitions experience while fighting with the Spanish Army in the cause of Catholicism. But the very next day, the Lord Chamberlain, Thomas Howard the Earl of Suffolk, accompanied by Monteagle, and John Whynniard, searched the Parliament Buildings. Upon their inspection they came across the unusually large pile of materials in the cellar, not to mention John Johnson himself. Describing him as a "very bad and desperate fellow", they inquired as to the nature of the pile, and were told it belonged to Thomas Percy, for whom he worked. Unconvinced, they reported this information to the King. Their feelings that Johnson "seemed to be a man shrewd enough, but up to no good" was all they needed to warrant a second inspection of the cellar. This time accompanied by Sir Thomas Knyvett, Westminster magistrate and Gentleman of the Privy Chamber, a closer inspection of the pile uncovered the gun powder. Johnson, who had in the meantime left to warn Percy and then returned, was arrested on the spot. Incriminating him even further at the time of his arrest was "a watch, slow matches and touchwood" in his possession. 
In the early morning hours of November $5^{\text {th }}$, the Privy Council met in the King's bedchamber, and Johnson was brought in under armed guard. He refused to give any information other than that his name was John Johnson, and that he worked for Thomas Percy. When asked by the King how he could have participated in such a treasonous plan, he replied in essence that desperate times called for desperate measures, adding that he'd like to 'blow all the Scotsman present back to Scotland'. James I would have none of this insolence, and on November $6^{\text {th }}$ prescribed a written decree of torture that was to advance from "the gentler tortures [...] et sic per gradus ad mia tenditur [and so by degrees proceeding to the worst] and so God speed your goode worke". Torture was contrary to British common law, unless specifically authorized by the King or by the Privy Council. Upon the commencement of his torture, it didn't take long for Johnson to be broken. He confessed to the details of the plan, as well as to his belief that he had been acting according to the will of God for the advancement of the Catholic faith. Doing so, he believed, would atone for his soul.

Though he began without revealing the names either himself or of his fellow conspirators, his unrecorded tortures were too much. He gave himself up on the first day, but it was to take fully two more before he would name anyone else. His final scrawl was barely legible, an indication of the suffering he had been made to endure. It was his signature. His real name was Guy Fawkes, and he was hanged, drawn, and quartered on January 31,1606 . A bonfire was reportedly set on the first night after his capture on November $5^{\text {th }}, 1605$. It was said to celebrate the fact that the King had survived an assassination attempt. 
This story is significant because to this very day, November $5^{\text {th }}$ is remembered and celebrated as "Guy Fawkes Day". Modern celebrations revolve around a bonfire, the burning of assorted effigies, and fireworks, all of which celebrate that a plot was averted at the same time it celebrates there was even a plot in the first place. ${ }^{2}$ It is this ambiguity, though, which makes 'Guy Fawkes Day' an interesting way to cut into larger questions about the similarities between conspiracy theories and carnivalesque practices. Though the 'Gunpowder Conspiracy' isn't a theory at all, it provides a handy historical example that draws together many of the broader themes under study. At the center is a concern about power. In this particular case, that concern was accompanied by a clash of religious tensions. The perceived persecution of Catholics by James I, which had followed 'more of the same' by Elizabeth I, was behind the planning of the plot. Protestant fears and conspiracy theories about the enlightened threat of Jesuits and the Catholic Church, are clearly echoed here in the annual ritual of Guy Fawkes Day. The Catholic plot to blow up the British Houses of Parliament, including the King himself, could have done very little to dispel these fears at the time. Still, it also goes a long way to explaining as well as contextualizing the continued existence of the ritual today. The willingness to believe in a larger Jesuit conspiracy won out over the actual significance of the Gunpowder Plot itself. ${ }^{3}$ At the same time, Guy Fawkes Day wouldn't be happening if there hadn't

\footnotetext{
${ }^{2}$ For example, among the effigies which have been burned are a wide array of political and historical figures. Key among them, of course, its namesake "Guy". He is traditionally joined in the flames by Pope Paul V, the Pope at the time of the original plot. In more recent years, honourees have included Hitler, Idi Amin, Margaret Thatcher, Tony Blair, Osama bin Laden, and Bill Clinton. (In a weird coincidence in 1972, just months before the official opening of the World Trade Center, the East Sussex town of Cliffe's bonfire tableau included an Arab Terrorist on an airplane entitled "Hijack".) In due course, almost seven months after the start of the Iraq War, George W. Bush was consigned to the flames in 2003 (www.truebrits.tv/pope trivia.html [05/03/20]). To this day, there are people who joke that Guy Fawkes was the only man to get into Parliament with the right idea.

${ }^{3}$ As Geoffrey Cubitt (1993) puts it in The Jesuit Myth: Conspiracy Theory and Politics in NineteenthCentury France: "The record of intrigue and criminality which passed, in anti-jesuit eyes, for Jesuit history was in general highly standardized, at least as far as the period before the order's suppression was concerned. The assassinations of Henri III and Henri IV, the Gunpowder Plot, the Ligue, the Revocation of the Edict of Nantes, the
} 
been an actual conspiracy in the first place. Its failure then, as well as the attempt itself, are what is commemorated every November $5^{\text {th }}$.

In this chapter, the carnival will be cast a productive way to try and understand the dualities at play within conspiracy theories themselves. Carnival traditions, and the symbolic practices associated with them, will be shown to be inseparable from the circumstances out of which they arise. Carnival traditions are those which simultaneously express dominant interests while those interests are being challenged by the dominated. They speak in a voice which transcends time, history, politics, and culture. They predate religions, economies, priests, kings, and tyrants. They underpin the material and moral circumstances out of which even perspectives such as Marxism grow. In being all of these things among others, they inform and buttress various systems of meaning in some unique ways. This is primarily because these forms depend on contradictory forces operating within them at the very same time they are being expressed. As will be developed more fully in the following chapter, there are strong critical traditions which have grappled with this relational contradiction in different ways. As an epistemological category itself, the carnival is shown to be an effective way of drawing these contradictory forces together into the same discussion.

persecution of Port-Royal, the downfall of the Stuarts, the misbehaviour of Jesuit missionaries in the Indies, the Orient, and Latin America (especially Paraguay), the attempted assassination of Louis XV by Damiens, the Lavalette bankruptcy, the suspected poisoning of Clement XIV after his suppression of the Society of Jesus: these, among others, were the events which the readers of anti-jesuit histories could, and no doubt did, expect to hear about" (pp. 188-189). Cubitt continues that later, "Regicide remained, in the nineteenth century, the most salient theme of antijesuit historiography. Lists of the Jesuit theorists of 'tyrannicide', and of the instances (including, besides French examples, the Gunpowder Plot and a series of attacks on Elizabeth I) in which their teachings had allegedly been put into practice, were part of the standard repertoire of the anti-jesuit pamphleteer" (p. 197). 
In light of all of this, one of the interesting characteristics of Guy Fawkes Day is the carnival environment which has surrounded its celebration right up into the present day. While carnival practices take many forms and, like conspiracy theories, should never be essentialized down to an immutable set of properties either, the spirit of rebellion and symbolic challenges to authority are foundational to its own existence. 'Carnivale' is nothing if not a reminder of the sometimes tenuous arrangements by which power has historically maintained itself over time. As in the case of the annual celebration of the 'Gunpowder Plot' and its eponymous principle effigy, the event is a very complex mixture of jubilation and justification. And in this particular case, the actual conspiracy to blow up the British Houses of Parliament, and assassinate a King in the process, makes it a particularly useful instance to build a synthesis between the politics of carnival and the pervasive popularity of conspiracy theory. What is needed at this point is an extended consideration of what it means to think about the carnival as an epistemological category, with specific attention to how it is that conspiracy theories fit in to it. ${ }^{4}$

\section{From Carnival to Transgression ${ }^{5}$}

Considering the trajectory of the present study, an idea from Edward Said might be an interesting place to start. Stallybrass and White begin The Politics and Poetics of Transgression, ${ }^{6}$ by pointing

\footnotetext{
${ }^{4}$ My thanks to Prof. Christopher Dornan for making me aware of 'Guy Fawkes Day' and the significance it might hold for my thesis.

5 I borrow this section title from Stallybrass and White 'The Politics and Poetics of Transgression' (p. 6). It is fitting considering how much else I will be drawing from that section in the following pages. 1986.

${ }^{6}$ Peter Stallybrass and Allon White, The Politics and Poetics of Transgression, Cornell University Press,
} 
to one of the characteristic representational features of the Arab 'Other'. They do so in the context of a growing body of research on the study of hierarchy inversion, or the 'World Upside Down' thesis. Simply looking at the ritual inversion of political hierarchies, though, is not the point of their book. Instead, they focus on the many contradictions between hierarchies in the symbolic realms of literature, the body, and the social formation. Across even these three, it is immediately obvious how central the tensions between 'high' versus 'low' descriptions are, with the 'low' constituting the space where both are reviled and desired. As they put it, "[r]epugnance and fascination are the twin poles of the process in which a political imperative to reject and eliminate the debasing 'low' conflicts powerfully and unpredictably with a desire for this Other."7 All this means, is that there is a dialectical tension between 'low' and 'high' which cannot help but play itself out except in ones' relation to the other. As Said points out in Orientalism, ${ }^{8}$ the myth of the Middle East as constructed by Europe “...depends for its strategy on [a] flexible positional superiority, which puts the Westerner in a whole series of possible relationships with the Orient without ever losing him the relative upper hand." Said also suggests that "European culture gained in strength and identity by setting itself off against the Orient as a sort of surrogate and even underground self." 10

It is this idea of an 'underground self with the upper hand' that for the authors captures the power nexus between 'desire' and the ideological construction of the 'low-Other'. In other words, it is the

\footnotetext{
${ }^{7}$ ibid., pp. 4-5; emphasis in original.

${ }^{8}$ Edward Said, Orientalism, Vintage Books, 1994.

${ }^{9}$ ibid., p. 7.

${ }^{10}$ ibid., p. 3.
} 
very same fascination with difference that fuels feelings of superiority by comparison. They point out over the course of their study that a recurrent pattern emerges when they trace out the contradictory representations of low-Others. Like Hegel's 'master-slave', the 'top' seeks to eliminate the 'bottom' as a matter of prestige and status. In the process however, they find that not only are they often dependent on the low, but that the 'low' are already a symbolic component of what it means to be 'top'. Over the next few pages, the significance of this binary opposition to and within the carnival will be traced out in order to understand conspiracy theories in much the same way.

Stallybrass and White begin that there is a large and growing body of work which sees carnival "not simply as a ritual feature of European culture but as a mode of understanding, a positivity, a cultural analytic."11 They ask how it is that a festive ritual which has been virtually eliminated from most of European popular culture could become so central as an epistemological category. They wonder in turn if the disappearance of the physical practice of carnival is in any way related to its emergence in artistic and academic discourse. They point out that in literary and cultural studies, the carnival has without doubt become a model, or analytical tool, but in a way that appears somewhat puzzling at first.

\section{Bakhtin and the 'Carnivalization' of Experience}

Stallybrass and White trace the beginnings of this Western analytical interest in the carnivalesque

\footnotetext{
${ }^{11}$ Stallybrass \& White, op. cit., p. 5; emphasis in original.
} 
to the work of Mikhail Bakhtin. Specifically, it is the 1968 translation of Rabelais and his World ${ }^{12}$ which marked the carnival as a site of interest for the analysis of literature and symbolic practice. They cite authors such as Krystyna Pomorska who wrote in 1978 that "Mikhail Bakhtin is today one of the most popular, if not the most popular, figures in the domain of humanistic studies." ${ }^{13}$ Tony Bennett suggests that Bakhtin's study of Rabelais should hold an exemplary place in materialist cultural criticism. ${ }^{14}$ Intended as a study of Rabelais' indebtedness to the popular 'low' folk humor of the French Renaissance, Bakhtin's tome is self-consciously iconoclastic. To cite an example, Bakhtin writes that "[no] dogma, no authoritarianism, no narrow-minded seriousness can coexist with Rabelaisian images; these images are opposed to all that is finished and polished, to all pomposity, to every ready-made solution in the sphere of thought and world outlook. This accounts for Rabelais' peculiar isolation in the successive centuries." challenges, the central importance of Bakhtin's work is not only his development of the 'carnivalesque' to include much beyond the specific study of Rabelais, but also as a tool to understand the critical inversion of all official words and hierarchies. Bakhtin elaborates on this as he writes that

As opposed to the official feast, one might say that carnival celebrates temporary liberation from the prevailing truth of the established order; it marks the suspension of all hierarchical rank, privileges, norms and prohibitions. Carnival was the true feast of becoming, change and renewal. It was hostile to all that

\footnotetext{
${ }^{12}$ Mikhail Bakhtin, Rabelais and his World, Indiana University Press, 1984.

${ }^{13}$ Pomorska, 1978; p. 379, cited in Stallybrass \& White, op. cit., p. 7.

${ }^{14}$ Bennett, 1979; pp. 90-92, cited in Stallybrass \& White, op. cit., p. 7.

${ }^{15}$ Bakhtin, op. cit., p. 3.
} 
was immortalized and complete. ${ }^{16}$

In its most wide sense then, carnival was comprised of the ritual spectacles of the fair, feasts, processions, masked and costumed amusements, comic shows, dancing, freaks, trained animals, parody, farce, curses, slang, jokes, scatological forms, and other similar forms of expression. What is important to retain here is the 'earthy' quality of these forms which together comprise what is collectively understood as 'carnivalesque practice'.

Though there is a lot more detail that could be included, more immediate to the purposes here is specific attention to the politics of the carnival. It is here where the most important and substantive contributions to an understanding of the carnival as an epistemological category are made. There is no question that certain aspects of the carnival can be thought of in ways which harken utopian visions of emancipation, and the unbridled vitality of festive populism. But there is another side to that coin which cannot be ignored. Terry Eagleton provides an ideal place to start teasing out some of the more puzzling aspects of carnival.

Eagleton points immediately to Bakhtin's optimism and positive embrace of carnival as problematic. This is because in Eagleton's eyes, it is the licenced nature of carnival that prohibits it being considered as a truly emancipatory cultural form. He writes that

Bakhtin's utopia, by contrast, could not be more bulging with positive life. Indeed carnival is so vivaciously celebrated that the necessary political criticism is almost too obvious to make. Carnival, after all, is a licensed affair in every sense, a permissible rupture of hegemony, a contained popular blow-off as

\footnotetext{
${ }^{16}$ ibid., p. 109; cited in Stallybrass and White, op. cit., p. 7.
} 
disturbing and relatively ineffectual as a revolutionary work of art. As Shakespeare's Olivia remarks, there is no slander in an allowed fool. ${ }^{17}$

They go on to show that most politically thoughtful authors, like Eagleton, wonder if the 'licenced release' of carnival is nothing more than another form of social control. By allowing the temporary release of pent-up tension, it ends up serving the long-term interests of the official culture which created the tension in the first place. What they cite as the classic formulation of this is Max Gluckman's Order and Rebellion in Tribal Africa. ${ }^{18}$ In it, Gluckman describes a ritual of gender reversal in an African tribe. He writes that this

temporary dominant rôle of the women - a dominant rôle that was publically instituted, indeed approved, and not exercised tactfully in the background - contrasted strongly with the mores of these patriarchal peoples. Hence it is my first example of a ritual of rebellion, an instituted protest demanded by sacred tradition, which is seemingly against the established order, yet which aims to bless that order to achieve prosperity. To understand how this rebellion worked we must contrast the women's behaviour here with their accustomed behaviour. ${ }^{19}$

A more recent commentator makes the same point in more detail. Roger Sales writes that [t]here were two reasons why the fizzy, dizzy carnival spirit did not necessarily undermine authority. First of all, it was licenced or sanctioned by the authorities themselves. They removed the stopper to stop the bottle being smashed altogether. The release of emotions and grievances made them easier to police in the long term. Second, although the world might appear to be turned upside down during the carnival season, the fact that Kings and Queens were chosen and crowned actually reaffirmed the status quo. Carnival was, however, Janus-faced. Falstaff is both the merry old mimic of Eastcheap and the old corruptible who tries to undermine authority, or rule, of the Lord Chief Justice. The carnival spirit, in early-nineteenth century

${ }^{17}$ Terry Eagleton, Walter Benjamin or Towards a Revolutionary Criticism, Verso, 1981; p. 148, emphasis in original.

${ }^{18}$ Max Gluckman, Order and Rebellion in Tribal Africa, Cohen \& West, 1971.

${ }^{19}$ ibid., p. 114. 
England as well as in sixteenth century France, could therefore be a vehicle for social protest and the method for disciplining that protest. ${ }^{20}$

Or as Georges Balandier put it more succinctly in Political Anthropology, "The supreme ruse of power is to allow itself to be contested ritually in order to consolidate itself more effectively."21

All of this helps to make the case that it makes little sense to fight about whether or not carnivals are intrinsically radical or conservative. This is because such a debate would essentialize carnivalesque transgression. One of the important things that can be said about carnivalesque transgression, however, is that "for long periods carnival may be a stable and cyclical ritual with no noticeably politically transformative effects but that, given the presence of sharpened political antagonism, it may often act as catalyst and site of actual and symbolic struggle ${ }^{22},{ }^{23}$ There have been many occasions, for example, where the carnival itself provided a venue for the outbreak of real violence, and even armed struggle. Le Roy Ladurie writes in Carnival in Romans (1981) that the 1580 carnival at Romans in eastern France became an armed conflict and turned into a bloody massacre. Many other examples are listed, and so the temptation to consider them mere coincidences needs to be resisted. After all, as Peter Burke points out, it was only in the late eighteenth and early

${ }^{20}$ Sales, 1983; p. 169, cited in Stallybrass \& White, op. cit., p. 14.

${ }^{21}$ ibid.; emphasis in original.

22 [Author's footnote from original citation] Kateryna Arthur: 'The question I shall be addressing throughout my exploration of carnivalesque activity is: how can the carnival be simultaneously revolutionary and law-abiding?' (Arthur 1982: 4). Terry Eagleton: 'Carnival laughter is incorporating as well as liberating, the lifting of inhibitions politically enervating as well as disruptive. Indeed from one viewpoint carnival may figure as a prime example of that mutual complicity of law and liberation, power and desire, that has become the dominant theme of contemporary post-marxist pessimism.' (Eagleton 1981: 149).

${ }^{23}$ ibid.; emphasis in original. 
nineteenth centuries - and even then only in certain areas - that it was even meaningful to talk about popular politics as separate from the carnival.

John Brewer adds to this perception as he describes politics in eighteenth century England as "essentially a calendrical market". By this he means to refer to the mixture of holiday and political events. He writes that there has been too little attention paid to the rise, during the eighteenth century, of a Hanoverian political calender which was intended to inculcate loyalty in the populace and to help create a national political consensus. He points out that almost every English market town celebrated the conventional political landmarks of the nation, and that according to most almanacs of the period, were barely distinguishable from the time honored dates of May Day, Plough Monday, Twelfth Night, and Shrove Tuesday. These dates were also often occasions for conflict.

\begin{abstract}
The year of the Jacobite Rebellion, 1715, was especially contentious, with Hanoverian Mug House clubs fighting it out in the streets with Jacobite apprentices and artisans. On October 30, frequenters of a Jacobite alehouse on Ludgate Hill were beaten up by members of the Loyal Society who were celebrating the birthday of the Prince of Wales, the future George II. A Jacobite attempt to burn William III in effigy on November 4 was thwarted by the same Whig clubmen who the next day tried to cremate effigies of the Pretender and his supporters. On 17 November further clashes ensued and two Jacobites were shot dead. ${ }^{24}$
\end{abstract}

So again, this poses a warning against the false essentializing of carnival and politics. On the one hand, carnival proper was without doubt a specific set of practices, at a specific time of year, for a

${ }^{24}$ Brewer et al., 1983; p. 247; cited in Stallybrass and White, ibid.; pp. 14-15). 
specific length of time. All of this was, of course, followed by a strict period of abstinence and fasting during Lent in accordance with the strictures of the very institutions which let them slip for the brief reign of carnival. On the other hand though, carnival was something else entirely. It was a "mobile set of symbolic practices, images and discourses which were employed throughout social revolts and conflicts before the nineteenth century." ${ }^{25}$ It is this mobility which becomes one of the more significant characteristics of carnivalesque discourses and symbolic practices.

Other work on the social history of carnival shows its political dimensions to be much more complex than even Bakhtin or his detractors may have imagined. For example, popular carnival practices were central in the struggles against Catholicism in the German Reformation. As we shall see later in more detail, this was particularly so in the ways that such imagery was employed as propaganda in the ritual defilement of the Pope. Fears were such that the ecclesiastical powers in Rome during the early 1600 's set about trying to upstage the popular carnival through a patrician counter-festival which was intended to "repress, control and mutilate the carnival of the common people." Dutch carnival forms, in another example, were put to directly political use during the War of the Netherlands. ${ }^{26}$

In England, there is a whole history of study on the intersections between popular culture and class conflict. These studies help demonstrate the long battle waged by the State, ecclesiastical, and

\footnotetext{
${ }^{25}$ ibid., p. 15.

${ }^{26}$ ibid.
} 
bourgeois interests against popular rituals and customs, a battle that extends well back beyond the Renaissance. From the Renaissance onward, however, these local festivities themselves became sites of struggle against the very extensions of power by the propertied classes and the State. At issue were the many tensions between the laboring poor, and the increasingly wealthy landowners and proprietors, over the rights of the people to protect their own views and community cohesion. Ironically then, carnivals, festivals, and fairs, were politicized by the very act of authorities trying to restrict or eliminate them. This was true even in those instances when there had been no overtly oppositional elements to speak of. Though there is much more that could be said about the historical complexity of tensions like these, and how they are manifested within the carnival, the important point is that understanding specific manifestations of carnival politics requires a close historical examination of the circumstances surrounding them. Stallybrass and White remind us that "there is no a priori revolutionary vector to carnival and transgression." 27

In Bakhtin's study of the carnival, he anticipated the main lines of argument in symbolic anthropology by some thirty years. It is his investigation of the relational nature of the high/low binarism in carnival festivity, its inversion of and 'ambivalent dependence on official culture', that, for Bakhtin, gives it a fundamental place within culture. It is this 'doubleness' between the unofficial expressions and the official versions they depend upon which is key to Bakhtin's analysis of carnival. They are locked together in the sense that "[s]ymbolic polarities of high and low, official and

${ }^{27}$ ibid., pp. 15-16. 
popular, grotesque and classical are mutually constructed and deformed in carnival." ${ }^{28}$ One of the better synopses of Bakhtin is that his work, and that of someone like Levi-Strauss, have a lot in common with their understandings of the various oppositions within ritual or carnival practices. Levi-Strauss himself expresses that a chief aspect to both the ritual and the myth is the discovery of what we might today call a hyperlink between "members of a binary opposition: a process known as mediation."29 As Bakhtin puts it, the "carnival image strives to embrace and unite in itself both terminal points of the process of becoming or both members of the antithesis: birth-death, youth-age, top-bottom, face-lower bodily stratum, praise-abuse." ${ }^{30}$

\section{Carnival, Conspiracy Theory, and Communication}

The reference to the idea of 'mediation' has significance for a couple of reasons. First, it opens debate on the question as to whether conspiracy theory, when viewed as a carnivalesque practice itself, can be thought of as its own form of communication. This question will be addressed more fully in the conclusions, but for now, it is enough to point to an emerging consistency in theme and scope between carnival and conspiracy theory as cultural practices. Both of them challenge official narrative and discourse in completely different ways, but at the same time accommodate their unique formal tensions within their respective forms. This is to say, that regardless of the symbolic [if not overt] challenges to official narrative and discourse which characterizes each form as unique, and

\footnotetext{
${ }^{28}$ ibid., p. 16.

${ }^{29}$ Bakhtin, op. cit.; p. 238.

${ }^{30}$ ibid.
} 
distinguishes each from the other, they are ultimately reinforcing influences on the very narratives and discourses they challenge. Having said this though, there should be no forgetting the simmering revolutionary tensions that threaten to break out from under the surfaces of carnival gloss. At the same time, attention must also be paid to the ways that forms like these are historically able to coexist more or less peacefully within the strictures of institutional power. A focus like this makes the carnival an interesting form through which to interrogate the very tensions which give rise to the carnival [not to mention conspiracy theories] in the first place. Recalling the caveat that 'there is no a priori revolutionary vector to carnival and transgression', it is as obvious that revolutionary sensibilities are given voice through and within the carnival. Likewise for conspiracy theories. Michael Holquist may have put it best when he suggests in the 1984 prologue to Bakhtin's Rabelais and His World that "carnival" is the most productive concept in his book, writing that it is "not only an impediment to revolutionary change, it is revolution itself." 31

The authors argue that the convergence of Bakhtin's ideas with current symbolic anthropology is very significant. They note, for example, the similarities between Bakhtin's inversion of high/low in the carnivalesque, and a collection of essays edited by Barbara Babcock in The Reversible World. ${ }^{32}$ They point out that Babcock is apparently unaware of Bakhtin's work, but nonetheless, her study assembles a wide range of writing on anthropology and literature with a focus on 'symbolic inversion and cultural negation' which helps to bring a broader perspective to studies of carnival.

\footnotetext{
${ }^{31}$ Michael Holquist, p. xviii; cited in Bakhtin, op. cit..

${ }^{32}$ Barbara Babcock (ed.), The Reversible World: Symbolic Inversion in Art and Society, Cornell University Press, 1978.
} 
In her introduction, she writes that "symbolic inversion"

may be broadly defined as any act of expressive behaviour which inverts, contradicts, abrogates, or in some fashion presents an alternative to commonly held cultural codes, values, and norms be they linguistic, literary or artistic, religious, social and political. Although, perhaps because, inversion is so basic to symbolic processes, so crucial to expressive behaviour, it has not, until recently, been analytically isolated except in its obvious and overt forms such as "rituals of rebellion," role reversal, and institutionalized clowning. Precisely because it is such a widely observed form of symbolic action and because the nature of symbols and expressive behaviour has become a focus of anthropological concern, symbolic inversion merits specific discussion. ${ }^{33}$

At this point, considering conspiracy theory as an act of "symbolic inversion" should be a relatively easy thing to do. By their very nature, conspiracy theories invert, contradict, and present alternatives to commonly held cultural understandings and versions of history. They are expressed in linguistic and literary ways, as well as in artistic forms such as film and television entertainment. Together, they accommodate various narratives on social inequality and injustice, including of course those which are religious, political, and economic in nature. Although and perhaps because conspiracy theory is such a common symbolic response, one which is so pervasive to human expressive behavior, it has not been until relatively recently that they have been analytically isolated, except in its obvious and overt forms such as 'the paranoid style in American Politics', or in terms of the right/left dialectic, or as belief in a 'U.S./Zionist conspiracy against Islam', for example. It is precisely because conspiracy theory is such a widely observed form of symbolic activity that it deserves specific discussion. It is this kind of symbolic inversion that Stallybrass and White refer to as "transgression" in their book. In fact, they specifically state that "in our view, the current

\footnotetext{
${ }^{33}$ ibid., pp. 14-15.
} 
widespread adoption of the idea of carnival as an analytic category can only be fruitful if it is displaced into the broader concept of symbolic inversion and transgression." 34

Having just drawn this very important distinction above between Bakhtinian usages of the carnival, and what it is that will be applied in these pages, one must be careful not to dismiss the usefulness of the carnival as both a utopian and counter-hegemonic 'modeling' of the political and social world. There are a number of authors who feel this way, such as Roberto da Matta, who does acknowledge that carnival festivity is licenced release, but also that it represents the 'deep modeling' of a "different, pleasurable and communal ideal 'of the people"'- even when that ideal cannot be acted upon. Victor Turner envisions carnivalesque reversal as "a moment when those being moved in accordance to a cultural script were liberated from normative demands, where they were...betwixt and between successive lodgements in jural political systems." 35 Terry Eagleton also wants to retain Bakhtin's carnivalesque as a utopian modeling of ideological constructs of domination, a "kind of fiction: a temporary retextualizing of the social formation that exposes its 'fictive' foundations." 36 In this more general view then, the carnivalesque becomes a reservoir of images, roles, and actions which may be simultaneously invoked to legitimate desire, as it degrades all that is abstract and spiritual. In an engaging description of the utopian/critical role of the carnival, both positive and

\footnotetext{
${ }^{34}$ Stallybrass and White, op. cit., p. 18.

${ }^{35}$ ibid.

${ }^{36}$ Eagleton, op. cit., p. 149.
} 
negative appear simultaneously.

On the positive side, carnival suggests the joyful affirmation of becoming. It is ecstatic collectivity, the superseding of the individuating principle in what Nietzsche called 'the glowing life of Dionysian revellers'...On the negative, critical side, the carnivalesque suggests a demystificatory instrument for everything in the social formation which renders such collectivity difficult of access: class hierarchy, political manipulation, sexual repression, dogmatism and paranoia. Carnival in this sense implies an attitude of creative disrespect, a radical opposition to the illegitimately powerful, to the morose and monological. ${ }^{37}$

As much as this captures the iconoclastic sensibilities of conspiracy theory, it still does very little to resolve the inherent problems in the politics of carnival, namely, its nostalgia, "its uncritical populism (carnival often violently abuses and demonizes weaker, not stronger, social groups - women, ethnic and religious minorities, those who 'don't belong' - in a process of displaced abjection); its failure to do away with the official dominant culture, its licenced complicity." ${ }^{\text {38 }}$ It is important to take note and remember that writers and critics who focus solely on the celebratory aspects of Bakhtin's formulation will never be able to resolve the dilemmas of carnival. It is only by completely shifting the terms of the debate, "by transforming the 'problematic' of carnival", that it is even possible to do so.

The remainder of this chapter will map out a political and aesthetic analysis of conspiracy theory which builds on this observation. In Dionysos Slain, Marcel Détienne writes that a "system of thought...is founded on a series of acts of partition whose ambiguity, here as elsewhere, is to open up the terrain of their possible transgression at the very moment when they mark off a limit. To discover the complete horizon of a society's symbolic values, it is also necessary to map out its transgressions, its

\footnotetext{
${ }^{37}$ Stamm, 1982; p. 55, cited in Stallybrass and White, op. cit., pp. 18-19, emphasis added.

${ }^{38}$ ibid., p. 19.
} 
deviants." 39 When considering conspiracy theory as transgression, and conspiracy theorists as one of society's deviants, this positions the current study in such a way that the symbolic nature of their collective challenge to normative definitions of reality and social ascendancy is shown to be inseparable from the very conditions which give rise to the challenges themselves.

\section{Conspiracy Theory and the Body Politic}

At first glance, a focus on 'the body' as a site of analysis might seem to be an odd one indeed. But when thinking about it as a medium of communication, it becomes an actively political symbolic entity. Political inflections in bodily representation communicate very quickly in everyday life. An approach like this goes a long way to understanding how invaluable 'the body' actually is to the politics of carnival. In fact, it can even be said that carnival politics are largely predicated on the politics of the body. For example, the 'cerebral pursuits' of the upper classes can be said to stand in direct opposition to the carnal pleasures of the teeming mass. Attention to the body as an 'active symbolic entity' quickly becomes a means to assemble a range of transcendent discourses around it. Once again, as in other cases, carnivalesque 'doubleness' simultaneously plays itself out through a mutual negation of its opposite.

In their own work, Stallybrass and White track the 'grotesque body' and conceptions of the 'lowOther' across different symbolic domains of bourgeois society since the Renaissance. They demonstrate that there is an unusual perspective to be taken on the "inner complexity of disgust and

\footnotetext{
${ }^{39}$ Détienne, 1979; p. ix, cited in Stallybrass and White, ibid.; pp. 19-20.
} 
desire which fuels its crises of value." They go even further as they state that "the classificatory body of a culture is always double, always structured in relation to its negation, its inverse." ${ }^{" 40}$ By this they draw a sharp distinction between what they describe as the 'grotesque' and 'classical' bodies. A brief metaphorical aside is useful for what it reveals of this dialectical dependancy of opposites.

Bakhtin was struck by the differences between representations of the human body in popular festivity, versus the ways it was represented by classical statuary in the Renaissance. He was very aware of the stark contrast between how each 'embodied' different natures of being. Most obvious, was that the classical statue was always mounted on a plinth, and so was raised above the viewer. It was inherently meant to be gazed up at and admired, to inspire awe and wonder. This is compared to the grotesque body, which was always multiple, teeming, and part of a throng. Stallybrass and White put it well when they write that the simple presence of the statue is "a problematic presence in that it immediately retroflects us to the heroic past, it is a memento classici for which we are the eternal latecomers, and for whom meditative imitation is the appropriate contrition." It has no orifices or openings, whereas the grotesque costume and masks emphasize the gaping mouth, the prominent belly and buttocks. If the classical statue signifies a bourgeois "transcendent individualism", the grotesque body stands in opposition. It is mobile, multiple, engaged in a process of pleasurable exchange from which there is no divorce from its social context. The classical body keeps an almost disembodied distance, and "appears indifferent to a body which is 'beautiful', but which is taken for granted."41

\footnotetext{
${ }^{40}$ ibid., p. 20.

${ }^{41}$ ibid., pp. 21-22.
} 
The classical form though, stood for much more than a simple bodily or physical ideal. Drawing on the canon of Ancient Greek and Roman authors, the classical body encapsulated the 'high' discourses of philosophy, the state, theology, law, and literature as they emerged out of the Renaissance. Eventually, these would come to identify themselves with rationalism itself. They point out how compatible this is with certain ideas from Foucault and Weber, for whom "regimen" and "rationalization" prefigured by the eighteenth century in England, the wave of institutionalization in forms such as the prison, the asylum, and the hospital, not to mention houses of insurance and finance. It is by virtue of these "outsiders-who-make-the-insiders-insiders (the mad, the criminal, the sick, the unruly, the sexually transgressive) [which] reveals just how far these outsiders are constructed by the dominant culture in terms of the grotesque body. The 'grotesque' here designates the marginal, the low and the outside from the perspective of a classical body situated as high, inside and central by virtue of its very exclusions." Likewise the grotesque body, too, has its own set of norms and exclusions. These include impurity, masking, protuberant distension, disproportion, exorbitancy, a focus on gaps, orifices, and symbolic filth, needs and pleasures of the 'lower bodily stratum', and parody. ${ }^{42}$ In this they echo Barbara Babcock, who writes that all symbolic inversions define a culture's lineaments at the same time as they question the usefulness and the absoluteness of this ordering. Clown or trickster or transvestite never demand that we reject totally the orders of our sociocultural worlds; but neither do these figures simply provide us with a cautionary note as to what would happen should the "real" world turn in to a perpetual circus or festival [...] Rather, they remind us of the arbitrary condition of imposing an order on our environment and experience, even while they enable us to see certain features of that order more clearly simply because they have turned insight out. For, as Nietzsche has epigrammatically reminded us: "Objections, digression, gay mistrust, the delight in mockery

42 ibid., pp. 22-23. 
are signs of health: everything unconditional belongs in pathology.",43

Conspiracy theories serve this idea well. They unquestionably do remind us of the arbitrary conditions of imposing orders on environment and experience, at the same time they enable us to see certain features of that order more clearly. In this way, a critical analysis of conspiracy theory as an epistemological category can be modeled after that of the carnival. This is because in many ways conspiracy theory can be thought of as a carnivalesque practice itself. Both the carnival and the conspiracy theory symbolically upend dominant social hierarchies, and challenge the legitimacy of the reasoned order of things. They imagine a social world where things "need not be as they necessarily are'. Similarly, the carnival and the conspiracy theory draw on the margins of respectability while at the same time remaining symbolically central to the ordering of the natural world. Babcock provides some support for a position like this when she writes that "[t]he process of symbolic inversion, far from being a residual category of experience, is its very opposite. What is socially peripheral is often symbolically central, and if we ignore or minimize inversion and other forms of cultural negation, we often fail to understand the dynamics of symbolic processes generally." 44

Stallybrass and White consider this characterization to be a "scrupulously accurate and indispensable formulation" and go on to suggest that forms like the carnival, the gypsy, the circus, and the lumpenproletariat, all play a symbolic role in the operation of bourgeois culture out of proportion to their actual social importance to it. It makes sense to think of capitalism in this regard, placing its

\footnotetext{
${ }^{43}$ Nietzsche, 1966; p. 90, cited in Babcock, op. cit., p. 29.

${ }^{44}$ ibid., p. 32.
} 
"most powerful symbolic repertoires at borders, margins and edges, rather than at the accepted centres." ${ }^{45}$ This is an interesting position to consider. While it is obvious that capitalism lays no exclusive claim on conspiracy thinking, the case study to follow will demonstrate that conspiracy theories were indeed symbolically central to the legitimation of the Iraq invasion precisely because they were both socially and politically peripheral. In parallel terms, the symbolic significance of the World Trade Center and the Pentagon to global economic and military might were as central to the rationale for the $9 / 11$ attacks, as the belief in a U.S./Zionist conspiracy against Islam was to their planning and execution. Seen from this vantage point, Islam may be said to have been socially and politically peripheral to the exercise of global capitalism until it became symbolically central on September $11^{\text {th }}, 2001$.

It is in the spirit of framing the politics of carnival this way, that authors such as Babcock et. al. suggest transgressive symbolic domains and the fetishism they tend to attract are never simply diversionary. On the contrary, they write that despite the fact that there is "no simple fit between the imaginary repertoire of transgressive desire and economic and political contradictions in the social formation, [...] the two are always deeply connected." In other words, conspiracy theories, like the carnival, are much more than simple diversions from the ups and downs of lived experience; they are intimately related to those practices to the point of being inseparable from them. By focusing on what they call the 'taboo-laden' overlap between high and low discourse, they have tried to transpose "the Bakhtinian conception of the carnivalesque into a framework which makes it analytically powerful in

\footnotetext{
${ }^{45}$ Stallybrass and White, op. cit., p. 20.
} 
the study of ideological repertoires and cultural practices." Stallybrass and White continue that if

we treat the carnivalesque as an instance of a wider phenomenon of transgression we move beyond Bakhtin's troublesome folkloric approach to a political anthropology of binary extremism in class society. This transposition not only moves us beyond the rather unproductive debate over whether carnivals are politically progressive or conservative, it reveals that the underlying structural features of carnival operate far beyond the strict confines of popular festivity and are intrinsic to the dialectics of social classification as such. The 'carnivalesque' mediates between a classical/classificatory body and its negations, its Others, what it excludes to create its identity as such. In this process discourses about the body have a privileged role, for transcodings between different levels and sectors of social and psychic reality are effected through the intensifying grid of the body. It is no accident, then, that transgressions and the attempt to control them obsessively return to somatic symbols, for these are ultimate elements of social classification itself. $^{46}$

It can be no accident either that conspiracy theories as transgressive symbolic practices and the attempt to 'control' them also returns obsessively its own somatic symbol, that of the conspiracy theorist. Stereotypical depictions of the conspiracy theorist in western popular culture are not difficult to draw to mind. The picture that emerges no matter the path one takes to see it is, interestingly enough, one that is amenable to many of the same political categories which Stallybrass and White spend such ample time developing in their own analysis. These symbolic elements can be discussed along a number of different axes, some of which intersect while others run parallel. When conceived of in terms of culture, class politics, the economy, religion, and the body, symbolic inversions operating across even these broad categories hold a pastiche of influence over the formation of meaning.

\footnotetext{
${ }^{46}$ ibid., p. 26.
} 


\section{In the Beginning: Symbolic Inversion in Religion and Classical Thought}

It is useful at this point to expand somewhat on the contributions already cited, in order to help assemble the central theoretical traditions around the present study in the next chapter. Having just problematized the politics of carnival as an analytical tool, and 'resolved' them through a transposition into symbolic inversion, it becomes clear that the underlying structural dynamics of the carnival have a significance well beyond and outside of popular festivity. As noted above, these dynamics are "intrinsic to the dialectics of social classification as such." What this means, is that the "politics of exclusion' can be seen operating in so many different spheres that it becomes arguably meaningless to talk about social classification at all without reference to symbolic inversion. Demonstrating this centrality is not difficult. It is important to do, however, because of the opportunities it opens up to discuss a whole range of very different symbolic practices at the very same time. As the case study shows, the 9/11 attacks and the subsequent invasion of Iraq lie at the intersection of many competing symbolic practices, and so require an approach which can accommodate all of them without becoming so complex as to be unworkable. In this regard, the simplicity of conspiracy theories becomes a medium of access to the very complexities they fail to explain. The paradox that such an approach presents is anything but a limitation.

Barbara Babcock introduces her edited volume The Reversible World ${ }^{47}$ by pointing out that even the very term 'symbolic inversion' is somewhat redundant. She suggests that this is because in its cultural uses, inversion itself is always symbolic. This is an important distinction because it draws attention

\footnotetext{
${ }^{47}$ Babcock, op. cit.
} 
to an aspect of symbolic inversion itself, that it is "deliberate, self-conscious, patterned behavior." In view of the ways that the term itself is used as a springboard into a variety of different analyses [including my own], Babcock provides a semantic and etymological background to the idea of symbolic inversion. As it is used in her edited volume, the term symbolic inversion derives from and conflates a number of discipline-specific uses with both older and modern uses and concepts. She points out that since the early Renaissance at least, the term inversion has meant "a turning upside down" or "a reversal of position, order, sequence, or relation." ${ }^{48}$ More specifically, she writes, it was used as a synonym for the rhetorical and grammatical figures of metaphor, anastrophe (or the reversal of the order of words), and antistrophe (which refers to the turning of an opponent's argument against itself).

The concept, however, is even older than the word. She points out that the topos of the world upside down, mundus inversus, is as old as Greek parody of the Homeric journey to Hades. She adds that it has a history which is ancient and widespread, and which is found extensively in literature and popular art throughout European history right back to classical times. The 'world upside down' in this regard, becomes a more or less familiar terrain which is deliberately arranged in contrast to the way that the world appears and is commonly experienced. Symbolic inversion then, is one of the simplest of a whole host of "paradoxical commonplaces." 49

\footnotetext{
${ }^{48}$ Oxford English Dictionary, p. 1477; cited in Babcock, ibid., p. 15.

${ }^{49}$ ibid., p. 16.
} 
In literary terms, of course, symbolic inversion is central to the techniques of irony, parody, as well as paradox. Irony is a particularly useful way to demonstrate how the actual intent can be expressed through words which carry the opposite meaning. As she puts it, Kierkegaard demonstrates "there is a gap between saying and meaning in which the ironist is negatively free: he is not bound, in meaning, to what he says." Parody, on the other hand, involves the burlesquing or imitation of one piece of literature within another. But Babcock reserves her most extensive comments for her discussion of paradox. Like irony, it operates at the limits of discourse by directing attention to the limited if not faulty structures of thinking. Paradox plays with human understanding. Importantly too, it is everpresent within dialectics. As has already been seen, the idea that identity is structured in relation to its opposite is central to the topsy-turvy world of the carnival. Like all forms of symbolic inversion, "paradox is at once self-critical and creative, 'at once its own subject and its own object, turning endlessly in and upon itself,' one inversion leading to the making of another, into the infinite regress of self-regard."50

As far as symbol systems go, Kenneth Burke follows Hegel and Nietzsche in suggesting that religion is perhaps the most explicitly 'negativistic' of them all. He points out that the very idea of man as a 'moral being' is predicated on the negative command 'thou shalt not.",51 Religions themselves, he continues, are often built in antithesis to other orientations. Evidence for this claim has already been discussed in the previous chapter. Even the understanding of 'God' is itself an exercise unavoidably

\footnotetext{
${ }^{50}$ ibid., pp. 16-17.

${ }^{51}$ Burke, 1968; pp. 12-13, cited in Babcock, op. cit., p. 18.
} 
rooted in what is commonly explained as impossible for human beings to comprehend. The result is a transcendent realm where we have a "positive-seeming word for what is really the function of the negative." 52 Recalling the irreverent spirit of the carnival, Babcock reminds us that what is assembled in her volume, is actually a negation of a negative, what Burke refers to as an "aesthetic negative." It is a situation "whereby any moralistic thou-shalt-not provides material for our entertainment, as we pay to follow imaginary accounts of 'deviants' who in all sorts of ingenious ways are represented as violating these very Dont's." ${ }^{53}$ Similarly, Umberto Eco draws attention to the famous forbidding of the apple in the Garden of Eden as the moment where Adam only comes to truly understand the system at the very moment he violates it.

\begin{abstract}
Adam has arrived at a comprehension of the system at the very moment in which he is calling the system into question and therefore destroying it. Just as he comes to understand the rigid generative law of the code which had governed him, so he realizes that there is technically nothing to stop him from proposing a new code.... While bent on destroying the system, he comprehends its full range of possibilities and discovers he is master of it. ${ }^{54}$
\end{abstract}

\title{
Turning the World Upside Down
}

David Kunzle carries this theme forward in his analysis of the World Upside Down (WUD) broadsheet. In a study of about sixty distinct broadsheets from seven different countries spanning three centuries, Kunzle suggests that despite the fact WUD motifs were familiar in ancient and medieval times, modern versions began to do something unique. He defines the modern era as being one which

\footnotetext{
${ }^{52}$ Burke, 1968; p. 437, cited in Babcock, ibid.

${ }^{53}$ Burke, 1968; p. 13, cited in Babcock, ibid., p. 19.

${ }^{54}$ Eco, 1973; p. 173, cited in Babcock, ibid.
} 
is characterized by chronic challenges to constituted power. It is also in the modern era that WUD was first systematized and made available to mass audiences. He contends that certain genres of broadsheet traditionally regarded as neutral, such as the proverb illustration, actually helped serve the interests of a "newly entrenched bourgeoisie" by upholding and reinforcing the immutability of the social structure. The WUD broadsheet on the other hand, had a potentially different kind of appeal: "to discontented, lower-class elements who sought or fantasized about the subversion of the existing order., 55

The motifs employed in WUD imagery are seen across many different domains, but there are a few that stand out in particular. These are i) human to human (such as husband/wife, master/servant), ii) human to animal (hunter/hare, peasant/ox), iii) animal to animal (cat/mouse, cock/hen), and iv) animal to element (such as 'fish fly' and 'birds swim'). Though there is no need to spend a great deal of time in description, a few examples provide a light-hearted aside to help to capture the flavor of the genre. The principle of inversion at work is typically straightforward: There are two parties, one dominant and one dominated, "whose roles, in some action typifying their relationship, are simply reversed." The nature of the inversion is always hierarchical, representing some form of power relationship. The exception is the fourth category where elements, usually air and water, are reversed with respect to the creatures involved. The most ubiquitous motif, which should come as no surprise, is that of gender roles. Husbands hold babies while wives stand by holding a weapon. In a social climate where marital beating was not uncommon, wives lashed husbands, and husbands scrubbed floors. Generational

\footnotetext{
${ }^{55}$ Kunzle, in Babcock, ibid.; p. 40. It is worth attending to the value of this kind of approach for grounding a discussion of different communicational media.
} 
inversions took the shape of elders playing with toys, children scolding the parents, pupil beating his teacher with a birch, or child lecturing elders. In an interesting passage, Kunzle writes that "(there is some resemblance here to compositions showing the boy Jesus teaching the elders in the temple, in which painters often exaggerated the youth of the former and the wizened crabbiness of the latter)."56

In another representational realm, the human/animal inversions are as funny as they are sometimes graphically violent and explicit. Kunzle states outright that there are a few things about the human/animal, as well as animal/animal inversions that can be taken for granted in WUD imagery. For example, it can be taken for granted in WUD (as in fable or proverb) that humanlanimal and animal/animal inversions stand in for human social relations. ${ }^{57}$ As an example, broadsheet satire is rife with examples of 'riding' and 'driving' where the power relations are reversed. There is a high incidence of ox driving peasants at the plough, or with what Kunzle describes as a subinversion, ox driving gentlemen. Another is the ass riding man. Rivaling this motif in popularity, with possibly greater "symbolic and ritual significance, is the motif of the ox butchering the butcher." He points out that even in the primitive workmanship of WUD prints, the spectacle is gruesome. The "human carcass suspended upside down, disemboweled, hands and feet cut off like the vilest criminal,

\footnotetext{
${ }^{56}$ ibid., p. 50. This is a theme I will be developing in the conclusions along the lines of what has been written about to this point. It is interesting to think about the threat to the established order that the symbolic Jesus undoubtedly plays in the biblical tales. This is in part because of the consonance between the accounts in the Christian Gospels of the boy Jesus teaching the Rabbis and carnivalesque inversion itself. Considering the central role that the Church has historically played as an impetus for carnival imagery and festivity, the survival of the tale in this form is worth thinking about. Also interesting, is that the celebrated foundation of Christian faith, the Resurrection, is itself synonymous with the much older pagan fertility ritual of 'oestrus', now celebrated as 'Easter'.
}

${ }^{57}$ ibid., p. 52. 
quartered by the huge beast wielding a massive cleaver." ${ }^{58}$ Furthermore, the ox in many WUD prints is also the executioner, and is cast "in topical prints showing particularly barbaric punishments, or as the soldier in engravings of military atrocities. $" 60$

Footnote ten of Kunzle's chapter contains an interesting contemporary example which simultaneously has a much older significance. He relates a modern image showing the chickens slaughtering Colonel Saunders in a dark Atlanta alley, which he writes "is not so distant from the original WUD spirit of tyrannicide." ${ }^{61}$ It can hardly be coincidental that such a constituent feature of WUD imagery would parallel the conspiratorial mythology seen earlier around Jesuits and the Catholic Church so closely.

\section{Inversion and Conspiracy Theory in the Reformation}

Considering the central role of the Catholic Church as an impetus for carnivalesque inversion and challenges, it is perhaps not surprising that WUD imagery would also play a key role in the Protestant Reformation. The antithetical relationship between the material world and early Christian teachings was brought into political use by those hostile to Rome. As tensions built between the Reformers and the Vatican, this sort of juxtaposition took on a distinctly polemical hue. Martin Luther intensified and

${ }^{58}$ [Footnote from original citation] "There is only one significant variation to this formula: Italian prints of the neoclassical period "dignify" it by adapting classical representations of sacrificial ritual - the man kneeling, the ox slamming him with a hammer." Fawkes.

${ }^{59}$ It is also worth noting the gruesome similarities between WUD imagery like this and the fate met by Guy

${ }^{60}$ ibid., p. 53.

${ }^{61}$ ibid. 
mobilized these tensions, and heightened awareness of the chasm between the behavior of the Church and primitive Christian principles, through the technique of inversion. Luther's Passional Christi und Antichristi (1521) [itself a clear oppositional inversion] equated the Pope with the Antichrist, and helped to move Luther's theological conflict with Rome into the socio-political arena. It used simple German language (later translated into others) and woodcuts (later transferred to other media) to create a widespread appeal for the lay middle classes. In a series of parallel images, the activities of the Pope were shown to be inversions of that of Jesus:

the Pope is arrogant, corrupt, and greedy, lives in selfish luxury, and wages war. Jesus was humble, pure, and selfless, lived in poverty, and brought a message of peace. Christ was crowned with a crown of thorns, the Pope with a triple gold tiara. Christ washed his disciples' feet, the Pope's disciples kiss the Pope's foot. Christ protects his flock, the Pope attacks his by force of arms. ${ }^{62}$

Other Lutheran images had the Pope likened to an Ass playing bagpipes while issuing his 'infallible' pronouncements. But the revolutionary appeal of such imagery and language would also eventually [and unintentionally] help fuel long-simmering tensions between peasants and feudal lords, culminating in the peasant revolt of 1525 . Luther had indeed stoked and legitimized resistance to Rome, but as Kunzle writes, "it was one thing to show the peasant, satirically, defecating into the papal tiara (as a Lutheran cartoon did), and another for the peasant actually to assert his rights against his local lord." In light of these connections, Luther himself would later join the side of the nobility in their call to "destroy peasants who tried to turn a revolution in religious thinking into a social reality, and to translate into action the hierarchical reversals for which Luther had provided the images and

\footnotetext{
${ }^{62}$ ibid., p. 62.
} 
symbols."

Kunzle goes on to trace an interesting parallel between proverbs and WUD themes, showing that as much as they seem to share at the level of technique and intention, they depart from each other very quickly in terms of politics. He points out that there is an evident "verbal-structural similarity" between WUD and a certain form of proverb, since both emphasize brevity, symmetry, and paradox. But there is also very little direct duplication between the proverb and WUD. ${ }^{64}$ Furthermore, he suggests that it cannot be a coincidence either that printed collections of illustrated proverbs and WUD emerge in popularity at about the same time. ${ }^{65}$ Their purposes, however, are contrary or complementary from the very beginning, with both appealing to "a different taste, a different cast of mind". Interestingly, he notes that though both began with prints of comparable if not equal quality, the subsequent degradation in quality for the WUD variety compared to the proverb type, confirms his hypothesis that the WUD variety appealed to lower-class, dissident elements versus the "self-satisfied upper bourgeoisie" who were the clientele for the proverb collections. In his words, the proverb accepts the world 'as it is,' preaching worldly guile, cynicism, and Machiavellian morality. WUD, if it represents an existing world, defines it as perverse; if it imagines a fantasy or future world, it shows that the existing order is not permanent. The proverb accommodates to the hierarchy of the day; WUD mocks and

${ }^{63}$ ibid., pp. 61-63.

64 "Putting the cart before the horse" is one of the few true WUD motifs that exists in the same form as a proverb [footnote 28, p. 72 ].

${ }^{65}$ [From footnote in original citation] "Although most surviving prints from the second half of the sixteenth century appear to be Venetian, we must remember that there was a great deal of copying and importation , in both directions, between the Netherlands and Italy. A print entitled Mondo alla Riversa is listed in the catalogues of two Roman printsellers, Antonio Lafréry 1572, and Andrea and Michelangelo Vaccari1614 [...] Mondo alla Riversa is no. 361 in the Lafréry list where it is immediately followed, significantly, by a print called Proverbij. Vaccari also lists both Mondo alla Riversa and Proverbi" (p. 72). 
challenges it [...] The WUD print recognizes social contradiction and conflict that the proverb tries to mask. The proverb of the early capitalist era, like its late capitalist equivalent, the political and advertising slogan, presents readily understood and often craftily formulated, moral and social catchphrases. In an extraordinary proliferation of printed collections, the proverb established itself over the second half of the sixteenth century as a major vehicle of popular moral authority and a readily internalized means of social regulation [...] Following the example of proverb-rich writing by Luther and Erasmus, the sermons (and, one may assume, letters and conversations) of the bourgeoisie became larded with proverbial wisdom and maxims, designed to bolster its new moral and social power. ${ }^{66}$

The role of proverb and its inverse relationship with WUD themes and imagery then, was much more than a passing fancy. It clearly demarcated two distinct socio-political classes and ideologies from each other. At the same time, each depended on the other in order to hold any meaning for their respective audiences. In the meantime, they work very well as a metaphor to try and understand conspiracy theory as a manifestation of the political complexities of symbolic representation. Already it is clear that in the case study to follow, there is an obvious overlap between the formative clashes of religious tension, the spiritual [not to mention economic] benefits believed to be at stake, and the alleged conspiracies which inhere in the bargain. In the next chapter, the theoretical traditions typically associated with questions like these are assembled around the study at hand.

${ }^{66}$ ibid., pp. 74-75. 


\section{Chapter Three - Conspiracy Theory and the Political Economy of Meaning}

It is perhaps surprising that despite a millennial history of human conflict, the term "conspiracy theory" only first appeared in the supplement to the Oxford English Dictionary in 1997. Less surprising, considering the well documented conspiratorial imagination in American politics, is that the OED entry specifically lists the first recorded English usage as being from an article in the 1909 American Historical Review. As has already been seen, speculation about the alleged wrongdoing by some or another group has a well established presence in both American and world political history. So even though the phrase itself is relatively new, the suspicions engendered by political influence and activity are perhaps as old as recorded history itself. Regardless, the inclusion of the term in the Oxford Dictionary in 1997 stands as a convenient indicator of how much of a buzzword it has become in recent decades. It was to take quite a number of years after its first recorded usage in 1909 though, for it to reach into academic writing in the 1950's with the work of Karl Popper, and not until the 1960 's that it really came into common currency. ${ }^{1}$

In this chapter, the dialectical tension between 'high' and 'low' developed in relation to the carnival and World Upside Down is extended through a consideration of the dialectic in Marxian thinking. This is done in order to bridge the discussion of carnival and conspiracy theory with ideology and hegemony. The concepts of ideology and hegemony hold their own significance to Marxist traditions, and each have their own somewhat complicated histories. These will not be explored in 17.

\footnotetext{
${ }^{1}$ Peter Knight (ed.), Conspiracy Theories in American History: An Introduction, ABC CLIO, 2003; p.
} 
any great detail here, but they are concepts which are very useful in helping to broaden the understanding of conspiracy theory as a form of carnivalesque expression. This is because the carnival is predicated on its relationship to various forms of institutional power while it necessarily represents a symbolic challenge to them. In being so, the carnival represents one aspect of a larger ideological repertoire whereby social contradictions are given voice. The conspiracy theory is another of these aspects, and also stands in a similar relationship to institutional power. Like the carnival, conspiracy theories play a significant role within the hegemonic systems of meaning from which they spring.

The analytical significance of 'conspiracy theory', as we have already begun to see, extends well beyond its compatibility with carnival and symbolic inversion. It stands in its own dialectical relationship to conspiracy itself. To put it another way, 'conspiracy' and 'conspiracy theory' are literally opposites. The political and historical reality of conspiracy is as much a predicating influence on the formation of conspiracy theories, as conspiracy theories are a 'negation' of political and historical reality.

This simple statement requires a more complicated extrapolation. Having made a case for the idea that the social and political history of carnival provides a model for an investigation of conspiracy theories, a detailed unpacking of this inverse relationship between conspiracy and conspiracy theory is necessary. However, the dialectical tension between conspiracy and conspiracy theory not only needs to be pointed out, it needs to be incorporated into any analytical approach which seeks to understand them not only socially and politically, but across different historical circumstances as 
well. It is only through an approach which transcends the specific instances of either, that it is possible to more fully understand the generative dynamic between them.

In the previous chapter, the relational nature of high/low binarism was discussed at length. In carnival festivity, the inversion of and ambivalent dependence upon 'official culture' gave these forms a "doubleness" that at once places them outside of official culture, at the same time they have a fundamental symbolic place within it. In Bakhtin's analysis, polarities like these are locked together in the sense that they are mutually constructed and deformed within the carnival. It was suggested that forms like this 'mediate' the symbolic polarities of high and low, thereby accommodating their unique formal tensions within their respective forms. In this way, it was noted that the classificatory body of a culture is always double, always structured in relation to its own negation, its own inverse. Various classificatory schemes were considered, such as religion for example, all of which did demonstrate a compellingly consistent dualism that was itself inseparable from the very understandings or identities it helps to construct. In moving beyond the literal study of the carnival into the sphere of symbolic inversion which brings it to life, the 'taboo-laden overlap' between official discourses and those which seek to challenge them was also seen to be remarkably consistent. This transpositional shift renders carnival an analytically powerful tool in the study of various other ideological repertoires and cultural practices. Seeing how easy it has been to point to various examples of inversion across the realms of culture, class, economics, religion, and the body, it isn't difficult to appreciate how this could be the case. That said, it does become an effective tool to help understand the 'dialectics of social classification as such,' and so requires that dialectics itself forms the basis of any synthesis with, or application to, a study of conspiracy theory. 


\section{Conspiracy Theory and the Dialectical Imagination}

Roy Bhaskar writes in Bottomore's A Dictionary of Marxist Thought $^{2}$ that dialectics is perhaps "the most contentious topic in Marxist thought, raising the two main issues on which Marxist philosophical discussion has turned, viz the nature of Marx's debt to Hegel and the sense in which Marxism is a science." ${ }^{\prime 3}$ Considering the emphasis on symbolic inversion as key to the dialectics of social classification, a more detailed look at the concept is useful for a number of reasons. Among them is how well a focus on carnivalesque inversion is able to incorporate the dialectic into a general study of power. Though it is not necessary to attempt a full examination of the concept here, Bhaskar's synthesis hits on a number of important aspects which have some obvious overlap with the current study.

There are three main emphases in Marxist writing on dialectics; epistemological dialectics, which refers to the usually scientific method of analysis to be employed; ontological dialectics which is concerned with some set of laws or principles governing the whole of reality; and the relational dialectics of the movement of history. Each of these is seen most clearly in the methodological comments in Marx's Capital, Engel's philosophy of nature in Anti-Dühring, and what Bhaskar refers to as the "out-Hegeling Hegelianism" of the early Lukács in History and Class Consciousness respectively. Within Hegel, there are two inflections of the dialectic. First, it exists as a logical process and second, as the dynamo of that process. Leaving aside the specifics of its Socratic,

\footnotetext{
${ }^{2}$ Tom Bottomore (ed.), A Dictionary of Marxist Thought, Harvard University Press, Cambridge, Mass., 1983.

${ }^{3}$ ibid., p. 122.
} 
Platonic, and Aristotelian roots, the important element to retain is the conception of the dialectic as a self-generating, self-differentiating, and self-particularizing process of reason. It is a process which actualizes itself by alienating itself. The unity of the concept resides in the way that this alienation is its own natural manifestation. This becomes somewhat clearer when shifting focus to the 'motor' of the dialectical process.

Hegel refers to the 'motor' of a dialectic as being the "grasping of opposites in their unity or of the positive in the negative." ${ }^{4}$ This method is said to enable the dialectical commentator to see the process by which certain forms of consciousness, categories, or notions, arise out of each other to form even more complete systems. 'Truth' resides in a full conception of the whole, while 'error' lies in one-sidedness, incompleteness, or abstraction. Truth can be recognized by the contradictions it generates, and remedied by their incorporation into more full and inclusive conceptual forms. In viewing the dialectic this way, no partial insight is ever lost, and in Hegel's eyes, progresses or unfolds in two ways. First, "by bringing out what is implicit, but not explicitly articulated, in some notion," and second, "by repairing some want, lack or inadequacy in it." In contrast to reflective or analytical thought then, dialectical thought grapples with conceptual forms in terms of their systematic interconnections, not just their differences, in such a way that there is always an inherent tension or irony at the center.

Before going any further, it is worthwhile to return quickly to the relationship between conspiracy and conspiracy theory as a way of trying to clarify this somewhat complicated and abstract concept.

\footnotetext{
${ }^{4}$ Hegel, 1812-16 [1969]; p. 56, cited in Bottomore, ibid.; p. 122.
} 
Beginning with the notion of conspiracy theory, we can see quite easily that it is 'motivated' or 'logically driven' by conspiracy, even though the two are opposites of each other. Conspiracy theory brings out that which is implicit within conspiracy, without explicitly articulating an 'actual' conspiracy. In fact, it cannot even do so without destroying its own 'status' as a conspiracy theory, as much as it is precisely this act of self-annihilation which is ultimately driving it forward. The existence of 'actual' conspiracy in the abstract, then, does repair some 'want', 'lack', or 'inadequacy' in the conspiracy theory. This is because pointing to real conspiracies, in whatever degraded forms they exist, provides further justification for the existence of conspiracy theories. It is necessarily the case, also, that 'no partial insight is ever lost' because partial insight is the very thing upon which a conspiracy theory depends. The more motivated the pursuit and accumulation of partial insight, the more full-blown the conspiracy theory. Thinking about conspiracy theory dialectically looks through the obvious differences that exist between it and conspiracy in order to see the systematic interconnections between them. In this we can see how conspiracy theory actualizes itself by alienating itself.

Of course, the same is true of the opposite. Real-life conspirators could only dream of achieving the levels of control and omniscience that conspiracy theorists would ascribe to them. However, as impossible as this level of conspiratorial control is to achieve in real life, it represents the unattainable ideal of any conspiracy. In doing so, it does repair a want, need, or inadequacy in the conspiracy through the chimera of perfect control. By the same token, 'partial insight' is one of the keys to success of any conspiracy, since full disclosure would automatically undermine it. The more completely and thoroughly maintained this partial insight is, then, the more successful the conspiracy 
becomes. Between and because of this dialectical tension, we see the grasping of opposites in their unity; we see the positive in the negative.

There are a whole host of differences and digressions between Hegelian dialectics and Marx's use of the term which do not need to be fully elaborated. But there is one aspect to this debate which has a direct currency here, and that is the concept of inversion. It is interesting to note, especially in light of what has already been written, that Marx's own view of dialectics stands as an inversion of Hegel's. There are three important phases in the development of Marx's thinking in this regard. The first is his analysis of Hegel's "mystified" logic in the Critique of Hegel's Philosophy of the State. It is a theme he picks up again in the Economic and Philosophical Manuscripts where Hegel's idealist conception of labour is his focus. The second phase is in his following works, The Holy Family, The German Ideology, and The Poverty of Philosophy, where Bhaskar writes that "the critique of Hegel is subsumed under a ferocious polemical assault on speculative philosophy as such." The third and final phase is from the time of the Grundrisse onward, where there is a definite positive re-evaluation of the Hegelian dialectic by Marx. Though the extent of this reevaluation is "a matter of lively controversy" two things seem clear, that Marx remained critical of the Hegelian variety as much as he believed himself to be working with a version related to it. As he wrote in a personal correspondence regarding a December 1867 review of Capital by Dühring: "He knows very well that my method of development is not Hegelian, since I am a materialist and Hegel is an idealist. Hegel's dialectics is the basic form of all dialectics, but only after it has been

\footnotetext{
${ }^{5}$ ibid., pp. 122-123.
} 
stripped of its mystified form, and it is precisely this which distinguishes my method." ${ }^{\prime \prime 6}$ Furthermore, in the Afterward to the second edition of Capital, Vol. I, he writes that the "mystification which the dialectic suffers in Hegel's hands by no means prevents him from being the first to present its general forms of motion in a comprehensive manner. With him it is standing on its head. It must be inverted to discover the rational kernel within the mystical shell." ${ }^{, 7}$ In an interesting turn of a phrase considering some of the themes addressed earlier, Bhaskar writes that these two metaphors - of the inversion and of the kernel - have been the subject of almost theological speculation. The kernel metaphor seems to indicate that Marx thought it possible to extract part of the Hegelian dialectic - against both (i) the Young Hegelian and Engelsian view that a complete extraction of the dialectical method from Hegel's system is possible and (ii) the view of positivistically-minded critics from Bernstein to Colletti that no extraction at all is possible, that the Hegelian dialectic is totally compromised by Hegel's idealism. ${ }^{8}$

Once again, there is only so much background detail that is required, but what is useful about this debate is the way it mimics or echoes the inherent tension which should be at the center of studying conspiracy theories. Though it is obviously a qualitatively different set of questions, the similarity hinges on the materialist-idealist dialectic which is itself at the heart of Marx's quarrel with Hegel. As we have already seen in the discussion of the paranoid style in American politics, its proponents did not view conspiracies 'here-and-there', but rather in a way that saw history itself as a conspiracy. As Hofstadter put it, "they regard a 'vast' or 'gigantic' conspiracy as the motive force in historical events. History is a conspiracy, set in motion by demonic forces of almost transcendent power, and

\footnotetext{
${ }^{6}$ Letter to Kugelmann, March 6, 1968; cited in Bottomore, ibid., pp. 122-123; emphasis in original.

${ }^{7}$ ibid., p. 123.

${ }^{8}$ ibid. emphasis added.
} 
what is felt to be needed to defeat it is not the usual methods of political give-and-take, but an all-out crusade." 9

Having already highlighted the similarities, or 'fit', between the paranoid style and evangelical Christian beliefs, we only get closer to understanding the frictions that exist between materialist conceptions of history like that of Marx, and the idealist sort we see reflected in the paranoid style. This debate, then, parallels the present discussion of conspiracy theory very closely. This is because there is a similar kind of 'mystification' which needs to be stripped away from the study of conspiracy theories before we can try to understand how they function in the material world. Though the inflections of idealism are completely different between the philosophical debate and the conspiracy theory, the ways that conspiracy theories envision 'the ultimate answer' to the unfolding of history stands in a similar relation to reality, and so animates a similar tension.

Both dialectics and idealism are complicated concepts, each with their own labyrinthine histories and points of emphasis. But in the interest of focus, a look at other ideas helps to highlight some of the ways that a dialectical orientation to the study of conspiracy theory presents a unique vantage point from which to see the full spectrum of its usefulness as a conceptual tool. Returning for a moment to the three main emphases in Marxist writing on dialectics, it is clear how much this is the case. Epistemological dialectics refers to the usually scientific method of analysis to be employed. Though the method to be employed here is not scientific, it has already been noted that studying conspiracy theory as a form of carnivalesque inversion is already an epistemological dialectic.

\footnotetext{
${ }^{9}$ Hofstadter, op. cit., p. 29; emphasis in original.
} 
Ontological dialectics were said to be concerned with some set of laws or principles governing the whole of reality, and conspiracy theories most certainly reflect a belief in a particularly malevolent version of those. Finally, the relational dialectics of the movement of history are easy to demonstrate in terms of conspiracy theory and the 9/11 attacks. A widely-held Arab belief in a Judeo-Christian conspiracy against Islam was a factor in the execution of the $9 / 11$ attacks, as much as the Iraqi accent on the retaliation for them has since worked to reinforce it. Moreover, as the case study demonstrates, American conspiracy theories about the same events worked in their own ways to uphold and mobilize the Bush Doctrine in the Middle East.

\section{Ideology}

Considering the focus of the case study to follow, it would be difficult to set aside the concept of ideology and still pretend to be conducting a reasoned analysis. Ideological tensions, along with a whole host of others of course, lie at the center of the $9 / 11$ attacks as surely as the 'War on Terror' is itself an ideological construct. Like dialectics, ideology is a concept with its own complicated history, but one which can still be very useful nonetheless. Building off of this discussion, the general concept of ideology is not only compatible with it, but is necessarily composed of and predicated on many of the same tensions. Bearing in mind that an extended examination of ideology could get cumbersome rather quickly, it is still worthwhile to highlight some of its compositional features. From there, we can proceed to a definition of the concept which will help to frame the present study in terms of meaning and power. 
"Consider the following paradox." So begins Terry Eagleton in his Ideology: An Introduction. ${ }^{10}$ He writes that the 1980's were a decade that saw the resurgence of ideological movements the world over. In the Middle East, Islamic fundamentalism emerged as a potent force. Revolutionary outbursts like the Falkland Islands and the workers movement in Poland, were matched by Thatcherism in the U.K. and a "peculiarly noxious brand of Christian Evangelicalism" in the United States. Despite all of this, Eagleton bemoans the fact that at the very same time the notion of ideology was being dismissed as obsolete. ${ }^{11}$

The reasons for this alleged obsolescence are themselves quite involved. In essence, they harken an older "end-of-ideology" debate after the Second World War. It was here where the Nazified extremities of fascist rhetoric and Stalinism were vanquished by a 'post-ideological' sensibility which was itself, after all, an ideological posture of the political right. Eagleton suggests that where 'end-of-ideology' theorists saw ideology as inflexible, closed, and dogmatic, 'postmodern' thinkers considered it teleological, totalitarian, and grounded in metaphysics. Dismissing the concept of ideology as "outmoded", he writes, similarly dispatches a more pervasive naivete about such 'metaphysical' matters as class, production, and revolutionary agency. He declares it an embarrassment to positions like these that at the same time they were denouncing the concept of revolution as so much "metaphysical claptrap", the very thing was itself breaking out in the heartland of Stalinist bureaucracies in Eastern Europe. With his characteristic wit, Eagleton writes that, "[n]o doubt President Ceausescu spent his last moments on earth reminding his executioners that

\footnotetext{
${ }^{10}$ Terry Eagleton, Ideology: An Introduction, Verso, 1991.

${ }^{11}$ ibid., p. xi.
} 
revolution was an outmoded concept, that there were only ever micro-strategies and local deconstructions, and that the idea of a 'collective revolutionary subject' was hopelessly passé."12

One of the interests Eagleton has in the concept of ideology, then, is how to understand the ways in which ideas can act as material and motive forces in history. It is one thing, he argues, to understand how it is a human being can plot and kill for 'good' material reasons - such as their own survival for example. It is another thing entirely to consider how this can be done for something as abstract and 'immaterial' as an idea. Though questions like this have an obvious currency for a study of $9 / 11$, they are by no means new ones. In order to understand these questions, and in order to develop a 'critique of ideology', Eagleton draws an important methodological distinction between 'criticism' and 'critique'. 'Criticism', as an Enlightenment concept, amounts to somehow indicating to some imagined subject what is wrong with their current situation from some other external or 'transcendental' vantage-point. 'Critique', on the other hand, is "that form of discourse which seeks to inhabit the experience of the subject from the inside, in order to elicit those 'valid' features of that experience which point beyond the subject's present position." ${ }^{13}$ A simple sleight-of-hand at this point over the notion of the 'subject', shows how the focus on conspiracy theory is intended to do the very same thing. It seeks to 'get inside' conspiracy theory in order to elicit and understand the valid features which point beyond its position as a marginal form of discourse. To put it in other terms, the fact that there is no international Judeo-Christian conspiracy against Islam does not change the reality of $9 / 11$ and all that has ensued in its wake. By the same token, the fact that there is no

\footnotetext{
${ }^{12}$ ibid., p. xiii.

${ }^{13}$ ibid., p. xiv.
} 
conspiracy should not detract from recognizing the complex realities of Middle Eastern politics, not the least of which is the favorable policy history of the American government with regard to Israel. What it does show, is that the question of ideology cannot be left out of a critical study of conspiracy theory. On the contrary, it raises the question as to what extent conspiracy theories are actually manifestations of ideological conflict.

Interestingly, the notion of 'inversion' remains a unifying and central concept here, even as the scope is extended to encompass ideology. On the origins of the concept in the Marxian sense, Jorge Larrain writes that there are two strands of critical philosophical thought which directly influenced Marx's and Engels' concept of ideology. The first of these is the critique of religion developed within French materialism and by Feuerbach. The second, is the critique of traditional epistemology and the revaluation of the subject's activity by the German philosophy of consciousness, especially by Hegel. Larrain states that while these critiques did not succeed in connecting metaphysical or religious distortions with specific social conditions, the critique by Marx and Engels sought to show that there was a necessary link between 'inverted' forms of consciousness and man's material existence. It is in this sense that they envisioned the relation between inverted forms of consciousness and material existence in terms of 'ideology'. Ideology expresses itself as a distortion of thought which is both rooted in, and at the same time conceals, social contradictions. From its very inception then, the concept of ideology has a deliberately negative and critical connotation. ${ }^{14}$ As was the case with dialectics, it is necessary to consider Marx's thinking about ideology in relation

\footnotetext{
${ }^{14}$ Larrain, in Bottomore, ibid., p. 219.
} 
to different stages of his work. This is not to make the case for any sort of radical epistemological break between these stages. Instead, it is more accurate to think of it as growing from "a basic nucleus of meaning" which found new dimensions as he developed his position and tackled new issues. The first stage corresponds to his early writings up until 1844. Though he does not use the term 'ideology' in this stage, it is during this early period that his ongoing philosophical debates, primarily with the ideas of Hegel and Feuerbach, sets the groundwork for his later thinking on the concept. It is a period which is strongly influenced by Marx's critique of religion, and Hegel's conception of the state. ${ }^{15}$ Each of these are described by Marx to be 'inversions' which conceal the true nature of material reality. His general point here is relatively easy to see in relation to religion where, in effect, 'man creates God, so God can create man'. Experience and struggle with the real world may foster a religious faith that the 'meek shall inherit the earth' or that it is 'easier for a camel to pass through the eye of a needle than a rich man to enter the kingdom of God'; but in the meantime, the hardship and struggle which result from real-world contradiction and inequality are rationalized into faith-based oblivion. The world in this sense is 'inverted' because it is not "God's Plan" which creates the need for hardship and suffering, it is the hardship and suffering which creates the need for a faith in God's Plan. Religion in this way is "ideological" because it inverts and conceals the material conditions of reality at the very same time it expresses them.

The second stage in Marx's thinking about ideology runs from 1845 to 1857 which corresponds to Marx and Engel's development of historical materialism. It is in their attempt to work out the general premises for their ideas in this regard that the term 'ideology' is used for the first time. Of

\footnotetext{
${ }^{15}$ ibid.
} 
course, the idea of 'inversion' is retained, but it is extended in some rather interesting ways. It comes to encompass the work of the so-called 'young Hegelians' and the critiques they had put forward on the subjects of religion and Hegel's philosophy. The root of Marx's criticism of the young Hegelians lies in the fact that they had sought to enlighten or liberate men from 'mistaken ideas'. In this way, Marx pointed out that their own ideas were themselves dependent on Hegelian premises. ${ }^{16}$ As Marx wrote, "[t]hey forget, however, that to these phrases they themselves are opposing nothing but phrases to these phrases, and that they are in no way combating the real existing world when they are combating solely the phrases of this world." ${ }^{17}$ So the inversion that Marx is here calling ideology consists in the practice of putting primacy on 'consciousness' or 'ideas' instead of material reality. Marx suggests that it is precisely the other way around. Larrain writes that "Marx affirms the real problems of humanity are not mistaken ideas but real social contradictions and that the former are the consequence of the latter." 18

Some elaboration on this last point is useful. The suggestion that ideas about social contradictions arise from material circumstances is meant to address the relationship between certain kinds of ideas, and how they function in relation to the material conditions which help to produce them. When individuals are confronted with seemingly insurmountable inequalities, such as those which

16 ibid.

${ }^{17}$ Karl Marx and Frederic Engels, The German Ideology, Prometheus Books, 1998; p. 36. This is a very interesting idea for a thesis that is seeking to understand conspiracy theories, paradoxically, as a hegemonic form of discourse. Conspiracy theories do, of course, also seek to enlighten or liberate men from a form of 'mistaken' ideas about reality in various ways. Similar to religion, conspiracy theories invert and conceal the material conditions of reality at the very same time they express them.

${ }^{18}$ Larrain, in Bottomore, op. cit., p. 219. 
comprise race, class, or gender, for example, Marx believes that these tend to be projected into ideological forms of consciousness. In other words, these forms represent purely mental or discursive 'solutions' to these inequalities or contradictions which, in turn, mask or distort these inequalities or contradictions in some way. The masking or distortion of these contradictions facilitates their reproduction, and this in turn serves the interests of the ruling classes. These distorted ideas serve the interests of the ruling classes because, in refracting the material conditions which created them, they work to "reproduce" them in the sense that they discourage acknowledgment of the real-world root causes. It is as necessary as it is interesting to point out that the relationship between ideological and non-ideological ideas cannot be understood in terms of 'truth' and 'error', despite the oft-quoted references to ideology as false consciousness. Nor can ideological distortions be overcome through criticism, they only disappear once the originating contradictions are practically resolved.

Though this need not be taken as a full-on parallel, it already harkens conspiracy theories in some significant ways. This study addresses the relationship between conspiracy theories and how they function in relation to the material conditions which help to produce them. They most certainly do arise when individuals, or groups of them, are confronted with difficult circumstances where it appears that there is no way out. This is all the more true when it even appears that there are tangible systemic factors which seem to work to maintain these inequalities and social contradictions. For example, there are all kinds of conspiracy theories which reflect race, class, and gender politics. It is clear that many if not all of them do represent purely mental or discursive 'solutions' that try to explain 'why it is, that everyday, everything always turns out this way'. But by attributing root 
causes to unseen malevolent forces, more prosaic explanations fall by the wayside. This can easily be said, then, to reinforce the more immediate interests of ruling classes in ways that are specific to whatever case is being studied. As has already been shown, there is no easy distinction between 'truth' and 'error' when thinking about conspiracy theories dialectically. Nor can conspiracy theories be easily dispelled by criticism. Like religious faith, conspiracy theories thrive in the absence of proof, and are only reinforced by those who 'fail to see'.

The third and final stage, once again, begins with the Grundrisse in 1858. In this stage, the term ideology all but disappears. What remains, however, is a "concrete analysis of advanced capitalist social relations which culminates in Capital". Within the analysis in Capital is a sustained use and re-working of the concept of inversion. It is interesting, considering the World Upside Down imagery discussed in the previous chapter, that Marx by this point had already drawn the conclusion that if some ideas distorted or inverted reality, it was because reality itself was upside down. But since nothing is ever this direct and unmediated, Marx's specific analysis of capitalist social relations leads him to a more sophisticated conclusion.

His conclusion was that the relationship between inverted consciousness and inverted reality was mediated by a plane of appearances, or 'phenomenal forms', which were themselves constitutive of reality itself. ${ }^{19}$ Marx, of course, discusses these forms in terms of the operation of the market and competition in capitalist societies. However, if it is safe to assume that we can include religion into this sphere of 'phenomenal forms', then we can easily append this list of phenomenal forms with

\footnotetext{
${ }^{19}$ ibid., p. 220.
} 
conspiracy theories. In order to do so, however, it is first necessary to expressly adopt a definition of ideology which is useful for an analysis of conspiracy theories.

Eagleton introduces his first chapter 'What is Ideology' by writing that “[n]obody has yet come up with a single adequate definition of ideology, and this book will be no exception." The same holds for this thesis. Still, it is an interesting paradox that a concept which has been employed so frequently would itself be so resistant to definition. So while Eagleton and many others grapple with the finer points of this complicated debate, it is enough to acknowledge that there are many competing and even contradictory definitions of the concept of ideology, and that I have found the definition offered by John Thompson in Ideology and Modern Culture: Critical Social Theory in the Era of Mass Communication ${ }^{20}$ to be particularly useful. For Thompson, and against this contested and contradictory history, studies of ideology should be primarily concerned with the ways that symbolic forms circulate and intersect with relations of power. Thompson's definition is meant to highlight an understanding of the ways that meanings are mobilized in the social world in such a fashion that they reinforce individuals and groups who are in positions of power. "Let me", he writes, "define this focus more sharply: to study ideology is to study the ways in which meaning serves to establish and sustain relations of domination." He goes on to write that ideological phenomena are meaningful symbolic phenomena to the extent that they serve, in particular socialhistorical circumstances, to establish and sustain relations of domination. Thompson immediately takes pains to make clear that "symbolic phenomena, or certain symbolic phenomena, are not

\footnotetext{
${ }^{20}$ John Thompson, Ideology and Modern Culture: Critical Social Theory in the Era of Mass Communication, Stanford University Press, 1990.
} 
ideological as such, but are ideological only in so far as they serve, in particular circumstances, to maintain relations of domination." In other words, Thompson is reminding us that the ideological character of symbolic forms cannot be manifestly read off the symbolic forms themselves; we can only truly grasp symbolic forms as ideological, and therefore study ideology, only by situating these forms within the social and historical contexts within which these symbolic phenomena may [or may not] establish and sustain power relations. ${ }^{21}$

In formulating this perspective on ideology and ideological forms, Thompson draws on what he calls Marx's latent conception of ideology. He contrasts these with a polemical conception and an epiphenomenal one that he feels characterizes Marx's use of the term at different times in somewhat different ways. For Thompson, the polemical conception is rooted in Marx's familiarity with the work of the French idéologues, as well as Napoleon's attack on it. While exiled in France in 1844-5, Marx read and excerpted parts of Destutt de Tracy's work, and very shortly after began writing The German Ideology with Engels. In this book, they were very critical of the young Hegelians, and echoed Napoleon's use of the term "ideology" in his disparagement of the work of the French idéologues. In this way, they drew a parallel between the French idéologues and the young Hegelians, and coined a particularly negative use of the term ideology in the process. By labeling the views of the young Hegelians this way in The German Ideology, Marx and Engels were seeking to discredit them by associating them with doctrines that had been denounced decades earlier in France. Clearly then, ideology here is used as a term of abuse. For the purposes of clarity, Thompson defines the polemical conception of ideology as " $a$ theoretical doctrine and activity which

\footnotetext{
${ }^{21}$ ibid., p. 56.
} 
erroneously regards ideas as autonomous and efficacious and which fails to grasp the real conditions and characteristics of social-historical life." 22 In this polemical fashion, then, Marx and Engels characterize the work of the young Hegelians as ideologically inverse to 'the real conditions and characteristics of social-historical life'.

The epiphenomenal conception is slightly different. It refers to use of the term ideology in a more general way. Thompson points out that this more general usage was already evident in The German Ideology, as they began to connect the production and dissemination of ideas to the broader relations between social classes. It is on this point where they famously remarked that the "ideas of the ruling class are in every epoch the ruling ideas: i.e., the class which is the ruling material force of society is at the same time its ruling intellectual force. The class which has the means of material production at its disposal, consequently also controls the means of mental production, so that the ideas of those who lack the means of mental production are on the whole subject to it." ${ }^{23}$ Thompson terms this the epiphenomenal conception because of the way it regards ideology as being derived from and dependent on the economic and class relations of production. It is a conception which views ideology as " $a$ system of ideas which expresses the interests of the dominant class but which represents class relations in an illusory form." ${ }^{24}$

It is the latent conception of ideology, however, that receives Thompson's most extensive attention.

\footnotetext{
${ }^{22}$ Marx and Engels, 1998, op. cit., pp. 34-35; emphasis in original.

${ }^{23}$ ibid., p. 67.

${ }^{24}$ Thompson, op. cit., p. 37.
} 
Thompson describes the latent conception of ideology as being based in parts of Marx's work where the movement of history is presented as being less straightforward, where the present is seen as a multiplicity of complex schisms rather than some sort of unified progression. Against a more 'traditionally' Marxian progression of social antagonism, depicted as a gradual reduction of all social conflicts to opposition between bourgeoisie and proletariat, and with the enlightenment of the proletariat as a result, the vision of one grand opposition falls away to include individuals captivated by images and expressions from the past. As Thompson writes, it consists in people "acting out their historical roles on the basis of pre-given scripts rather than knowledge derived through experience and scientific investigation." It tells a story of defeat and disappointment. It is a predisposition which looks to the past, longingly even, while ignoring or not articulating their own class interests. Thompson suggests that there are elements here of a different conception of ideology, which he formulates as " $a$ system of representations which serves to sustain existing social relations of class domination by orienting individuals towards the past rather than the future, or towards images and ideals which conceal class relations and detract from the collective pursuit of social change." 25

Thompson describes this as a latent conception of ideology for two reasons. First, and most obvious, it is because Marx didn't use the term 'ideology' in the written contexts where the latent conception emerges. Instead, he uses words like 'illusions', 'ghosts', 'spirits', or 'fixed ideas'. One of the more famous of these, of course, is his assertion from the Eighteenth Brumaire that the "tradition of all dead generations weighs like a nightmare on the brains of the living." Thompson, though, makes a very important caveat in this regard. He writes that we can only extend the term 'ideology' to these

\footnotetext{
${ }^{25}$ ibid., pp. 40-41.
} 
instances if we acknowledge that we are doing so to refer to a whole range of social phenomena that Marx described, but did not name. In Thompson's words, these were "phenomena which he perceptively and disconcertingly portrayed in his analyses but which, at the level of theory, he did not subsume under a discrete conceptual label." ${ }^{26}$

The second reason that Thompson refers to this as a latent conception of ideology, is because it encompasses that same range of phenomena which do not fit neatly into the theoretical framework put forward by Marx in the 1859 Preface to The Critique of Political Economy, or the account of the modern era presented in The Communist Manifesto. In a key passage, Thompson writes that the phenomena referred to by the latent conception

are not mere epiphenomena of economic conditions and class relations; rather, they are symbolic constructions which have some degree of autonomy and efficacy. They constitute symbols and slogans, customs and traditions which move people or hold them back, propel them or constrain them, in such a way that we cannot think of these symbolic constructions as solely determined by, and fully explicable in terms of, the economic conditions of production. ${ }^{27}$

It could be suggested at this point that the carnival, and by extension the conspiracy theory, make a pair of strong running-mates as 'discrete conceptual labels'. Though there are some distinct differences between what Thompson is referring to with regard to Marx, and what I hope to accomplish here, it is a matter of climbing both sides of the same fence. They both address specific but contradictory social and political practices whereby dominant institutional arrangements are, nonetheless, largely upheld. In the case of Marx and the Eighteenth Brumaire of Louis Bonaparte,

\footnotetext{
${ }^{26}$ ibid., p. 41 .

${ }^{27}$ ibid.
} 
these occur on the side of bourgeois interests. In the carnival they do the same thing, but from behind a mask of symbolic rebellion.

Thompson goes on to say that the phenomena which are described by the latent conception "attest to the persistence of traditional symbols and values, of that "train of ancient and venerable prejudices and opinions' at the very heart of modern bourgeois society." He points out that these traditional symbols and values are not swept away, despite the constant revolutionizing in production. On the contrary, "they modify and transform themselves, indeed they reappear as a potent reactionary force on the very eve of revolution itself." He goes on to write that the

latent conception of ideology calls attention to the fact that social relations may be sustained, and social change arrested, by the prevalence or diffusion of symbolic constructions. It calls attention to what we could describe as a process of social conservation within a society undergoing unprecedented social change, a process which Marx acutely discerned but the implications of which he was, perhaps, reluctant to draw out fully. ${ }^{28}$

It is interesting at this point to consider how closely what Thompson describes as his latent conception of ideology mirrors the perspective of the present study. For now, it is enough to recall Holquist's comments about Bakhtin's notion of carnival being 'the most productive concept in his book, it is not only an impediment to revolutionary change, it is revolution itself.'

\section{Language, Meaning, and Ideology}

Valeri Vološinov, himself a contemporary of Bakhtin and a member of what has become known as the 'Bakhtin Circle', introduces a range of interesting ideas to the study of ideology in Marxism

\footnotetext{
${ }^{28}$ ibid.
} 
and the Philosophy of Language. ${ }^{29}$ Drawing on linguistics and semiotics, he is concerned primarily with the social role of verbal utterances, considering them a form of social interaction. It is a perspective that helps to flesh out the emphasis that Thompson brings to the study of symbolic forms from the point of view of ideology. Like Bakhtin, Vološinov is interested in the dialogic aspects of meaning and communication. For Vološinov, "the refraction of existence in the human consciousness originates solely in verbal communication which, by its very nature, is anchored in social interaction." By this, he suggests that the study of human language cannot be detached from its social existence in time or space, nor from the impact of socioeconomic circumstances. As Matejka and Tituunik put it in the translators' preface, the "conceptualization of dialogue in the dialectical method is regarded by Vološinov as the only way of understanding the fundamental significance of language for all aspects of human civilization." 30

Vološinov writes in the introduction that at the time of his writing, there was yet to be a single Marxist work on the philosophy of language. He starts out then by setting himself some very modest objectives in this regard, and goes on to say that nothing approaching a systematic and conclusive Marxist analysis of the philosophy of language is possible without a sustained and collaborative effort. He writes that the task is made especially difficult by the fact that Marxist literature as yet contained "no conclusive and commonly accepted definitions as to the specific

\footnotetext{
${ }^{29}$ Valeri Vološinov, Marxism and the Philosophy of Language, Harvard University Press, Cambridge, Mass., 1986.

${ }^{30}$ ibid., p. viii.
} 
nature of the reality of ideological phenomena." ${ }^{31}$ He continues that in the majority of cases, ideological phenomena are interpreted from the point of view of consciousness, or as he puts it, "psychologistically". This is detrimental in the extreme to a "correct approach", Vološinov feels, because the specific characteristics of ideological phenomena are under no circumstances reducible to the individual psyche or consciousness. He points out that this is precisely why the "role of language as the specific material reality of ideological creativity has failed to be adequately appreciated" (pp. xiii-xiv)."32

Vološinov then embarks on a discussion of the sign. He writes that signs themselves are particular, material things. They do not simply exist as part of reality, instead, they reflect or refract another one. These signs, then, may distort reality or be truthful to it. They may also perceive it from one or another point of view. The key distinction he draws is that the domain of the sign and the domain of ideology coincide with each other. Where signs are present, ideology is as well. "Everything ideological possesses semiotic value. ${ }^{" 33}$ He points out right away that within the realm of signs, or, the realm of ideology, profound differences exist. For example, there is the artistic image, the religious symbol, the scientific formula, and the judicial ruling; each of these fosters its own distinct orientation toward reality and performs a different function within the unity of social life. But it is

\footnotetext{
${ }^{31}$ ibid. [Footnote from original citation] "Definition of the place of ideology in the unity of social life was provided by the founders of Marxism: ideology as superstructure, the relation of superstructure to the basis, and so on. But as far as questions connected with the material of ideological creativity and the conditions of ideological communication are concerned, those questions, as secondary matters for the overall theory of historical materialism, did not receive concrete or conclusive resolution."

32 ibid., pp. xiii-xiv.

${ }^{33}$ ibid., p. 10; emphasis in original.
} 
their semiotic character which, for Vološinov, "places all ideological phenomena under the same general definition." Ideological signs in this regard, are never just shadows or reflections of reality, there are themselves material aspects of it. Ideological signs always have some form of material embodiment, whether it be in the form of sound, color, physical mass, or body movement, for example. As such, they exist as phenomena in the external world and are amenable to objective study. As obvious as this is, Vološinov notes that it is a point of extreme importance. In his time, "the study of ideologies [had] not drawn all the conclusions that follow from it."34

After excoriating "the idealistic philosophy of culture and psychologistic cultural studies" over their obsessive emphasis on consciousness, he proceeds to show that the ideological simply cannot be explained in terms outside of material social reality. "The objective social regulatedness of ideological creativity, once misconstrued as a conformity with laws of individual consciousness, must inevitably forfeit its real place in existence and depart either up into the superexistential empyrean of transcendentalism or down into the presocial recesses of the psychophysical, biological organism." Its real place, he contends, is in the social material of signs made by man. These signs derive their specificity through their social 'position' between organized individuals, "in its being the medium of their communication". If anything, it is the individual consciousness that needs to explained from the vantage point of the social, ideological medium. ${ }^{35}$

It is when Vološinov turns his attention to language that he begins to more concretely discuss the

\footnotetext{
${ }^{34}$ ibid., p. 11.

${ }^{35}$ ibid., p. 12; emphasis added.
} 
relationships between the sign, ideology, and Marxism. It is in language that the conditioning factors of semiotics are fully expressed. It is the word which is "the ideological phenomenon par excellence". This is because the function of words is wholly absorbed in the role of being a sign. Words, literally, cannot do anything else. Not only is the word the purest form of sign, it is also, paradoxically, a neutral one. Whereas other kinds of signs are created for specific purposes and remain inseparable from them, such as a crucifix for example, the 'word' is neutral with respect to any specific ideological function. But, it can perform an ideological function of any kind, whether that be religious, scientific, or conspiratorial. It is a short step from here to see that human communication itself cannot be pinned down to any one ideological sphere. Words and language surround and accompany other, more inert ideological symbols. It should be obvious, of course, that words can in no way replace these other forms. As Vološinov puts it, none of the "fundamental, specific ideological signs is replaceable wholly by words. It is ultimately impossible to convey a musical composition or pictorial image adequately in words. Words cannot wholly substitute for a religious ritual; not (sic) is there any really adequate verbal substitute for even the simplest gesture in human behavior." At the same time, he points out, words and language embellish and augment these (and all other) ideological form. ${ }^{36}$

At the level of culture, it stands to reason that no cultural sign lives in isolation; they are always already part of the verbally constituted unity of social consciousness. Like ripples on a pond, language and utterance encircle each and every ideological sign. Words are present in each and every act of understanding and interpretation. "The only possible way of bringing the Marxist

\footnotetext{
${ }^{36}$ ibid., pp. 14-15.
} 
sociological method to bear on all the profundities and subtleties of 'immanent' ideological structures," Vološinov concludes, "is to operate from the basis of the philosophy of language as the philosophy of the ideological sign. And that basis must be devised and elaborated by Marxism itself." 37

The problem of the relationship between base and superstructure is, Vološinov states, one of the fundamental problems of Marxism. It is also, he feels, closely linked to the questions of the philosophy of language, and could benefit from a reasonable consideration of these questions. The causal relationship envisaged between base and superstructure is true enough, he says, but it is by no means sufficient because it is far too general and ambiguous. This is because it is meaningless to try and understand a connection between some "base" and some other isolated fact "torn from the unity and integrity of its ideological context." On the contrary, it is essentially important to appreciate any given ideological change in terms of a much larger system of interconnections and relationships.

If a given "domain of ideology", be it scientific, religious, or any other, is understood as a more or less unified whole which reacts to and between those other domains, it is clearly not enough to try and understand them as some "mere outward conjunction of two adventitious facts belonging to different levels of meaning." In other words, this sort of mechanistic approach misses the processual overlaps and interrelations between different systems of ideological meaning. To put it another way still, how is one to fully understand the perspectival shifts wrought by science without a

\footnotetext{
${ }^{37}$ ibid., p. 15 .
} 
corresponding accommodation, in one fashion or another, by the ideological domain of religion? Similarly, how is it possible to extract either of these from the economic, political, or cultural domains which themselves play a determined hand in the success (or not) of one, or both? In too tight a nutshell then, it is all about understanding the necessarily dialectical generation of 'society' out of its various bases, and how they come to a form of 'completion' in its competing superstructures. ${ }^{38}$ By the same token, it begs the question as to how one is to understand conspiracy theories except as an amalgam of the above.

The challenge here is to try and understand some of the ways that the "base" helps to determine the sign, and how the sign in turn works to 'reflect and refract' experience in the process of its formation. It is in this sense, then, that Vološinov says the 'word' becomes the most suitable means with which to investigate this complex of influences in basic terms. What is important about the word in this regard is not so much its 'purity' as its 'social ubiquity'. Since words are implicated in precisely every act of exchange between people, whether on the job, in political relationships, or even chance encounters on the street, countless threads of ideological influence flow through them and register their effect within the word. The word is able to gradually accumulate these precipitates of meaning over time. It has the capacity to "register all the transitory, delicate, momentary phases of social change."39

\footnotetext{
${ }^{38}$ ibid., pp. 17-18.

${ }^{39}$ ibid., p. 19.
} 
It is a very short step from here to a consideration of the hierarchies of meaning and social classification in words and language. When the meaning of a word carries with it an implicit evaluative judgement on its own social import, as many do, it begs attention to the very processes by which these pejorative elements are created and sustained within the political and social world. It also draws attention to the fact that individual choice ceases to be a relevant indicator of social and political meaning. A sign derives meaning from its social milieu. It exists inter-individually by the simple virtue of being a cultural symbol. In other words, "only that which has acquired social value can enter the world of ideology, take shape, and establish itself there." So even when produced by individuals situated in social contexts, ideological accents are necessarily social in orientation. It is only ever on the strength of this social recognition that any symbolic form can be discussed in terms of ideology. It is also only on this same strength that these symbolic forms can be deployed as ideological material. ${ }^{40}$

All of this raises a rather interesting observation that the 'theme' and 'form' of an ideological sign are inseparable from each other, except for analytical convenience. This is simply because the "same set of forces and the same material prerequisites bring both the one and the other to life." A simple example will help to illustrate this. All one needs to do is think of a religious symbol, such as a crucifix, to see right away that the material form is inseparable from its religious theme. There is no natural relationship between these two things except by ideological convention. But it is more problematic to think about conspiracy theory, or its allegedly material embodiment in the conspiracy

\footnotetext{
${ }^{40}$ ibid., p. 22.
} 
theorist, quite the same way. Though there should be little doubt at this point that the conspiracy theory is itself an ideological construct, it is much more difficult to try and think about the 'materiality' of the conspiracy theorist. The very notion of a conspiracy theorist exists as a freefloating signifier. It is a conceptual frame which is attached to individuals who, in some way or another, perform a social role which deems them 'worthy' of such a dubious moniker. Individual manifestations of this social figure are everywhere. What is important to think about, however, is that there is no single one of them which stands for all of them. The label itself, then, preexists any individual application. It is an ideological construct first and foremost.

The suggestion was made earlier that ideas about social contradictions arise from material circumstances, and that Marx meant to address the relationship between certain kinds of ideas and how they arise out of and function in relation to material conditions. When confronted with systemic inequality, these ideas tend to be projected into ideological forms of consciousness. Taking conspiracy theory as one of these ideological forms of consciousness requires a broadening of the focus on ideology to encompass the formative material conditions which give rise to them. Only by doing so can we begin to try and understand how it is that conspiracy theories act as a 'reflection and refraction' of social contradictions as a natural part of their own production. If it can be accepted that conspiracy theories represent purely mental or discursive 'solutions' to these inequalities or contradictions, which in turn mask or distort them in some way, then it can be demonstrated that they paradoxically serve the interests of dominant institutional arrangements. But as the case study demonstrates, this does not happen in any sort of mechanistic fashion. If ideological forms work to serve the interests of the ruling classes by refracting material conditions and working to "reproduce" 
them by discouraging acknowledgment of the root causes, conspiracy theories do the same thing in exactly the opposite fashion. They exaggerate and foreground certain aspects of those material conditions to such an extent that they no longer hold any resemblance to reality.

\section{Hegemony}

One of the criticisms leveled at classical Marxian theories of ideology is that they are too economically reductive, and are excessively totalizing and pessimistic. There is, the argument runs, insufficient recognition of the often compromised, negotiated, and contested nature of ideology. Critics who have made such arguments have suggested that the concept of hegemony is a more useful analytical tool than the older Marxian concept of 'dominant ideology'. ${ }^{41}$ Some attention to this concept will build on the discussion of ideology in such a way that it is incorporated into a focus on conspiracy theories, while also highlighting and giving sufficient recognition to the often compromised, negotiated, and contested nature of carnival and carnivalesque forms.

The name Antonio Gramsci is now synonymous with the concept of hegemony. Born to lower middle-class parents on the island of Sardinia, an impoverished part of Italy, he was later to win a scholarship to the University of Turin. His experiences in both a backward peasant society and a industrial city were later prove significant in the development of his political thought. Perry Anderson (1976) began a review of Gramsci's work with a statement that today "no Marxist thinker after the classical epoch is so universally respected in the West as Antonio Gramsci. Nor is any term

\footnotetext{
${ }^{41}$ Thanks to Richard Gruneau for the wording here.
} 
so freely or diversely invoked...as that of hegemony, to which he gave currency."42 Neither the praise nor the qualification is overstated. His sometimes cryptic writing style in the Prison Notebooks, necessary to bypass prison censors, has opened his work and ideas to a number of often contradictory interpretations. Anderson puts it well as he writes that the "price of so ecumenical an admiration is necessarily ambiguity: multiple and incompatible interpretations of the themes in the Prison Notebooks." 43

Though hegemony could be understood, in part, as the means by which a popular or dominant ideology is produced, it is by no means the same thing as an ideology. Eagleton, also picking up on the importance of symbolic forms, distinguishes ideology from hegemony at a number of points, writing that "hegemony is a broader category than ideology: it includes ideology, but is not reducible to it." ${ }^{44}$ He goes on to write that

Hegemony, then, is not just some successful ideology, but may be discriminated into its various ideological, cultural, political and economic aspects. Ideology refers specifically to the way power struggles are fought out at the level of signification; and though such signification is involved in all hegemonic processes, it is not in all cases the dominant level by which rule is sustained. ${ }^{45}$

p. 5 .

${ }^{42}$ Perry Anderson, The Antimonies of Antonio Gramsci, New Left Review, \#100, Nov. 1976 - Jan. 1977;

43 ibid.

${ }^{44}$ Eagleton, 1991 ; op. cit., p. 112.

${ }^{45}$ ibid., p. 113. 
Joseph Femia ${ }^{46}$ also speaks to the idea of hegemony as a system of internal control, or "an order in which a common social-moral language is spoken, in which one concept of reality is dominant, informing with its spirit all modes of thought and behavior. It follows that hegemony is the predominance obtained by consent rather than force of one class or group over other classes." ${ }^{47} \mathrm{He}$ goes on to describe the two elements Gramsci distinguished which work together to produce cultural hegemony. Though a purely analytical distinction, the spheres of political society and civil society are important concepts to understand in Gramsci's overall contribution. Political society is made up of all those institutions which secure consent through domination or coercion, such as the government, the legal system, or the police and law enforcement agencies. Civil society, on the other hand, is made up of all that falls outside of that realm, into what can be considered 'private'. This includes the education system, religious affiliations, corporate organizations, and other similar social institutions, such as the mass media. What is important to note, is that hegemony is exercised primarily within the domain of civil society, and " is attained through the myriad of ways in which the institutions of civil society operate to shape, directly or indirectly, the cognitive and affective structures whereby men perceive and evaluate problematic social reality"48

It is clear, even from Femia's title, that authors like himself (as well as Anderson) are concerned with an explanation of the concept of hegemony that largely adheres to the project of orthodox Marxism.

\footnotetext{
${ }^{46}$ Joseph Femia, Gramsci's Political Thought: Hegemony, Consciousness, and the Revolutionary Process, Oxford University Press, 1981.

${ }^{47}$ ibid., p. 24.

${ }^{48}$ ibid.
} 
Much of their discussion is geared towards the clarification of Gramsci's ideas in concert with the imperatives of class struggle and revolutionary practice. By contrast, authors such as Todd Gitlin have been less concerned with maintaining any necessary reverence for a classical Marxian perspective. Gitlin seems willing to abandon the old Marxist formulae in the interest of a more contemporary application of the concept of hegemony. He writes that it is not necessary to accept "all of Gramsci's analytic baggage to see the penetrating importance of the notion of hegemony uniting persuasion from above with consent from below - for comprehending the endurance of advanced capitalist society." ${ }^{49}$ However, Gitlin does retain Gramsci’s central idea that those who are in charge of the dominant institutions of society are naturally concerned with maintaining them, often through their privileged position in the struggle for signification. He points out that mediated messages "must emanate outward from message-producers and then into the audience's minds, there to be interpreted ... [and since] the media aim at least to influence, condition, and reproduce the activity of audiences by reaching into the symbolic organization of thought, the student of mass media must pay attention to the symbolic content of media messages."

Gitlin's focus on the symbolic content of media messages in his perspective on hegemony is important to consider. For one thing, it promises to move away from some of the potentially confining debates of classical Marxism towards the point where media representation can be looked at as an important site of hegemonic struggle. Gitlin does not ignore the realities of the capitalist

${ }^{49}$ Todd Gitlin, The Whole World is Watching: Mass Media in the Making and Unmaking of the New Left, University of California Press, 1980; p. 10.

${ }^{50}$ ibid., p. 14. 
system and the specific role that mass media institutions play within it. Least of all does he forget about the very real types of counter-hegemonic struggle that have occurred over the past few decades. Still, it is the representations of these events themselves, and the ways that they are "framed" and circulated as symbols in culture, that is the essence of Gitlin's contribution on this point. Though the perspectives and interests of authors such as Anderson and Femia [not to mention Marx, Engels, and Gramsci] who concern themselves with clarifying the project of socialism are by no means irrelevant to the study of communication in contemporary societies, it is the work of authors like Gitlin, Thompson, Raymond Williams, and even Bakhtin/Vološinov, who have opened up in their own different ways newer critical theoretical perspectives on the politics of media content and representation. They help to incorporate the best ideas and concepts that the Marxist perspective has to offer for a study of media, of which hegemony is certainly one, without the economistic and Leninist trappings which have limited Marxist analysis in the past. ${ }^{51}$ Equally important, is that recent critics such as Gitlin and Thompson emphasize the importance of mass media in the critique of modern social life.

The shared emphasis on the importance of symbolic representation is conducive to the study of mainstream news coverage in the case study. The operation of mass media are without question a major influence on the production of symbolic meaning, and therefore, the reinforcement of particular ideologies. With a concept such as hegemony which has also been so diversely invoked, it is necessary to be clear about what definition of hegemony will be used. As Eagleton noted earlier,

\footnotetext{
${ }^{51}$ Thanks to Richard Gruneau for the wording here.
} 
hegemony is not just some successful ideology, but may be discriminated into its various ideological, cultural, political and economic aspects. For the purposes of this study, hegemony will be defined as a complex social and political system of meaning generation which works to normalize dominant ideas and marginalize oppositional ones.

\section{Structuration}

With a stated intention to focus on conspiracy theory and the political economy of meaning, what remains to be done at this point is expressly incorporate political economy into the present discussion. To do this, the process of structuration provides an essential means of addressing the dualities at play within carnivalesque practices which simultaneously challenge and accommodate the strictures of power as they find their own expression through them. Like many of the concepts already addressed, such an inclusion could become unwieldy in very short order. But given the emphasis already placed on the paradoxical politics of carnival, such a step can be taken rather effortlessly. This is because a focus on structuration already echos the debates addressed earlier over the extent to which the carnival itself is inherently conservative or progressive. As we saw in Holquist's assessment of Bakhtin's contribution, 'carnival is not only an impediment to revolution, it is revolution itself.' It is not one or the other; it is both at the same time.

Vincent Mosco $^{52}$ highlights the work of Anthony Giddens as developing the concept most prominently. For Giddens, the theory of structuration is meant to bridge the gap between theoretical

\footnotetext{
${ }^{52}$ Vincent Mosco, The Political Economy of Communication, Sage, 1996.
} 
perspectives emphasizing action or agency such as those of Weber, for example, and those like LeviStrauss and Althusser which foreground structure. Giddens suggests that structure itself be conceived of as a duality comprised of constraining rules and enabling resources. In Mosco's words, structuration "describes a process by which structures are constituted out of human agency, even as they provide the very 'medium' of that constitution." Mosco points out, and as Giddens is aware, the concept of structuration is by no means new, and even has a well-established precedent in Marx's contention from the Eighteenth Brumaire that 'men make history but not under conditions of their own making. ${ }^{53}$

Mosco writes that one of the important characteristics of structuration theory is the emphasis it places on the ubiquity of social change, whereby various structures are produced and reproduced via human agency operating through them. Structuration is a response to criticisms of other functionalist or structuralist positions which tend to view structures as fully formed, instead of as active processual features of social action and human agency. Citing Eric Hobsbawm on this point, a structural model envisaging only the maintenance of a system is inadequate. It is the simultaneous existence of stabilizing and disruptive elements which such a model must reflect ... Such a dual (dialectical) model is difficult to set up and use, for in practice the temptation is great to operate it, according to taste or occasion, either as a stable functionalism or as one of revolutionary change; whereas the interesting thing about it is, that it is both. ${ }^{54}$

Mosco continues that "structuration balances the tendency in political economic analysis to feature structures, typically business and governmental institutions, by addressing and incorporating the

\footnotetext{
${ }^{53}$ ibid., p. 212 (emphasis in original).

${ }^{54}$ Hobsbawm, p. 280; cited in Mosco, op. cit., p. 213.
} 
ideas of agency, social relations, social process, and social practice." In doing so, it correctly dispenses with the notion that one can even talk about agency in the absence of structures, since it is these structures which provide the medium through which agency operates. ${ }^{55}$

Though there is much more detail that could be included here,${ }^{56}$ it is perhaps most useful to draw attention to the resonance this already holds with what has been presented to this point. Key in this regard are the ways that a focus on structuration "deepens the substantive and methodological approach to power in political economy." Though political economy may be typically associated with large-scale or macro applications, Mosco shows that the agency inflection on structuration theory also renders it amenable to various interactive or micro-level approaches as well. Given the attention paid to Vološinov and his socially situated concern with language, meaning and ideology, the hegemonic apparatus developed through attention to Gramsci and Gitlin, and the historical specificities which bounce about within all of them, a focus on conspiracy theories once again shows itself to be a useful way of bringing them all into the same discussion.

Structuration is an important way to help frame such a discussion for a couple of reasons. First, is that it correctly harkens the importance of various institutional structures (and not just business and governmental ones) in the ongoing reformation of socio-political meaning and practice. Second, is that in its concern with structure constituting the medium through which agency operates, it readily

\footnotetext{
55 ibid.

${ }^{56}$ Indeed, Mosco's entire chapter is concerned with elaborating the many contours of this interesting concept.
} 
accommodates a focus on the carnival as one of those forms of mediation. Putting it this way is fine, though, only if it is acknowledged that it introduces an analytical distinction between the operation of these institutional arrangements and the social meanings which are reinforced by that operation. The carnivalesque 'mediates' these meanings by challenging and inverting them in ways that have already been discussed. In other words, structuration needs to be understood not only in terms of tangible institutional structures, but also in relation to the conceptual forms employed to resist them. For example, the Lutheran images and representations of papal excess did not manifestly constitute the Church itself, as much as the Church as an institutional structure was nonetheless inseparable from their expression in this fashion. Similarly, conspiracy theories about various structures or practices do not constitute a viable interpretation of reality either, as much as they, too, are inseparable and formative aspects of it. To put it another way, in the realm of meaning and ideology, structuration may also have an immaterial, conceptual component.

\section{Conspiracy Theory in Hollywood Film}

One of the handy ways to see all of this in action is through a brief look at Hollywood film. Though there is no 'magic' to the observation that historical tensions and the like come to be represented in entertainment forms like popular film, a specific focus on how conspiratorial themes have been typically addressed against a broader historical back drop provides a convenient segué into how conspiracy theories actually do precisely the same thing. In other words, conspiracy theories as a narrative frame can be thought of every bit as naturally as a typical Hollywood film. And, they do so with only marginally stronger claims to 'reality'. 
Ken Harris points out that the conspiracy genre in American popular film has been around as long as any other. A conspicuously early example is D.W. Griffith's The Birth of a Nation (1915) which depicted the original Ku Klux Klan in a positive light, engaged in a conspiracy by Southern whites to overturn the post-Civil War advances made by African Americans. As is the case with other genres of film, conspiracy plot lines tend to echo on-going historical trends, morphing and shifting right along with them. Harris suggests that there have been three major cycles in this process. The first runs from the late 1940 's in to the mid-1960's during the Cold War era, the second reflecting the post-Vietnam, post-Watergate era from the early 1970's until the mid-1980's, and the third from the early 1990 's to the present. While any attempt to categorize the prodigiously vast array of Hollywood film this way is sure to be fraught with limitations, the categories are of secondary importance in any case. What is important, is demonstrating through specific examples the pervasive and trans-historical interests held by audiences for conspiracy related themes, at the same time those themes are woven in to general popular conceptions of the conspiracy theorist as a socio-political entity.

\section{The Cold War and the "International Communist Conspiracy"}

After the end of World War II and the onset of the Cold War, it is not surprising that these tensions should be reflected so quickly in Hollywood films of the period, not to mention in the relatively new medium of television. Federal agents were the heroes in such films as I Was a Communist for the

\footnotetext{
${ }^{57}$ Harris, in Knight (2003), op. cit., pp. 256-257.
} 
FBI (1951) and the similarly-themed television series I Lived Three Lives (1953-1956) ${ }^{58}$. Western star John Wayne took his patriotic place alongside James Arness in Big Jim McClain (1952) as a pair of agents for the House Un-American Activities Committee foiling a Communist plot to take control of shipping ports in Hawaii by infiltrating labour unions. Where these and other films more or less traced the outlines of the prototypical 'paranoid style' in their outward looking orientation, others looked closer to home.

The idea that those close to us could secretly be Communists themselves, was played up in films like Conspirator (1949) and I Married a Communist (1950). Both of these held to plots where a woman discovers her husband to be working for the other side. A war veteran's girlfriend in The Red Menace (1949), a couple's son in My Son John (1952), and even one's coworkers in The Fearmakers (1958) were like dozens of others at the time that reinforced the possibility that almost anyone was susceptible to the creeping insidiousness of Communism. Harris highlights the fact that none of these were particularly successful at the box office. They likely reflected, however, the climate of real suspicion that attended the production of Hollywood movies during a time when many film workers, especially writers, were being blacklisted and even jailed in some instances. The propagandistic tinge to films such as these was reflected in the fact that no real attempts were made to understand the Communist villains. Their motivations were simple enough, greed and a hunger for power.

\footnotetext{
${ }^{58}$ Harris notes that for this show the scripts were vetted in advance by the F.B.I.
} 
As popular fears of the Communist threat waned and the relations with the Eastern bloc moved towards détente, John Frankenheimer directed a couple of films that were to become classics. One of them, The Manchurian Candidate (1962) typified the genre, while his next, Seven Days in May (1964) began to reflect a growing cynicism about Cold War paranoia. In that film, opposition to nuclear disarmament inspires a plot to overthrow the U.S. government and install a military regime. But by the end of the 1960's the genre itself began to collapse into spoof, most notably in the James Bond movies.

A related spin on this theme is commonly held to be evident in the alien invasion and body snatcher films of the same period. These films, owing to the latitude their fantastic subject matter afforded them, were more able to criticize or even ridicule the paranoia of anti-communism. Invaders from Mars and It Came from Outer Space (both 1953) were joined by Invasion of the Body Snatchers (1956) and the less memorable The Brain Eaters (1958). All have been said to comment in their own ways on the paranoid political climate of the time. Invasion of the Body Snatchers in particular takes the metaphor to the verge of satire on the exaggerated Communist menace, and the blindly rigid conformity to traditional 'American values'.

\section{The Post-Vietnam, Post-Watergate Era ${ }^{59}$}

With the waning of interest in tales about an international Communist conspiracy, another wave of conspiracy related themes began to appear in the wake of real social and political upheaval. The

\footnotetext{
${ }^{59}$ ibid., pp. 257-259.
} 
1960 's provided ample influence in this regard, with various assassinations, ghetto uprisings, and protest marches, not to mention the widely unpopular American participation in the Vietnam War. Adding fuel to the fire was the public cynicism which grew stronger amid news of the Watergate scandal, as well as the pressures wrought by the energy crisis and the resulting recession.

Accompanying all of this in the early to mid-1970s was a general downturn in cinema attendance for American audiences. This in part led to the emergence of a "Hollywood renaissance" where the major studios uncharacteristically took a number of chances, giving many new and up-and-coming film makers such as Francis Ford Coppola and Martin Scorsese unprecedented freedom to pursue their directorial visions. Also a result of this new sensibility was the 'blaxploitation' boom after African-American directors, too, were given more of a chance to explore American racial politics in film. The combination of a widely perceived mood of general unrest, with Hollywood's sudden willingness to take a few risks, helped make possible a whole slew of anti-establishment films. What set this wave apart from the Cold War era was, in part, a turn towards stories about evil conspiracies which didn't originate elsewhere and seek to undermine American values, but which were perpetrated instead by dark forces within the American government itself.

A few of these films echoed the political unrest wrought by the assassinations of the 1960s like Executive Action (1973) which dramatized a conspiracy theory about the Kennedy assassination, and Winter Kills, a 1979 film about the assassination of a fictional president. Alan J. Pakula's The Parallax View (1974) followed the exploits of a reporter's investigation into a shadowy corporation 
that carries out assassinations. According to Karen Gai Dean, the film "epitomizes the U.S. conspiracy film canon. It invokes the social unease that followed the assassination of John F. Kennedy, the findings of the Warren Commission, and subsequent assassinations." ${ }^{60}$ Pakula would return two years later with the still well-remembered All the President's Men (1976), and revisits the theme of secret government agendas from the point of view of the activities of the Nixon White House. Along with presidential malfeasance, the intelligence community received its share of political suspicion in films like Three Days of the Condor, The Killer Elite (both 1975), and The Osterman Weekend (1983). Not to be forgotten, the ever-evil nuclear power industry was the villain in films like The China Syndrome (1979), and Silkwood (1983). Though both stories are based in fact, the emphasis on the deaths of brave women trying to expose the environmentally destructive practices of the industry heighten and help carry the conspiratorial theme.

Notions of surveillance and control also play recurring roles in this period, and reflect the Watergateera revelations of secret tape recordings and surveillance regimens. In The Conversation (1974) a sound surveillance specialist unwittingly becomes an accomplice to a murderous conspiracy, while another soundman accidentally discovers a political conspiracy in Blow Out (1981). NASA embarks on a conspiracy to deceive the world about a fake Mars landing in Capricorn One (1978). The film's premise of information control is picked up and taken to an extreme in David Cronenberg's Videodrome (1983). In this film, surveillance and control of the population is accomplished through television signals which exert an almost ubiquitous power over viewers.

\footnotetext{
${ }^{60}$ Gai Dean, in Knight, ibid., p. 571.
} 


\section{The Contemporary Period ${ }^{61}$}

Since the 1990 's, the conspiracy theme has done anything but subside, proving itself to be a popular and effective entertainment vehicle for mainstream Hollywood film. The same can be said of television entertainment. Like in other periods, the nature of the conspiratorial appeal has continued to shift right along with ever-changing historical circumstances. More contemporary representations on this theme have moved beyond the traditionally left- or right-wing, Cold War, or domestic Watergate variety, and now are so vast in size and/or power that they now tend to appear in ways that could be unfolding anywhere at anytime. The individuals participating in these conspiracies seem to have no specific goals whatsoever beyond simply expanding the conspiracy. Further still, they appear to be discrete individuals in appearance only, when actually they are members of a seamless totality. Lastly, the new-style conspiracy tales feature individuals who no longer effuse illusions of normality to mask some subversive reality; the idea of reality itself is undercut by the pervasiveness of the conspiracy. Every facet of existence casts doubt on the distinction between reality and illusion altogether.

Attempts to explain the reasons behind the current popularity of conspiracy-related themes run the gamut. Jonathan Romney sees it as a consequence of CGI technology and suggests that it reinforces an existential paranoia about a disrupted relationship between what we are actually seeing versus what we think we are seeing. "The new paranoia movies," he writes, "have less to do with political anxieties, more to do with the feeling that there is little verifiable reality in the screen image itself

\footnotetext{
${ }^{61}$ Harris, in Knight, ibid., pp. 259-262.
} 
and, by extension, in the world we know through visual media." Others have taken a more analytical position, such as Mark Fenster, who follows Frederic Jameson in writing that it signals a not consciously planned but nonetheless justified discontent with the status-quo among the general population. Peter Knight argues that globalization has rendered conspiracy theory less as a political orientation, than a "default mode" for understanding culture in a New World Order. Timothy Melley has suggested that an "agency panic" is at the root of it all, where individuals no longer feel they can effect meaningful social action. ${ }^{62}$

Whatever the reason for the continued popularity of conspiracy films, and whether or not there necessarily needs to be one in any case, the foundational tensions that pervade the modern examples are not that different once the straw men of international Communists and shadowy government operatives are duly swept aside. Enemy of the State (1998) carries the surveillance theme forward in new ways, and positions the National Security Agency as engaged in an insatiable pursuit of all things informational. What is new here is the extent to which the Agency is cast as being able to erase the identity of the hero of the film, a theme which was also played up in 1995's The Net. In a spate of White House cover-up films all produced in 1997, which probably in some way reflects the pre-Clinton/Lewinsky rumour mill (ie: Whitewater, Vince Foster, etc.), Shadow Conspiracy, Absolute Power, Murder at 1600, were capped off by Barry Levinson's satire Wag the Dog in which a fake war is launched to divert attention away from a Presidential indiscretion with an underage girl.

\footnotetext{
${ }^{62}$ What has evidently escaped all attention here is the more banal (and so perhaps most likely) explanation, that there is a 50 year history of films with a conspiracy-related theme which has been consistently profitable with mainstream, recreational moviegoers. Stagnation of earlier plot lines and the abilities opened up by CGI to push the visual and narrative envelope help to keep the form fresh and entertaining. However, and as we shall see, this process itself is in no small way connected to the questions being pursued here.
} 
The anti-establishment theme is also given a new sheen. And while the films in this regard are harder to place in the typical 'right' or 'left' categories [no doubt enhancing the films' overall marketability], they do demonstrate the decentered, vaguely defined, anywhere/anytime feel of conspiracy films alluded to earlier. Fight Club(1999) captures these elements well in a tale of angstridden anomie which becomes violently channeled into acts of corporate vandalism. Similarly in Arlington Road of the same year, the film's protagonist becomes an unwitting accomplice in an antiFBI plot, and is posthumously blamed for the very event he died trying to prevent. Twelve Monkeys (1995) takes the anti-establishment theme to its zenith, featuring a plot to return the earth to the animals, through the release of a virus that kills only humans.

The motif of epidemic disease is one with its own history, and received quite a bit of play in the 1990s, no doubt aping the global spread of AIDS and other infectious diseases. Outbreak (1995) tells the story of scientists who are co-opted by the military to weaponize organisms from Africa. These medical experiments also took the form of a conspiracy directed at specific individuals without their knowledge in films like Jacob's Ladder (1990) and The Capitol Conspiracy (1999). Both films featured Vietnam-era figures who had been modified to become better fighters in the former, and to enhance extrasensory powers in the latter.

The mid-1990's saw a new twist in the narrative of conspiracy films. In conspiracies of infinite regress, it is never certain exactly what the conspiracy is, or even if there really is one. Revelations within the plot lines of films like these put the lie to the existence of a conspiracy, at the very 
moment they indicate the revelations themselves may be evidence of an even larger one. The Game (1997) epitomizes this type of plot line. The billionaire protagonist eventually discovers that the employees of an entertainment company, Consumer Recreation Services, could be anyone and everyone he has recently encountered. What he takes to be the real world filled with real people could be just that, or an elaborate fiction designed as a birthday present from an admiring younger brother, or a plot to steal his money that his brother may or may not be involved in, or as a benign attempt to help him overcome the childhood trauma of his father's suicide, or a malicious one designed to see that he follows suit or even another one still that the film refuses to reveal. It ends cagily, leaving open the possibility that the 'game' is still being played, and even that there may never have been a time when it wasn't.

A trio of very popular films from the end of the ' 90 s take this theme even further. Not only is the conspiracy so vast, beyond politics, and with existential implications, it involves everyone. The Truman Show (1998) features a character whose whole existence is part of a reality show of which he is completely unaware. The town in which he was raised and subtly prevented from ever leaving is actually a massive television studio equipped with hidden cameras and microphones. Everyone he has ever known is actually an actor, all of whom are employed by an aptly named director, Christof. At the same time everyone in the real world, a world Truman has never encountered, has followed his life voyeuristically in a round-the-clock television show that is wildly popular.

In Dark City (1998) a different artificial world is created in space and populated with kidnapped 
humans by a dying race of aliens. 'The Strangers', as the aliens are called, have the power to alter physical reality by will alone. A psychiatrist working with the aliens manipulates the entire population's memories so the aliens can do experiments on them. All of this memory alteration happens at night, while the aliens are busily occupied altering physical reality. One of the humans in turn discovers that he too has the power to alter physical reality, and, after doing battle with and defeating the Strangers, simply takes their place. The Matrix (1999) features renegade computers in the distant future which have imprisoned the majority of the human race in pods in order to live off the electrical energy produced by their bodies. Meanwhile, the pod-dwellers are kept in a cybernetically induced illusion that they are in 1999 New York. As one of the Virtual Reality villains puts it at one point, they are merely "billions of people just living out their lives, oblivious."

So it is clear that even by turning attention to the 'lowly' Hollywood film, we can see the significance of the theoretical. The dialectical tensions which inhere in the notion of conspiracy theory anyway, already pervade the plot premises summarized here. Central to this is the very notion of reality itself. Appearances can be deceiving, the old adage runs, but in the conspiracy film it is a directive. Others may or may not be communists, aliens, or brain-eaters for that matter, but they all play a role in keeping the scripted dialectical tension alive. Not surprisingly, they also configure and reflect the ideological debates of their day, whether it comes in the form of a communist threat to American values, or from a more insidious source, dark forces working from inside the American government. It is also obvious at this point too, that despite the shifting rationales of the conspiratorial imagination as reflected in the genre, they are already a key aspect in a larger hegemonic apparatus whereby dominant meanings and perspectives are symbolically challenged 
and/or upheld. This is not to ascribe an overly powerful influence to the Hollywood entertainment machine. Instead, it is merely meant to draw attention to the vast and pervasive character of the image makers across all entertainment media, and to make the rather pedestrian observation that it cannot help but be implicated in our very understandings of what it means to talk about a 'conspiracy theory'. This happens in a couple of ways; either real life stories and events are co-opted into and dramatically heightened by the mainstream, or, the stories themselves are so fantastic that everything but the fringe-like character of the conspiracy is lost in the suspension of disbelief. In either case, the meanings and resonances live on outside of the theater. The marginal figuration of conspiracy theory remains symbolically central even as the world is turned upside down within it.

\section{Conspiracy Theory}

In the early 1980's, the Church of the SubGenius was created by Doug Smith (now known as Reverend Ivan Stang) and Philo Drummond. The Church claims to reveal 'the truth' via the teachings of J.R. "Bob" Dobbs. To the faithful, it was revealed that an alien named JHVH-1 had been masquerading as G-D, and that there was a conspiracy created by normal people to deplete the "slack"of the so-called abnormals, also known as 'the SubGeniuses'. The Church was formed to this end, and is one which gleefully takes money. It offers its teachings through flyers, poster art, and recorded rants which were first broadcast on community radio, exchanged through tape trading, and are now available on-line. For a mere thirty dollars, one can buy salvation, redemption, and the title of 'Reverend'. The primary icon of the Church is an illustration of "Bob's" head [trademarked, of course], showing that of a middle-aged smiling white man smoking a pipe, and which looks as if it 
was cut out of a 1950's advertisement. Over the years, some 10000 people have paid the fee.

The "Church" is an extremely elaborate practical joke which feeds on the subculture of conspiracy theory, while satirizing religious observance and conventional morality. The 'Rapture' of orthodox Christianity is replaced by the 'Rupture'; 'devivals' take the place of revivals. Together, the SubGenii rant about the world and everything in it. Annual meetings around the globe, or 'clenches', are held on July $4^{\text {th }}$, commemorating the day the aliens were supposed to return in 1998 (X-Day). Many an excuse has been offered by the loyal SubGenii as to why the aliens did not come, as prophesized. Explanations include the idea that the aliens in fact did arrive, but that the visit was either not noticed or was erased from our minds by superior technology. The SubGenii use this as an excuse to have a good time, thumb their noses at organized religion, orderly behavior, and of course themselves. Every SubGenius clench is required to have a non-believer among them, and the core belief of the Church is to believe nothing and everything, preferably at the same time. ${ }^{63}$

As an example which has all the thematic hallmarks of religion, carnival inversion, laughter, technology, conspiracy theory, and the Declaration of Independence, the Church of the SubGenius is about as good as it gets. It embodies one of the central dynamics of conspiracy theory, which is to offer an alternative view on the outward appearance of reality. That it does so in such a way that directly echoes Bakhtin's notion of carnival laughter makes it particularly useful. As a way of demonstrating how it is that various identifiable themes can be spun together in a 'carnivalized'

\footnotetext{
${ }^{63}$ ibid., p. 170.
} 
version of a conspiracy theory, it segués nicely into a more focused analysis of bonafide conspiracy theories as a means of highlighting other consistent features with a more day to day currency.

\section{Conspiracy Theory in Popular Culture}

Considering the parameters to be covered in the case study, conspiracy theories about George H.W. Bush are as good a place as any to start. His connections to various organizations such as the CIA and the infamously secretive Yale fraternity 'Skull and Bones', have kept him in the middle of various conspiracy theories. One of the ring-leaders in the anti-Bush conspiracy theories is the Lyndon LaRouche group. ${ }^{64}$ Beginning during the 1980 election campaign, LaRouche and some of his associates have written many unauthorized biographies. The 'true' story of his life, the group claims, is marked by connections to Nazi bankers, international cabals, the East Coast elite, and 'insiders' of all description.

In reality, Bush's connections to the "networks of power" in the United States are quite impressive. He was the permanent representative to the U.N. from 1971 - 1973, the first chief of the U.S. Liason Office in China from 1974 - 1975, and director of the CIA from 1975 - 1976. By 1979, he was a board member of the Council on Foreign Relations and a member of the Trilateral Commission dealing closely with Henry Kissinger. Also raising red flags for the conspiracy minded are his 1940's

\footnotetext{
${ }^{64}$ It should be noted that LaRouche himself has a somewhat sketchy past which includes multiple failed presidential bids and a prison sentence for mail fraud and other crimes. One of the two staple strategies of his political career was smear tactics, and the planting of outlandish rumors and stories about political enemies. He is known to have attacked the personal reputations of many public figures this way, including Henry Kissinger and Hugh Hefner. His organization has been described as "a cultlike political organization that subscribes to a host of conspiracy theories that defy categorization as left or right wing” (Knight, ibid., p. 423).
} 
membership in the Skull and Bones Society at Yale, and his membership in the Bohemian Grove ${ }^{65}$ group (again with Kissinger) who allegedly meet annually in the forests north of San Francisco to perform 'pagan rituals'. Furthermore, during the first year of his vice-Presidency John Hinckley Jr. shot Ronald Reagan, and for his critics, the circumstances around the assassination attempt seem to implicate Bush. Despite the fact Hinckley had yet to be properly questioned, public statements were made by officials stating that he had acted alone. Also, no one had investigated the fact that Bush's son Neil was to have had dinner with Hinckley's brother Scott the night following the attempt. For the LaRouche group, this information was not so much covered up as it was completely ignored. Also ignored, they felt, was that the Hinckley family were major contributors to Bush's presidential campaign. In the ' $2+2=7$ ' logic of the conspiracy crowd, this means that Hinckley may well have been a Manchurian Candidate, a product of the MK-Ultra program ${ }^{66}$ that had supposedly been terminated before Bush was CIA director. Hinckley's parents recalled notes that their son had written while in prison that described an "imaginary conspiracy" to kill the president which the LaRouche group felt were suppressed. Then the plot thickened more still. While Reagan was recovering in the hospital and Bush was in charge of the government, an attempt was made on the life of Pope John Paul II. Bush's erstwhile biographers imply that he may well have had something to do with it, writing that it was if a there was a new and malignant evil which had erupted, unleashing unprecedented violence and terror in its wake.

\footnotetext{
${ }^{65}$ Sociologist G. William Domhoff wrote a landmark study of groups like the Bohemian Grove in The Bohemian Grove and Other Retreats: A Study of Ruling-Class Cohesiveness, Harper and Row, 1974.

${ }^{66} \mathrm{~A}$ darling of conspiracy theorists, this refers to a covert mind-control research program run by the CIA between 1953-1963 (Knight, ibid., p. 490).
} 
Soon after his own election to president, on September 11, 1990, Bush addressed Congress to announce the coming of a "New World Order" which would guarantee heretofore unseen prosperity and peace through international cooperation. His use of the phrase seemed designed to draw the ire of conspiracy theorists, which it may have actually been. ${ }^{67}$ In any case, the conspiracy theories have followed him out of office and found new life in the 2000 presidential election results. The role of his own appointees to the Supreme Court was suspected in shifting the balance of power in its decision to stop the Florida re-count.

The CIA, quite apart from the involvement of the senior Bush, is effectively synonymous with a whole range of different conspiracy theories. This is hardly surprising, given its mandate as an intelligence gathering agency whose activities go well beyond intelligence gathering. In addition to espionage and counter-espionage, the Agency was involved in many covert actions around the world, including the training of rebels around but not directly connected to Osama bin Laden as they fought against the Soviet Union in Afghanistan. ${ }^{68}$ It is a government agency charged with the duty of

\footnotetext{
${ }^{67}$ There are various reports that George H.W. Bush used the phrase 'New World Order' precisely because he knows that he is a 'person of interest' in conspiracy circles, and wanted to wind them up for a laugh.

${ }^{68}$ There is a popular misconception that Osama bin Laden received direct training and assistance from the C.I.A., reinforced by films such as 'Bowling for Columbine'. There is no truth to these stories, as Steve Coll maintains in Ghost Wars (Penguin, 2005) "CIA archives contain no record of any direct contact between a CIA officer and bin Laden during the 1980s. CIA officers delivering sworn testimony before Congress in 2002 asserted that there were no such contacts, and so did multiple CIA officers and U.S. officials in interviews. The CIA became aware of bin Laden's work with Afghan rebels in Pakistan and Afghanistan later in the 1980s but did not meet with him even then, according to these record searches and interviews. If the CIA did have contact with bin Laden during the 1980s and subsequently covered it up, it has so far done an excellent job" (p. 87). bin Laden himself made strenuous denunciations on this point in an interview with al-Jazeera in December 1998. In that interview, bin Laden was asked "There has been talk in the international media about America's support for the Afghan jihad against the Soviet Union, in which you took part both physically and financially, and it has also been mentioned that you were linked to the CIA, or that it was the CIA who were funding your activities and supporting you in this jihad against the Soviet Union. What is the truth of these allegations and what is the truth of the link between you and America at that time?" bin Laden replies: "It's an attempt to distort by the Americans, and praise be to God that He has thwarted
} 
secretly conspiring; as such, it is in no small way a lot like the conspiracy theorists they routinely dismiss as crackpot extremists. One of the main differences between the CIA and the archetypal conspiracy theorist, however, is that the CIA has both the will and the power to act on its theories. ${ }^{69}$ Considering this linkage in relation to the Iraq invasion, it begs the observation that the allegedly "slam-dunk"intelligence assessment of Iraq's weapons programs was itself closer to the 'realityoptional' status of the typical conspiracy theory. ${ }^{70}$

Formed in 1947 by the National Security Act of that year, it was the object of collective suspicions from the beginning. With memories of the German Gestapo still fresh, the wisdom of extending the wartime power of its predecessor, the Office of Strategic Services (OSS), to the peacetime operation of the CIA with respect to subversive operations against foreign powers was questioned. But with the passing of the Central Intelligence Act of 1949, the director of the CIA was granted the authority to finance operations that were felt to be necessary, without the need to give any account to Congress. A series of botched covert actions abroad and at home, particularly in the $1970 \mathrm{~s}^{71}$, caused

their conspiracy. Every Muslim, from the moment they realize the distinction in their hearts, hates Americans, hates Jews, and hates Christians [...] The Americans are lying when they claim they helped us at any point, and we challenge them to present a single shred of evidence to prove it. In fact, they were a burden on us and the mujahidin in Afghanistan, and there was no agreement between us. We were doing our duty, which is supporting Islam in Afghanistan, even if this did coincide with American interests" (see Messages to the World [2005], also on p. 87).

${ }^{69}$ Knight, op. cit., p. 155.

${ }^{70}$ In fact, as the case study shows, there is a whole history behind the belief that Saddam Hussein is the root of all Middle Eastern evil, including the often discredited links between him and bin Laden, which is itself a bonafide conspiracy theory.

71 "A series of high-profile government inquiries kept the CIA on the front pages for years: the Commission on CIA Activities within the United States in 1975 ('The Rockefeller Commission'); the Select Committee to Study Governmental Operations with Respect to Intelligence Activities ('The Church Commission'); the Senate Select Committee on Intelligence's hearings on the MK-Ultra program in 1977; and the 1979 report of the House Select Committee on Assassinations. These hearings - the transcripts of which are publically available - provided key 
the Agency much grief. Though it strives to maintain a cloak of 'plausible deniability', its actions are often discovered well after the fact. For example, in August 1953, the Iranian government of Prime Minister Mohammed Mosaddeq was overthrown. It was after this that a new imperial government was set up and led by the Shah. Former CIA agents claim that the coup was engineered by a small band of five Agency operatives with $\$ 1$ million in cash as their only weapon. The money was allegedly used to fund and organize street mobs to create dissension. This CIA conspiracy wound up keeping the vast Iranian oil fields from being nationalized, securing the West's energy interests, and gaining U.S. oil companies such as Gulf, Standard, Texaco, and Mobil, a lucrative share of Iranian oil rights (pp. 155-156). ${ }^{72}$

In Guatemala in 1954, the CIA helped to overthrow the president Jacobo Arbenz Guzman, replacing him with the dictator Colonel Carlos Castillo Armas. The CIA's involvement in the coup was said to help the United Fruit Company, whose profits in Guatemala were threatened to be cut into by the newly elected government. In 1970, the leader of Cambodia was also overthrown with CIA help. And in September 1973, revolutionary forces in Chile toppled the socialist government of Salvador Allende with CIA assistance. Allende was killed. It bears mention that in all cases, the deposed leaders had been democratically elected by their people. But as numerous as incidents like this are,

information for historians and conspiracy buffs alike. Furthermore, the sheer strangeness of many of the stories contribute to the general belief that the CIA was capable of anything, and, thus, expanded the possible range of CIArelated conspiracy theory" (Knight [ed.], 2003; p. 158). Some of these stories included wanting to make Castro's beard fall out in order to rob him of his "machismo", wanting to soak one of his cigars in LSD, as well as such school-boy antics as creating stink bombs and diarrhea stimulation as a way of embarrassing foreign leaders. The parallels to carnival themes here should be noted.

${ }^{72}$ ibid., pp. 155-156. 
the Agency is better remembered for its failures. Attempted coups in North Vietnam in 1954, and Indonesia in 1958 did not go as planned; but the most famous failure was the Bay of Pigs fiasco in 1961. ${ }^{73}$ The Bay of Pigs Invasion of Cuba was to have been conducted by Cuban exiles hostile to the "Marxist" government of Fidel Castro which had taken power in 1959. The invasion, which was orchestrated by the CIA and approved by President Kennedy, was just one episode in a larger conspiracy to provoke a conflict with Castro, an effort which continued right up through and beyond the Cuban Missile Crisis of $1962 .^{74}$

There is plenty more to say regarding conspiracy theories and the CIA, but sticking to those with a more direct connection to George H.W. Bush, the Trilateral Commission presents another example which spins out into mainstream conspiracy theories. As the brainchild of David Rockefeller, chairman of the Chase Manhattan Bank and grandson of John D. Rockefeller, the idea came to him after reading a book by Columbia University professor Zbigniew Brzezinski called Between Two Ages. The book called for strengthening alliances between the three dominant economic powers North America, Western Europe, and Japan. Brzezinski formed the Trilateral Commission in 1973 following a request from Rockefeller. Its stated purpose was to "help think through the common challenges and leadership responsibilities of these democratic industrialized areas in the wider world." The commission, which is essentially a high-level discussion group, was originally intended to last for only three years. But since then, it has continually elected to continue, and its membership

\footnotetext{
${ }^{73}$ ibid., p. 156.

${ }^{74}$ ibid., p. 117.
} 
has broadened and diversified. The Japan Group has expanded into the Pacific Asian Group, Mexican members have joined the North American Group, and the European Group now includes members of the expanding European Union.

There are a couple of conspiracy theories regarding the Trilateral Commission. The first is that the commission conspired to make massive loans to the Third World during the 1970s oil crisis, and then strengthening the International Monetary Fund to offer additional credit as a way of guaranteeing their previous loans. The second conspiracy theory regarding the Trilateral Commission, which is also more pervasive, is that the commission is designed to take over the world through control of the U.S. presidency. This idea is rooted in the fact that one of the original membership was Georgia governor Jimmy Carter, who was contemplating a run for the White House in 1976. The theory holds that Brzezinski and Rockefeller were so taken with Carter, that they began to engineer his victory through a series of backroom deals and mass media manipulation. Once Carter was elected, he appointed a number of the Trilateralists to various posts in his administration. These included Cyrus Vance as Secretary of State, and Brzezinski as his National Security Advisor. As if this wasn't enough in 1976, the 1980 campaign included two more commission members: Congressman John Anderson, and former United Nations ambassador, CIA director, and Congressman George H.W. Bush. Conspiracy theorists had a brief respite from their fears after Anderson and Bush were out of the running; but this was to be only temporary relief. Eventual Republican nominee Ronald Reagan named Bush as his running mate, and then after he succeeded Carter, appointed Casper Weinberger, another commission member, as his Secretary of Defence. Conspiracy theories about the Trilateralists reached a zenith in 1984, when Reagan hosted a party 
at the White House for commission members. The theories have ebbed in the meantime even though two more commission members have since been elected president, George H.W. Bush and Bill Clinton. $^{75}$

But it is Bush's connections to Yale's 'Skull and Bones' fraternity that may have garnered the most attention to date. The fraternity may be the most mythologized and powerful secret society left in the twenty-first century United States. Known as 'the order' to its own members it is housed on the Yale campus in a windowless crypt called 'the Tomb'. It is also the oldest and most prestigious of Yale's secret societies. Every year since its founding in 1832 by William $\mathrm{H}$. Russell and Alfonso Taft, fifteen juniors are "tapped' to become members once they reach their senior year. In part due to the long list of elite members and the many rumors and exposés involving the group, it has been connected to or said to run everything from the CIA and the East Coast establishment to the New World Order and the Bavarian Illuminati. Whatever its allegedly conspiratorial influence, it has been described as performing the role of "converting the idle progeny of the ruling class into morally serious leaders of the establishment."76

The society is, of course, highly secretive. Members are allegedly required to leave the room if ever asked about the Skull and Bones. Despite this, lists of its illustrious members' names are available and include the only president to become the chief justice of the Supreme Court, William Howard

\footnotetext{
${ }^{75}$ ibid., pp. 691-692.

${ }^{76}$ ibid., p. 656.
} 
Taft. It has also included Henry Lewis Stimson, who was Franklin D. Roosevelt's secretary of war, and three members of the Bush family, Prescott, George Sr. And George W. Bush. It is no secret that Yale has long been a center of recruitment for the CIA, and many of those involved with the foreign policy and intelligence establishment of the United States have been Bonesmen. This includes Kennedy's national security advisor McGeorge Bundy and his brother William who was later head of both the CIA and the Council on Foreign Relations. The CIA station chief in Chile during the overthrow of Allende, Dino Pionzio, and former director of Clandestine Services for the CIA, Hugh Cunningham, are members, as well as many others connected to international organizations and commissions with their own conspiratorial intrigue, such as the Bilderberg Group and the Trilateral Commission. Their business connections are also impressive. Not only does the Skull and Bones operate a number of major investment and law firms such as Brown Brothers Harriman, but members include such luminaries as Averell Harriman, Dean Witter, Harold Stanley, as well as Time-Life founder and media tycoon Henry Luce, along with conservative pundit William F. Buckley.

The rites of membership are shrouded in secrecy. Most reports involve tales of a coffin, nudity, and intimately detailed accounts of one's personal and sexual history. The contents of the Tomb are rumored to include the skulls of Geronimo (procured by Prescott Bush) and Pancho Villa. Rumored perks are a no-strings-attached gift of $\$ 15000$ and a promise that members will receive an income for life. But this is only a prelude to the real benefits for members. Upon graduation, they are exposed to the society's vast network of connections and contacts within the U.S. ruling class. It is also here where the 'real' conspiracy theories start. The curiosity is by no means limited to outsiders, 
as many raids over the years on the Yale campus have only fueled the rumors and interest in the society. The first occurred on September 29,1876 by a group mockingly calling itself the 'Order of the File and Claw'. They found a lot of skulls and bones, occult symbols, portraits of the founders, and German slogans which led to the allegations of its connections to the Bavarian Illuminati. A second rash of break-ins occurred about a century later. Even the writer and producer of the 2000 movie 'The Skulls' claimed to have infiltrated the Tomb in the 1980's during his days as a student there. In a more recent transgression of the secrecy of the Skull and Bones, a group of students armed with a night vision camera and climbing equipment took video of the melodramatic initiation rites. It was an event filled with shrieking and mock violence where a member dressed up as George W. Bush can be heard saying "I'm gonna kill you like I did Al Gore!."77

While George H.W. Bush was running for president in 1988, fellow Yale graduate Bob Woodward (who was a member of a competing secret society named 'Book and Snake') found a number of Bush's fellow Bonesmen who were willing to talk openly about the non-sexual details of his lifestory confession. It revealed his profound sense of loss over a fellow Bonesman who was killed when Bush was shot down during World War II. After his oil baron background and CIA directorship, a first for a president, Pat Buchanan accused George H.W. Bush of running a "Skull and Bones presidency." There was no such luck for those seeking information on the junior Bush's Skull and Bones experience. In a campaign interview he refused to publicly admit that he was a member, and claimed not to know if the society still existed. However, it is widely rumored around

\footnotetext{
${ }^{77}$ ibid., pp. 657-658.
} 
Yale that Bush had his 1968 class of Skull and Bones to the White House after the inauguration to thank them for their support and silence. ${ }^{78}$

\section{Conspiracy Theory, Hegemony, and Ideology?}

Conspiracy theory presents an interesting problem for those interested in the study of hegemony and ideology. On the one hand, there is no doubt that the tone and direction of conspiracy theory is counter-hegemonic; it is predicated on various oppositions to various other dominant arrangements. The common denominators to even a few of the conspiracy theories connected to George H.W. Bush already reveal a collective concern with powerful elites making self-serving decisions in secret backroom deals. The perceived ability of the wealthy to affect the outcome of world history through connections like these is a hallmark feature of conspiracy theory. But it is also its Achilles heel. Though there is no question that the act of conspiracy theorizing is, by definition, an act hostile to the interests of ruling elites, no matter how these 'elites' are conceived and configured in the popular imagination, it is still only part of the picture. As much as the power of these elites is imagined to be ubiquitous and omnipotent, this imagination is at the same time the fatal flaw of conspiracy theory. Conspiracy theories are, necessarily, imagined solutions to contradiction and inequality in the material world. So even though on the one hand conspiracy theories only exist because of these material contradictions, they do little [if anything] to rectify them. On the other hand, then, they are nothing other than imagined solutions. And therein lies the problem. 'Everyone knows' this is what is meant by conspiracy theory.

\footnotetext{
${ }^{78}$ ibid., p. 658.
} 
From Thompson, a definition of ideology was derived to emphasize the ways that symbolic forms circulate and intersect with relations of power. It highlights an understanding of the ways that meanings are mobilized in the social world which tend to reinforce individuals and groups who are in positions of power. Thompson also pointed out how certain symbolic phenomena are not ideological as such, but are ideological only in so far as they serve to maintain relations of domination. In other words, the ideological character of symbolic forms is seen only by situating these forms within the social and historical contexts within which they establish and sustain power relations.

Thompson drew on what he calls Marx's latent conception of ideology to formulate his own definition. He described the latent conception of ideology as being based in parts of Marx's work where the present is seen as a multiplicity of complex schisms, and where individuals are captivated by images and expressions from the past. He wrote that from this conception, people 'acted out their historical roles on the basis of pre-given scripts' which told a story of defeat and disappointment. These ideological forms were "not mere epiphenomena of economic conditions and class relations; rather, they are symbolic constructions which have some degree of autonomy and efficacy." They are forms which "modify and transform themselves, indeed they reappear as a potent reactionary force on the very eve of revolution itself." Through this, Thompson calls attention to the fact that social relations may be sustained, and social change arrested by the prevalence or diffusion of symbolic constructions. 
Vološinov, too, introduced a range of interesting ideas to the study of ideology. His was a perspective which helped to flesh out the emphasis that Thompson brings to the study of symbolic forms. He wrote that signs themselves are material things which do not simply exist as part of reality, but reflect or refract another one. This means that these signs either distort reality, are truthful to it, or perceive it from another point of view. Ideological signs in this regard, are never just shadows or reflections of reality, they are themselves material aspects of it. In this, the social material of signs made by man derive their specificity through their social 'position' between organized individuals as the medium of their communication. At the level of culture, then, no sign lives in isolation.

Building off of his perspective on language, Vološinov wrote that what is important about the word/sign is not so much its 'purity' as its 'social ubiquity'. They are implicated in precisely every act of exchange between people. From here, the hierarchies of meaning and social classification in words or ideas draw attention to the processes which sustain these pejorative elements in the political and social world. It also draws attention to the fact that individual choice is not always a relevant indicator of social and political meaning. A sign derives meaning from its social milieu.

It was suggested that conspiracy theory is an ideological construct, and that the notion of a conspiracy theorist is a free-floating signifier. As a conceptual frame, it is attached to individuals who in some way or another have earned it. What hasn't been addressed to this point, is how relatively little that actually takes. It was suggested that the label itself preexists any individual 
application, and is an ideological construct first and foremost.

Two of the important elements to retain is how certain ideas about social contradictions arise from material circumstances, and how Marx addressed the relationship between these ideas and how they function in the material world in terms of ideology. When confronted with systemic inequality, these ideas tend to be projected into ideological forms of consciousness. Taking conspiracy theory as one of these ideological forms of consciousness required a broadening of the focus on ideology to encompass the formative material conditions which give rise to them. By doing so we begin to understand how it is that conspiracy theories act as a 'reflection and refraction' of these social contradictions, and that they do so as a natural part of their own production. It can be accepted that conspiracy theories represent purely mental or discursive 'solutions' to these inequalities and contradictions which simultaneously mask or distort them. Conspiracy theories serve the interests of the ruling classes by refracting material conditions to such an extent that they no longer hold anything but a passing resemblance to reality.

It is from this point of view that conspiracy theories become more difficult to accept as simply counter-hegemonic forms of discourse, though they are certainly that to a point. The problem arises once these forms of discourse are accepted, de facto, as conspiracy theory. There is no difficulty imagining an independent political party or individual in some way working to achieve some sort of large-scale institutional change. We need look no further than the women's movement, or the civil rights marches, and anti-globalization protests to understand very quickly what conventional 
counter-hegemonic activity looks like. There is little confusion here about whether they were marching for a conspiracy theory or not. But a conspiracy theory is always a conspiracy theory. It always stands outside of accepted definitions of reality. It can never be normative; by its very nature, a conspiracy theory is predicated against everything that is. If it can be granted that hegemony might be defined as a complex social and political system of meaning generation which works to normalize dominant ideas and marginalize oppositional ones, then the case study will demonstrate that the notion of 'conspiracy theory' worked to do both simultaneously in the post 9/11 lead up to the invasion of Iraq. 


\section{Chapter Four - The Paranoid Style in Middle East Politics}

One might say that, in a manner of speaking, the 9/11 attacks actually began at 12:01 a.m. on May 14,1948 , when the United States became the first country to officially recognize the independence of Israel. As starting points go, this one as about as arbitrary as it gets. But in terms of what would later transpire in New York City and Washington, D.C., it is one that nonetheless brings together many of the same historical tensions which played themselves out on September 11, 2001. U.S. financial and military support of Israel since that day in 1948 has been and remains a central factor in the contentious nature of Middle Eastern politics.

This chapter looks at the paranoid style and conspiracy theory against a backdrop of the history of American involvement and intervention in the Middle East. Specifically, it is concerned with providing a context for understanding some of the ways this history is symbolically tied up with [primarily] American apocalyptic belief systems such as evangelical Christianity. As was noted earlier, Hofstadter himself was aware of the potential for extreme right wing religious beliefs to become self-fulfilling prophecy, and this point will be picked up and developed in this chapter. The belief in a strong Jewish homeland which conforms to biblical borders is central to these apocalyptic evangelical belief systems. This is because the return of Jesus, as prophesied in the Book of Revelation in the Christian bible, is believed to be dependant on returning the Jewish state to its original biblical foundations. This is counterposed with another long-running theme, that of a belief in a worldwide Jewish conspiracy that has taken many different forms over the centuries. Remembering Hofstadter's caution that the 'paranoid style' is not an exclusively American 
phenomenon, these same beliefs in a worldwide Jewish conspiracy are widely held in the Arab world generally, and are espoused by Osama bin Laden specifically. Complicating matters even further still, is that the Battle of Armageddon predicted in the Book of Revelation is said to occur along the banks of the Euphrates River which runs right through modern-day Iraq. All of this is brought together in this chapter as a means of establishing a few parallels between belief systems such as these and the archetypal conspiracy theory.

While there is no intention to suggest or imply any causal relationship between the recent spike in political influence by the religious right in the United States, the current circumstances require that its co-presence with these circumstances should not be ignored either. Though U.S. foreign policy in the region is a broad topic that could be taken in many directions, it is still an important aspect of any attempt to understand, not only the $9 / 11$ attacks, but also the ramifications of the Iraq invasion to overall Middle Eastern stability. The region's importance to the global economy should not be exaggerated by any means, but it can hardly be ignored. In fact, it is little exaggeration to say that in some significant ways, the very 'way of life' perceived to be under threat by proponents of the paranoid style in the United States is partially influenced by that stability.

With a focus on the same dialectical tensions addressed earlier, the chapter demonstrates the reciprocal paranoia of conspiratorial thinking in this regard. It positions conspiracy theory not only as a convenient analytical device, but also as a central component of Middle Eastern politics generally. Drawing on various sources to do so, a picture of foreign influence emerges which is easily framed by conspiracy theory. At the same time, it lays out a methodological approach which 
incorporates journalistic sources as primary research material in order to set the stage for the case study in the following two chapters.

Phyllis Bennis ${ }^{1}$ writes that the American response to $9 / 11$ in the form of its global war on terror reflects the three main pillars of U.S. strategy in the Middle East which have not changed since the mid-1960's: oil, Israel, and stability. However, in order to understand why the implementation of these policy goals has inflamed the anger of so many in the region, it is necessary to go back much further than that. She points out that direct U.S. influence in the Middle East is a relatively recent phenomenon, even though its strategic and economic importance has been known for centuries. Historically, control of the Arab world was left mainly to European and nearby empires, such as the Ottomans, the French, and the British. As the $19^{\text {th }}$ century came to a close, however, all of this began to change. As described in chapter one, the U.S. had begun to enjoy the benefits of a thriving economy after the elimination of much of the Native population in its continued expansion westward. It began to eye Spanish colonies in the South Pacific and elsewhere. As Bennis puts it, "the US was ready to go seriously global."2

At the same time, the area which stretched from Egypt and the coastline of Syria and Palestine eastward through modern-day Iraq to the border of Iran, and south through the Arabian peninsula to the port city of Aden, in Yemen, had been controlled by the Ottoman empire for 400 years. Ilan 2003.

${ }^{1}$ Phyllis Bennis, Before and After: U.S. Foreign Policy and the War on Terrorism, Olive Branch Press,

${ }^{2}$ ibid., p. 22. 
Pappe $^{3}$ writes that during the 1880 s, the Palestinian economy became irrevocably tied to the world market. Imports from and exports to Europe were increasing dramatically, as steamers and large ships arrived with manufactured goods from industrialized Britain and France. The same ships left again loaded with raw materials, most of which originated elsewhere, but which still had to pass through Palestine. On top of this, Palestine provided access to markets in Egypt, Lebanon, and Syria, and so became an important and "clearly defined station on the world economic map." The shift away from subsistence agriculture (the musha' system) to marketable crops in the rural areas, undermined peasants' self-sufficiency. As a result, life would eventually become unsustainable for the poorer peasants who had been totally dependent on their land. In the process, it had the dramatic effect of producing the first ever pockets of hired labor in Palestine. Ottoman land reforms during the same period overturned the older system of land leased from the state, via taxes and the like to the sultan, and opened up the possibilities of private ownership, which of course favored the wealthy. Though there is only so much detail that is needed, the important point is that the peasants were not just moving away from traditional means of production; "they were abandoning a way of life, a set of beliefs that had helped them make sense of their lives, but without a blueprint for the future." It was circumstances like these that underscored a rise in Palestinian nationalism, particularly the sort rooted in religious or spiritual views of reality. ${ }^{5}$

During World War I, the U.S. fought alongside the British, French, and Russian empires, against the

\footnotetext{
${ }^{3}$ Ilan Pappe, A History of Modern Palestine: One Land, Two Peoples, Cambridge University Press, 2004.

${ }^{4}$ ibid., p. 24.

${ }^{5}$ ibid., pp. 24-25.
} 
Ottomans, Germany, and the Austro-Hungarian empire. Despite this, the U.S. was only an up-andcomer on the world stage at the time. Its rise to dominance in the Middle East was still decades off in the future. The Western effort to gain control of the region from the Ottoman Turks was largely a collaborative effort conducted by Britain and France, with the Americans doing little more than watching.

One of the strategies employed during this period by the French and British was the formation of key alliances with local Arab leaders. One of these was the Grand Sharif of Mecca, who accepted a British proposition to lead an Arab revolt against the Ottoman Turks in exchange for a promise to be made leader of an independent Arabia after the end of the war. But Britain and France also had a few secret deals of their own. At the same time, they had been putting the finishing touches on their 1916 Sykes-Picot Agreement which effectively divvied up the post-Ottoman Arab world between themselves. Complicating things even further, was another position taken by Britain in 1917, when it announced the Balfour Declaration. It promised the Zionist movement, which was then gaining strength among Jews across Europe, Russia, and elsewhere, that Britain would look favorably upon the creation of a national Jewish home in Palestine. Needless to say, not all of these promises could be kept.

Some attention to the question of why the British should have been concerned to support the Zionist cause is deserving of an extended aside. Pappe offers three interesting possibilities. Documents at the time reveal that British ministers put a heavy emphasis on the perceived role of Russian Jews in the new reformist tsarist government there, and believed they could be influential in rallying the 
tsarist government to the Allied cause in subjugating Germany. This perceived Jewish role turned out to be exaggerated, and it was later discovered that there was no evidence of Jewish influence in the Tsar's court. Second, was that the British Foreign Office had also become aware of the importance of Jews to the Bolshevik movement, and hoped that a pro-Jewish position would help consolidate support from the Bolsheviks. ${ }^{6}$ It is curious, however, that Pappe makes no mention at this point of the Protocols of the Learned Elders of Zion, which was anti-Semitic propaganda fabricated by the Tsarist secret police, and which told of an imaginary Jewish plot to take over the world. It begs the question as to whether the British belief in Jewish prominence in Russian affairs was at all influenced by the Protocols. The timing is right, after all. They first appeared around 1900 , and were not first proven to be a forgery until $1921 .^{7}$

Margaret MacMillan ${ }^{8}$ offers another compelling clue on this point. She writes that as a figure, British Foreign Secretary Arthur Balfour was difficult to pin down. It appears he was thought of none-to-highly by both Churchill and Lloyd George. "If you want nothing done," she quotes Churchill as saying, "A.J.B. was undoubtedly the best man for the task." Lloyd George was even less charitable. After being asked what he thought Balfour's place in history would be, his response was, "He will be just like the scent on a pocket handkerchief." A very wealthy man through inheritance, Balfour (who had himself been British Prime Minister between 1902-1905) was notoriously unprepared, though exceptionally clever with a gift for improvisation. Though

\footnotetext{
${ }^{6}$ ibid., pp. 67-68.

${ }^{7}$ Knight, op. cit., p. 595.

${ }^{8}$ Margaret MacMillan, Paris 1919: Six Months that Changed the World, Random House, 2003.
} 
MacMillan makes it clear he was not known as an anti-Semite, in a conversation with American Colonel Edward House, Balfour remarked that "someone had told him, and he was inclined to believe it, that nearly all Bolshevism and disturbances of a like nature, are directly traceable to the Jews of the world. They seem determined to either have what they want or to upset present civilization."

In digging a little deeper on this point, it seems very likely that the Protocols did in fact have some sort of influence over this period, though what that may have been is difficult to say. $\mathrm{Knight}^{10} \mathrm{offers}$ some illuminating background on the origins and significance of the text. Though the actual writer of the Protocols is unknown, a good portion of the material is derived from a nineteenth-century French political satire by Maurice Joly called Dialogue aux Enfers entre Montesquieu et Machiavel (1864). In it, the political philosophers are engaged in a debate with Montesquieu (the hero in the satire) arguing the liberal case, and Machiavelli (the villain and stand-in for Napoleon III) taking the side of cynical despotism. In any case, the Protocols have been used by generations of antisemitic conspiracy theorists to view every liberal/progressive development in politics, such as the formation of the U.N., labor unions, liberal trade policies, etc., as evidence of a creeping international Jewish conspiracy. ${ }^{11}$

Knight [ed.] points out that the "rampant forces of globalized capitalism were indeed causing many

\footnotetext{
9 ibid., pp. 414-415.

${ }^{10}$ op. cit.

11 ibid., p. 595.
} 
changes throughout Europe, and the Protocols are quite clearly offering a distorted - and ultimately deadly - metaphor for the new world economic order." And while the specifics are not as important here, the general consensus is that the text is at least partly the work of Pyotr Ivanovich Rachkovsky, the head of foreign operations for the Okhrana, or, the tsarist secret police. The feeling is that he may have well commissioned the Protocols as part of an attempt to create support for a FrancoRussian league to 'counter' this international Jewish conspiracy. But the reasons were no doubt much more practical, to establish a military alliance with the French as a response to the rise of other European military powers.

The numerous references to the French political scene in the Protocols have led some scholars to believe that the text was produced in France about 1897 or 1898 . However, they appear in print for the first time in Russia, in their "canonical" form, as early as 1903, in a book by a Russian mystical writer named Sergey Nilus. His ominously titled, The Great in the Small: Antichrist Considered as an Imminent Political Possibility (1905), was revised and expanded in 1917, just in time for the Russian Revolution. In its revised form, it was titled, He is Near, at the Door...Here Comes the Antichrist and the Reign of the Devil on Earth. The ideas in his book were eventually to become a startlingly popular explanation for both the Russian revolution, and World War I. ${ }^{12}$

The opponents of the Bolsheviks, the White Russian forces, seized upon the Protocols as a foreign policy tool. If they didn't believe it themselves, they certainly wanted others to believe that the revolution was in fact the work of the mysterious elders. Copies of the Protocols were distributed

\footnotetext{
${ }^{12}$ ibid., pp. 595-596.
} 
by the White Russians to delegates at the Paris Peace Conference of 1919 , as well as to other government officials across Europe and the United States, in an effort to secure support for their civil war against the Bolsheviks ${ }^{13}$. By 1920 , the Protocols were being taken quite seriously in the mainstream European press, such as the London Times. However, it is the inconsistencies which emerged out of the subsequent repetition of the myth of an international Jewish conspiracy, which makes it worth noting here. In various ways, the conspiracy theory was warped within each nation in such a way as to fit with the national strategic interests.

Though there was no question for antisemites in each country that Jews were behind a secret world government or conspiracy, there was wild disagreement over who, exactly, was supposed to be in league with them. In Germany, for example, it was believed that London was the center of operations, and that it was the English who financed the Bolsheviks. In England, on the other hand, it was Germany that was in a dark alliance with the elders and the Bolsheviks. Regardless, in both cases it is clear that the Jews were merely an appendage to broader efforts at shoring up resistance and opposition to each country's economic and military rivals. Interest in the Protocols dropped off sharply after August of 1921 , after the London Times proved them to be a forgery. ${ }^{14}$ And so while none of this offers any specific insight into the writing of the Balfour Declaration, it does provide a rather engaging insight into the collective conspiratorial mind-set of the period around the issue

\footnotetext{
${ }^{13}$ This may have been effective. MacMillan (2003) notes in Paris 1919 that "By the end of 1918 there were over 180,000 foreign troops on Russian soil and several White Russian armies receiving Allied money and Allied guns. People were starting to talk about a crusade against Bolshevism" (p. 71). Bolsheviks would later use this as part of a propaganda tool themselves as "world capitalism in all its might arrayed against their revolution" when in fact, owing to corruption, inefficiency, and waste, Allied help actually did very little to stave off White defeat ( $p$. 73).

${ }^{14}$ Knight, op. cit., pp. 596-597.
} 
at hand. To return to more direct attempts to explain the British interest in the Zionist cause though, Pappe offers his third possibility, "that pious Christians, such as British prime minister David Lloyd George, were motivated by a wish to facilitate the return of the Jews to precipitate the second coming of the Messiah."15

In any case, after the war, the Ottoman leaders were overthrown and a Turkish state was established under the rule of Mustafa Kemal. Under the terms of the Sikes-Picot Agreement, Britain took control of Egypt, Transjordan, Palestine, and Iraq, while the French got Syria and Lebanon. The Arabia peninsula also remained a British protectorate, an arrangement that would stay in place until Saudi Arabia's nominal independence in 1924. The British would also establish a monarchy in what is today known as Iraq ${ }^{16}$, with its protection, until Iraq was granted independence in 1932 . Kuwait was carved out of Iraq at this same time, in order to ensure British access to oil and ports. Kuwait would only gain independence from Britain in 1962. In the meantime, a 1907 agreement between

\footnotetext{
${ }^{15}$ Pappe, op. cit., p. 68.
}

${ }^{16}$ The creation of Iraq itself out of disparate religious, historical, and geographic circumstances occurred against common sense, save for the fact that, from an administrative point of view, Basra, Baghdad and Mosul should remain under British control. As MacMillan (2003) writes, it "never seems to have occurred to [British political officer Arnold Wilson] that [Iraq as] a single unit did not make much sense in other ways. In 1919 there was no Iraqi people; history, religion, geography pulled the people apart, not together. Basra looked south, toward India and the Gulf; Baghdad had strong links with Persia; and Mosul had closer ties with Turkey and Syria. Putting together the three Ottoman provinces and expecting to create a nation was, in European terms, like hoping to have Bosnian Muslims, Croats, and Serbs make one country. As in the Balkans, the clash of empires and civilizations had left deep fissures" (pp. 397-398). Nevertheless, on August 23, 1921 in a 'make-good' gesture to Faisal*, the British appointed him king after stage managing a stream of supplicants asking him to stay on as their ruler (p. 408). It is worth noting the irony that the country now at the center of the controversy over non-existent weapons of mass destruction was itself non-existent. It is equally ironic that the brutal suppression of the sectarian strife noted by MacMillan under sometime-U.S. ally Saddam Hussein, was the very thing which helped to maintain a degree of stability in the region.

* [ibn Husayn Faysal \{1885-1933\}. Born in the Hejaz, third son of Sharif Husayn of Mecca. Headed Arab revolt army and assisted in occupation of Damascus. King of Greater Syria \{1918-20\} and then Iraq $\{1921-33\}$ (Pappe, 2004; p. 295)]. 
Russia and Britain was dissolved in Persia after the war, when Persia was recognized as independent, with the new Soviet Union renouncing all claims to the country in 1921. It remained, however, largely under British control. Later that same year, Reza Khan overthrew the Qajar dynasty, and four years later, crowned himself Shah of what would soon be Iran.

After the European powers had agreed on the division of land in the Middle East, the Sykes-Picot Agreement was submitted to the League of Nations for approval, which was little more than a formality. The bi-lateral provisions of the Agreement would set the terms for Europe's colonial influence and control in the region for at least the next two decades. The European victors, with a bow to Woodrow Wilson's Fourteen Points and their emphasis on self-determination, went about trying to find out the wishes of the people who had lived for so long under Ottoman rule. Their attempts, though, were half-hearted at best. And while the people in the region adjusted uneasily to a new dominating power, the Inter-Allied Commission, which was set up to survey the population, languished and died an inconclusive death.

U.S. President Woodrow Wilson then began a campaign for more influence in the Middle East. After fighting on the winning side in WWI, the U.S. was now positioned to try and challenge the European powers by insisting on a share in international economic and strategic influence. Curiously, it did so under the guise of ending colonial empires. As Bennis points out, the United States was not popularly understood to be a real colonial power. This was despite the 1823 Monroe Doctrine and its claims to Latin America, and the U.S. conquest of the Philippines, Puerto Rico, and Cuba after the 1898 Spanish-American War. Wilson's approach to international diplomacy was, 
however, grounded in his feeling that the older model of classical colonialism was passé. In its place, Wilson sought the creation of an unofficial and unacknowledged influence over dependent governments, as well as over their accessible resources, and their malleable populations.

Though the U.S. did not join the post-WWI League of Nations, Wilson still played a major role in the drafting of its Covenant. Considering this influence, and the fact that he had become known as the father of 'self-determination', it is quite significant that the document itself contains no reference to self-determination. Furthermore, at the Versailles Conference of 1919, U.S. representatives did not object to the idea that it was perfectly legitimate for victorious powers to take over the colonies ruled by their defeated opponents. During this same discussion, the Zionist movement, which was emboldened by the Balfour Declaration, began to push for the approval of its own goals. In complete contrast to the general notion of self-determination, the intelligence section of the U.S. delegation wrote an internal report, which supported the transformation of the entirety of Palestine into a Jewish state under a British mandate. Speaking on the matter in Chicago on March 2, 1919, Wilson made it clear he had been persuaded by Allied nations that Palestine would become the foundation of a new Jewish Commonwealth. It bears mention that only about ten percent of the population of Palestine was Jewish at the time.

Two months later in May 1919, Wilson dispatched the King-Crane Commission to Syria, Lebanon, and Palestine, in order to find out what public opinion was on post-Ottoman settlement. Bennis notes that the American delegation took their task much more seriously than their European counterparts previously had. They based their approach on the Anglo-French Declaration of 
November 9, 1918, which had expressed a commitment to the complete and definite freeing of peoples long oppressed by Turks, as well as the establishment of national governments chosen freely by native populations. Much of the team's work, however, involved assessing public opinion of the Balfour Declaration. What they learned was that, despite their initial predisposition to favor the Zionist cause, the facts found in Palestine led them to oppose the British plan for an unlimited immigration of European Jews into Palestine. After all, as a result of their research, the American report reflected their findings that the Zionists had actually been looking forward to a virtually complete dispossession of all non-Jewish inhabitants of Palestine.

The commission, Bennis continues, did indeed recognize the imminent danger of Palestine becoming an entirely Jewish state. This was, in part, because Palestine was sacred not only to Jews, but to Muslims and Christians as well. The fear was that one effect of this plan would be the intensification of anti-Jewish sentiment, in both Palestine and in other parts of the world that looked to Palestine as their Holy Land. "That part, at least," she writes, "certainly proved to be true."17

During the World War II Years, the British plan to defend the Middle East required more troops than Britain had available. As a result, they needed to recruit support from Arab armies. Despite the fact that Britain had backed large-scale Jewish immigration to that point, it issued a White Paper in 1939 which promised to restrict it. This restriction, though, infuriated the Zionist leadership, because

\footnotetext{
${ }^{17}$ Bennis, op. cit., p. 25 . At the time of this writing [August 18, 2005] Jewish settlers are being forcibly removed from settlements in the Gaza Strip as part of Israeli Prime Minister Ariel Sharon's plan to return portions of land to Palestinian control. The plan has been received with much consternation by some Jews in the settlements, and an understandable but counterproductive jubilation by some Palestinians. Slogans to the effect of 'First Gaza, then the West Bank, and then Jerusalem' have been chanted by some in celebratory marches within sight and earshot of the holdouts in Gaza.
} 
without sufficient numbers to augment their still relatively small Jewish community, there would be no way they could ever establish a viable Jewish state. Interestingly, however, it was precisely this sort of policy accommodation on the part of the British, that was simultaneously needed, in order to help foster and secure the Arab support they desperately relied on for the war. Though this, in itself, did not spark the eventual Jewish turn towards the U.S. to become the new patron saint of Zionism, it did reinforce the gravitational shift in geo-political emphasis from the U.K. to the United States. Bennis cites David Ben-Gurion, one of the leading founders of Israel, as saying that for his part "our political efforts had shifted from Great Britain to America, who was making sure of being the world's leading power and where the greatest number of Jews, as well as the most influential, were to be found." 18

The rise of Zionist organizations in the United States was accomplished, in part, by their expansion to include many American Jews who had initially been opposed to Zionism. The Zionist cause for the establishment of a Jewish homeland in Palestine had eventually come to be seen as the best response to both Hitler's genocide, and the lingering effects of American anti-Semitism which kept most Holocaust survivors out of the United States. As the movement grew, though, it came to represent the majority position among the American Jewish community. Simultaneously, it predictably began to influence U.S. policy makers. At the height of the Second World War, in 1942, an International Zionist conference was hosted in New York City. The timing of the conference closely followed Hitler's tactical shift from merely expelling Jews from Germany, to instigating their mass extermination along with Slavs, Communists, gays, and others. It marked the first time that

\footnotetext{
${ }^{18}$ ibid., p. 26.
} 
there was an explicit call for the establishment of a Jewish state in Palestine by the Zionist movement, and support for Zionism surged among Jews all over the world. ${ }^{19}$ Not the least of the reasons for this was the fact that, even while they publically trumpeted the Zionist cause, the Americans were ultimately seen to be paying little more than rhetorical concern for the plight of Jews at the hands of Hitler. ${ }^{20}$

\section{The Zionists, The Oil Companies, and Washington ${ }^{21}$}

Since the discovery of oil in the Middle East in the 1920s, French and British oil companies had been competing for influence in the region. The Russians, in the meantime, sought alliances with oil-rich Iran. American oil companies were trolling for opportunities in the Middle East as well, but the British were still the dominant player. It would be a dominance that would extend well into the 1930s. However, when vast oil reserves were discovered in Saudi Arabia in the early '30s, the stage was set for a massive transformation of a previously nomadic and impoverished region. It would soon become a wealthy, and pseudo-modern country. But there was serious conflict between American and British oil companies at this point over access to Saudi crude, ${ }^{22}$ and the tide quickly

${ }^{19}$ ibid.

${ }^{20}$ For example, during the 1943 Warsaw Ghetto uprising, the U.S. did nothing to support the Jewish fighters who held off the Nazi army for 6 months before being killed, and in 1944, refused to bomb the railroad tracks to Auschwitz because of the diversion it would represent from the main military objectives in the air campaign against Hitler's forces.

${ }^{21}$ ibid., pp. 27-29.

${ }^{22}$ MacMillan (2003) notes that "Walter Long, the British minister of fuel, and Henry Bérenger, his French counterpart, a man who believed that oil was the "blood of victory," were put to work. They produced an agreement under which France would have a quarter-share of the Turkish Petroleum Company and in return would allow two pipelines to be built across Syria from Mosul to the sea. Both sides agreed that they did not want the Americans, who were starting to take an interest in Middle East oil, muscling in" (p. 396). 
turned in favor of the Americans. The reason for this was that the British had gone deeply into debt to America during World War I. Effectively then, the U.K. had mortgaged its empire to finance the war, and with stiff repayment terms, the Americans called in their debts. In 1933, the ArabianAmerican Oil company [Aramco] was granted exclusive concession by the Saudi monarchy for oil exploration. Aramco was essentially a conglomerate of four U.S. oil companies: Esso, Texaco, Mobil, and Socal, and it marked the beginnings of American supremacy in the region. It was to be a geo-political economic rise that would be further consolidated with the onset of World War II.

It was the Second World War which would transform the power and status of the U.S. in global terms. As is often mentioned about the American experience of WWII, they were spared the massive civilian casualties, as well as the debilitating physical, economic, and social destruction suffered by Europe. As Bennis puts it, the "French and British economies, infrastructures, and colonial empires, lay in ruins, as did their sense of power and international influence. ${ }^{, 23}$ Furthermore, America was at the time the world's only nuclear power. The Soviet Union, too, had suffered horrendous loss of life; over 20 million people died during the war, and its cities and countryside were also devastated.

When U.S. president Franklin Roosevelt died just before the end of the war on April 12, 1945, it left the new president, Harry Truman, with a big problem. Like the French and British before them, the Americans had made a number of contradictory promises in order to shore up allies for the U.S. in the post-war Middle East. Though Truman had supported Zionism as a senator, Bennis notes that this was probably more due to vote getting than for any truly strategic purposes. But as president,

\footnotetext{
${ }^{23}$ Bennis, op. cit., p. 27.
} 
it became much more important in terms of what the Americans needed to do in order to secure and consolidate their access to Middle Eastern oil.

At the end of the war, three American oil companies, Socal, Esso, and Socony, controlled 42 percent of known oil reserves in the Middle East. Oil companies comprised three of the top five American corporations owing to their ties to the region. Not unlike today, top officials in those companies served in key posts at both the State Department and the Pentagon where they were concerned to maintain American control. In fact, one component of the Marshall Plan aid to Europe was that it created a market for 'U.S. oil'. With oil replacing coal as the key fuel source all across Europe, the U.S. further consolidated its power while acting as the guarantor of European and Japanese access to oil through their respective rebuilding phases.

It will come as no surprise that the only objections to this audacious arrangement came from the Middle East itself. With the United States claiming rights to oil from their own countries, and supporting harsh governments such as Saudi Arabia and then still British-controlled Kuwait, it was not long before Arab nationalists and others began to oppose the U.S. presence. Labor protests formed the backbone of this resistance, and in 1945-46, strikes erupted in the Iranian oil fields. They would soon be followed by Iraq's oil workers. But one of the key aspects to point out here is that part and parcel with this labor unrest was an accompanying demand to reverse the movement towards establishing a European Jewish state in Palestine.

Shortly after his inauguration, President Truman met with Rabbi Stephen Wise, the leader of the 
American Zionist movement. Like many U.S. policymakers at the time, Truman believed that an America-friendly, European-populated, Jewish state in Palestine would be beneficial to U.S. interests in the volatile region. It was certainly preferable to the sometimes unpredictable Arab regimes. As Bennis puts it, "it could serve as a junior partner in defending US interests; it could provide key onthe-ground logistical or even military support should the US military involvement in the area be required; it could help maintain US and broader Western control of Middle East oil; it could help make sure the Suez Canal and other key routes were protected and remained open to Western shipping." 24 Additionally, since the Cold War was already getting underway, it could serve as a vanguard in the U.S. efforts to limit or curtail Soviet influence in the region, which was already present in places like Iran. Furthermore, it would consolidate American Jewish voices that had become loud proponents for a solution to the problem of European Jewish refugees. It must have seemed like a pretty good idea at the time. As Bennis reports, 75 percent of Americans who had heard of Palestine supported the creation of a Jewish state there. Of course, there was still the matter of the fate of local Palestinian Arabs.

With everything looking rather sunny from the American point of view, Europe was still mired in conflict. Holocaust survivors filled camps across Europe, awaiting passage to Palestine since neither Britain nor the States wanted them. Arab states clung to the hopes of receiving the independence they had been promised under agreements with France and Great Britain. A few of the Arab states, which included Iraq, and later, Syria and Lebanon, already had or were on track towards full independence. But things were different in Palestine, whose mandate was still held by the British,

${ }^{24}$ ibid., p. 29. 
as well as the League of Nation's mandates for Egypt and Transjordan. In the specific case of Palestine, this was especially significant because had the Palestinians been given independence, they would have halted the large-scale immigration of Jews immediately, and both the Americans and the British knew it. With a population that was overwhelmingly Muslim and Christian Arab in Palestine, that would have left both Washington and London with a mass of European Jews with nowhere to go. But with the Palestinian mandate under their purview, the British in particular had a bigger problem when tensions between the indigenous Palestinian Arabs and the immigrating Jewish refugees began to escalate rapidly.

With this sort of trouble brewing, Truman was eager to assume a larger role, with the goal of eventually replacing the British as the chief outside regional power. Though diplomatically cautious, he saw the creation of a Jewish state in Palestine as one step towards a potentially crucial alliance. Washington felt that Arab states would eventually accept the Jewish one. Across the United States, ideological momentum for the project had continued to grow. Interestingly, considering some of what has already been addressed, industrial growth was exploding at the time in the United States, and even the U.S. Department of Labor felt that the economy could easily absorb 400000 new immigrants.

Despite this pronounced need for new workers, however, there was the problem of lingering American anti-Semitism. This was itself very closely tied to the concurrent boom in post-war anticommunism, which would mushroom in the McCarthy era. Fears at the time revolved around the idea that these Jews could be secretly harboring socialist ideas that would undermine the 
unprecedented economic prosperity of the United States. Instead, a series of public campaigns were launched across the country to support mass emigration for the Jewish refugees out of Europe and into Palestine.

Ironically, but perhaps not surprising, the two populations most directly concerned with the outcome were hardly consulted at all. First, the Palestinian Arabs who were faced with losing their land and their nation were largely ignored. One of the famous slogans, popular at the time in the United States, does a lot to show how this was the case. The new Jewish state was packaged as "a land without a people for a people without a land". This was, to say the least, a slight exaggeration. Secondly were the European Jews themselves, who if given their preferences, would have almost certainly chosen the United States. In fact, in a report submitted to the American Jewish Congress, a Zionist organizer, Chaplain Klausner, admitted as much, stating that most of the refugees wanted to come to the U.S. Bennis cites him as being convinced that the refugees would have to be forced to go to Palestine. ${ }^{25}$

The campaigns, though, were to have the desired effects. Editorial writers excoriated Britain for its conservative immigration quotas in Palestine, and Americans sent over $\$ 130$ million in private donations to Palestine to assist in the transportation of the refugees. Anyone who challenged this Zionist move was quickly labeled an anti-Semite. At the very same time, American anti-Semitism itself was a predicating factor in the 'anywhere-but-here' push to establish a permanent Jewish state in the middle of the Arab world. In 1945, the United States officially began to pressure the British

\footnotetext{
${ }^{25}$ ibid., p. 31 .
} 
government to admit 100000 refugees into Palestine. British Prime Minister Clement Atlee reminded Truman that the U.S. had promised to consult with Arab leaders on matters such as these, and warned that a massive immigration like this might "set aflame the whole Middle East."26

London and Washington did finally establish a joint Commission of Inquiry to go to Palestine and look into the immigration question. The report they received from the Arab Office in Jerusalem left little room for interpretation:

The whole Arab people is unalterably opposed to the attempt to impose Jewish immigration and settlement upon it, and ultimately to establish a Jewish State in Palestine. Its opposition is based primarily on right. The Arabs of Palestine are descendants of the indigenous inhabitants of the country... and they claim the democratic right of a majority to make its own decision in matters of urgent national concern. ${ }^{27}$

Despite this, the Committee's final report, in March 1946, supported the admission of the 100000 refugees to Palestine, but not the establishment of a Jewish state; nor did it support the idea that all Jews would have an automatic right to go to Palestine. Britain counter-offered with a pledge to admit the refugees, as long as the Zionist militias would disarm. Three months later, those militias responded by blowing up eight bridges in Palestine, and in July of the same year, the extremist militia group Irgun blew up the wing of the famous King David Hotel in Jerusalem where the British government stayed, killing 80 people including Jews, Arabs, and British. Armed clashes between British soldiers and the Zionist militias followed, and war began to look more likely.

\footnotetext{
${ }^{26}$ ibid.

${ }^{27}$ ibid.
} 
With American pressure on the British continuing over the fate of the Jewish refugees, the U.K. responded by announcing in early 1947 that it was turning over its problems in Palestine to the newly formed United Nations. This pleased the Americans, as it meant that Washington could effectively call the shots in the form of a United Nations settlement. Bennis points out that unlike its rocky relationship with the League of Nations, Washington had embraced the U.N. as it was the single most powerful of the fifty-five member states at that time. Most of the world still lived in colonies without independent governments, and so were denied membership. Furthermore, most of the other member states relied heavily on the U.S. to assist them in rebuilding their war-torn economies. Having already cast its lot with the Zionist side, Washington seemed poised to get its wish.

The U.N. General Assembly formed the U.N. Special Commission on Palestine (UNSCOP), though it had no African or Arab members. The proposal called for partitioning the land into two states, one Arab, and one Jewish. 55 percent was to become Jewish, and 45 percent was to become a Palestinian Arab state ${ }^{28}$. Though the Soviet Union was at first opposed to Zionism, it came to support the plan after thinking that the partition would weaken British influence in the Middle East. In the end, the decision hinged on the votes of smaller, undecided states, and through various diplomatic and economic means and pressures, was able to attain the two-thirds majority to pass the sometimes harshly debated plans for partition.

\footnotetext{
${ }^{28}$ At the time of the proposal, Jews in Palestine accounted for only 30 percent of the population, and owned 6 percent of the land. On the other hand, over 400000 Arabs lived in area designated to become the Jewish state.
} 


\section{Israel}

The partition did not bring peace between the Jews and Arabs in Palestine after Israel declared independence in May 1948, and actually brought several armies from neighboring Arab countries into the war in Palestine. Despite being outnumbered by the Egyptian, Trans-Jordanian, and Syrian forces, the Arabs were defeated by the better-equipped Israeli military, along with the new Israel Defense Force created out of the pre-State Zionist militias (the Haganah and Palmach), and the extremist Zionist groups (the Irgun and the Stern Gang). One of the goals of this fighting was to force the Palestinians out, and clear the area of Arab residents in order to consolidate the Jewish presence. By the time the fighting was over, Israel had much more than the initial 55 percent that the partition plan had provided for. A full 78 percent of the land of mandate Palestine was now under Israeli control, and over 750000 Palestinians had been forced off of their land and into exile.

\section{Iran}

In terms of U.S. policy in the region, conflicts over oil continued to erupt throughout the Middle East. In 1951 in Iran, Mohammed Mosaddeq was a democratic nationalist who rose to power on a platform of nationalizing Iranian oil. The Iranian industry at the time was dominated by the Britishcontrolled Anglo-Iranian Oil Company (now British Petroleum, or BP). Britain feared that a precedent could be set after nationalization that would result in additional British losses, and so it solicited the aid of Washington in removing Mosaddeq from power. The Americans obliged, and in August 1953 a coup was engineered by the CIA which toppled Mosaddeq, and replaced him with the repressive and unpopular Shah Reza Pahlevi. For the next four and a half decades, this set the tone for widespread Iranian anger toward the United States. The Shah's regime was permanently 
removed with the 1978 Islamic Revolution, and the rise to power of the fiercely anti-American Ayatollah Ruhollah Khomeini. ${ }^{29}$

\section{From Vietnam to the Middle East Oil Embargo ${ }^{30}$}

Jumping ahead, not to mention also jumping over many other instances that ultimately reinforce many of the same points, the focus can be shifted to somewhat more recent events. In the early 1970s as U.S. defeat in Vietnam was lurking on the horizon, the strategic importance of the Middle East once again loomed very large, as fears grew that the more radical elements in the OPEC membership might attempt to limit U.S. access to their oil fields. The fears were not unfounded. Some of the oil producing countries had indeed began to talk openly about using oil as a weapon against the U.S. and Israel. Pressure was put on the U.S. to back off its support of Israel in order to avert rising oil prices.

In 1973, Saudi Arabian King Faisal indicated to then U.S. president Richard Nixon, and to Henry Kissinger, that Saudi Arabia would need Arab allies in order to help maintain U.S. oil interests in OPEC. As long as the U.S. continued to back the Israeli occupation of Arab land, the king would not be able to guarantee those allies. Kissinger and the U.S. oil companies agreed. As Kissinger himself was already a longtime associate of the Rockefeller family of oil barons, he recognized that changes were needed, but was unwilling to risk a battle with Congress over the pressure needed for Israel to withdraw from the occupied territories.

\footnotetext{
${ }^{29}$ ibid., p. 35.

${ }^{30}$ ibid., pp. 43-47.
} 
About the same time, however, Egypt and Syria were formulating their own plans for a limited war that they hoped would force a change to political alliances. On October 6, 1973, they launched a surprise attack. The Egyptians attacked across the Suez Canal into the Israeli-occupied Sinai, and the Syrians stormed Israeli positions in the Golan Heights. Bennis points out that the fighting was very intense, and Israeli losses were heavy. In time, however, the momentum shifted, with the Israeli air force striking hard into Damascus. In an attempt to destroy the Syrian economy, ports, factories, and oil refineries were also bombed. A massive U.S. airlift on the Egyptian front helped provide much needed rearmament for the advancing Israeli army. Many Arab governments, even those with traditional ties to the Americans, were outraged. Led by King Faisal, the Arab membership in OPEC announced a 25 percent reduction in oil production, along with an embargo on shipments to the U.S. But then things got even worse. As the Israeli army was about to encircle Egypt's Third Army, threatening to destroy it, the Soviet Union stepped in. The Soviets had maintained diplomatic relations with Egypt, despite other tensions between them, and word got to Nixon and Kissinger that the Soviets would not stand by and let Egypt's Third Army be overrun. With nuclear threats being what they were at the time, in the throes of the Cold War, the threat of a U.S./Soviet showdown on top of the embargo proved too much. On October 22, the U.S. and Soviet Union co-sponsored a cease-fire call, and made plans for peace talks in the UN Security Council.

Increased gas prices, however, led to tidy profits for U.S. oil companies. For example, the 1973 profits for Exxon Oil, one of the owners of Aramco, shot up 59 percent. But the American oil companies were not the only ones in the black. Saudi Arabia and the Shah-ruled Iran also became much more wealthy, and eventually, important customers for U.S. arms. On the other side of the 
ledger, though, things were not so good for Israel. The October war had been terribly expensive, and had caused a major economic crisis in the country. Tel Aviv turned to the U.S. for help. While total U.S. aid to Israel over the first 25 years of its existence totaled about $\$ 3$ billion, in 1973 the U.S. began considering an additional $\$ 8$ billion over the next four years. This, too, would set another tone for the U.S. over the next quarter-century, where support for Israel was matched by protection of American access to oil, as two of the three main policy goals for the U.S. in the Middle East.

Although the U.S./Soviet sponsored peace talks collapsed almost as quickly as they began, the October war had enabled the U.S. to reopen negotiations in the region. Kissinger's now-famous 'shuttle diplomacy' resulted in conditions that were far more favorable for Israel. In helping to negotiate individual agreements between Israel and Arab countries one at a time, Kissinger avoided the more difficult situation of negotiations between Israel and a unified Arab front. Despite Kissinger's diplomatic efforts, he had ignored the Palestinians, and this was later to prove very costly for U.S. policy. His approach had dealt with the Palestinians only as refugees. Palestinian opposition to the so-called Jordanian option, which would have placed the Israeli-occupied West Bank under the rule of Jordan's King Hussein, was all but unanimously opposed, an opposition that spread around the world. One of the results of this was a major increase in support for, and recognition of, the PLO, which culminated in Arafat's appearance at the UN General Assembly in November 1974. The UN voted 105 to 4 in favor of recognition of the right of Palestinians to selfdetermination. In addition, the PLO was granted observer status at the UN itself. Only the U.S. and Israel, and two other U.S.-dependent countries (Bolivia and the Dominican Republic) voted against the resolution. It was a stinging rebuke of American policy. 


\section{The Carter Doctrine ${ }^{31}$}

By the late-1970s, the American position as champion of Israel continued to isolate it from some allies. In its Venice Declaration of June 1980, the nine-member European common market reaffirmed Europe's commitment to Israeli security, even offering to help secure it, but not at the expense of the principle of Palestinian self-determination. It also condemned Israel's settlement policy, which was being expanded at the time, and called for the PLO to become a part of the peace process. Washington once again reiterated its unwillingness to deal with the PLO, and the Europeans backed away from diplomacy in the Middle East.

But there was yet another important factor emerging at the time which would impinge on U.S.-Israeli relations. The threats posed by the Iranian revolution to regional power balances, and U.S. access to oil in the Persian Gulf, were soon to be followed by the decade-long Iran/Iraq war. This, coupled with a guerilla war against the U.S.-backed dictatorship in Nicaragua, which was subsequently overthrown by the Sandinistas, led U.S. president Jimmy Carter to craft his "Carter Doctrine". In it, he pledged to use force, if necessary, to protect U.S. access to the Middle East's crude, something he referred to as "our oil." Among many other policy initiatives, one of them included sending AWAC communications planes and F-15 fighter jets to Saudi Arabia in 1980, at the King's request. After the overthrow of the Shah of Iran, a former ally, it appears the king was feeling a little skittish.

Israel and its U.S. supporters were in staunch disagreement with this plan, and fought bitterly to resist the sending of U.S. jets to the Saudis. Bennis notes that it was the first major public break

\footnotetext{
${ }^{31}$ ibid., pp. 47-50.
} 
between the pro-Israel lobby and the foreign policy establishment. After a very close Senate vote, oil trumped Israel, and the sale was approved, albeit with the caveat that the security of Israel not be threatened. Not to be outdone, Israel's ambassador to the U.S., Ephraim Evron, announced the expectation that his country would be proportionately compensated, through increased U.S. military funding. This was fine with the U.S., since Israel could become a useful advocate in implementing the Carter Doctrine. After all, it had both the willingness and strategic advantages of intervening directly in any developing crises in the Middle East, and elsewhere. This sort of strategic advantage could be particularly useful in those instances where the U.S. might feel constrained from intervening directly due to domestic political pressures.

Though it is tempting to continue with a layered historical summary of American involvement in the Middle East right up until the $9 / 11$ attacks, it is not necessary to try and summarize all of it here. Many other examples, such as the Reagan years and the Sabra-Shatila Massacre ${ }^{32}$, would only add

\footnotetext{
${ }^{32}$ On September 16, 1982, the Christian Phalangist militia [the most anti-Palestinian of the Christian militias] entered the Sabra and Shatila refugee camps on the outskirts of West Beirut. With the tacit acceptance of Israeli forces under the leadership of then Israeli Defense Minister Ariel Sharon, an untold number of Palestinian men, women, and children were killed. Bennis (2003) writes: "The massacre of unarmed children, women, and old men went on for three days. It resulted in the deaths of between 2,000 and 3,000 Palestinians, most of them left piled up or hastily buried in mass graves. The Red Cross later said it would be impossible to know the exact number of deaths. There was no question that the Israeli soldiers knew what was going on inside - it was visible even without their high-powered binoculars, and the sound of machine-gun fire continued throughout the days and nights. Finally, the US pushed Israel to withdraw the Phalangists. US Special Envoy Morris Draper told the Israeli officers: 'You must stop the massacres. They are obscene. I have an officer in the camp counting the bodies....They are killing children. You are in absolute control of the area and therefore responsible for that area"' (p. 53).

It must be noted that Israeli public reaction to news of the massacre was profound. Over 400000 Israelis, about 10 percent of the entire population marched in protest, leading to a high-level commission of inquiry to investigate. One of the many findings was that Defense Minister Sharon was 'indirectly responsible'. U.S. public opinion was also swayed away from support of Israel. Though U.S. officials spoke strongly against the killings, they did not act on their words. The UN General Assembly voted 147 to 2 to condemn the massacres, with only the United States and Israel voting against condemnation (pp. 53-54).
}

Pappe (2004) writes: "The low point of the invasion was the massacre in September 1982, by Christian Phalangists, 
to a more nuanced understanding of the symbolic significance of the $9 / 11$ attacks in large swaths of the Arab world. It is worth highlighting key instances like these in the development of U.S. foreign policy in the Middle East. Among other things, it provides a means of contextualizing the genesis and popularity of Arab conspiracy theories regarding American support for Israel, as well as various others which are only fueled by Arab cooperation with the 'Zionist Infidels'.

But there is another thing that is clearly highlighted in a brief historical summary like this, and that is the lingering centrality of religious tension. Even when restricted to the Judeo/Christian/Islamic triumvirate, as it will be here, there are stunningly consistent undercurrents which inform and mobilize various other political and economic policies, each in relation to the others. Christian support of the Jewish cause has as much to do with Islamic suspicion, as it does with its own selfinterest in securing a Jewish homeland for the second coming of Christ. Since unrepentant Jews who fail to convert to Christianity after the Messiah returns are doomed to be cast into the lake of fire, Christian support of Jews is paradoxically rooted in anti-Semitism. Policy initiatives concurrent with such beliefs, whether or not they are actually motivated by them, mirrored both of these sentiments in the creation of a Jewish homeland in Palestine, to the roiling unrest of Arab populations. As the rest of the thesis will show, there is a collective logic at play here which is itself inextricably tied up with the progression (and limitations) of globalized capital. And yet neither can be understood, solely, on their own terms. They, too, are always reciprocally connected.

\footnotetext{
of the inhabitants of two refugee camps, Sabra and Shatila, in southern Beirut. Hundreds of Palestinians, men, women and children, were slaughtered by a Maronite militia, encouraged and incited by Israeli military officers of the highest rank. The connection with the IDF was clear enough to convince 400,000 Israelis to protest against the massacre, and led to the establishment of a commission of inquiry headed by a former Supreme Court judge. The commission dismissed several senior officers involved and ruled that Sharon, the minister of defense, was unfit to serve in such a high position. He became Israel's prime minister in February 2001"' (p. 223).
} 


\section{Marx and Engels on Islam}

Considering the emphasis given to Marxian themes in the previous chapter, some brief consideration of the subject of Islam in the writing of Marx and Engels is surprisingly timely and topical to the present study. Its inclusion here is intended to help strengthen and consolidate the central focus on religious tensions being developed here. On the subject of Islam, Marxist thinkers have been relatively silent on its origins and historical role. However, both Marx and Engels at different times made some rather interesting observations on Islam which resonate very strongly today. Stepping off of the focus on ideology noted earlier, Marx wrote a letter to Engels on the nature of Asiatic society itself. In it, he posed a central question as to why it is that the history of the East appears to be a history of religions? Equally significant is an article on the history of early Christianity by Engels. He hits upon one of the fundamental features of the history of Islamic social structure; it is the "political oscillation" between its nomadic and the more sedentary cultural aspects. In this, Engels was noting that Islam itself was well adapted to the nomadic Bedouin and the Arab townsmen, but also contained within it the seeds of periodically recurring conflict. "The townspeople grow rich, luxurious and lax in the observation of the 'law'. The Bedouins, poor and hence of strict morals, contemplate with envy and covetousness these riches and pleasures." This led to a situation where the poor nomads periodically united behind a prophet, to sweep away the decadence of the townspeople and restore the moral purity of the faith. Over a few generations, the Bedouin, too, would become lax in religious observance and individualistic in morals. Once again, a Mahdi would rise from the desert and the spiritual cleansing would begin anew. What is striking, however, is that despite the constant transformation of political leadership in this way, the underlying 
economic base remained remarkably consistent. ${ }^{33}$

Engels interpreted the messianic and sectarian movements within Islam as a manifestation of the perennial political conflict between nomads and townspeople. It is possible though, to look at Islam itself as growing out of the contradictions between nomadic pastoralism and sedentary society. As was noted earlier in the work of Armstrong, Islam needs to be understood in its relation to the mercantile culture in the trades centres of the Arab peninsula. It was the religion of the primarily urban elites who were reaping the rewards of the expansion of trade through Mecca. By the seventeenth century, it would come to dominate the Arabian economy. It was Islam, then, which was "the blending of urban piety and tribal virtue, [and] provided a new principle of political integration based on faith rather than blood, organized around loyalty to a prophet and universalistic values. By uniting the fissiparous tribes within a single religious community under urban, commercial leadership, Islam protected trade and proved a peculiarly dynamic political force."34

\section{Osama bin Laden and the Paranoid Style}

Hofstadter takes pains to remind his readers that, as much as he draws on American examples, the paranoid style is an international phenomenon, one which is not limited to modern times. He cites a study by Norman Cohn called The Pursuit of the Millennium. In it, Cohn traces the millennial sects of Europe from the eleventh to the sixteenth century, which Hofstadter felt traced his own work rather closely. It also echoes the current course of study quite well. Cohn writes that

\footnotetext{
${ }^{33}$ Bottomore, op. cit., p. 238.

${ }^{34}$ ibid., p. 238-239.
} 
the megalomaniac view of oneself as the Elect, wholly good, abominably persecuted yet assured of ultimate triumph; the attribution of gigantic and demonic powers to the adversary; the refusal to accept the ineluctable limitations and imperfections of human existence, such as transience, dissention [sic], conflict, fallibility whether intellectual of moral; the obsession with inerrable prophecies ... systematized misrepresentations, always gross and often grotesque ... ruthlessness directed towards an end which by its very nature cannot be realized - towards a total and final solution such as cannot be attained at any actual time or in any concrete situation, but only in the timeless and autistic realm of phantasy ${ }^{35} \cdot{ }^{36}$

Osama bin Laden himself embodies these traits every bit as clearly as does George W. Bush. This is strikingly obvious in bin Laden's only full interview after the 9/11 attacks. It was given to al-Jazeera in October $2001,{ }^{37}$ and provides a remarkable insight into the dialectical forces behind the newly refurbished 'global war on violent extremism'.

At the time of the interview, there was yet to be any clear indication as to who was really behind the attacks. As we shall see in the next chapter, many inside the Bush administration, including the president himself, were looking for connections to Iraq and the nefarious efforts of Saddam Hussein. The interviewer makes reference to allegations by the Americans about bin Laden's involvement which reflects the idea, noted above, that Iraq was somehow a state-sponsor of the attacks. The charge is dismissed out-of-hand by bin Laden as typical of the American propaganda against Muslims everywhere around the world. At the same time, he describes the brave efforts of the individuals "who took the

\footnotetext{
${ }^{35}$ [Footnote from original citation] "The Pursuit of the Millennium (London, 1957), pp. 309-10; see also pp. 58-74. In the Middle Ages millenarianism flourished among the poor, the oppressed, and the hopeless. In AngloAmerican experience, as Shepperson has observed, such movements have never been confined to these classes, but have had a more solid middle-class foundation. 'The Comparative Study of Millenarian Movements', in Sylvia Thrupp (ed.): Millennial Dreams in Action (The Hague, 1962), pp. 49-52.

${ }^{36}$ Cohn, 1957; pp. 309-310, cited in Hofstadter, op. cit., p. 38. 106-129.

${ }^{37}$ Bruce Lawrence (ed.), Messages to the World: The Statements of Osama bin Laden, Verso, 2005, pp.
} 
battle to the heart of America and destroyed its most famous economic and military landmarks." This is an important admission for a number of reasons, not least among them being the expressed desire to do global economic harm to the United States. ${ }^{38}$ But bin Laden puts immediate emphasis on the role of the United States, in its support of Israel and the occupation of Palestine, as being behind their execution. Though he initially takes issue with the use of the term "terrorist" to describe the actions on September $11^{\text {th }}$, he concedes that, "if inciting people to do that is terrorism, and if killing those who kill our sons is terrorism, then let history be witness that we are terrorists."

bin Laden freely admits that he and others have been actively involved with acts of agitation like this for years, and that they had already issued many statements and fatwas to that effect. In a passage that begins to reflect the similarity of his position to the 'classical' paranoid style, he expresses his belief that incitement to terrorist action, especially given the circumstances he describes of the plight of Palestinians, is the will of God. Quoting Mohammed, who he calls "the best of all mankind", bin Laden believes that to incite the faithful in a battle for the sake of God is a noble act. Though he says that it is true they "have incited battle against Americans and Jews", this is not the same thing as al-Qaeda declaring war against the U.S.. In fact, it is a much broader struggle, one which pits Muslims against

\footnotetext{
${ }^{38}$ A videotaped statement released after the Madrid bombings and the Spanish election of 2004 which toppled one of President George W. Bush's allies, bin Laden said "For example, al-Qaeda spent $\$ 500,000$ on the September 11 attacks, while America lost more than $\$ 500$ billion, at the lowest estimate, in the event and its aftermath. That makes a million American dollars for every al-Qaeda dollar, by the Grace of God. This is in addition to the fact that it lost an enormous number of jobs - and as for the federal deficit, it made record losses, estimated at over a trillion dollars. Still more serious for America was the fact that the mujahidin, forced Bush to resort to an emergency budget in order to continue fighting in Afghanistan and Iraq. This shows the success of our plan to bleed America to the point of bankruptcy, with God's will." The quote contains an editor's footnote that "On October 25, 2004, Pentagon and Congressional figures announced that the Bush administration intended to seek around $\$ 70$ billion in emergency funding for the wars in Iraq and Afghanistan, pushing total spending to $\$ 225$ billion since the 2003 invasion of Iraq." ibid., p. 242.
} 
what he calls the "global Crusaders." He cites the successes of the mujahedeen in Afghanistan against the former Soviet Union. He recalls a time when the whole world feared them; and then he rhetorically asks, 'where are they now?' It was because God supported them and kept them steadfast that they were able to win in battle, he said. It is the same support that he believes will lead to the eventual defeat of the United States. "We believe that the defeat of America is possible, with the help of God," bin Laden says, "and is even easier for us, God permitting, than the defeat of the Soviet Union was before."

Asked by the interviewer to support that belief, bin Laden looks no further than Somalia. At that time, he points out, the Americans were every bit as feared as the Soviet Union had been going into Afghanistan. But what Muslims learned from Somalia, bin Laden claims, was that the Americans had no power worthy of mention. The losses they suffered there, still memorialized in Hollywood 's 'Black Hawk Down', showed that the Americans had no stomach for real battle. "There was a huge aura over America -- the United States -- that terrified people even before they entered combat" he said. "Our brothers who were here in Afghanistan tested them, and together with some of the mujahedeen in Somalia, God granted them victory. America exited dragging its tails in failure, defeat, and ruin, caring for nothing. America left faster than anyone expected. It forgot all that tremendous media fanfare about the new world order, that it is the master of that order, and that it does whatever it wants." bin Laden contrasts this with the decade of experience he and his fighters had against the Russians in Afghanistan. At the time the interview was conducted, the coalition forces led by the Americans had been in post-9/11 Afghanistan for only two weeks, and bin Laden suggested that there is absolutely no comparison between the groups fighting the Americans there at that time, and the groups that once fought the Soviets during the 1980 's. 
bin Laden points to what he sees as the real problem at the root of the struggle with the U.S.. "America is against the establishment of any Islamic government. The prophet has said, 'They will be target because of their religion [sic]." The origins of the struggle, he continues, have nothing do to with him specifically. "When I came here the first time it was because of a desire to revive the Muslim spirit and an attempt at rescuing the children and the powerless. The British attacked Afghanistan before Osama bin Laden was here, Russians came here before me and now the Americans." He expressed the hope that their prayers would again be answered. "We ask God to give us the power to defeat them as we did others before."

On the specific events of September the 11th, bin Laden believes they were great on all levels, but that their repercussions were far from over. Although he thinks that the collapse of the twin towers was hugely significant, he feels that the events which have followed are much more important. "I'm not just talking about the economic repercussions, those are continuing, [but] the events that followed are dangerous and more enormous than the collapse of the towers." This is because the values of Western civilization also came under attack that day, he says, and under the leadership of America have also been destroyed. "Those awesome symbolic towers that speak of liberty, human rights, and humanity have been destroyed. They have gone up in smoke." For bin Laden, the proof of this lies in the reluctance of American mainstream media to air their statements, even though they are only a few minutes long. "They felt that the truth started to reach the American people," he said, "the truth that we are not terrorists as they understand it but because we are being attacked in Palestine, Iraq, Lebanon, Sudan, Somalia, Kashmir, the Philippines and everywhere else." In a prescient comment considering some of the steps taken by the U.S. government, in the name of Homeland Security and Patriot Acts since this 
interview was conducted, bin Laden continues that "I tell you freedom and human rights in America are doomed. The U.S. government will lead the American people and the West in general will enter an unbearable hell and a choking life because the Western leadership acts under the Zionist lobby's influence for the purpose of serving Israel, which kills our sons unlawfully in order for them to remain in their leadership positions."

From bin Laden's point of view, real terrorism is embodied in Bush's 'with us or with the terrorists' dichotomy. All the while, and forced to muffle their own criticisms of U.S. foreign policy, many Western and Eastern leaders began calling for the real causes of terrorism to be dealt with, meaning the Palestinian situation. To bin Laden, this makes it clear that his actions and those like them are righteous ones. He claims that other nations simply can't admit this out loud for fear of the Americans. "They say we are terrorists but [then on the other hand say] solve the Palestinian cause. All of a sudden," bin Laden goes on, "Bush and Blair declared, 'The time has come to establish an independent state for Palestine.' Throughout the past years the time hasn't come, until after these attacks, for the establishment of the Palestinian state." According to bin Laden, this proves "[t]hey only understand the language of attacks and killings. Just as they're killing us, we have to kill them so that there will be a balance of terror. This is the first time the balance of terror has been close between the two parties, between Muslims and Americans, in the modern age."

This marks an appropriate point of departure from the text of bin Laden's interview. Though there is much more of interest in it, for now it is enough to depart into a brief consideration of the role of religion 
generally in the rise of some of the more important global tensions at the present time. In keeping with the present approach to the study of conspiracy theories, it is interesting to note the dialectical dependance of Western conspiracy theories about the Middle East [and specifically those which relate to Saddam Hussein and Iraq], as it is to consider the role of Middle Eastern conspiracy theories in the execution of an increasingly globalist U.S. foreign policy in the region after the $9 / 11$ attacks.

\section{The Paranoid Style, the Protestant Ethic, and the Spirit of Capitalism}

R.H. Tawney ${ }^{39}$ writes in the forward to Max Weber's The Protestant Ethic ${ }^{40}$ that Weber was a scholar "whose intellectual range was unusually wide, and whose personality made an even deeper impression than his learning on those privileged to know him." ${ }^{41}$ According to Tawney, in addition to Weber's academic interests and pursuits, which were many, he travelled widely and participated actively in the various social and political movements facing Germany after the war, even attending the Versailles conference in May 1919 with the German delegation. ${ }^{42}$ He notes that The Protestant Ethic and the Spirit of Capitalism was published initially in the form of two articles in the Archiv für

\footnotetext{
${ }^{39}$ Tawney expands on Weber's work in his own book, Religion and the Rise of Capitalism (John Murray Publishing, London; 1964).

${ }^{40}$ Max Weber, The Protestant Ethic and the Spirit of Capitalism, Charles Scrivner's Sons, 1958.

${ }^{41}$ ibid., p. 1[a].

${ }^{42}$ MacMillan notes on the issue of German reparations for WW I: "The German reaction was different partly because they had been nervously anticipating the accusation for months. Liberals, who had criticized their own government during the war, had been arguing that Germany should not have to carry the burden of guilt. The great sociologist Max Weber and a group of leading professors issued a public manifesto: 'We do not deny the responsibility of those in power before and during the war, but we believe that all the great powers of Europe who were at war are guilty.' By the time the peace terms appeared, Germans of all political persuasions saw their worst fears being realized" (p. 466). It is interesting to ponder the effects of these economic burdens on the experiences of a young Hitler, especially in light of the influence that the Protocols were known to have had on his thinking about Jewish influence in world affairs.
} 
Sozialwissenschaft und Sozialpolitik in 1904 and 1905. On their first appearance, they aroused an interest which quickly extended beyond historians, and sold out in a manner which was unusual for scholarly publications at the time. It was an interest that continued into Tawney's own time (1958) and was the result of Weber's "new avenue of approach to a range of problems of permanent interest, which concern, not merely the historian or the economist, but all who reflect on the deeper issues of modern society." 43

Weber's central question is one which also reflects the popularity and widespread interest in psychology at the time. He was interested in trying to understand the psychological conditions which gave rise to capitalist civilization. And while a volley of criticism could be launched at this immediately, the point here is simply to help frame the current study in terms of the paranoid style as a global phenomenon, its competing religious contingencies, and the claims that both make on capital interests as a validation in one sense, and the repudiation of an 'Other'. Tawney points out that capitalism, in the sense of vast financial resources yielding riches to their masters as a result of lending, speculation, commercial ventures, and war, is as old as history. Capitalism, as a social and economic system on the other hand, is a modern phenomenon. He writes that like any successful revolution, it now appears as natural and inevitable, but was actually the result of a centuries-long struggle. It required the establishment of a new code of economic conduct and human relations which stood at odds with the venerable traditions such as the Church, not to mention the laws of most European states. In the face of challenges like these, he wonders rhetorically about the tenacity of purpose and originality required of those who effected that

\footnotetext{
${ }^{43}$ ibid., p. $1[\mathrm{~b}]$.
} 
transformation, and likens it to the task at hand for those who would today try and break from the net it has woven. "What nerved them to defy tradition", he asks. "From what source did they derive the principles to replace it?"

The standard answers to questions like these, Tawney claims, is to deny their premises. New forms of economic enterprise were the result, the argument runs, of shifts in the character of the economic environment. Whether the influx of precious metals from the Americas in the sixteenth century, the accumulation of capital from extra-European trade, the expansion of markets organized by industrial principles, population growth, technological innovation, or progress in the natural sciences, all of these are aspects to be sure. But for Weber, it is an exercise in confusing causes with occasions. Tawney writes that it can be taken for granted that "the economic conditions of the sixteenth and seventeenth centuries were, in some respects, though by no means all, unusually favourable to an advance in economic technique, such conditions had existed from time to time in the past without giving birth to the development of capitalist industry. Nor can it be explained in terms of some identifiable difference in "acquisitive instincts", a position that Weber felt was childish. Writing in what became his posthumous General Economic History, Weber felt that "the moving spirits of modern capitalism are not possessed of a stronger economic impulse than, for example, an Oriental trader." ${ }^{44}$ In his introduction to The Protestant Ethic, he puts the same idea even more clearly. In short, the pursuit of money for money's sake has in itself nothing to do with capitalism. "This impulse exists and has existed among waiters, physicians, coachmen, artists, prostitutes, dishonest officials, soldiers, nobles, crusaders,

${ }^{44}$ Max Weber, General Economic History, pp. 355-356; cited in Weber, ibid., p. 1 [e]. 
gamblers, and beggars. One may say that it has been common to all sorts and conditions of men at all times and in all countries of the earth, wherever the objective possibility of it is or has been given." Weber goes on to say that it should be taught in the "kindergarten of cultural history" that this naïve notion of capitalism is to be dispensed with once and for all. Unadulterated greed for gain is by no means identical with capitalism, and certainly less so its spirit. In fact, Weber continues, capitalism "may even be identical with the restraint, or at least a rational tempering, of this irrational impulse." 45 Without question, though, he recognizes that the pursuit of profit is identical with capitalism, and more importantly, a forever renewable profit by means of a rational capitalistic enterprise. In fact, as Weber himself states, "it must be so: in a wholly capitalistic order of society, an individual capitalistic enterprise which did not take advantage of its opportunities for profit-making would be doomed to extinction."

It is his use of the term "rationalism' that begins to get at the core of Weber's interest in the Protestant Ethic. Tawney describes it as a term Weber uses to describe an economic system not based on custom or tradition, but rather on the deliberate and systematic employment of economic means to the production of pecuniary profit. However, Weber is careful to point out that very different things can be understood by the term 'rationalism'. "There is, for example, rationalization of a mystical contemplation," he writes, "that is of an attitude which, viewed from other departments of life, is specifically irrational, just as much as there are rationalizations of economic life, of technique, of

\footnotetext{
${ }^{45}$ This is an important distinction which will be developed more fully in the conclusions. It lies at the heart of the working title.

${ }^{46}$ ibid., p. 17.
} 
scientific research, of military training, of law and administration." ${ }^{47}$ Even still, each of these divisions can yet be further discriminated and rationalized in terms of different values and ends, each of which may view another as irrational from its own point of view. It is a process which has wide and varied history, and which occurs in all areas of culture. In Weber's view, the "magical and religious forces, and the ethical ideas of duty based upon them, have in the past always been among the most important formative influences on conduct." 48

The question then becomes, how did this economic, rational sensibility replace and triumph over the conventional attitude which regarded a lust for unlimited gain as immoral and anti-social? Weber's answer was that it resulted from the changes wrought by the religious revolution of the sixteenth century. After having to fight tooth and nail against the established aristocracy in land and commerce in the form of the Church, it worked to help create a new conception of religion which saw the pursuit of wealth not only as an advantage, but a moral duty. It emboldened and solidified the bourgeoisie. ${ }^{49}$ What is significant then, is not the desire for favourable economic circumstances, which is commonplace and requires no explanation, but "the change in moral standards which converted a natural frailty into an

\footnotetext{
${ }^{47}$ It is worth noting the juxtaposition Weber makes here between mystical forms of rationalization and the rationalization of economic life.

${ }^{48}$ ibid., pp. 26-27.

${ }^{49}$ Interestingly, this is the same division of interests shown in the discussion of the World Upside Down (WUD) broadsheet in chapter two. David Kunzle's study of about sixty broadsheets from seven countries spanning three centuries showed that, though WUD motifs were familiar in ancient and medieval times, it was in the modern era when WUD was first systematized and made available to mass audiences. He showed that certain genres of broadsheet, such as the proverb illustration, helped serve the interests of a "newly entrenched bourgeoisie" by upholding and reinforcing the immutability of the social structure. The WUD broadsheet on the other hand, had an appeal "to discontented, lower-class elements who sought or fantasized about the subversion of the existing order" (Kunzle, in Babcock (ed.), 1978; p. 40).
} 
ornament of the spirit, and canonized as the economic virtues habits which in earlier ages had been denounced as vices. The force which produced it was the creed associated with the name of Calvin. Capitalism was the social counterpart of Calvinist theology."

Weber pins this development on the changes in and differences between the notion of a "calling". Tawney points out that most medieval theologians, Luther included, conformed to a definition which saw one's 'calling' as an immutable state of life for an individual, set by heaven, which was wrong to rebel against. For the Calvinist, a 'calling' was something different entirely. It was not a condition into which one was born, but was instead, an exacting course to be chosen for oneself, and which was to be pursued with a religious zeal. Business, once considered a peril to the soul, was instead a new form of sanctification. "Covetousness," as Tawney puts it, "if a danger to the soul, is a less formidable menace than sloth." Furthermore, the virtues of a pious lifestyle, sobriety, diligence, thrift, and prudence, were also very conducive to making money. And so the idea that the pursuit of riches was the enemy of religion, that money was the root of all evil, was reconfigured as a match made in heaven.

There are, of course, many limits and criticisms that can be made of Weber's position, and Tawney outlines a few of them. He shows that in demonstrating the connection between religious radicalism and economic progress, Weber identified and called attention to something that other writers had hinted at, but none had examined in such detail. But the significance to be ascribed to it, as well as the relation of Calvinist influence on other factors in economic development, is a more difficult set of questions.

\footnotetext{
${ }^{50}$ Weber, op. cit., p. 2.
} 
Weber's essay on the protestant ethic was intended to focus on the part played by religious movements in the creation of favourable conditions for economic growth. Tawney acknowledges, however, that Weber was careful not to underestimate the importance of many parallel developments in the realms of commerce, industry, and finance. Rather than Calvinism producing the spirit of capitalism, Tawney suggests that it is equally plausible that the two reinforced each other as different aspects of larger changes in the social structure and economic organization.

"It is the temptation of one who expounds a new and fruitful idea," Tawney opines, "to use it as a key to unlock all doors, and to explain by reference to a single principle phenomena which are, in reality, the result of several converging causes." Weber's essay is open to this sort of critique, and Tawney suggests that some of what is hitched to the wagon of intellectual and moral influence is more readily explained by more mundane and prosaic forces, which operated quite apart from any one religious creed, but which flourished just the same where the circumstances were conducive. Even the very notion of "capitalism" itself is ambiguous, as much as it is also indispensable, and Weber's definitions of it, at times, seem crafted to best suit his argument. There was certainly no lack of a 'capitalist spirit' after all, in fourteenth century Venice and Florence as seen already in reference to the thriving print-selling trade in the second chapter. The development of capitalism in England and Holland, it could be argued, might have had less to do with the fact that either they, or some social group within them, accepted Calvinism, than it did the large-scale social changes which resulted from equally large economic movements. ${ }^{51}$ In keeping with one of the WUD images with a direct correlate in the world of proverb, Weber, too, may be putting the

\footnotetext{
${ }^{51}$ ibid., p. 7.
} 
cart before the horse. In any case, it is precisely this aspect to the debate which returns us to some familiar terrain. As Tawney concludes, in taking as his theme,

not the conduct of Puritan capitalists, but the doctrines of Puritan divines, he pursues a single line of inquiry with masterly ingenuity. His conclusions are illuminating; but they are susceptible, it may perhaps be held, of more than one interpretation. There was action and reaction, and, while Puritanism helped to mould the social order, it was, in its turn, moulded by it. It is instructive to trace, with Weber, the influence of religious ideas on economic development. It is not less important to grasp the effect of the economic arrangements accepted by an age on the opinion which it holds of the province of religion. ${ }^{52}$

It is difficult to miss the emerging 'fit' between the protestant ethic described by Weber and Tawney, the paranoid style described by Hofstadter, and what might be loosely referred to as the 'spirit of capitalism'. While being necessarily mindful of the pitfalls of reductionism, and there are many of those, it is still useful to consider the present state of affairs and the task at hand in terms of this 'perspective on the historical'. Without committing the very same overemphasis on the mitigating influence of Protestantism in the spread and development of global capital, leaving it out of the equation is no option either. Simply put, it must be addressed, if for no other reason than that George W. Bush, the shepherd of the Iraqi invasion, has publically declared himself to be imbued with the divine mission to spread freedom and democracy around the world. He himself, not to mention his wealthy Republican and piously Christian 'base', are emblematic of the very forces described by Weber, Tawney, and Hofstadter [and in no small degree either]. It has been obvious for quite some time, that the $43^{\text {rd }}$ President of the United States appeals to the very people who today represent the religious and political mind-set very familiar to the same authors in their own times.

\footnotetext{
${ }^{52}$ ibid., pp. 10-11.
} 


\section{Onward Christian Soldiers}

The apparent influence of religion in the second Bush administration is staggering to say the least. "One of the biggest changes in politics in my lifetime," writes Bill Moyers, ${ }^{53}$ "is that the delusional is no longer marginal. It has come from the fringe, to sit in the seat of power in the Oval Office and in Congress. For the first time in our history, ideology and theology hold a monopoly of power in Washington." Moyers then proceeds to outline some of the reasons for taking such a strong position. He recalls a reference in what he describes as his favourite on-line environmental journal, Grist, to James Watt, President Reagan's first secretary of the interior. In a statement to Congress, it appears Watt had been privy to some pretty earth-shattering information; in light of the immanent return of Jesus Christ, protecting natural resources was unnecessary. In public testimony, he declared that "after the last tree is felled, Christ will come back." Moyers records that the Beltway elites snickered, and the press corps didn't know what he was talking about, but nonetheless, Watt was serious. Like the millions of others like him, those who believe the Bible is literally true, their saviour will return when world conditions are right.

But sentiments like this are hardly an aberration. ${ }^{54}$ Moyers cites the results of a Gallup poll in which fully one-third of the American electorate fall into this category. In the 2004 election, that same

${ }^{53}$ Bill Moyers; 'There is No Tomorrow', Minneapolis StarTribune, January 30, 2005. Accessed on January 30, 2005.

54 As a current example of this same belief-set, current Secretary of State, Condoleezza Rice, had this to say while attending church services at Pilgrim Rest AME Zion church in her native Alabama, during the aftermath of the destruction of New Orleans and surrounding areas by Hurricane Katrina: "The Lord is going to come on time - if we just wait” (Lara Jakes Jordan, 'Rice Defends Bush's Katrina Response', San Francisco Gate; September 4, 2005. Accessed on September 4, 2005). The article goes on to point out that Rice, herself, is the daughter of a Presbyterian minister. 
percentage went to the polls believing in the 'rapture index' - a measure of the state of world affairs that provides an indication as to how close we are to the end-times. Popularized by the twelve-volume "Left Behind" series by Christian fundamentalist Timothy LaHaye, the 'Rapture' refers to the bodily ascent into heaven by good and faithful Christians, and is said to spare them the suffering endured at the end of the world by those who are 'Left Behind'. The outline of events is simple. Once Israel has returned to its biblical lands, the antichrist will attack, and trigger the final showdown between good and evil. The recently raptured Christians, now seated at the right hand of God, witness the comeuppance of their political and religious foes as they endure the tribulation - plagues of boils, sores, and of course, the requisite locusts and frogs.

Moyers protests that he is not making any of this up, and indeed, anyone at all familiar with the netherworld of biblical prophecy knows this already. In fact, Moyers himself has reported on people like this, following them from Texas to the West Bank. He reports that they are "sincere, serious and polite as they tell you they feel called to help bring the rapture on as fulfilment of biblical prophecy. That's why they have declared solidarity with Israel and the Jewish settlements and backed up their support with money and volunteers." As one might imagine, the recent war in Iraq is no cause for alarm. On the contrary, it is a warm-up to the final showdown predicted in the Book of Revelation. Four angels "bound in the great river Euphrates ${ }^{55}$ will be released" to slaughter a third of mankind. A Middle Eastern war with Islam is nothing to fear. It has to happen in order for the prophecy to come true.

\footnotetext{
${ }^{55}$ A geographical note: The Euphrates River does indeed flow right through modern-day Iraq.
} 
Moyers states that there are obvious implications for environmental policy with this sort of thinking. He cites another article in Grist by journalist Glenn Scherer, called "The Road to Environmental Apocalypse." It shows that, not only do millions of Christian fundamentalists believe that fears about environmental destruction are unfounded, but that environmental destruction should be sped up. And their numbers are not trifling. Nearly half of the U.S. Congress, 231 legislators before the 2004 election, and even more since, are beholden to these beliefs by virtue of being backed by the religious right. Forty-five senators and 186 members of the $108^{\text {th }}$ Congress received approval ratings in the $80-100$ percent category from the three leading and influential Christian advocacy groups. These include Senate majority leader Bill Frist, and Assistant Mitch McConnell, House Speaker Dennis Hastert, Conference Chair Rick Santorum of Pennsylvania, and Majority Whip Roy Blunt. Moyers notes that only one Democrat received a 100 percent score. It was Senator Zell Miller of Georgia, who quoted from the biblical book of Amos on the Senate floor saying: "The days will come, sayeth the Lord, that I will send a famine in the land."

It seems that Moyers is correct in his feeling that there is a constituency for this sort of thing. A TimeCNN poll in 2002 found that 59 percent of Americans believed that the prophecies in the Book of Revelation are going to come true. Almost 25 percent believe the Bible predicted the $9 / 11$ attacks. It is a message which can be heard across the more than 1600 Christian radio stations and 250 Christian television stations in the United States. Citing the Grist piece, Moyers asks rhetorically, "Why care about global climate change when you and yours will be rescued in the rapture? And why care about converting from oil to solar when the same God who performed the miracle of the loaves and fishes can whip up a few billion barrels of light crude with a word?" 
At the core of these beliefs is the overarching one that God will provide. Moyers draws attention to a high school history text named "America's Providential History" which claims that the "secular or socialist has a limited-resource mentality and views the world as a pie ... that needs to be cut up so everyone can get a piece." However, he continues, "[t]he Christian knows that the potential in God is unlimited and that there is no shortage of resources in God's earth ... while many secularists view the world as overpopulated, Christians know that God has made the earth sufficiently large with plenty of resources to accommodate all of the people." He then expresses no surprise that Karl Rove, who reportedly moves about the White House whistling “Onward Christian Soldiers”, was able to turn out millions of them on November 2, 2004, and for whom the apocalypse is a driving political force in modern American politics.

Though there is no need to digress into any lengthy analyses of the Bush administration's environmental policies, the writing is on the very same wall one ends up speaking to when matters like this are addressed to evangelicals. Moyers closes with a handy summary. The administration wants to re-write the Clean Air and Clean Water Acts, as well as the Endangered Species Act protecting rare plant and animal species. It wants to relax pollution limits for ozone, eliminate vehicle emission inspections and ease pollution standards for cars, SUV's, trucks and heavy equipment. It wants new international audit laws that would allow corporations the chance to keep certain information about environmental problems secret, and wants to drop all its new-source review suits against coal-fired energy plants, and open the Arctic National Wildlife Refuge to oil drilling. 
Though there is nothing new to 'end-of-times' evangelical thinking in the United States, as Hofstadter and others have amply shown, there is something to be said for its presence in the administration of George W. Bush. Maureen Farrell has reported on a number of aspects of the extreme religious right, not only in America, but in the Bush administration specifically. The connections she outlines between well-known political figures, such as former Attorney General John Ashcroft and Senate Majority Leader Tom DeLay for example, and key figures in the ultra-conservative Christian movement, are striking to say the least.

To start, Farrell quotes Rev. Bob Edgar, the general secretary of the National Council of Churches. The Council represents the United States' Lutherans, Episcopalians, Methodists, Presbyterians, and 32 other denominations. Though the Council has traditionally enjoyed access to the US president, going all the way back to George Washington, George W. Bush became the exception, favouring instead the evangelicals who have since enjoyed unparalleled access. "Bush has shown an ideological commitment to the literalist Christian tradition at the expense of the broader view of the larger Christian community," Edgar said. "He is the first president not to meet with the leadership of mainline Christian traditions since George Washington. We've been able to talk with the prime minister of Britain and the chancellor of Germany, but not our own president." 56 Commenting on the same snub in the Washington Post, another pastor, Reverend Fritz Ritsch wrote, "The president apparently believes that he can talk about theology from the bully pulpit without talking to theologians. Which begs the question: When did the

\footnotetext{
${ }^{56}$ Mary Jacoby, 'The Gospel According to Karl', Salon Magazine; July 6, 2004. Accessed on August 24, 2004.
} 
president become theologian in chief?"57

It was no less a figure than the Reverend Billy Graham who told viewers of ' $T$ he $700 \mathrm{Club}$ ' in 1985 that he was all "for evangelicals running for public office and winning if possible and getting control of the Congress, getting control of the bureaucracy, getting control of the executive branch of government." 58 In any case, Graham's comments no doubt now appear prophetic in their own right to his followers. There is little question that the evangelical movement considers the $43^{\text {rd }}$ president to be one of their own. $\mathrm{ABC}$ news, too, has openly speculated for years that Christian conservatives were responsible for Bush's nomination to the presidency, and the Guardian has reported that American fundamentalists are "at the heart of power." 59

Farrell notes that all of this would not be of any real concern if, as she puts it, "evangelicals were happy to live and let live." It hardly needs to be pointed out that this is clearly not the case, and Farrell provides a long list of individuals and organizations with either direct ties to the Bush administration, or who are staunch supporters. One is Howard Ahmanson, who is a millionaire and chief financier of the Christian

${ }^{57}$ Fritz Ritsch, 'Of God, and Man, in the Oval Office', The Washington Post, March 2, 2003 [B03]. Accessed online August 24, 2004.

${ }^{58}$ Katherine Yurica, 'The Despoiling of America: How George W. Bush Became the Head of the New American Dominionist Church/State', The Yurica Report; February 11, 2004. Accessed on August 24, 2004.

${ }^{59}$ George Monbiot, 'Their Beliefs are Bonkers, But They Are at the Heart of Power: US Christian Fundamentalists are Driving Bush's Middle East Policy', The Guardian; April 20, 2004. Accessed on August 24, 2004. 
Reconstructionist movement with ties to the voting machine company ES\&S. ${ }^{60}$ It is a movement which wants to impose biblical law, and create the 'Kingdom of God' on earth. He has publically declared that he is on "a mission from God to stop gay marriage, fight evolution, defeat 'liberal' churches - and reelect George W. Bush." ${ }^{\text {"1 }}$ They advocate tossing out the U.S. Constitution, overturning the authority of the Supreme Court, and turning the United States into a theocracy which would make homosexuality and other sins punishable by death ${ }^{62}$. Ahmanson is also affiliated with the Council for National Policy, which is innocent sounding enough, except for the fact that Rev. Timothy LaHaye of "Left Behind" fame is one of the co-founders. LaHaye, in turn, was one of the Reconstructionist movement's original framers. LaHaye is also known to believe that the Bible is the literal word of God, and that Armageddon will be unleashed from "the Antichrist's headquarters in Babylon" (i.e. Iraq). Newsweek points out that "Bush and LaHaye have a history, and share a sense of mission,"63 while Rolling Stone has suggested that LaHaye "played a quiet but pivotal role in putting George W. Bush in the White House." has counted John Ashcroft, Ralph Reed, Pat Robertson, and Jerry Falwell as part of its long list of influential members. It was also the organization at the centre of an ABC investigation in 1999

\footnotetext{
${ }^{60}$ Bob Fitrakis, 'Diebold. Electronic Voting, and the Vast Right-Wing Conspiracy', Common Dreams; September 3, 2005. Accessed on September 4, 2005.

${ }^{61}$ Max Blumenthal, 'The Avenging Angel of the Religious Right', Salon; January 6, 2004. Accessed on August 24, 2004.

${ }^{62}$ Another individual espousing such views is Gary North, a former Council for National Policy member. North has noted that Article Six of the U.S. Constitution provides a legal barrier to Christian theocracy. However, he hopes that upcoming social upheaval will allow such protections to fall away, so that Dominionists might "build a harsh biblical order where sinners, such as adulterers and gay men, can be severely punished, even executed, preferably by stoning" (Declan McCullagh, 'There's Something About Gary', Wired; January 7, 1999. Accessed on August 24, 2004). 2004.

${ }^{63}$ Howard Fineman, 'Religion: Apocalyptic Politics', Newsweek; May 24, 2004. Accessed on August 24,

${ }^{64}$ Robert Dreyfuss, 'Reverend Doomsday: According to Tim LaHaye, The Apocalypse is Now'; Rolling Stone, January 28, 2004. Accessed on August 24, 2004.
} 
following Bush's "king-making" speech to them while campaigning for president. ${ }^{65}$ The Apostolic Congress, who call themselves 'The Christian Voice in the Nation's Capital', believes that all of Old Testament Israel must belong to Jews in advance of Christ's return. What makes the group noteworthy here, is that they recently met with Bush White House officials to ensure that U.S. policy towards Israel conforms to biblical prophecy. ${ }^{66}$

Many news sources have reported on the question of the extent to which biblical prophecy may be an influence in the foreign policy of the Bush administration. For example, Matthew Engel wrote a piece in the Guardian on another of these groups, the Christian Zionists, which highlighted the involvement of Bush and Tom DeLay in the movement. ${ }^{67}$ Not surprisingly, their campaign to oust the Palestinians to make way for the Second Coming of Christ is marked by the doctrine of 'dispensationalism' which is popularized in the LaHaye and Jenkins' 'Left Behind' novels. It involves the rapture, the Second Coming, and the conversion of the Jews. "In other words," Engel explains, "these Christians are supporting the Jews in order to abolish them."

\footnotetext{
${ }^{65}$ Another organization, the 'Committee to Restore American Values' was the recipient of a barely noted visit by George W. Bush during the 2000 Election campaign. Bush met with about two dozen fundamentalist leaders, and the committee was chaired by Rev. Tim LaHaye (Robert Dreyfuss, 'Reverend Doomsday: According to Tim LaHaye, The Apocalypse is Now'; January 28, 2004). Accessed on August 24, 2004. LaHaye's wife Beverly runs her own group, called Concerned Women for America. She recently demonstrated her own degree of mediasavvy with her group by speaking out against Ron Reagan Jr.'s push for stem-cell research by insinuating via a nonmedical doctor that Reagan's real agenda was to push human cloning (Stacey Holliday, 'Ron Reagan Disguised ProCloning Message Behind Research Label, Says Dr, Janice Crouse', Concerned Women For America; July 28, 2004. Accessed on August 24, 2004.
}

${ }^{66}$ Rick Perlstein, 'The Jesus Landing Pad: Bush White House Checked with Rapture Christians Before Latest Israel Move', The Village Voice; May 18, 2004. Accessed on August 24, 2004.

${ }^{67}$ Matthew Engle, 'Meet the New Zionists', The Guardian; October 28, 2002. Accessed on August 24, 2004. 
Tom DeLay found the Lord after watching a video by Dr. James Dobson ${ }^{68}$ in 1985 , while working as an exterminator. In 1998, he would champion Dobson's cause through the formation of the Values Action Team. DeLay would later nominate Rep. Joseph Pitts to head the team as it funnels the religious right's agenda to Capital Hill. Pitts is a member of an informal group called 'The Family' which holds prayer groups at both the Pentagon and Department of Defence. According to Harper's, its members include mostly public officials with strong ties to the oil and aerospace industries, including a dozen Senators and Congressmen who prefer theocracy and consider "democracy a manifestation of ungodly pride." 69 In 2002, according to the Washington Post, DeLay told a group of evangelical Christians that "God was using him to promote 'a biblical worldview' in American politics." ${ }^{\text {70 }}$ More recently, he has stated that one of his policy goals will be "to reestablish what he sees as the rightful role of religion in public places..."71 Gary Bauer is also a former executive member of Council for National Policy, and the current president of American Values. He was one of the signatories for the mission statement of the Project for the New American Century along with Dick Cheney, Jeb Bush, Donald Rumsfeld, and Paul Wolfowitz. He also signed an open letter to George W. Bush dated September 20, 2001 urging him to attack Iraq, and if necessary, Syria and Iran as well. ${ }^{72}$

\footnotetext{
${ }^{68}$ Dobson is the founder of 'Focus on the Family' and its sister organization, the Family Research Council. Dobson has been very critical of Republicans in the past, stating that they were not adequately promoting the Religious Right's agenda. This was taken to heart by DeLay and others, who then formed the 'Values Action Team' after attending the 1998 Values Summit. Conservative Christians subsequently increased their clout in Congress.

${ }^{69}$ Jeffrey Sharlet, 'Jesus Plus Nothing', Harper's Magazine; March 2003. Accessed on August 24, 2004.

${ }^{70}$ Alan Cooperman, 'DeLay Criticized for "Only Christian" Remarks', The Washington Post, April 20, 2002 [A05]. Accessed on August 24, 2004.

${ }^{71}$ Ralph Z. Hallow, 'DeLay to Offer Own Hill Agenda', The Washington Times; March 8, 2004. Accessed on August 24, 2004.

${ }^{72}$ Signatories Listed in Text, 'Open Letter to George W. Bush', Project for the New American Century Website; September 20, 2001. Accessed on August 24, 2004.
} 
The evangelical Christian influence in American governmental affairs also extends safely into the United States Judiciary. Figures such as Clarence Thomas, Antonin Scalia, and State Judge Roy Moore (betterknown as the 'Ten Commandments Judge'), have each made their own interesting contributions to the fundamentalist Christian power base in Washington. ${ }^{73}$ Moore was behind the Constitution Restoration Act of 2004 which states that the Supreme Court should have no jurisdiction over "any matter" where public officials acknowledge "God as the sovereign source of law, liberty, or government." However, as the Christian Science Monitor's Frederick Clarkson points out, although Moore's movement "has gained some political traction, its core premise has a fundamental flaw: It aims to 'restore' a Christian constitution that never existed." ${ }^{74}$ Supreme Court Justice Antonin Scalia, who wrote the decision granting George W. Bush the presidency after the recount-delayed 2000 election, bemoans "the tendency of democracy to obscure divine authority behind government." It is a form of government which according to Biblical interpretation "derives its moral authority from God" and is the "minister of God" with the power to exact "revenge" and "execute wrath." 75 The Guardian reported that after John Ashcroft was named Attorney General of the United States, Supreme Court Justice Clarence Thomas

\footnotetext{
${ }^{73}$ On September $3^{\text {rd }}, 2005$, Chief Justice William Rehnquist of the U.S. Supreme Court passed away. Both Justices Thomas and Scalia have long been touted as possible replacements, though President Bush named John Roberts as his nomination for Chief Justice on September $5^{\text {th }}, 2005$. It marks the first time since the Nixon administration in 1971 that there have been two open seats on the United States Supreme Court at the same time, the other being the one to be vacated by Justice Sandra Day O'Connor. Ironically, one of the Justices named at that time, was Rehnquist. Roberts had originally been nominated to replace O'Connor, but after the death of Renhquist and the destruction of the city of New Orleans by Hurricane Katrina, Bush upgraded the Roberts nomination to Chief Justice. O'Connor had agreed to stay on until her replacement was confirmed.
}

${ }^{74}$ Frederick Clarkson, 'On Ten Commandments Bill, Religious Right has it Wrong', The Christian Science Monitor, April 21, 2004. Accessed on August 24, 2004.

${ }^{75}$ Antonin Scalia, 'God's Justice and Ours', First Things Journal of Religion, Culture, and Public Life, May, 2002. Accessed on August 24, 2004. 
anointed him with cooking oil in the manner of King David. ${ }^{76}$

Considering such strongly held convictions, it should come as no surprise that the U.S. Constitution itself has been the target of various conspiracy theories since the time of its ratification in $1787-1788 .{ }^{77}$ At the time, it was viewed as a deliberate attempt to roll back the gains achieved, and liberty won, in the American Revolution. Modern versions, on the other hand, tend to reflect the fear of a plot to create and enforce an illegal, centrist interpretation of the Constitution. When it was drafted in Philadelphia in 1787, and then ratified by conventions in several states, it replaced the Articles of Confederation which had mandated a very limited form of federal government, and left most power in state hands. A number of nationalist politicians at the time were very vocal in their support of a much stronger federal government, and managed to persuade Congress to call for a Federal Convention to revise the Articles of Confederation. This sparked fears of a nationalist plot, which prompted some revolutionary leaders, such as Samuel Adams, to protest against the Federal Convention by declining to serve as delegates. Another was Patrick Henry, who refused to participate because he "smelt a rat". As it turned out, their fears were not entirely unfounded, as the Convention did not just revise the Articles of Confederation, but instead, produced an entirely new Constitution.

The 'Anti-Federalists', as they came to be known, argued that centralized power was inherently corrupt, and that the Constitution would eliminate individual liberty along with the states' autonomy. In the

\footnotetext{
${ }^{76}$ Julian Borger, 'Staff Cry Poetic Injustice as Singing Ashcroft Introduces Patriot Games', The Guardian, March 4, 2002. Accessed on August 24, 2004.

${ }^{77}$ Knight [ed.] 2003; pp. 196-197.
} 
worst case scenario, they feared it would produce the very kind of despotic government they had fought the British to prevent. Radical Anti-Federalists went as far as interpreting the Constitution as part of a conspiracy by the Society of the Cincinnati [sic.], which was an organization of veteran Revolutionary war officers. They were said to want to introduce a hereditary aristocracy, or even monarchy, to the United States. These and other more moderate charges did register an effect, however, over the ratification process. In several states, the Constitution was ratified by the smallest of margins, and even then, only after urging various changes that would later become the Bill of Rights in 1791.

In the 200-plus years since it was passed, the Constitution has grown to become one of the most venerated symbols in the United States. However, this has not meant that it has been free from conspiratorial suspicion. While it is next to impossible to reject the Constitution of the United States today, and still claim to be a patriotic American, contemporary conspiracy theories claim that it has been intentionally misinterpreted or subverted. As Knight [ed.] puts it, “[s]uch conspiracy theories of constitutional subversion are most typically endorsed by right-wing religious or libertarian groups and individuals, who feel that the federal government in the course of the twentieth century became the tool of secularism, social collectivism, feminism, multiculturalism, and racial equality.",78

All of this may raise the question "what has any of this got to do with the paranoid style in Middle East politics?' Before getting to that one-word answer, it is first necessary to situate the sort of evangelical Christian rhetoric evinced by those within or connected to the Bush administration, and the various fears

\footnotetext{
${ }^{78}$ Knight, op. cit., p. 196.
} 
of Constitutional abuse (alá Roe v. Wade), against a much broader history of the conspiracy theories which often accompany an apocalyptic worldview. ${ }^{79}$ The point is to demonstrate that the current Bush administration may represent a unique case. However, if Moyers is correct on this point, it must be acknowledged that not only is it continuous with American political history, as has already been demonstrated through Hofstadter, but it also runs parallel to versions of the very same thing in both Judaism and Islam, as well as many other religions, ancient or otherwise. ${ }^{80}$ The very terms 'apocalypse', 'revelation', and 'prophecy' share common root words, all of which refer to the uncovering of hidden truths, which is also the predicating impulse of conspiracy theory. Damian Thompson ${ }^{81}$ notes that Hofstadter was aware of the striking similarities between apocalyptic belief and the paranoid style, but that he stopped short of drawing a more direct connection between them. He did not consider the possibility that conspiracy thinking may actually be derived from apocalyptic belief systems. In Western society, apocalypticism is, of course, rooted in the Book of Revelation, the last book in the New Testament in the Bible. It contains a prophecy about the execution of God's wrath over the rising tides of greed, sloth, lust, and sin. The Four Horsemen of the Apocalypse are dispatched the world over to spread war, disease, civil strife, and natural disasters. Satan, the prophecy runs, seizes this time of chaos to send in the Antichrist, who to the rest of the world appears as a populist world leader. He promises

${ }^{79}$ excerpted from Knight, ibid., pp. 85-91.

${ }^{80}$ The work of Norman Cohn is extremely valuable in this regard. His contribution is worth much more than a simple footnote could possibly do justice to. His breadth of historical focus and meticulous attention to detail places him outside the parameters of my brief look apocalyptic belief systems, but for those interested in reading more about the topic, Cohn is an acknowledged authority. The three titles I have looked and can highly recommend are; The Pursuit of the Millennium: Revolutionary Millenarians and Mystical Anarchists of the Middle Ages (Temple Smith, London; 1957), Warrant for Genocide: The Myth of the Jewish World Conspiracy and the Protocols of the Elders of Zion (Eyre \& Spottiswoode, London; 1967), and Cosmos, Chaos, and the World to Come: The Ancient Roots of Apocalyptic Faith (Yale University Press, New Haven; 1993).

${ }^{81}$ in Knight, op. cit., p. 85. 
peace through the building of one world government while his underling, the False Prophet, urges all religions to unite. A rumour develops that the Antichrist is actually the Second Coming of Christ, and some Christians are fooled.

The real aim underpinning all of this, however, is actually the destruction of Christianity. Once the conspiracy to deceive the world is in place, Satan sends his minions to find the true Christians. When caught, they are offered the mark of the beast to save themselves by renouncing their faith; holdouts are tortured and killed. Eventually, God intervenes, and the final battle between good and evil occurs on the plains of Armageddon in the Middle East. Good triumphs over evil, and the world is set for a millennium of Christian rule. ${ }^{82}$ This is not to suggest that all Christians see the Book of Revelation as anything more than metaphorical, but some clearly do not only take it literally, but attempt to act in such a way as to bring these prophetic events about.

Most Christian fundamentalists believe that the Second Coming of Christ begins a one thousand year

\footnotetext{
${ }^{82}$ One extended aside from Cohn is useful on this point. It bears noting how similar this tale is to various 'world-battle myths' passed down through thousands of years of prehistory. Cohn (1993) writes: "Until around 1500 BC peoples as diverse as Egyptians, Sumerians, Babylonians, Indo-Iranians and their Indian and Iranian descendants, Canaanites, pre-exilic Israelites were all agreed that in the beginning the world had been organized, set in order, by a god or several gods, and that in essentials it was immutable. For each people, security - meaning fertility of the land, victory in war, stable social relations sanctioned by custom and law - was the outward and visible sign that a divinely ordained order did indeed exist.
}

However, that order was never untroubled, it was always threatened by evil, destructive forces - sometimes identified as flood or drought, famine or plague, inertia or death itself - but sometimes also as hostile peoples or tyrannical conquerors. In the combat myth, in its various formulations, the conflict between universal order and the forces that threatened and invaded and impaired it - between cosmos and chaos - was given symbolic expression. A young hero god, or divine warrior, was charged by the gods with the task of keeping the forces of chaos at bay; and in return he was awarded kingship over the world" (p. 227). It is also worth recalling Armstrong at this point, and the connections she drew between the rise of monotheistic religion, and the capitalist success which deemed it to be a sign of God's good favor. 
reign, while some believe that godly Christians must seize control and rule for a thousand years before Christ can return. Demonizing versions of apocalyptic Christian millenarianism have nonetheless played a key role in establishing conspiracism as a key point of reference for European cultures, and later the new colonial settlements in America. It was when contemporary events in Europe started to be interpreted as 'signs of the End', that all hell broke loose so-to-speak. Scapegoating became commonplace, and those working against one's interests became agents of the Antichrist. In this sense, the ancient Manichean dualism which sees the world as a contest between absolute good and absolute evil, between "Us" versus "Them", often led to the creation of an apocalyptic "Other".

For Christians, this "Other" often took the form of Jews. Even as early as the second century, early Christians portrayed Jews as in league with the Antichrist. By the twelfth century, Jews were being accused of poisoning wells, ritualistically murdering children, and other heinous acts. Over the next few centuries, during the Inquisitions, Jews were routinely tied to claims they were part of a vast conspiracy. In the sixteenth century, evidence of this sort of sentiment can be found in the writings of Martin Luther. For him, the Reformation was a necessary act of purification in preparation for the approaching end times. In later years, a Christian reading of Revelation became part of their political discourse, which took the form over the centuries as a vast global conspiracy of high level government figures betraying the decent productive citizens, while subversive agents ate away at society from below.

In modern times, even events such as the establishment of the Federal Reserve and the implementation of income tax were woven into Christian apocalyptic conspiracism. This was especially true during the 
administration of Franklin D. Roosevelt, the father of Social Security. These were sometimes seen as efforts to socialize and collectivize all societies under one world government, just like it said in the Book of Revelation. Communism had its run from the 1920s right through the 1960s and beyond, but the forces imagined to be behind the "red menace" were peppered with references to the more traditional forms, such as Freemasonry, the Jews, or both. Of course, the United Nations, the Trilateral Commission, and liberal secular humanism, have at different times been subjected to the searingly judicious gaze of Christian fundamentalism. The return to "traditional values" has since become the rallying cry of-late for those who believe it is the only way to fend off the impending collapse of society.

\section{George W. Christ? ${ }^{83}$}

Against a backdrop such as this, George W. Bush's invocations of the Almighty need to be taken very seriously. As David Domke and Kevin Coe write in a Seattle Post-Intelligencer guest column, ${ }^{84}$ there is nothing uniquely special about a president using the name of God in public address. All of them do it. What sets the $43^{\text {rd }}$ president apart from the others, however, is not only how frequently he has done it, but "what he says when he does so."

Since Franklin Roosevelt took office in 1933, no other president of the United States has invoked God so often in his Inaugurations or State of the Union speeches. Bush has averaged six references in each.

${ }^{83}$ The title belongs to William Rivers Pitt for his article on truthout.org dated May 05, 2003. Accessed on May 06, 2003.

${ }^{84}$ David Domke \& Kevin Coe, 'Bush Changes White House Rhetoric about God', Seattle PostIntelligencer, January 19, 2005. Accessed on January 21, 2005. 
It will surprise no one that he is followed next on the list by Ronald Reagan, who averaged 4.75 in his comparable speeches. Jimmy Carter had only two mentions in four outings, and Roosevelt edged out Lyndon Johnson with 1.69 to Johnson's 1.50. But the more unsettling aspect of all this is precisely in the ways that God is referred to by Bush that really sets him apart. Whereas presidents have typically spoken as petitioners of God, seeking favour and guidance, Bush positions himself as a prophet. He issues proclamations of divine desire, not only for the United States, but for the entire world. Only Reagan spoke in a similar fashion among modern presidents, and even he did so less often. Domke and Coe provide some examples. In Roosevelt's famous 1941 address outlining the four freedoms threatened by fascism, he said, “This nation has placed its destiny in the hands and heads and hearts of its millions of free men and women; and its faith in freedom under the guidance of God." Similarly, during the height of the Cold War in 1954, Dwight Eisenhower said,

\footnotetext{
Happily, our people, though blessed with more material goods than any people in history, have always reserved their allegiance to the kingdom of the spirit, which is the true source of that freedom we value above all material things...So long as action and aspiration humbly and earnestly seek favor in the sight of the almighty, there is no end to America's forward road; there is no obstacle on it she will not surmount in her march toward a lasting peace in a free and prosperous world.
}

Consider the difference with Bush speaking in 2003: "Americans are a free people, who know that freedom is the right of every person and the future of every nation. The liberty we prize is not America's gift to the world, it is God's gift to humanity." This is an exclamation of divine will to be made manifest through the actions of the Bush administration, not a humble expression of Christian piety. Where he may stand in out in comparison to modern presidents, he is in lockstep with the evangelical rhetoric noted earlier. 
There are much more than a few simple instances of this sort of rhetoric to point to in this regard, and its consequences are far more serious in the aftermath of $9 / 11$. Domke, writing later in another publication, ${ }^{85}$ notes that since the $9 / 11$ attacks

\begin{abstract}
the president and his administration have converged a religious fundamentalist worldview with a political agenda - a distinctly partisan one, wrapped in the mantle of national interest but crafted by and for only those who share their outlook. It is a form of political fundamentalism, that is, the adaptation of a self-proclaimed conservative religious (Christian) rectitude, that uses strategic language choices and communication approaches designed for a mass-media culture to shape and implement political policy.
\end{abstract}

Domke has examined hundreds of administration public communications about 'war on terrorism' by the president, John Ashcroft, Colin Powell, and Donald Rumsfeld. His time frame was the 20 months between September 11, 2001, and the "end of major combat" in Iraq in the spring of 2003. The results of his research illuminate a glaring uniformity with the apocalyptic worldview noted earlier. In his words, his 'research showed that the administration's public communications contained four characteristics rooted in religious fundamentalism while offering political capital:

- Simplistic, black-and-white conceptions of the political landscape, most notably good vs. evil and security vs. peril.

- Calls for immediate action on administration policies as a necessary part of the nation's "calling" and "mission" against terrorism.

- Declarations about the will of God for America and for the spread of U.S. conceptions of freedom and liberty.

- Claims that dissent from the administration is unpatriotic and a threat to the nation and the

\footnotetext{
${ }^{85}$ David Domke, 'Bush, God, and the Media: How the president has used religion to control American politics', Mediatransparency.org, March 7, 2005. Accessed on March 7, 2005.
} 
globe."

Domke concludes that it is arguably difficult to tell the difference between extremist positions like these, and those of the very terrorists being fought.

In a Los Angeles Times piece, ${ }^{86}$ William Thatcher Dowell echoes this position. Coming on the heels of the 'Ten Commandments' debate referred to earlier, he notes the irony that the passionate defence of the right to display the monument in front of Roy Moore's courthouse, actually violates the second commandment, which admonishes the creation of graven images and imbuing them with spiritual power (whether it be a golden calf or a two-ton slab of granite). ${ }^{87}$ Still, his main point is to show that, over history, it is the simple question 'what is to be enshrined?' which has been responsible for religious massacre over the ages. In fact, it was the slaughter of Calvinist Scots in the $17^{\text {th }}$ century by King Charles in his efforts to impose the Church of England's prayer book on them, which played a leading role in the decision by the American founding fathers to separate church and state. The push by those wishing to blur the boundaries of church and state is motivated by a fear that they are losing out in the culture wars. This makes them not too much unlike the Islamic fundamentalists who fear 'losing out' to Western values. Their respective reactions are very similar. In the Arab Middle East, and Iran, it comes in the form of insistence on the establishment of Islamic law as the basis for political life. In the United States, school districts impose the euphemism of "intelligent design" over evolution in science

${ }^{86}$ William Thatcher Dowell, 'Made-in-America Wahhabism: The Christian right is our own brand of extremism', Los Angeles Times, March 8, 2005. Accessed on March 8, 2005.

${ }^{87}$ In an interesting aside, he points out that it also glances over the fact that there are several versions of the commandments; Exodus 20:2-17, Exodus 34:12-26, and Deuteronomy 5:6-21 fall on top of different language in both Catholic Bibles and the Jewish Torah which add still more variants to the mix. 
and biology classes, tax money funds 'faith-based' initiatives, and the Ten Commandments become the foundation of moral righteousness.

Thatcher Dowell shows that George W. Bush may be in a very similar situation to that which befell Saudi Arabia's founder, King Abdulaziz ibn Saud. As discussed earlier, to gain political support, Saud mobilized the ultra-religious Wahhabi movement - of which al-Qaeda is the spiritual heir. The Saudi Royal family eventually found itself in the midst of a pitched battle between an alliance with the West, and the hardline extremist factions who want a return to the "spiritual purity" they believe once belonged to their forefathers, but which has now been lost. Bush, on the other hand, has ridden the radical rightwing Christian agenda into the White House a second time. Just as in the Middle East, the religious right in the United States, with its puritanical beginnings, is rooted in a nostalgia for an imaginary past. It is a fantasy United States made up of Northern Europeans who all worship and understand God in the same way. Instead, and as we saw in chapter one, the founding fathers opted instead for a Constitution which reflected the ideals of the secular Enlightenment. Rather than establish a country anointed by a single religious interpretation, it provided the safety and space for people to seek and worship God in their own way.

"Religion," writes Thatcher Dowell, "when incorporated into a political structure, is almost invariably diluted and deformed and ultimately loses its most essential power. Worse, as we have seen recently in the Islamic world (as in the Spanish Inquisition and the Salem witch trials in the Christian world), a fanatical passion for one's own interpretation of justice under God often leads to horror." Where this 
leaves us, as attention is turned to the case study in the next chapter, is in a place where the very fundamental principles upon which the United States was based have become deformed and distorted, and now stand eye-to-eye with an Islamic incarnation of the same thing. It is in no way a coincidence that each needs to see the other like this as a way of defining themselves. The case study will seek to understand the dialectical tensions between each against the Other, and will use conspiracy theory as a way to demonstrate that at the same time, each needs that Other in order to exist on its own. 


\section{Chapter Five - Sixteen Little Words}

President Bush could not have been aware of the irony of what he was about to say, as he stood before the United Nations General Assembly on November 10, 2001. In a speech to a world still reeling from the $9 / 11$ attacks, he was already beginning to articulate a dire new reality. Amid the clamouring rhetoric about civilization, humanity, God, and weapons of mass destruction, the President sought bold and decisive action against evil. "The conspiracies of terror are being answered by an expanding global coalition" he said. "Not every nation will be a part of every action against the enemy. But every nation in our coalition has duties. These duties can be demanding, as we in America are learning." As if to invite invidious comparison in later years, he continued that "[e]very nation has a stake in this cause. As we meet, the terrorists are planning more murder -perhaps in my country, or perhaps in yours. They kill because they aspire to dominate. They seek to overthrow governments and destabilize entire regions."

But it was another quote from that same speech which was to gain notoriety. After re-iterating the need for a commitment to the newly-minted war on terror, Bush warned there was never any justification for the deliberate murder of innocent people. "Any government that rejects this principle," he said solemnly, "trying to pick and choose its terrorist friends, will know the consequences. We must speak the truth about terror. Let us never tolerate outrageous conspiracy theories concerning the attacks of September the 11th; malicious lies that attempt to shift the blame away from the terrorists, themselves, away from the guilty. To inflame ethnic hatred is to advance 
the cause of terror."

Regardless of the no-doubt varied reasons why this presidential invocation of conspiracy theory has been so widely picked up on, it is notable here for what, at the time, was not yet on the public radar. Steeped in the language of 'Afghanistan' and 'al-Qaeda', Bush's speech is devoid of any mention of Iraq or Saddam Hussein. It is highly ironic, then, that the President's admonition about 'outrageous conspiracy theories concerning the attacks of September the $11^{\text {th' }}$ should even be there at all. ${ }^{1}$ This is because the belief in Saddam Hussein as the root of all Middle Eastern evil is itself a bonafide conspiracy theory with its own interesting history.

This chapter will begin by deconstructing the origins and chief proprietors of this particular conspiratorial vision about the alleged role of Saddam Hussein in the 9/11 attacks. It will do so in order to set the stage for a more detailed examination of how the general idea of conspiracy theory was deployed through mainstream news media by the Bush administration, in the aftermath of 9/11. This will be done in order to demonstrate that, not unlike earlier attempts by the Catholic church to construct patrician counter-festivals, which were intended to "repress, control and ultimately mutilate the carnival of the common people", the Bush administration's wielding of the charge has had a chilling effect on the coverage of the very tensions inflamed by the invasion of Iraq.

\footnotetext{
${ }^{1}$ As we shall see in the coming pages, this same observation takes on its own interesting turn once it is revealed in January 2004 that, in fact, Iraq had been on the Administration's agenda since early 2001.
} 
The name Laurie Mylroie may not be familiar to most people, but to the so-called 'neo-conservative' movement, she is allied and well-connected. In the December 2003 edition of Washington Monthly, Peter Bergen ${ }^{2}$ wrote a detailed article which traces these connections and their development in relation to the Iraq invasion. In his words, "the belief that Saddam Hussein posed an imminent threat to the United States amounted to a theological conviction within the administration, a conviction successfully sold to the American public." Given this state of affairs, Bergen feels it is only fair to ask where this faith in an 'Iraqi conspiracy' came from. Though Bergen himself does not use the phrase in his article, it is evident that the belief in an Iraqi connection to global terrorism is built upon the same characteristically spurious claims of the archetypal conspiracy theory.

Mylroie certainly has impressive-sounding credentials. She has held faculty positions at both Harvard and the U.S. Naval War College, has worked for the Washington Institute for Near East Policy, and also served as an advisor on Iraq to the 1992 Clinton presidential campaign. Bergen writes that during the 1980's, Mylroie was an apologist for Saddam before reversing her position after the Iraqi invasion of Kuwait in 1990. With the "zeal of an academic spurned," Bergen adds, "[she] became rabidly anti-Saddam." In the lead-up to the first war in the Gulf, Mylroie, along with New York Times reporter Judith Miller, ${ }^{3}$ wrote a best-seller called Saddam Hussein and the Crisis

\footnotetext{
${ }^{2}$ Peter Bergen, 'Laurie Mylroie: The Neocons' Favorite Conspiracy Theorist', Washington Monthly, December 2003.

${ }^{3}$ On July 5, 2005, Miller was sent to prison by Special Prosecutor Patrick J. Fitzgerald for refusing to cooperate with the investigation into the leak of a CIA operative. Miller had been a key journalistic proponent of stories about Hussein's alleged duplicity with regard to weapons of mass destruction while writing for the New York Times during the lead-up to the invasion of Iraq in 2003. At the time of this writing, it remains unclear as to the specific reasons why Miller was jailed, seeing that she never even wrote a story outing the CIA agent.
} 
in the Gulf which was later translated into over a dozen languages. Bergen reports that though there was nothing controversial about Mylroie at this point in her career, this was all to change with the first World Trade Centre bombing in 1993. As the first act of terrorism on US-soil, it sparked her efforts to prove that Saddam was a key sponsor of global terrorism. In another book, Study of Revenge: Saddam Hussein's Unfinished War Against America (2000), ${ }^{4}$ she worked closely with neo-con hawks such as Richard Perle, John Bolton, Lewis "Scooter" Libby, and Paul Wolfowitz.

Mylroie became consumed by her theory that Hussein was the key wire-puller of anti-U.S. terrorist insurgency the world over. The only thing remarkable about this, however, was the fact that it flew in the face of all expert opinion and evidence to the contrary. Bergen writes that Mylroie's position amounts to the discovery of a "unified field theory of terrorism." Suddenly, Mylroie imagined Saddam was not only responsible for the first Trade Centre bombing, but also every other terrorist incident against the U.S. over the previous decade. This includes everything from the bombing of embassies in Tanzania and Kenya, the Oklahoma City bombing, the attack on the USS Cole, not to mention 9/11. "She is, in short," Bergen writes, "a crackpot, which would not be significant if she were merely advising say, Lyndon LaRouche." But her connections include not only those now running the war in Iraq, they also derive from her position as a consultant to the Pentagon.

\footnotetext{
${ }^{4}$ It should be noted that her book was published by the American Enterprise Institute, a conservative think tank with strong ties to the policy advisory infrastructure on the Iraq question. This includes Richard Perle, a key architect of the aggressive foreign policy on Iraq. Another is President Bush's controversial nomination for Ambassador to the UN, John Bolton, who was named UN Ambassador though a recess appointment on August 1, 2005. Perle would later gush about Study of Revenge that it was "splendid and wholly convincing." Another figure central to the leak investigation, I. Lewis 'Scooter' Libby, Vice President Cheney's chief of staff, is thanked in the acknowledgments for his "generous and timely assistance." Of Wolfowitz, she writes that "[a]t critical times, he provided crucial support for a project that is inherently difficult."
} 
The evidence against an Iraqi connection to $9 / 11$ is quite compelling. Despite this, as Bob Woodward records in Bush at War ${ }^{5}$, Deputy Secretary of Defence Paul Wolfowitz felt that there was a 10-50 percent chance that Saddam was involved. ${ }^{6}$ This belief flew in the face of findings by the criminal investigation which chased down a half-million leads and interviewed over 170000 people, none of which turned up any evidence of Iraq's involvement. The authoritative annual report by the U.S. State Department's counterterrorism office in 2000, concluded that Iraq had not been involved in any anti-Western actions since the failed attempt on the life of the first President Bush in Kuwait in 1993. Bergen openly wonders how it is that, given this and other evidence against an Iraqi connection to the $9 / 11$ attacks, so many key members of the Bush administration were able to believe so strongly in one. The answer to this question, he contends, begins with Mylroie's Study of Revenge, and its laughable contention that Saddam orchestrated the first World Trade Centre attacks. Bergen points out that hundreds of law enforcement and national security professionals combed through the evidence of the 1993 bombing, no doubt looking for precisely this kind of evidence, and found nothing connecting Iraq to it.

Mylroie's conviction hinges on a point she claims everyone else missed. It was that the mastermind of the plot, commonly known as Ramzi Yousef [one of his many aliases], was in fact an Iraqi intelligence agent who had assumed the identity of Abdul Basit, a Pakistani whose family lived in Kuwait. During a comparative examination of Basit's passport records, Mylroie noted a four-inch

\footnotetext{
${ }^{5}$ Bob Woodward, Bush at War, Simon \& Shuster, 2003.

${ }^{6}$ ibid., p. 83. Bush was to say a few days later that "I believe that Iraq was involved, but I'm not going to strike them now. I don't have the evidence at this point." That point, was September 17, 2001 (Woodward, 2003; pp. 97-99).
} 
difference in height between the two. She then assumed that Yousef had been given access to Basit's passport information, following the Iraqi invasion of Kuwait. However, the position of U.S. investigators ran contrary to this wafer-thin evidence of Iraqi involvement, and concluded that Yousef and Basit were actually the same person. The result of the U.S. investigation held that Yousef/Basit was a Pakistani with ties to al-Queda, and not an Iraqi with ties to Saddam Hussein.

There is a mountain of evidence to support this connection, none of which Mylroie considers because it would undermine her already flimsy case. For example, when Yousef travelled to New York from Pakistan in 1992, in advance of the first WTC attack, he was in the company of Ahmad Ajaj. Ajaj was arrested on immigration charges at Kennedy airport, and was later found to have an al-Qaeda bomb making manual in his luggage. Another al-Qaeda figure, Jamal al-Fadl, told a New York jury in 2000 that he had seen Yousef at a training camp for the group on the Afghan-Pakistani border between 1989 and 1991. While he was living in the Philippines in the early 1990's, Yousef had a partner in crime named Wali Khan Amin Shah who had trained with bin Laden in Afghanistan. The 'Afghan Refugee Center' in Brooklyn, N.Y. was the American arm of an organization which was known to have been started by bin Laden in the mid-1980's in Pakistan, and a number of Yousef's co-conspirators had ties to it. Furthermore, Yousef's uncle, Khalid Sheikh Mohammed, who was also to become al-Qaeda's chief planner and commander for the 9/11 attacks, sent him money for the first attacks on the World Trade Center. "I could go on," Bergen states. "The point is that the 1993 attack was plotted not by Iraqi intelligence, but by men who were linked to al Qaeda." 
If this isn't enough, Yousef gave what would be his only interview to an Arabic newspaper in 1995 where he was quoted as saying "I have no connection with Iraq, the Iraqi people must not pay for the mistakes made by Saddam." Mylroie is definitely aware of this interview, because she sources it in her book. Furthermore, in that same interview, he confirmed that his real name was indeed Abdul Basit, and that he was a Pakistani born in Kuwait. He also confessed to an admiration for Sheikh Omar Abdel Rahman, a spiritual force in the al-Qaeda movement, and one of the people who the U.S. government would later go on to convict for the plotting of terror attacks in New York. Yousef is also on record as having wanted to help Ayman al-Zawahiri, who was then leading Egypt's Jihad group, and who has since been considered to be bin Laden's top deputy. Bergen goes on to write that Yousef's interview:

has the ring of truth as he freely volunteered that he knew Sheikh Rahman, the cleric whom the U.S, government had by then already identified as the inspiration for several terrorist conspiracies in New York during the early ' 90 s and has also explained that he was part of an Islamic movement which planned to carry out attacks in Saudi Arabia to avenge the arrests of [others] who have profoundly influenced both bin Laden and al Qaeda. Yousef knew that he was likely facing a lifetime in prison at the time of this interview, and so had little reason to dissemble.

Bergen shows here that in Mylroie's Study of Revenge, she is careful not to mention any of this, for reasons that seem obvious in light of her own theories. In his words, "Mylroie's broader contention that the first Trade Center attack was an Iraqi plot is, to put it mildly, not shared by the intelligence and law-enforcement officials familiar with the subsequent investigation." Bergen continues that the head of the CIA Counterterrorist Center in the early 1990s, Vince Cannistraro, has told him that "Laurie has an obsession with Iraq and trying to link Saddam and global terrorism. Years of strenuous effort to prove the case have been unavailing." 
Even former CIA analyst Ken Pollack, not one to be 'soft' on Saddam according to Bergen, made his own persuasive case for toppling of the Iraqi dictator in a book called The Threatening Storm:

The Case for Invading Iraq. In it, Bergen shows that despite having made an authoritative argument for the overthrow of Hussein himself, Pollack nonetheless dismissed Mylroie's theories to Bergen this way: "The NSC [National Security Council] had the intelligence community look very hard at the allegations that the Iraqis were behind the 1993 Trade Center attack. Finding those links would have been very beneficial to the U.S. government at the time, but the intelligence community said that there were no such links."

However much Mylroie's theories contradicted the findings of the mainstream intelligence community, she clearly found kindred sprits at the AEI and elsewhere, as seen in the glowing reviews of her work. ${ }^{8}$ After all, over the same period of time, the so-called 'neo-cons' were formulating their own alternative vision of U.S. foreign policy to challenge what they saw as the weak stance taken by the Clinton administration. ${ }^{9}$ Significantly, the book was re-released after $9 / 11$ as The War Against America, with former CIA director James Woolsey contributing a new forward that declared Mylroie's work to be "brilliant and brave." All of this, though, raises the question as

\footnotetext{
7 "In sum", Bergen writes, "by the mid-'90s, the Joint Terrorism Task Force in New York, the F.B.I., the U.S. Attorney's office in the Southern District of New York, the C.I.A., the N.S.C., and the State Department had all found no evidence implicating the Iraqi government in the first Trade Center attack."

${ }^{8}$ For example, Paul Wolfowitz gushed that "Her provocative and disturbing book argues that...Ramzi Yousef, was in fact an agent of Iraqi intelligence. If so, what would that tell us about the extent of Saddam Hussein's ambitions? How would it change our view of Iraq's continuing efforts to retain weapons of mass destruction and to acquire new ones? How would it affect our judgements about the collapse of U.S. policy toward Iraq and the need for a fundamentally new policy." To this Bergen adds the bracketed aside "(How indeed...)"

${ }^{9}$ Most notable among these was the Project for the New American Century which, not surprisingly, has also figured prominently in conspiracy theories about the U.S. case for invading Iraq. These will be addressed later in the chapter.
} 
to how seriously this was really taken by those involved.

Bergen concedes that it is possible that the neo-cons "did not find Mylroie's research to be genuinely persuasive, but rather that her findings simply fit conveniently into their own desire to overthrow Saddam." Having described her first book as "wholly convincing", Bergen reports that Richard Perle now says that "not everything she says is convincing" and that Mylroie's ideas were "not very important" to the development of his own views on Iraq. He does, however, continue to praise Mylroie's investigative skills, to the point of suggesting she should be put in charge of 'quality control' at the CIA. Quite apart from her alarmist stance towards Hussein and Iraq, it bears repeating that Mylroie was the one member of the neo-con team with serious credentials on Iraq, and so no doubt had an influence in strengthening any convictions that may or may not have already existed.

A subsequent book by Mylroie carried the conspiracy theory even further forward. In Bush vs. the Beltway: How the CIA and the State Department Tried to Stop the War on Terror, she makes the charge that the U.S. government deliberately suppressed information about the Iraqi role in antiAmerican terror and 9/11. Aside from additional praise from the likes of Woolsey and Perle, the book claims that the recently captured mastermind of the 9/11 attacks, Khalid Sheik Mohammed was, like Ramzi Yousef, an Iraqi intelligence agent who adopted the identity of a Pakistani living Kuwait. According to Mylroie, the U.S. government has not explored this theory because there is a plot to prevent his unmasking. Testifying as an expert witness before the $9 / 11$ commission, ${ }^{10}$ she

\footnotetext{
${ }^{10}$ Mylroie is listed in The 9/11 Report: The National Commission on Terrorist Attacks Upon the United States as having been a witness during the $3^{\text {rd }}$ Public Hearing in the Russell Senate Office Building, Washington D.C.. "The Commission held 12 public hearings during the course of its investigation, convening for a
} 
stated that "there is substantial reason to believe that these masterminds [of both the ' 93 and $9 / 11$ Trade Center attacks] are Iraqi intelligence agents." She claimed that this had not been discovered by the U.S. government because "a senior administration official told [her] in specific that the question of the identities of the terrorist masterminds could not be pursued because of bureaucratic obstructionism." Once again, her point of view is undermined by the fact that Khalid Sheik Mohammed, since his capture in Pakistan, has specifically denied any connection to Iraq while providing actionable intelligence about other terror plots in the United States. Luckily for her readers, there is a hero in her story Bush vs. the Beltway. It was the president, "who could not be rolled, spun or otherwise diverted from his most solemn obligation."

In closing, Bergen relates that his only chance to speak with Mylroie occurred on Canadian television in February of 2003, when they debated the rationales for the impending invasion of Iraq. As soon as the interview started, he writes

Mylroie began lecturing in a hectoring tone: "Listen, we're going to war because President Bush believes Saddam Hussein was involved in 9/11. Al Qaeda is a front for Iraqi intelligence...[the U.S.] bureaucracy made a tremendous blunder that refused to acknowledge these links ... the people responsible for gathering this information, say in the C.I.A., are also the same people who contributed to the blunder on $9 / 11$ and the deaths of 3,000 Americans, and so whenever this information emerges they move to discredit it." [Bergen] tried to make the point that Mylroie's theories defied common sense, as they implied a conspiracy by literally thousands of American officials to suppress the truth of the links between Iraq and $9 / 11$, to little avail.

Whatever the many problems with Mylroie's ideas that Bergen spends ample time summarizing,

total of 19 days and receiving testimony from 160 witnesses [...] All witnesses appearing during the 2004 calendar year testified under oath" (p. 623). Mylroie testified on July 9, 2003 (p. 626). 
there is one undeniably important fact that comes out of all of this. It is that she was nonetheless very influential in bolstering the arguments for the invasion of Iraq to key members of the Bush administration, ${ }^{11}$ who then proceeded to sell the idea so successfully, that at one point seven out of ten Americans believed that Saddam had a key role in the attacks.

\section{Parsing Paranoia}

Once again, the ideas and work of Laurie Mylroie represent a stark case of what Hofstadter described four decades ago as the paranoid style. Conveniently, Hofstadter makes specific and extended mention of Mylroie's sort of paranoid literature. "One of the impressive things about paranoid literature," he writes, "is precisely the elaborate concern with demonstration it almost invariably shows. One should not be misled by the fantastic conclusions that are so characteristic of this political style into imagining that is not, so to speak, argued out along factual lines." In fact, Hofstadter goes on to say that it is the very nature of the fantastic conclusions which, in turn, leads to "heroic strivings" for "evidence" which proves "that the unbelievable is the only thing that can be believed." He points out that there have always been low-, mid-, and high-brow paranoids, and that paranoid movements since the Middle Ages have always been attractive to what he calls "demiintellectuals.” In contrast, 'respectable' paranoid literature starts from a morally defensible position which is non-offensive to non-paranoids, but then still sets out "carefully and all but obsessively"

\footnotetext{
${ }^{11}$ Bergen wrote an embellished summary of this piece later in The Guardian. In it, he cites a quote from Richard Clarke's then just released book Against all Enemies (2004). According to Clarke as he recounted a seniorlevel meeting on terrorism pre-9/11 (pp. 231-232), Deputy Secretary of Defence Paul Wolfowitz said, "You give Bin Laden too much credit. He could not do all these things like the 1993 attack on New York, not without a state sponsor. Just because the FBI and CIA have failed to find the linkages does not mean they don't exist." Clarke continued that "I could hardly believe it, but Wolfowitz was spouting the Laurie Mylroie theory that Iraq was behind the 1993 truck bomb at the World Trade Centre, a theory that had been investigated for years and found to be totally untrue" (The Guardian, 'Did One Woman's Obsession Take America to War?; July 5, 2004).
} 
to accumulate 'evidence'. After all, Hofstadter suggests, there is something to be said for antiMasons, for example. The fact that it was a secret society composed of influential men with their own set of obligations and loyalties, hardly makes one paranoid to wonder about conceivable threats to the civil order.

Hofstadter outlines the typical procedure for higher paranoid scholarship. It begins with a set of defensible assumptions that progresses to include a very careful accumulation of facts, or at least apparent facts. These are then marshalled towards an overwhelming 'proof' of whatever particular conspiracy is being envisioned. Hofstadter puts it best in saying that this sort of 'proof' "is nothing if not coherent - in fact, the paranoid mentality is far more coherent than the real world, since it leaves no room for mistakes, failures, or ambiguities." Though they may not be 'rational' in the strict sense, they are strenuously rationalistic. It believes its enemy has an access to evil and infallible rationality which then must be matched, step-for-step, "leaving nothing unexplained and comprehending all of reality in one overarching, consistent theory. It is nothing if not 'scholarly' in technique. McCarthy's 96-page pamphlet McCarthyism contains no less than 313 footnote references, and Mr. Welch's fantastic assault on Eisenhower, The Politician, is weighed down by a hundred pages of bibliography and notes." So what distinguishes paranoid scholarship is not, in itself, an absence of facts. Still though, it needs to be conceded, as Hofstadter does, that "in his extravagant passion for facts the paranoid occasionally manufactures them". Rather, it is the leap of faith that is always made at some critical point in the assembly and presentation of these facts that is of real interest. As an example, Hofstadter again cites the case of John Robison and his zealous pursuit of the Illuminati. His case study unfolds meticulously over a century and a half, where he 
records, page after page, all the details he has been able to collect. Suddenly, the French Revolution happens and it is because the Illuminati caused it. What is lacking here, then, is not information. Instead, it is the more sober judgement about the complex circumstances which bring revolution about. $^{12}$

So it is that the plausibility which the paranoid position holds, for those who do indeed find it plausible, which can end up being taken as 'convincing evidence' for the most fantastic of conclusions, or what Hofstadter calls "the careful preparation for the big leap from the undeniable to the unbelievable." One of the things that is unique about this situation, and one which distinguishes it from true intellectual exchange, is the distinctly 'one-way' character of paranoid rhetoric once oppositional views are encountered. There is little hope that the paranoid subject will convince a hostile and suspicious world. The amassing of evidence, then, takes on the spectre of a defensive manoeuvre which pre-emptively shuts out contradictory information. He becomes a transmitter rather than a receiver. ${ }^{13}$

It is with this sort of caveat in mind that the current case study will proceed. Absent of such a qualification, it may be all but impossible for any serious and extended examination of the general subject of 'conspiracy theories', much less a case study of an American presidential administration which repeatedly invoked the phrase itself in dismissing criticism of its own actions. As we shall see, examples of this kind of rhetoric from the Bush administration since the lead up to the invasion

\footnotetext{
${ }^{12}$ Hofstadter, op. cit., p. 37.

${ }^{13}$ ibid., p. 38.
} 
of Iraq are plentiful. What is necessary, in order to study them in a manner appropriate to the cautions laid out by Hofstadter, is a clear demarcation between the present study and the sort of paranoid literature he describes. In keeping with that goal, it is worthwhile to highlight a few important points. First, I will endeavour to provide full and accurate sourcing of all information cited, in ways that may even resemble the type of paranoid literature Hofstadter describes. However, this should not be construed as an attempt to document 'evidence'. This is an examination of news coverage of the time frame under study which traces its inflections out of and through the conspiracy theories connected to it.

\section{Conspiracy Theory, 9/11, and the Global War on Terrorism}

If there is a common denominator to Western conspiracy theories about the $9 / 11$ attacks, it is that President George W. Bush, and/or key figures in his administration, somehow had foreknowledge of the attacks, and allowed them to happen in order to justify an aggressive and interventionist foreign policy with regard to Middle East oil. ${ }^{14}$ Though it is not necessary to try and categorize all the different permutations these conspiracy theories have taken with regard to the $9 / 11$ attacks, one thing about them is strikingly clear. In their own ways, they all cut back and forth across the same sets of very real geo-political tensions discussed to this point in the thesis. One of these, in the form of a press release from a group called the 'Patriot Saints for the Kingdom of God on Earth', bore the title "George W. Bush was Complicit with the 911 Attack on America". ${ }^{15}$ Immediately citing as

\footnotetext{
${ }^{14}$ For example, a Google search for “9/11 + Bush + conspiracy” returned 3880000 hits (September 24, 2005).

${ }^{15}$ Stirling D. Allen, October 13, 14, 2003; accessed at www.patriotsaints.com/News/911/Conspiracy/Bush/031012_Bush911Complicit.htm on September 24, 2005.
} 
historical precedents the alleged role of President Roosevelt in allowing the Pearl Harbour attacks to happen, drawing America into World War II, and Hitler's Reichstag fire, the release proceeds to cite the subsequent curtailing of civil liberties under the Patriot Act, as well as the increased U.S. military presence in the Middle East resulting from the Iraq invasion, as cause for concern. "The question as to why and to what extent President George W. Bush was involved in the terrorist attack on America will [conveniently] ${ }^{16}$ take years of investigation and probing to conclude with any degree of finality," the release runs. "But what can be determined with clarity at this point is that he had foreknowledge, and he had an agenda - and that his actions amount to high treason." It goes on to provide a "partial list of evidences" for the charge, which include the President's admittedly odd behaviour at the Booker Elementary School as the attacks commenced, his even more curious statements later on that he had seen the first plane hit the first tower on television while standing outside the classroom waiting to go in, ${ }^{17}$ and that wealthy multi-billionaire Warren Buffet was at a pre-scheduled charity event that day at Offutt Air Force Base where Bush later ended up after crisscrossing the country on Air Force One. "The likelihood of conspiracy or complicity is too high to ignore" the release continues. "It must be investigated at length [...] President Bush is not the

\footnotetext{
${ }^{16}$ [editorial emphasis added]

${ }^{17}$ In a televised town hall question and answer session in Orlando, Florida, Bush was asked by a third grade student how he felt when he heard about the terrorist attack. His reply was 'Thank you, Jordan. Well Jordan, you're not going to believe what state I was in when I heard about the terrorist attack. I was in Florida. And my Chief of Staff, Andy Card - actually, I was in a classroom talking about a reading program that works. I was sitting outside the classroom waiting to go in, and I saw an airplane hit the tower - the t.v. was obviously on. And I used to fly, myself, and I said, well, there's one terrible pilot. I said, it must have been a horrible accident. But I was whisked off there. I didn't have much time to think about it. And I was sitting in the classroom, and Andy Card, my Chief of Staff, who is sitting over here, walked in and said, 'A second plane has hit the tower, America is under attack'." (President Meets with Displaced Workers in Town Hall Meeting, Orlando County Convention Center, Orlando, Florida; December 4, 2001; www.whitehouse.gov/news/releases/2001/12/2001 1204-17.html). It should be noted that the Patriot Saints news release is riddled with errors that need not be highlighted here.
} 
leader of this conspiracy, but clearly he is one of its willing players, a fact that can be documented from a host of other evidences spanning back to his initiation into a lifetime membership in the Yale Skull and Bones fraternity. He is certainly not the first U.S. President to be illicitly controlled from behind the scenes."

In another version of this conspiracy theory, summarized in an online story called "9/11 was a Hoax: The American Government Killed its Own People"18, a John Kaminski begins with an editor's note which reads that his piece is "intended for people who have accepted the official version of the 9/11 story. It should be distributed widely to the uninformed few who still believe this tragedy was engineered by Muslim terrorists." 19 Kaminski's opening sentence captures the essence of conspiratorial rhetoric, that the illegal Iraqi invasion was opposed by "everyone in the world who was not bought off" and was undertaken for many reasons. These are, according to Kaminski, the "immanent replacement of the dollar by the euro as the world's primary currency, the tempting lure of untapped oil reserves, the desire to consolidate U.S./Israeli military hegemony over a strategically vital region - but the most important reason was to further obscure questions about the awesome deception staged by the American government that has come to be known as 9/11." The idea that 9/11 was a hoax, he protests, is no longer a "wild conspiracy assertion; it is a fact, supported by thousands of other verifiable facts" the foremost of which he proceeds to outline.

\footnotetext{
${ }^{18}$ Accessed online at www.sumeria.net/politics/bushknew/9-1 Thoax.html

${ }^{19}$ Right away, in glaringly contradictory logic, it begs the question as to why it would need to be widely distributed if it is only the "uninformed few" that need the information.
} 
It is not necessary to follow Kaminski through the finer points of his analysis, except to draw attention to the way that disparate and unrelated bits of information are woven together into an absolutist interpretation of the event, where all of them are shown to be connected. The failure of jets to scramble and intercept the hijacked planes is cast a "deliberate unplugging of America's air defenses", instead of an administrative failing in the face of an attack of unprecedented proportions. The "fact" that the twin towers "could not have collapsed as a result of burning jet fuel" because most of it would have been consumed on impact, is coupled with another that "burning jet fuel does not reach temperatures needed to melt steel." This may or may not be the case, but it skips over the obvious point that the WTC towers did not 'melt', and furthermore, the supporting steel structures would only need to be weakened by the fire in any case, which is exactly what happened. Even more suspicious to him, was that the fire "raged out of control" beneath the collapsed towers "for ONE HUNDRED DAYS" indicating the presence of some kind of substance responsible for their demolition. What seems to have escaped attention is that, even allowing for unused office space, 220 floors of computer equipment, carpeting, cleaning agents, office supplies, and all manner of other combustible materials would no doubt take a very long time to burn, especially with heaping mounds of concrete and twisted metal simultaneously hindering firefighting efforts as it provided ample air to fuel the flames.

This sort of fly-swatting could go on indefinitely, but there is only so much of it that is useful before it becomes tedious and counter-productive. The standard recitation that a plane did not hit the Pentagon, another common theme to conspiracy theories about that day, willfully ignores the fact that a whole plane full of people has to be explained away in the process. It defies common sense 
to even consider it. But curiously, all of this does very little to counter the popularity and wide dissemination of these kinds of ideas. In fact, on the very same bulleted list compiled by Kaminski where he argues for the "unplugging" of American air defenses, he suggests that the "plane in Pennsylvania was shot down and broke apart in midair. No other explanation can account for the wreckage, which was spread over a six-mile area, or the eyewitness accounts that describe debris falling from the sky."20

Paradoxically, however, it is this all-inclusive aspect to conspiracy theory which makes it analytically powerful at the same time it is its own Achilles heel. Not unlike Hofstadter's description of paranoid literature noted earlier, where he pointed to the elaborate concern with demonstration it almost invariably shows, one should not be, again, misled by the fantastic conclusions into imagining that it is not, "so to speak, argued out along factual lines." While this is not to suggest there is anything to the idea that Bush and his administration allowed the attacks to happen, the conspiracy theorists' "heroic strivings" for "evidence" to prove "that the unbelievable is the only thing that can be believed" nonetheless stumbles across, even if blindly, component features of real-world tension. For example, Kaminski, as a handy archetype, concludes that today, "millions of people around the world are protesting the criminal destruction of the nation of Iraq. But these protests won't change the number of minds necessary to stop America's criminal madmen from continuing with their genocidal aim of enslaving the entire world." In this, he embarks upon what might be called the fallacy of the conspiracy theorist; if only everyone could see this truth, the world would be better off. What makes it a fallacy, however, are not the innumerable ways the world arguably could be a better

\footnotetext{
${ }^{20}$ Emphasis added
} 
place for more people, but rather, that the very nature of conspiratorial communication works most immediately to reinforce the very thing it tries to unmask. What will stop these 'criminal madmen', according to Kaminski, is "spreading the realization that President George W. Bush and his billionaire accomplices in the oil industry perpetrated $9 / 11$ as an excuse to begin the militarization of America for the purpose of world conquest." Where he misses the target in one sense, by effectively shooting at phantoms, he hits the bullseye on the central importance of oil to the global economy. Key to the metaphor here, is that he does so at the same time with the same arrow.

In contrast to paranoid scholarship which begins with a set of defensible assumptions and progresses to include a careful accumulation of at least apparent facts marshalled towards an overwhelming 'proof', conspiracy theories like the ones noted above do the opposite. The idea that ' $9 / 11$ was a hoax', for example, starts out big and then works backwards towards the most minute details, even to the point of blatant contradiction. Anything and everything holds a clue to the heretofore unseen 'big picture'. In the process, those aspects that actually do hold currency in the real world, like the geo-politics of petroleum, become little more than an appendage to an otherwise groundless premise. And it is here where the ubiquity of conspiracy theories becomes important. When real world issues are painted in conspiratorial hues, a process which, as we've already seen, is completely natural and requires little more than acknowledgement, it raises some interesting questions about the very nature of discourse itself on issues which happen to be central to conspiracy theory. One need not be a conspiracy theorist at all, for example, to be interested in the role that Middle East oil played in the invasion of Iraq, as much as a concern with oil is endemic to post-9/11 conspiracy theories. One of the challenges for a project like this is to enter that space, and to emerge again in the conclusions 
unscathed.

Fortunately, as this chapter will demonstrate, the charge of conspiracy theory was a notable feature in the mainstream news coverage of the progression from $9 / 11$ to the Iraq invasion. As such, it affords an entirely appropriate pre-text for this kind of study in any case. At the same time, the global demand for oil continues to grow arithmetically, with countries such as China, India, and Pakistan among many others, competing ever more strenuously with the United States for a share of this essential and dwindling resource. A parallel but inverse arithmetic decline in American production over the past few decades has led to an increased dependence on foreign oil $^{21}$, often from countries already hostile in different ways to American global ambitions. It is hardly surprising, then, that each should inform the other in [conspiracy] theory and [political] practice.

\section{Blood and Oil: Iraq and Petro-Politics}

In late 2002, Presidential spokesman Ari Fleicher remarked in response to the "No Blood for Oil" refrain common among anti-war protestors, that the "only interest the United States has in the [Gulf] region is furthering the cause of peace and stability, not [Iraq's] ability to generate oil"'. As the preparations for war escalated, Defence Secretary Donald Rumsfeld remarked "This is not about oil, and anyone who thinks that, is badly misunderstanding the situation."22 As has already been

\footnotetext{
${ }^{21}$ For example, a milestone of sorts was passed in April of 1998, when for the first time, the United States began to import more than $50 \%$ of its oil needs from foreign countries (Michael Klare, Blood and Oil: The Dangers and Consequences of America's Growing Dependency on Imported Petroleum, Owl Books, New York, N.Y., 2004; p. 56).

${ }^{22}$ This is a particularly ironic comment coming from Rumsfeld. As we shall see later in more detail, he himself was a signatory of an open letter to President Clinton in 1998 entitled "Rebuilding America's Defenses" released by the Project for the New American Century (PNAC). The letter called for, among other things, a strongly
} 
demonstrated, and as Klare ${ }^{23}$ additionally remarks, "[w]e know that such statements cannot be true - the entire history of U.S. intervention in the Persian Gulf discredits them - yet most of us lack the information to see our way through these contradictions."24 In keeping with the parameters of the present study, the over-riding concern with oil in contemporary conspiracy theories about Iraq becomes a handy way of delimiting the focus.

"The degree to which the 2003 war with Iraq was driven by American concern over the safety of Persian Gulf oil supplies," Klare begins, "is a complex and controversial issue" that he goes on to explore in his book. He points out that is enough for now to simply acknowledge that the invasion of Iraq is only the most recent of a series of military incursions drawing their impetus from the Carter Doctrine described in the previous chapter. It bears remembering that the very first military objectives of Operation Iraqi Freedom involved securing the Iraqi oil fields against destruction from Saddam Hussein, as he had done in Kuwait in 1990, and the occupation of the Iraqi Oil Ministry, while other government buildings nearby were looted and destroyed.

Despite its present and future dependence on foreign oil, this was not always the case for the United

interventionist foreign policy in the Middle East and elsewhere, including the removal of Saddam Hussein with military force if necessary. The said rebuilding of America's defenses, not to mention Iraq, was to be funded in part by revenues from Iraqi oil fields. This Pax Americana along with PNAC have been, not inconsequentially, a central theme in post-9/11 conspiracy theories.

\footnotetext{
${ }^{23}$ Michael T. Klare, Blood and Oil: The Dangers and Consequences of America's Growing Dependence on Imported Petroleum, Owl Books, 2004.

${ }^{24}$ ibid., p. xvi. In light of what has just been described in relation to Hofstadter's notion of 'paranoid literature', it is useful to point out how rhetorically similar this may be said to be to conspiracy theory and paranoid authorship. However, it is worth noting that it is precisely this 'space' I intend to occupy for the remainder of the chapter, and is one which will be fully elaborated in the conclusions.
} 
States. In fact, from the 1860's until World War II, it was the U.S. who was the world's leading producer of oil. It was easily able to supply all of its own needs, and even to generate enough surplus for export. This self-sufficiency was in no small part behind the dominant role the United States was able to play with respect other nations. During WWII, for example, the U.S. was able to sustain not only all the oil it needed for its own massive war effort, but those of its major Allies as well. Over the course of the war, American wells accounted for six out of every seven barrels consumed by the Allied forces. After WWII, it was U.S. oil that helped allow the prosperity of the United States to flourish, as well as kick-starting the recoveries in both Europe and Japan. Along these lines, Klare cites a speech by Secretary of Energy Spencer Abraham from June 2002 to American energy company officials. "You and your predecessors in the oil and gas industry," Spencer observed, "played a large part in making the 20th century the "American Century". 25

But that same century has also witnessed the rise of a troubling reality for the United States. Since the late 1940 's, the trend towards reliance on foreign sources of oil to meet ever higher demand has continued to increase unabated. In the 1950 s foreign imports accounted for about 10 percent of U.S. consumption; in the 1960 s this figure rose to around 18 percent, and by the 1970 s this number had almost doubled. With the United States accounting for approximately 5 percent of the world's

\footnotetext{
${ }^{25}$ Remarks before the American Petroleum Institute, Dallas, Texas (June 27, 2002) cited by Klare, ibid., p. 10. Accessed and verified at www.energy.gov/engine/content.do?PUBLIC ID=13406\&BT CODE=PR SPEECHES\&TT CODE=PRESSRELE ASE on October 1, 2005. Right before this, Abraham remarked that "Clearly, we have a lot of work to do - a lot of challenges to overcome - to make the most of the exploration and production opportunities for oil and gas here at home and around the world. We need every barrel of oil and every thousand feet of natural gas that you can find and produce."
} 
population and consuming almost 25 percent of the world's total supply, it is clear that the current patterns of consumption, or even simple need, show no signs of letting up. The paradox here is that the very same thing which keeps the U.S. strong, also makes it weak. Dependency on foreign supplies of oil from increasingly unstable regions of the world unquestionably puts the United States in a very precarious position, in the long term, as a central actor on the world stage. ${ }^{26}$

Debates and concerns by American leaders about U.S. reliance on foreign energy sources have taken many forms over the years. But, they have received special attention in times of crisis, such as the oil embargo of 1973-74, and the disruptions to world supply during the Iranian revolution in 1979 which underscored the enunciation of the Carter Doctrine in his State of the Union address on January $23,1980 .{ }^{27}$ But this debate took on a new shape, according to Klare, when energy and oil concerns became campaign issues for the first time during the 2000 presidential election. With both major candidates making proclamations about energy matters and the steps they would take to overcome them, it was George W. Bush who would eventually pledge to make energy security a top priority. After taking office, he spoke to a group of energy officials saying "This administration is concerned about [the energy crisis], and we will make a recommendation to the country as to how to proceed." In the following weeks, the message became even more urgent. "If we fail to act," Bush said, “our country will become more reliant on foreign crude oil, putting our national energy security into the hands of foreign nations, some of whom do not share our interests." But nothing in the proposals put forward, such as drilling in the Alaska Northern Wildlife Refuge and other protected

\footnotetext{
${ }^{26}$ ibid., pp. 10-11.

${ }^{27}$ ibid., p. 46.
} 
areas, or speeding development of hybrid vehicles, really did anything to reverse or eliminate the dependence on the Persian Gulf. ${ }^{28}$

Klare outlines four worrisome trends that he feels need to be understood in order to fully comprehend the current dilemma. First, is one that has already been addressed, and that is the increased reliance on foreign sources due to steadily falling domestic production in the United States. The second is that, part and parcel with this increased dependency, is an evermore important forging of relationships with countries or regions of the world which are either unstable, unfriendly, dangerous, or a combination thereof. He points out that dependency is troublesome primarily on this basis, as it would hardly be a concern if all the energy required came from places like Norway, Canada, or any other peaceful country. But like the United States, these countries, too, have limited reserves and are also slowly running out of oil. And so it is that regions like the Middle East, Africa, and Central Asia, which are more volatile, will increasingly be needed to meet the shortfalls derived from Western consumption. The third trend follows very closely from the second. The growing American (not to mention world) reliance on these same unstable regions only works to exacerbate already existing tensions in terms of access to scarce resources. There is widespread resentment across the Middle East, for example, of the presence of Western or American corporate/military interests in the region. Considering the focus on oil here, one need look no further than Saudi Arabia. U.S. influence has aroused much hostility from those who reject American values, or who resent the concentration of wealth and power in American hands. That 15 of the 19 hijackers on September 11 were from Saudi Arabia is hardly a coincidence, any more than that their targets were

\footnotetext{
${ }^{28}$ ibid., p. 15.
} 
the symbolic centres of global economic and military power. But al-Qaeda, in the sense of representing anti-Western or anti-U.S. feelings, is hardly anything new. As we have already seen in the previous chapter, and even then only briefly, there is a whole history of antagonisms when it comes to foreign capitalization on economic interests in the area. The movement of troops into Iraq, led by the United States, has almost certainly already inflamed the hostilities of al-Qaeda and similar ideologies. As news accounts have already shown, the now U.S.-protected oil infrastructure of Iraq has come under repeated attack, severely hampering the output of Iraqi oil to levels even lower than during Hussein's rule. Indeed, concerns are by no means limited to Iraq. In May 2004, the headquarters of an American oil company in Saudi Arabia was attacked by several gunmen, who killed five employees and injured many others before being killed themselves. This kind of strife and difficulty is likely to spread elsewhere, with offshoots of al-Qaeda popping up in places like Africa and Central Asia. Klare puts it well as he writes that when "the divide between privileged and disadvantaged coincides with tribal or religious differences, as it often does, violence is a likely outcome. The Western press may describe such strife as 'ethnic' in character, but it comes largely from the pervasive effects of oil production. ${ }^{29}$

All of this leads to a fourth and final trend, according to Klare. All other oil consuming countries are in the same boat as the United States, and will also have to draw on the same unstable regions to continue expanding their own economies. Many, such as those in Europe, and Japan, have long relied on the Middle East and Africa for a large share of their energy requirements. But the upswing in economic development in places such as China and India, introduces a whole new vector to the

${ }^{29}$ ibid., pp. 15-22. 
equation. According to the Department of Energy, China's consumption alone will more than double over the next 25 years, as will India's. This will position both of them in a jostling match with the Americans, Europe, and Japan for access to the regions with excess petroleum.

The urgency of such a situation will only increase as worldwide supplies inevitably begin to dwindle in the future. The so-called 'Peak Oil' crisis, where the production capacity for these finite reserves of this essential commodity level off and begin an inexorable decline, is predicted by some to come as early as 2010, others say a decade or two later. All agree, regardless of when it actually happens, that "the planet's original petroleum inheritance has been substantially exploited and that a reduction in output is inevitable." The scarcity looming on the horizon, Klare continues, will almost certainly lead to a rise in the already well established practice of emphasizing the 'security dimensions' of energy production, and the consolidation of military ties with Gulf and other friendly nations. As we have seen already, the United States, along with countries like Russia and China, supply arms and military services in defence of their favoured status. ${ }^{30}$ Without making predictions, history gives pause.

\section{Saudi Arabia and the Path to 9/11}

One of the many countries that has benefited handsomely from just such an arrangement is Saudi Arabia. This, along with the fact that Saudi Arabia is home to the world's largest proven oil reserves, the country of origin for 15 of the $9 / 11$ hijackers, and the birthplace of Osama bin Laden, requires that Saudi Arabia receive specific attention in such a study of post-9/11 conspiracy theories.

${ }^{30}$ ibid., pp. 22-23. 
This attention is important because of the ways that these conspiracy theories in part reflect, without actually describing, the geopolitical realities of petroleum production. A central focus on oil, therefore, not to mention Saudi Arabia, should not be looked at as a version of conspiracy theory itself. Though oil does constitute one of the common denominators to archetypal conspiracy theories about the 9/11 attacks and the subsequent war in Iraq, it is worth remembering that one of the purposes of this study is to utilize the narrow-minded simplicities of conspiracy theory to nonetheless highlight very real geopolitical frictions. After all, conspiracy theories do not arise out of pastoral or utopian existences. On the contrary, they represent imagined solutions to the more mundane impediments to pastoral or utopian visions of the future (or visions of the past, for that matter). As we shall see, conspiracy theories about these 'mundane impediments' were central motivating factors on both sides of the current conflict. As such, a look at the Saudi Arabian inflections on this theme provide an essential element to a fuller understanding of not only the $9 / 11$ attacks, but the broader antagonisms inflamed by the invasion of Iraq.

Simply put, Saudi Arabia is singularly important to American interests. As we began to see in the previous chapter, the U.S.-Saudi relationship has a long history which has been carefully honed and cultivated by every American administration since the inception of the country under King Ibn Saud. With approximately one-quarter of proven world reserves, it has consistently shown itself to be an indispensable ally to the Americans. One example of this came in 1990 following the Iraqi invasion of Kuwait, when Saudi Arabia boosted production to offset the loss of oil from both those countries, and in turn, helped avoid an economic downturn in the United States. In return, the United States has been a key supplier of armaments, military and technical advisors, and the deployment of 
hundreds of thousands of troops during Operation Desert Shield in order to ward off a perceived threat from Iraqi forces after they had moved into Kuwait. In fact, despite later pronouncements about the U.S. intentions to liberate Kuwait, destroy Iraqi weapons of mass destruction, and bolster international sanctions against aggression of this sort, President George H.W. Bush highlighted American energy interests in a nationally televised speech on August 8, 1990. "Our country now imports nearly half the oil it consumes and could face a major threat to its economic independence," he said. Therefore, "the sovereign independence of Saudi Arabia is of vital interest to the United States." ${ }^{31}$ Then Secretary of Defence Dick Cheney echoed the same theme on September 11, 1990, while speaking to the Senate Armed Services Committee. "Once [Saddam] acquired Kuwait and deployed an army as large as the one he possesses," Cheney said, he would be "in a position to be able to dictate the future of worldwide energy policy, and that [would give] him a stranglehold on our economy." 32 However, this sort of foreign intervention would be looked upon dimly by sectors of Saudi society, especially if American forces remained in the country to maintain the southern nofly zone in Iraq. But it would be just such a situation that would eventually transpire, helping to feed anti-American sentiment, and itself becoming a factor in the rise of bin Laden as not only an enemy of Saudi royal family, but of the Americans as well. ${ }^{33}$

King Fahd had been well aware of this potential for unrest. For the better part of five decades since the days of Ibn Saud, the royal family was opposed to any conspicuous foreign military presence in

\footnotetext{
${ }^{31}$ New York Times, transcript of speech, August 9, 1990, cited in Klare, ibid., p. 50.

${ }^{32}$ Senate Armed Services Committee, Crisis in the Persian Gulf Region, p. 11, cited in Klare, ibid.

${ }^{33}$ ibid., pp. 26-27.
} 
the country, something he felt would provoke "violent criticism from reactionaries and fanatics". Concerns in that regard had not changed in 1990, and Fahd resisted Washington's request for permission to station American troops there. This prompted President Bush to send Cheney to the Saudi capital to try and convince Fahd to reconsider. Only after he was shown satellite images allegedly showing Iraqi tanks advancing to the Saudi border, did Fahd conclude that Hussein was a greater threat than the anger of his people. Permission for the placement of troops was given, but on the condition that they be withdrawn as soon as the threat from Saddam had passed. Cheney provided assurances on this, and within hours U.S. combat planes and paratroopers were on their way to the Gulf to commence Operation Desert Shield. ${ }^{34}$

While the Americans believed that their ground forces were the only way to assure the protection of Saudi Arabia, the Saudi leaders had been made another offer. It came from Osama bin Laden. bin Laden enjoyed access to the Saudi royal family due to his connections with Prince Turki al Faisal, the head of the Saudi intelligence service, after working closely with him during the conflict with the Soviets in Afghanistan. bin Laden's Arab-Afghan forces had since fought in the cause of Islam in places such as Bosnia, Kashmir, and elsewhere, and were scattered about the Middle East, available for immediate service in that same cause. He tried to persuade the Saudi King to employ his fighters instead of the Americans. As Klare puts it, "Fahd's decision to reject his offer and to rely instead on an army of 'infidels' infuriated bin Laden and turned him into an implacable foe of the royal family." ${ }^{35}$

\footnotetext{
${ }^{34}$ ibid., p. 51.

${ }^{35}$ ibid., p. 52.
} 
Soon after, Operation Desert Storm got underway, with another 250000 American troops joining the 250000 that were already in the region, and preparations for the full-scale assault on Iraqi positions in Kuwait began in earnest. On January 17, 1991, a five-week air campaign began followed by the ground offensive on February 24. Four days after that, Iraqi forces abandoned Kuwait, and Bush senior called an end to combat operations. But with the subsequent containment policy put into effect, Operation Southern Watch required that the United States continue to occupy the air bases it had established in Saudi Arabia during Desert Shield. This violated the promise Bush had made to King Fahd, and infuriated bin Laden even further. He accused the royal family of being subservient to the Americans, and exhorted his followers to topple the royal family and push the Americans out. In issuing his fatwa in 1998, bin Laden declared that "[f]or over seven years, the United States has been occupying the lands of Islam in the holiest of places, the Arabian peninsula, plundering its riches, dictating to its rulers, humiliating its people, terrorizing its neighbours, and turning its bases in the Peninsula into a spearhead through which to fight the neighbouring Muslim peoples." He went on to say that in order to correct this, it was "an individual duty for every Muslim" to "kill the Americans" and drive their armies "out of all the lands of Islam" bin Laden had already shown how serious he was. In 1995, he bombed the Saudi Arabian National Guard (SANG) military headquarters in Riyadh, killing five Americans, and attacked the Khobar Towers housing U.S. air force personnel in Dhahran in 1996. In 1998, American embassies were bombed in Nairobi, Kenya, and Dar es Salaam, Tanzania. October 2000 saw the bombing of the U.S.S. Cole as it was in the harbour of Aden, in Yemen, followed of course by the $9 / 11$ attacks almost one year later. ${ }^{36}$

\footnotetext{
${ }^{36}$ ibid., pp. 53-54.
} 
It is at this point, then, that the major pieces are in place for a much closer look at the conspiracy theories that have swirled around $9 / 11$ ever since. It will demonstrate how it is that conspiracy theories are inseparable from i) the rationale for the $9 / 11$ attacks themselves, ii) the popular understandings of the issues at play within and behind them, iii) the discourses employed to discuss those issues, iv) the Bush administration's responses to criticisms of its actions in Iraq, and v) the ratcheted-up tensions in the Arab world in response to all of the above. Quite apart from all this, as we have already seen, the reasons given for going to war with Iraq in the first place were themselves based on a conspiracy theory. Such a situation requires an approach which regards conspiracy theory as an important and integral optic on the dialectics of representation and reality.

\section{9/11 Conspiracy Theories}

It is anything but surprising that events on the magnitude of the $9 / 11$ attacks should produce an array of conspiracy theories from many different (and often competing) political viewpoints. In fact, one of the things that makes conspiracy theories interesting is the diversity of perspectives they accommodate on the very same event. However, it is this multi-perspectival nature which also renders them malleable, amorphous, and slippery. That said, a survey of different conspiracy theories from around the world about the 9/11 attacks and their aftermath provides useful sampling which demonstrates how readily inflected they become by previous historical and political experience. 
In his article for the Christian Science Monitor, ${ }^{37}$ Warren Richey writes that America's efforts to recruit street-level support among Arabs and Muslims in the Middle East for its fight against international terrorism were running into some serious difficulties. While most Americans considered Osama bin Laden to be a prime suspect in the 9/11 attacks, public opinion in the Arab and Islamic worlds was moving in a decidedly different direction. "Most Muslims," he writes, "are entertaining alternative theories, and many are embracing one theory above all - that the attacks were carried out by Israel's clandestine intelligence service, the Mossad." Richey points out that, among other things, it stood as a glaring indication of how badly the U.S. was faring in the so-called "PR war." But it was not just man-on-the-street types that held to positions such as these. Conspiracy theories were proliferating even among senior government officials. "The level of conspiracy theories just makes you want to scream," said one Western diplomat based in Amman, Jordan, after being lectured by a senior Jordanian official on the "obvious" role played by the Mossad. A similar position was expressed by the Syrian Defence Minister, Mustafa Tlass, during a meeting with visiting British academics. Richey points out that suspicious attitudes and conspiracy theories are nothing new in the Middle East, where the Mossad is often seen as an evil force that is behind otherwise inexplicable events. Beliefs like these were seriously undermining President Bush's attempts to generate sympathy for the victims of the attacks, and his attempt to build a concerted international campaign against terrorism. As Michael Hudson, director of the Arab Studies program at Georgetown University put it, "We are just not even in the ballpark here, and the Bush

\footnotetext{
${ }^{37}$ Warren Richey, 'Muslim Opinion Sees Conspiracy', Christian Science Monitor, November 6, 2001. Accessed on December 9, 2003.
} 
administration is aware of this." ${ }^{, 38}$

Between the lack of direct evidence proving a connection to bin Laden, and the Arab and Muslim perceptions of a rush to judgement by the Americans, a flood of elaborate theories were circulating in the Arab press, advanced by columnists in places like Jordan, Syria, Egypt, London, and the West Bank. Among the theories put forward was that the attacks were the work of "the great Jewish Zionist mastermind that controls the world's economy, media, and politics." 39 Others suggested that Bush had ordered the hijackings to consolidate his hold on power in Washington, and erase any memory of the election controversy in Florida following the 2000 election. Japanese extremists were the villains in another telling, carrying out the attacks as retribution for the Hiroshima and Nagasaki nuclear bombings in 1945. The militia movement in the United States provided another explanation, with the attacks seen as payback for the execution of Timothy McVeigh. Though Richey proffers a position on the genesis of conspiracy theories that is overly narrow when he writes that they "are an inevitable consequence in countries where the flow of news and information is controlled by the government" ${ }^{\prime 40}$, he correctly points out that reading between the lines in an effort to discern the truth is motivated by speculation on the basic question of 'Who benefits?'

"It is a lack of information and candor that feeds conspiracy theories, as people attempt to use their

\footnotetext{
${ }^{38}$ Address this in the conclusions from the point of view of his references to 'conspiracy theories' in relation to this audience compared to what he says to his own.

${ }^{39}$ Richey, ibid.

${ }^{40}$ As just one example of the problem with such a statement is that it contradicts the explosion of conspiracy theories on the Internet, not to mention their rampant popularity in open and democratic societies as well.
} 
own wits in trying to figure out what is being hidden from them," says Jon Anderson, a professor of anthropology at Catholic University in Washington, D.C. "There is a serious failure of public diplomacy [by the U.S.], which is feeding the generation of conspiracy theories." Along these lines, the U.S. is not seen as a force of good acting for peace, but rather, many Muslims question whether the real motivation is a war against Islam in order to keep the area safe for Israel. President Bush's unfortunate use of the word "crusade" in an earlier speech is often cited as "proof' of this. Regardless, Richey points out how at the street level, there is near complete distrust of the U.S. government's policies and aims. He relates that one of the most prominent of the theories circulating at the time, was the suggestion that Jewish Americans were given advance warning about the attacks, and were told not to report to work at the World Trade Center the morning of September 11. For many, this constituted 'proof' that the Israeli Mossad were indeed behind the attacks. "Why hasn't the media stressed the 4000 Jews who did not turn up for work on Sept. 11" asks Lina ${ }^{41}$, a Palestinian student quoted by Richey, and who was studying in Amman, Jordan where he was stationed. Her friends nodded in agreement. "The Israelis are the ones with the most to gain," says another, a dressshop clerk. The rationale here is that the Mossad conducted the attacks in order to goad the United States into what would become a joint U.S.-Israeli military effort against Islam. The Americans would target bin Laden in Afghanistan, and Israel would concentrate on the Islamic militants in Palestine.

The conspiracy theory about the 4000 Jews who did not turn up for work at the World Trade Center on the morning of the attacks has an interesting origin that is worth drawing brief attention to.

\footnotetext{
${ }^{4 i}$ For some reason, the abbreviation for 'September' appears in Richey's original quote for his article.
} 
Among other things, and in contrast to the quote cited above, it highlights the central role of modern communication systems in the wide circulation and popularity of this particular myth, while putting the lie to a belief in the centralized control of information inherent to so many conspiracy theories.

CBS.com reported this compelling anecdote shortly after 9/11 attacks. It stated that:

...the story of the 4,000 Jews is an example of the new kind of threat we face. There's always been a belief in the so-called "Jewish conspiracy" in the world of Islam. But it seems now to have just taken off, and gone into the almost unbelievable stratosphere.

How the myth of the 4,000 Jews became reality in the minds of Muslims around the world is a cautionary tale from the dark side of the information age.

It began on Sept. 13 in Jordan when rumors of Israeli involvement in Sept. 11 surfaced as news stories in two Arab papers.

The next day, a crucial element was added: the figure 4,000. That was the number of telephone calls an Israeli ambassador told reporters had come into his government from worried Israelis unable to contact their relatives in New York.

Then on Sept. 17 in Beirut, al Manar, a television station controlled by the radical Islamic group Hezbollah, aired the full fantasy for the first time. Billed as a special investigative report, al Manar claimed that 4,000 Israelis employed at the World Trade Center had not shown up for work on Sept. 11.

The next morning, this tale hit the Internet and began moving from one Islamic Web site to the next. In the days and weeks that followed, the story spread like wildfire all across the Muslim world, surfacing in newspapers, radio and TV reports and talk shows in Iran, Egypt, Pakistan, and beyond.

In just a matter of days, one falsehood piled on top of another, and passed on to audiences around the globe, had produced "the big lie" - a lie now accepted as fact throughout the Muslim world.

A couple of closing quotations from Richey demonstrates how true this actually is. "bin Laden is being framed for these attacks," says Mahmood, a Saudi student in Jordan. "There is no evidence of his involvement." Though at the time of the report, it is true that was no direct links to bin Laden, there was serious and growing circumstantial evidence pointing to al-Qaeda. Despite this, however, a comment by Ahmad, a restaurant worker in Amman, reflects an attitude typical of the archetypal conspiracy theorist. "We believe Osama bin Laden didn't do this, even if the evidence shows that he did." 
Another piece in Pravda ${ }^{42}$ contains an entirely different set of resonances. "History has a way of repeating itself and that certainly seems true at times," Bourke writes.

As the unfolding mess of post-war Iraq appears in front of our very eyes, it increasingly seems as if the same fanatical fervour with which Senator Joe McCarthy pursued what he saw as reds under the bed in every corner of America in the 1950s, is the same conspiracy theory mentality which sees the current Bush administration going to war against a country they seemed certain was out to get them, when it now seems likely that they actually did not have anything with which to get them in the first place.

The article goes on to suggest that with neo-cons in the White House like Rumsfeld, Wolfowitz, and Cheney convinced that Hussein was "one step away from nuking the US off the face of the earth," he claims it is no wonder that it took so very little factual information to convince them of their fantasy. It only took what he calls "the tiniest particles of intelligence" such as meetings in Hungary ${ }^{43}$ between Iraqi intelligence officers and al-Qaeda figures, and the purported purchase of yellowcake from Niger to lead them to conclude that "the Saddam-led apocalypse on America was due any minute now and counting." He goes on to predict that the CIA would take the fall for intelligence. And while conceding that U.S. intelligence agencies "will not win any awards for efficiency any time soon, the underlying dishonesty of this is the reality that quality of information is somewhat irrelevant anyway when you have already made your mind up beforehand on who the bad guy is and the need to wage war against him."

A German article ${ }^{44}$ shows, in its own ways, that collective memories of the Reichstag fire may be

\footnotetext{
${ }^{42}$ John Bourke, 'Bush Conspiracy Theories', Pravda, November 24, 2003. Accessed on December 9, 2003.

${ }^{43}$ Any stories I have read about these alleged meetings have had them taking place in Prague.

${ }^{44}$ Ralf Isermann, '9/11 Conspiracy Theories Gain Ground', iafrica.com, September 8, 2003. Accessed on December 9, 2003.
} 
burning brightly still. ${ }^{45}$ "Conspiracy theories on the September 11 attacks are gaining ground in Germany two years on," Isermann records, "with books claiming that the US government was behind the atrocities climbing bestseller lists." A number of these books, deemed 'non-fiction' in bookstores, were providing a forum for wild accusations regarding the attacks, and were gradually becoming a part of the public debate amid a sizable minority in Germany. Hamburg after all, he points out, was home to an al-Qaeda cell that produced three of the $9 / 11$ hijackers. He shows that though each book has a different take on the events of the day, they all share the fundamental premise that George W. Bush planned the attacks or allowed them to happen in order to advance a radical foreign policy agenda. A book by Mathias Broecker, a former journalist with a leftist daily, called "Conspiracies, Conspiracy Theories and the Secrets of September 11" sold more than 105 000 copies in its first ten months in release, with a follow-up volume hitting bookstores just before Isermann's article was written. 70000 copies of "The CIA and September 11" were purchased by Germans. It was written by Andreas von Buelow, a former German research minister, who claimed

\footnotetext{
${ }^{45}$ The burning of the Reichstag, or Parliament building, in Berlin on the night of February 27, 1933 was a key, though not determining, event in the emergence of Nazi dictatorship. It is sometimes considered to have been contrived by the Nazi government themselves in order to turn public opinion against its communist opponents. Though he had already secured the German chancellorship in November of 1932, Hitler and his party had not yet secured a majority government. After setting a quick date for a new election for March 5, 1933, it is here where the conspiracy theory comes into play. Hitler's propaganda minister, Joseph Goebbels, was supposed to have devised a plan whereby ten agents led by Karl Ernst gained access via a tunnel to the Reichstag from the official residence of the president of the Reichstag and Hitler's chief minister, Hermann Goring. Goring was then to conduct an official investigation that would find the communists guilty. A Dutchman, Marinus van der Lubbe, was officially charged with arson, but in keeping with contemporary conspiratorial mythology, had been brought to the scene of the crime by Nazi agents. Another position is that there was no Nazi complicity in the crime, but that they merely capitalized on van der Lubbe's individual act.
}

Regardless, the day after the fire, a decree was enacted "for the Protection of the People and the State" which dispensed with constitutional protections for political, personal, and property rights. After the March $5^{\text {th }}$ elections, however, the Nazis still could not claim a majority government, but still managed to persuade the Reichstag to pass an Enabling Act on March $23^{\text {rd }}$, and all legislative power was transferred to the Reich Cabinet by a vote of 444 to 94 , sanctioning the dictatorship (Encyclopedia Britannica Online. Accessed at www.propl.org/park/reichsta.htm. on October 9, 2005). 
that the planes were not piloted by Islamic extremists, but were instead directed via remote control into their targets. A third popular seller was "Operation 9/11" by public television reporter Gerhard Wisnewski. It echoed an American conspiracy theory, noted earlier, that the twin towers were wired with explosives. It was already enjoying a fourth-print run after only three weeks in stores. All of this comes on top of "9/11: The Big Lie" by France's Thierry Meysson whose book had already been a best-seller in Germany, as well as in his native France. It described the attacks on the Pentagon as an attempted coup d'etat by U.S. military officials to justify future wars.

Der Spiegel, the German news weekly, did not let this phenomenon go unnoted. Its edition in advance of the second anniversary of the attacks addressed the German popularity of 9/11 conspiracy theories for its cover story that week. The article took them to task, and meticulously knocked down the most popular conspiracy theories while attributing their success to the strong German distaste for the conservative administration of George W. Bush. Isermann cites Rudolf Stoeber, a mass communications expert, who felt that the shock of the September 11 attacks left people searching for simple answers. More striking, according to Stoeber, is that so many of the German youth found the theories believable. For example, a study by the respected Forza Institute published in another weekly, Die Zeit, found that $31 \%$ of Germans under the age of 30 believed the U.S. government was directly involved. When all age groups were factored in, the number dropped to a still surprising 19\%. Stoeber also suggested that cultural ignorance was a factor in why Germany had given such fertile ground to conspiracy theories which appear unthinkable to most. "We don't understand Islam and have no idea about the lives of the attackers," he said. "That is why we prefer to look in our own cultural circles for possible causes for the incomprehensible." 
Iraqi conspiracy theories ${ }^{46}$ before the capture of Saddam Hussein, display an interesting mixture of suspicions which reflect its British colonial history, its onetime-ally relationship with the United States, and Hussein's own Sunni minority status as he presided over the slaughter of so many of his own people. The case of Hussein is particularly interesting on this point for the ways that he is aligned, within Iraqi conspiracy theories, with outside powers. "Saddam is tanning in Tel Aviv;" the article begins, "his wife Sajida and three daughters are sipping tea in their mansion in Leeds, England; and his sons Uday and Qusay are gambling in Monte Carlo. Such wild conspiracy theories, widely believed by ordinary Iraqis, are why Washington released what it said were photographs of Saddam's slain sons amid great fanfare today." The photos were dismissed by many Iraqis as American military propaganda. ${ }^{47}$ "It's a show," laughs sculptor Mohammed Ghani Hikmat. "Some people say the family is in England. Some people say Morocco. Some people say they're in America." Paradoxically, the death of Uday and Qusay was, to many Iraqis, the ultimate proof of a secret pact between the United States and Saddam. "Welcome to the tired and feverish minds of Baghdadis," the article runs, "humiliated by war and occupation, hateful of their old ruler and

${ }^{46}$ AFP (author unknown), 'Conspiracy Theories: Saddam's Tanning and the Boys are Gambling', smh.com.au, July 25, 2003. Accessed on December 9, 2003.

\footnotetext{
${ }^{47}$ In fact, such suspicion is rather easy to understand, once cultural differences are factored in. A Reuters piece by Andrew Marshall released the same day (Reuters Sees Touched Up Bodies of Saddam Sons, Reuters, July 25, 2003. Accessed on July 27, 2003) states, “A U.S. military official said 'facial reconstruction' was used to repair wounds, particularly to the face of the elder son Uday, which had disfigured the bodies shown originally to the public in photographs taken by soldiers after the battle [...] Inside the tent, U.S. officials said it was standard practice to use morticians putty to prepare bodies for viewing and was not intended to fool the Iraqi people. But while it may be common in the United States, the move is unheard of in the Arab world. That could affect Washington's efforts to quash Iraqi conspiracy theories that the bodies are not in fact those of the once powerful and hated sons of Saddam, who [was] believed to be still in hiding in Iraq." Interestingly, this exact point is referenced at the very end of the AFP piece cited above. The last two sentences run, "Inside a cramped studio, plastics artist Fuad Haman, 41, guesses the two-day delay in showing pictures of Uday and Qusay comes from the elaborate preparations to fake their corpses. 'In a photo, you would never notice the difference', says Haman, an expert at making near-life plaster replicas of people." His observation glances over the fact that it was the pictures themselves which reinforced the conspiracy theories to begin with.
} 
distrustful of the new."

The article suggests that, not unlike the atmosphere in post-WWI Berlin, where many Germans believed that their country had been sold out by Jews and foreigners, Baghdad, too, was rife with conspiracy theories that "ooze a palpable sense of defeat." Ali Abdul Hassan Haidar, 52, and Nasser Hindi, 50, both from the Shiite majority long oppressed by Saddam, had many reasons to be happy about his overthrow, but still remained sceptical. To them, the reported last stand of Uday and Qusay had the air of a sell-out, just like the swift fall of Baghdad on April $9^{\text {th }}$ of that year. "There are a lot of possibilities," says Haidar. "Maybe the Americans pretended to kill them to get them out of the country in order to reduce the resistance." He then went on to suggest that the Americans were paying Saddam to sabotage the electrical system and oil pipelines in order to buy themselves time to entrench themselves more deeply into Iraq. "Maybe it's part of the deal," he adds. To emphasize the point, Hindi displays an Islamist newspaper, Iraqi Life, with a front page story about an alleged phone call between Saddam and George W. Bush, just hours before the bombing began on March 20. "Bush tells Saddam: 'You are to obey what our agent in Baghdad tells you. Keep holding military meetings and appearing on TV. You must not worry, our agent in Baghdad will get you out safe. Have all your belongings packed."”

Another Iraqi, Fallahan Hassan, 33, a vendor who had just finished selling a pair of refrigerators and a water cooler to U.S. soldiers, also hates Saddam. Ten of his relatives disappeared in the 1980s. But he still suspects that the Americans are here for oil, to control Islam, and to protect Israel. "Why did Iraq fall in 20 days and three months later, they still haven't arrested the president?" he asks. 
"Saddam is their secret agent." One of Hassan's customers, Iyad al-Mussawi adds, "Maybe he's in Tel Aviv. He's been their agent since 1980."

\section{Conspiracy Theory and Collective Memory}

It is interesting to consider the different inflections between each of these conspiracy theories in relation to each country's recent economic and political history. Though the introductory examples above are few in number, they are nonetheless indicative and chosen at random, and do reference to the same series of events in some unique ways. It is with examples such as this in mind that a more sustained examination of American conspiracy theories about the same events can be framed. With Hofstadter and others already pointing to a rich tradition of conspiratorial thinking in American history, the task becomes that much more meaningful. It shows that in contrast to positions which might view the response to September $11^{\text {th }}$ by the Bush administration as somehow unprecedented, there is a much stronger case to be made for the continuities which exist with the past, than there is for any radical break from it. Surely, it can be conceded that in some idiosyncratic ways the Bush team do bring some rather juicy additions to the discussion. For example, Bush's hyper-religiousity and sense of divine mission are indeed jarring at times, but are by no means unique to the U.S. presidency. The pre-emptive military invasion of Iraq is without question unprecedented in terms of scale, but only joins a whole range of other activities conducted by American military and intelligence agencies which were technically illegal. ${ }^{48}$ After all, the onset of anti-American sentiment the world over did not begin with George W. Bush's Inaugural Address on January 20, 2001. Likewise, the Bush administration did not invent the carrying of huge deficits, as much as the

\footnotetext{
${ }^{48}$ See as one example William Blum, Killing Hope
} 
current U.S. national debt is at a record level, and according to the International Monetary Fund, threatens the global economy. All of these will receive a fuller airing in the following chapter, but for now, the most that can be said is that it constitutes a difference in degree, rather than kind. The present focus on conspiracy theories works most immediately to demonstrate how consistent contemporary concerns are with the big ticket issues of yesteryear.

Christopher Andrew, a Professor of History at the University of Cambridge, provides a useful rationale for the contemporary study of conspiracy theory. In an article for History and Policy, ${ }^{49}$ Andrew begins by invoking Churchill's advice that 'The further backwards you look, the further forward you can see'. Just as when the Khmer Rouge entered Phnom Pehn, and Pol Pot declared it the beginning of Year Zero by insisting that Cambodia disown its past, likewise some eminent post 9/11 American voices were sounding something of the same alarm. The American intelligence community, according to Brent Scowcroft, needed to declare its own Year Zero. Andrew cites Scowcroft as saying "This is a very new world, to which none of the structures or habits of thought established within the intelligence agencies are geared." Andrew emphasizes the fact that Scowcroft does not simply feel that some of the structures and habits are out of date, but rather that all of them are. As Andrew puts it, though Scowcroft has "a remarkably distinguished record and is an improbable candidate for a US Pol Pot, his message for the future pays too little attention to the past."

${ }^{49}$ Christopher Andrew, Intelligence Analysis Needs to Look Backwards Before Looking Forward, History and Policy, Date unknown. Accessed on October 14, 2005. Andrew also published a shorter version of this article in The Scotsman called Why Lessons of the Past Can Help Fight Terror of the Future on July 10, 2004. Accessed on July 9,2004 . Both versions of the article are referred to here. 
Andrew writes that those who prophesy the future tend to fall into one of two categories, both of which are mistaken. The first, are those who say that we have seen it all before, and the second, that the world is entirely new, and that we need to start completely afresh. He feels that today's false prophets fall distinctly into the second category, and writes that there is "nowadays a widespread conviction that the experience of all previous generations save our own is irrelevant to present and future policy and intelligence analysis." He concludes that our current political culture is dominated by an unprecedented malady: Historical Attention Span Deficit Disorder or HASDD, to which he playfully asserts is the only medical term and the only acronym he has ever invented.

Disrespect for the long-term past, he continues, produces two serious intellectual shortcomings. The first is that the newest is necessarily the best and most advanced, and the other is that the recent past provides an adequate template from which to think about the future. He points out right away, however, that very little about future trends can be deduced from the simple study of a mere generation of human experience. He suggests that those who showed the most understanding of the threat posed by international terrorism before $9 / 11$ were those who took Churchill's advice, and that those who were most wrong were also those who ignored it. Using himself as an example, he refers to a paper he presented in February of 2001. In it, he said

The nature of the current terrorist threat has been widely misunderstood because it has been seen in too short-term a perspective. For the past generation the conventional wisdom has been that the terrorist's prime objective is publicity rather than victims, to terrify rather than to kill ... This is simply a short-term deviation from a much more dangerous longer-term terrorist tradition which is now reasserting itself. Until the $19^{\text {th }}$ century, terrorism was essentially Holy Terror. Over the last 20 years there has been a resurgence of traditional religious and cult-based terrorism.

He notes that this resurgence reflects the ideology of the religious wars of early modern Europe. Not 
incidentally, it is also the ideology of Osama bin Laden, among others. He claims that in the quarter century before $9 / 11$, much academic research actually lessened the understandings of terrorism by extrapolating short-term $20^{\text {th }}$ century trends at the expense of understanding the long-term threats posed by holy terror and ideologically driven terrorism. It is the latter type which seeks to destroy enemies, as opposed to bringing them to the bargaining table. ${ }^{50}$

Andrew outlines four methodologies for learning from long-term intelligence experience. Only one of them is pertinent to the present study, and that is his fourth, which he describes as the necessity to 'see ourselves as other see us'. It is on this count that he suggests intelligence communities have been slow to adapt. And yet, it is precisely this ability to unravel the mindset of opponents, and of fanaticism in particular, that most severely challenges strategic intelligence. When such fanaticism is armed with power, as it was in the cases of Hitler, Stalin, and Pol Pot, such an approach could have proven to be invaluable. Given the present circumstances, Andrew suggests that for the foreseeable future those likely to do the most damage in the $21^{\text {st }}$ century are those like bin Laden. What makes Andrew's perspective interesting here, however, is the emphasis he places on the role of conspiracy theories as a guiding influence of fanaticism.

Fanaticism, like the terrorism it spawns, needs to be interpreted from a long-term perspective. Andrew cites the example of British Foreign Secretary Jack Straw, who called bin Laden 'obviously

\footnotetext{
${ }^{50}$ Richard Clarke provides a useful adjunct to this idea, as he writes that "Al Qaeda planned attacks years in advance, inserted sleeper cells, did reconnaissance. They took the long view, believing that their struggle would take decades, perhaps generations. America worked on a four-year electoral cycle and at the end of 2000, a new cycle was beginning" (Richard A. Clarke, Against All Enemies: Inside America's War on Terror, 2004; p. 227).
} 
psychotic and paranoid as well' as an example of the limitations of a short-term point of view. From a long-term perspective, he claims, fanaticism itself looks very different. In adopting a long-term outlook, a couple of central consistencies emerge. One is that all fanatics are necessarily conspiracy theorists. Whether the enemies are perceived to be witches, Jews, Trotskyists, or some other manifestation, the hatred required to in order to exterminate them "can only be justified by substituting demonic, conspiratorial myth-images for reality." As Voltaire warned, 'Those who believe absurdities will commit atrocities'. Conspiracy theories are the common denominator of all the most dangerous terrorists of the past decade or so, such as the World Trade Center bombers, Ted Kazinsky, Timothy McVeigh, Aum Shinrikyo, and al-Qaeda. On the other hand, one can never forget that despite the reliance on conspiracy theories, these individuals and groups are often very calculating and dangerously effective, as all of the examples above certainly prove. One of the problems with the current approach to international terrorism, he goes on, is that it fails to take both of these important aspects into account. The historical record is full of examples which demonstrate the difficulties analysts have had in this regard, whether one looks at Adolf Hitler, Joseph Stalin, or, at least before 9/11, Osama bin Laden.

Andrew points out that Hitler could, when he wanted to, effectively play the role of international statesman. The Western assessments of his intentions, previous to WWII, failed to properly credit the fanaticism on display in Mein Kampf, which drove him and his generals to achieve the "most spectacular sequence of rapid military victories since Alexander the Great" during the first two years of the war. So his obsession with the conspiracy theory of a Jewish plot for world domination went all but unchecked as British intelligence learned an unprecedented amount of information about his 
military and spying capabilities.

Stalin, too, was equally difficult to understand. Khrushchev described him as 'sickly suspicious' and was one who saw spies and enemies everywhere. At different times, he too was "obsessed by huge and mostly non-existent conspiracies by Trotskyists, Titoists, Zionists and homicidal Jewish doctors." Many of the people who were shot or perished in the gulag as 'enemies of the people' were not enemies of Stalin or the Soviet system at all. "Yet," Andrew continues, "because Stalin was also a skilful negotiator who got the better of both Roosevelt and Churchill, Western analysts found it impossible to grasp the centrality of conspiracy theory in his world-view."

Andrew writes that bin Laden and his followers are every bit as dangerous because, like Hitler and Stalin, they combine obsessional conspiracy theories with great operational and tactical skill. He points out that among other conspiracy theories, they believe in the world Jewish conspiracy described in the Protocols of the Elders of Zion, and in what bin Laden refers to as the United States' subordination to the Jews. ${ }^{51}$ He concludes that we "cannot understand what al-Qaeda think they are fighting against and what they mean by "Jews and Crusaders" unless we explore their conspiracy theories. Noting the description of Stalin by British diplomat R.A. Sykes as 'a curious mixture of

\footnotetext{
${ }^{51}$ Indeed, in an audiotape released by al-Qaeda shortly after the capture of Saddam Hussein in December of 2003, bin Laden calls on Muslims to "continue the jihad to check the conspiracies that are hatched against the Islamic nation" and stated that the US-led war against Iraq was the beginning of the "occupation" of the Gulf states for their oil. "My message is to incite you against the conspiracies, especially those uncovered by the occupation of the crusaders in Baghdad under the pretext of weapons of mass destruction, and also the situation in [Jerusalem] under the deceptions of the road map and the Geneva initiative", he said (Associated Press, Bin Laden Tape Aired, The Globe and Mail, January 4, 2004. Accessed on January 4, 2004). This comes on top of many similar statements given in his only full interview after the $9 / 11$ attacks cited earlier.
} 
shrewdness and nonsense' he suggests that "a valuable addition to the $21^{\text {st }}$-century US national intelligence community would be a National Intelligence Officer for Fanaticism and Conspiracy Theory."

From a perspective like this, it remains important to consider what conspiracy theories illuminate about real ruptures within the societies from which they spring, while nonetheless representing the significance of these ruptures in completely illusory ways. There is no doubt something to bin Laden's conspiratorial suspicions about the role of Middle East oil, for example. After all, there is a whole history of Western involvement and attempts to exploit the natural wealth that it represents. But not too much unlike the perceived role of animal fat on bullet casings that helped spark the Sepoy rebellion, a deliberate war against Islam has nothing to do with it. The simple fact that beliefs about oil in this regard are shared with conspiracy theorists in the West, should not de-legitimate oil as a valid point of interest, despite the illegitimacy of the conspiratorial narratives which are sometimes employed to describe it. What it does do, and in this case particularly clearly, is illustrate how useful conspiracy theories can be in simultaneously highlighting oil as one of the common denominators of the global political economy, and the timeless millennial vistas infused with their expression. That the same region of the world should be the birthplace of the big three monotheistic religions, and home to the largest known reserves of petroleum is, of course, entirely coincidental. That it currently sits at the epicenter of so many conspiracy theories about global economic dominance is anything but. On the contrary, it would be much more perplexing if this were not the case. Considering the real global interests at stake in the region in the wake of $9 / 11$, it brings attention once again to the compositional spectrum behind the transparency of conspiracy theory. 


\section{Conspiracy Theory as Conceptual Tool}

Given what is now taken to be the obvious co-dependancies between religious faith and economic well-being, and the tendency for them to be articulated in terms of conspiratorial rhetoric when that equilibrium is challenged by 'evil' outside forces, it demands attention to how indispensable conspiracy theories are to even understanding the $9 / 11$ attacks at all. For example, the planning and execution of the attacks of that day were informed and invigorated by a belief in a Jewish world conspiracy against Islam to which the United States was a party through its historical support of Israel. bin Laden's own words have repeatedly confirmed this. ${ }^{52}$ This belief, in turn, eventually effected an actual conspiracy by bin Laden and others to fly planes into the World Trade Center, the Pentagon, as well as the foiled attempt on the White House. The attacks themselves immediately gave rise to conspiracy theories throughout the Arab world that they were actually the work of the Israeli Mossad, in order to frame bin Laden, and draw the United States more directly into the widely perceived Zionist war against Islam. In being so, it reinforced existing beliefs in that part of the world about a Jewish world conspiracy. Meanwhile, and almost certainly in response to the popularity of conspiracy theories such as these (not to mention still others in the United States which suggested the Bush Administration had let it happen), the president implored the world to never

\footnotetext{
${ }^{52}$ see Bruce Lawrence [ed.], Messages to the World: The Statements of Osama Bin Laden, Verso, 2005. bin Laden points out in his first interview with al-Jazeera in December 1998, four months after the bomb attacks on the U.S. embassies in Kenya and Tanzania, that "the fact is that the Israeli authority and the Jewish authority, which has become powerful inside the White House, as everyone can see - the Defence [sic] Minister is Jewish, the Secretary of State is Jewish, the CIA and National Security officials are Jewish, all the biggest officials are Jews led the Christians to clip the wings of the Islamic world" (p. 67). October 2002 in a letter posted on the Internet called 'To the Americans': "You are a nation that permits usury, which has been forbidden by all the religions. Yet you build your economy and investments on usury. As a result of this, in all their different forms and guises, the Jews have taken control of your economy, through which they have taken control of your media, and now control all aspects of your life making you their servants and achieving their aims at your expense..." (p. 167). And later in the same letter: "Your law is the law of the rich and wealthy, who hold sway in their political parties, and fund their election campaigns with their gifts. Behind them stand the Jews, who control your policies, media, and economy" (p. 168).
} 
tolerate outrageous conspiracy theories regarding the attacks of September the $11^{\text {th }}$. At the same time, members of his administration, including the president, were looking for ways to connect the 9/11 attacks to Iraq. It was an attempt which was itself rooted in yet another conspiracy theory about the role of Saddam Hussein in anti-U.S. terrorism. These efforts proved to be so successful, that at one point almost $70 \%$ of the American public believed Saddam Hussein was directly responsible for the 9/11 attacks. The language used to accomplish this is arguably identical to that which Hofstadter has described as the 'paranoid style in American politics'. Public support for the subsequent invasion of Iraq, then, was at least partially influenced by the Bush administration's own conspiracy theory implicating Saddam. Not at all surprising, is that this invasion only exacerbated the original Arab conspiracy theories about American complicity with Jewish influence which had contributed to the $9 / 11$ attacks in the first place. It has almost certainly played an ideological role in the rise of the violent insurgency now faced by coalition forces in Iraq. If all of this is not enough, emergent criticisms within the mainstream American press of the Bush administration's shifting rationales for the invasion of Iraq and foreign policy in general over this same time period, were repeatedly dismissed as 'conspiracy theory' by members of the Bush administration, including by the president himself. So it is to a more focussed consideration of this state of affairs that attention is now turned. 


\section{Chapter Six - Smoking Guns and Mushroom Clouds}

In a press conference ${ }^{1}$ with African print journalists in advance of his trip to Africa a few days later, President Bush was unwittingly enjoying what would be the last few days of relative calm before an initially low-level scandal involving unknown individuals began to really erupt in the mainstream press. It would be a scandal related to an entirely different trip to Africa from almost a year and a half earlier. Although Bush's press conference with African journalists has no direct connection to what would eventually become known as the 'CIA Leak Investigation', the timing of Bush's subsequent trip, as we shall see, would have everything to do with it. What is necessary at this point, then, is a bit of background on one of the issues floating behind the scenes at the time of Bush's 2003 trip to Africa.

In this chapter I will pick up on some of the ways that the Bush Administration has itself employed the notion of conspiracy theory while framing that within the coverage of the CIA Leak Investigation. There are a lot of reasons to take the Fitzgerald CIA Leak Investigation very seriously, not to mention devoting significant attention to it in a thesis like this. The story behind that investigation, however, begins with a request to look into reported attempts by Saddam Hussein to purchase significant quantities of so-called 'yellowcake' uranium from the African country of Niger. The request, according to most reports, came from the CIA in response to a query from the office

\footnotetext{
${ }^{1}$ Office of the Press Secretary, President Bush Discusses Upcoming Africa Trip with Reporters, White House.gov, July 3, 2003. Accessed on October 11, 2005.
} 
of the vice-president, Dick Cheney. ${ }^{2}$ It was partly prompted by a document which had surfaced within Italian intelligence circles claiming to constitute evidence of an Iraqi attempt to buy uranium from Niger. ${ }^{3}$ SISMI, the Italian intelligence agency, passed the information on to British intelligence, and it eventually found its way into American hands. During this period, in early- to mid-2002, the Americans were desperately looking for evidence to support an invasion of Iraq. ${ }^{4}$ It was during the summer of 2002, for instance, that the White House Iraq Group (WHIG) began its efforts to collect as much information as possible on linking Iraq to the $9 / 11$ attacks, thereby justifying an invasion of that country on the basis of weapons of mass destruction. Essentially, it was a group formed to figure out a way to 'market' the idea to the American people, never mind the rest of the world. It is worth remembering, after all, that it was White House chief of staff, Andrew Card, who, in a startling fit of candor regarding the fall 2002 timing of the WHIG campaign to oust Saddam Hussein, confessed to the New York Times' Elisabeth Bumiller that, "From a marketing point of view, you don't introduce new products in August."5 Even if Card was only trying to be funny, it does not change the fact that it was indeed during the fall of 2002 that a more direct case began to be made through the mainstream American media linking the 9/11 attacks, Iraq's alleged weapons of mass destruction program, and the urgent need to deal with Hussein as a direct threat to

\footnotetext{
${ }^{2}$ Joseph C. Wilson, 'What I Didn't Find in Africa', New York Times, July 6, 2003. Accessed on July 9, 2003.

${ }^{3}$ Footnote the fact that the document would be proven to be a forgery, and that there had been a break-in at the Nigerian embassy in Rome, where the document surfaced in December 2001. It is also worth noting the fact that it was turned down by certain publications in Italy due to its dubious quality, and that it was eventually published in a magazine owned by Italian prime minister Silvio Berlusconi, a charter member of the coalition of the willing.

${ }^{4}$ See Ron Suskind (2004) and Richard Clarke (2004) on this point.

${ }^{5}$ Frank Rich, 'Never Forget What?', New York Times, September 14, 2002. Accessed on September 30, 2002.
} 
the United States.

It had been only a few months before this, in February 2002, that an American diplomat was dispatched by the CIA to investigate the alleged uranium sales to Iraq. ${ }^{6}$ While the specifics of the trip are not important here, what is worth noting is that there was no credible evidence found for such a sale of uranium to Iraq, nor indeed had there been any credible evidence that an attempt had been made to procure it. This information was relayed to the proper channels at the CIA and, as far as the unnamed diplomat was concerned, the rumours had been put to rest. Though there is much more detail that could be included here, the crux of the matter is, that despite the dismissal of the alleged uranium purchase by Iraq, President Bush made the following claim in his State of the Union address on January 28, 2003. He began by reminding the world that the International Atomic Energy Agency "confirmed in the 1990s that Saddam Hussein had an advanced nuclear weapons development program [and that he] had a design for a nuclear weapon and was working on five different methods of enriching uranium for a bomb." This lead the president into what would later become known as the infamous 'sixteen words'. "The British government has learned that Saddam Hussein recently sought significant quantities of uranium from Africa." The president continued: "Our intelligence sources tell us that he has attempted to purchase high-strength aluminum tubes suitable for nuclear weapons production. Saddam Hussein has not credibly explained these activities. He clearly has much to hide."7

\footnotetext{
${ }^{6}$ Joseph Wilson, op. cit.

${ }^{7}$ Office of the Press Secretary, President Delivers "State of the Union", White House.gov, January 28, 2003. Accessed on January 22, 2005.
} 
There is, once again, a whole range of writing in the popular press regarding why the claims were limited to information received by British intelligence, how they were able to remain in a speech that was vetted by the CIA, and why the aluminum tubes were known not to be suitable for uranium enrichment. None of this needs to be developed here. The main point is that after the uranium claim was made in the State of the Union address, the same former envoy who had been sent to investigate the Niger claims began to be quoted anonymously by various news sources debunking the president's claim. ${ }^{8}$ In light of this information, suggestions began to circulate that the president's information in the State of the Union address had been deliberately exaggerated in order to justify the upcoming invasion of Iraq. Then, approximately three and a half months after the war began, former envoy, Joseph C. Wilson $4^{\text {th }}$, wrote an Op/Ed piece in the New York Times on July $6^{\text {th }}, 2003$, revealing himself to be the one who had been sent to investigate the claims in Niger. As he put it in his column, "Those news stories about an unnamed former envoy who went to Niger? That's me."

It is right here that the timing becomes significant, and not only because the president's press conference with the African journalists happened just three days before Wilson's column was to appear. It is very important to take note of and remember this emerging climate of suspicion regarding the rationales given by the Bush administration for the invasion of Iraq. This is because

\footnotetext{
${ }^{8}$ For example, see Walter Pincus, 'CIA Says it Cabled Key Data to White House', The Washington Post, June 13, 2003 [A16]. Accessed on June 15, 2003. Part of the story included information that the CIA "sent a cable to the White House and other government agencies in March 2002 that said the claim had been denied by officials from the central African country. But Bush administration officials acknowledged that the 11/2-page document did not include the conclusion of a former U.S. ambassador dispatched by the CIA to Niger the month before that documents outlining a transfer of uranium to Baghdad were not authentic. The CIA cable attributed the Niger officials' denials to an anonymous source, but failed to mention the name of the former ambassador, who was a recognized expert in Africa, or that it had sent him to Niger." See also, Walter Pincus, 'Report Cast Doubt on IraqAl Qaeda Connection', The Washington Post, June 22, 2003 [A01]. Accessed on June 22, 2003.
} 
the emergent suspicion cannot be factored out of a defensive invocation of conspiracy theory by President Bush in the press conference before his departure to Africa. Having just considered some of the real-world challenges facing the West in terms of ensuring access to reliable sources of petroleum in areas outside of the Middle East, it is hardly ironic, much less surprising, that an African journalist should have a question for the president of the United States about American energy concerns. Considering the already volatile circumstances in the Middle East in the wake of the $9 / 11$ attacks, not to mention the evermore shaky rationales for the three-month old invasion of Iraq, the question made a good deal of sense in light of Africa's noted role in the oil industry. Nigeria for example, as Klare has pointed out in much detail, has an oil industry that ranks it tenth among the world's top producers, ${ }^{9}$ and third in the world for proven reserves among non-Persian Gulf countries behind Venezuela and Russia. ${ }^{10}$ Bush's opening remarks ran the gamut of cooperation on terrorism, economic prosperity, and good will initiatives of, by, and for, the African people. But it was a question by a journalist from The Guardian in Nigeria that prompted the president's dismissive reply. The journalist began that he wanted to know what the president's reaction was "to people who say that the major driving force for your interest in Africa is oil and that, you know, what you are trying to do, essentially, is to shift the focus from Saudi, with first your relationship between Saudi and U.S. now, to Africa. Now, how much of that -." The President interrupted to clarify the question. "Saudi Arabia," he asked?

"Yes," the journalist continued. "So I'd like to know how much of that is actually for instance, in

\footnotetext{
${ }^{9}$ Klare, op. cit., p. 18.

${ }^{10}$ ibid., p. 117.
} 
your interest in Africa?"

"Well," the president began, "conspiracy theorists about everywhere, I guess. That's one of the most amazing conspiracies I've heard. Heck, no one has ever made that connection, and so I would say - well, first, look, I have been talking about Africa since I was sworn-in as President." The rest of the president's rambling answer had as little to do with the original question as the original question had to do with conspiracy theory. When he did finally get around to talking about Saudi Arabia, he stated that

We've got good relations with Saudi. I gave a speech - just to put it in context, I gave a speech - I sworein some folks the other day to reenlist in our military. I pointed out that the relationship with Saudi Arabia, when it comes to tracking down terrorists, is very strong. I reminded our citizens that Abu Bakr who is a key operative, and Swift Sword are no longer issues for American and Saudi Arabia because of the cooperation that is an ongoing cooperation inside the Kingdom.

The president then spoke specifically about Nigeria, reiterating the good relations he had with President Obasanjo.

Every time we have visited it has been a very cordial, up-front way [sic]. I appreciate his cooperation on the U.S.'s desire to work with countries such as Nigeria to train troops necessary to be able to handle some of the difficult situations on the continent. As a matter of fact, I believe the United States in working with Nigeria has trained five battalions of Nigerian troops, preparing them for issues such as Liberia - or other areas on the continent. ${ }^{11}$

There is nothing necessarily alarming about a sitting president dismissing a question as conspiracy theory. After all, this entire thesis is devoted to studying them, and has repeatedly emphasized that one of the things which makes them interesting is how pervasive and

\footnotetext{
${ }^{11}$ It should be noted that there is no direct reference whatsoever to oil in the president's reply.
} 
adaptable they are to shifting sets of historical and political circumstances. In itself, then, there is nothing remarkable about Bush's answer. What does make it interesting is the subject of oil, and the apparently default reaction to the topic in terms of conspiracy theory.

As a point of comparison, one need look no further than the response to another question by then Press Secretary Ari Fleischer a couple of months earlier. After a barrage of questions on the apparent difficulties in locating the much-discussed weapons of mass destruction, Fleischer was asked "Ari, there's a lot of concern around the world, the administration has been so eager to find weapons of mass destruction that we might be so eager as to plant it. Is there any plans [sic] to allow U.N. inspectors back into the country in order to increase -." Fleischer cut in. "Well, one, that entire notion is nothing but nonsense. It's stuff of conspiracy theories and I don't deal in that. As you know, the United States - we have many press in the region, and they're there for a reason. We want to free press [sic] to see what we see, to know what we know. And that's one of the reasons that they are embedded there." 12 What makes the comparison noteworthy is that the suggestion the United States government would clandestinely plot to plant weapons systems which were capable of threatening the United States in a foreign country, and would be able to do so without anyone in the world ever knowing that they had, is the stuff of conspiracy theory. It assumes a level of control of information that does not exist in the real world. Moreover, it fits well within the definition of what a conspiracy theory does from the beginning of the thesis. Cubitt wrote that at their

\footnotetext{
${ }^{12}$ Office of the Press Secretary, Press Briefing with Ari Fleischer, White House.gov, April 10, 2003. Accessed on October 11,2005 . Likely by coincidence, this ended the line of questioning on the missing weapons of mass destruction.
} 
most schematic level, "a conspiracy theory does three things: it attributes the events of history or current affairs to conscious human volition; it sharply distinguish[es] between the human forces of good and of evil; [and,] it implies a hidden reality beneath and at odds with the superficial appearances of the political and social world [...]"13 None of this applies to the former situation.

It would seem curious, then, that the question by a Nigerian journalist on American oil interests in Africa should be "one of the most amazing conspiracies [he's] heard." This is especially so, considering that oil clearly was already on the agenda for his Africa trip. Numerous news articles at the time confirm this. $\mathrm{CNN},{ }^{14}$ as one American example, opened that "U.S. President George W. Bush is set to visit Africa to talk about AIDS and to try and settle the situation in Liberia. But there may be one more issue on his agenda. Some are saying he's keen to further secure U.S. oil supplies." The CNN article goes on to quote Gus Selassei, a South African analyst with the World Market Research Center, who said: "With the Middle East continuing to remain volatile it is important for the U.S. national interest to source its oil from other less volatile regions, and Africa is one of those and becoming more significant." Nigeria, the top African producer, is mentioned as being one of the five countries that Bush was to visit. Another $\mathrm{CNN}$ article ${ }^{15}$ cited labour unrest in the oil industry there, and noted that

\footnotetext{
${ }^{13}$ Cubitt, op. cit., p. 2.

${ }^{14}$ Liz George, 'Is Oil Drawing Bush to Nigeria?', CNN.com, July 7, 2003. Accessed on October 23, 2005.

${ }^{15}$ CNN Wire, 'Union: Nigerian Police Kill 10', CNN.com, July 7, 2003. Accessed on October 23, 2005.
} 
10 protesting strikers had been shot dead by police in Lagos. South African press ${ }^{16}$ reported that "US President George W Bush was in Africa's oil giant Nigeria on Saturday for talks on energy security and the crisis in Liberia on the last leg of a whistle-stop, five-nation tour of Africa." The wire release goes on to state that "Washington's one main interest in Nigeria is in its huge oil reserves, described by one oil executive this week as a 'US strategic target,"' The South African article points out that the United States already imports three quarters of Nigeria's OPEC export quota, with expectations that it "expects to source much more of its energy in Africa in the years to come." And, in a rather clear demonstration of what Klare had noted earlier about the reportage of 'ethnic' strife in oil producing countries (and the military support it procures), it was in "March [of that] year that more than $40 \%$ of Nigeria's production was shut down for several weeks during an ethnic uprising which forced oil majors to evacuate their workers." Washington, in response, sent Nigeria two WWII-era naval patrol ships to help protect oil platforms, but that "other military aid [had] been cut by Congress over human rights concerns."

Another wire story from Inter Press Service ${ }^{17}$ echoed these human rights concerns. "It is purely an economic trip. It is to persuade (President Olusegun) Obasanjo to opt out of OPEC to ensure that the U.S. has a hold on the country's oil," said Segun Jedege, the director of the Lagos-based Committee for the Defence of Human Rights. U.S. oil giant Chevron/Texaco,

${ }^{16}$ SA Wire, 'Oil Tops Bush's Nigeria Visit', NEWS24.com, July 12, 2003. Accessed on October 23, 2005

${ }^{17}$ Inter Press Service, 'Bush's Safari to Benefit U.S. Investors', AEGIS.com, July 9, 2003. Accessed on October 23, 2005. 
the article continues, is one of the leading prospectors in Nigeria, and the company says it had spent five billion dollars in Africa in the previous five years. Chevron/Texaco also said that it had plans to spend another 20 billion on the African continent over the course of the next five.

Another article ${ }^{18}$ runs that Bush's visit, "coming barely three years after a similar one by former US President Bill Clinton, coincides with the discovery of a new deepwater offshore field with about 300 million barrel [sic] of recoverable oil reserves." The oil field, the story continues, is jointly owned by Total, Chevron/Texaco, and Exxon/Mobil, and would raise Nigeria's crude oil reserves to 33.3 billion barrels. "However, as Nigeria's oil reserves continue to grow amid tight production limit [sic] approved by the Organization of Petroleum Exporting Countries (OPEC), US may use the opportunity of Bush visit [sic] to the country today, to renew pressure on it to quit OPEC." Still another story reported that while in Nigeria, the president met with Chevron/Texaco CEO and chairman, Dave O'Reilly, as well as representatives from Exxon-Mobil, and Shell, and was accompanied by then National Security Advisor Condoleeza Rice. ${ }^{19}$

However interesting this digression is, as was stated at the outset, it need not be anymore than a handy coincidence that Bush responded to a question this way at that particular time. It is

\footnotetext{
${ }^{18}$ Josephine Lohor, Chuks Okocha, Ify Isiekwenagbu, 'Bush Arrives as Nigerian Oil Reserves Climb', This Day/All Africa Global Media, July 11, 2003. Accessed on October 23, 2005.

${ }^{19}$ Amy Goodman, 'President Bush Arrives in Nigeria Today', DemocracyNow.org, July 11, 2003. Accessed on October 23, 2005. Goodman's piece notes that Rice herself was a former Chevron board member, and that the company has named an oil tanker after her, the Condoleezza Rice.
} 
not incumbent upon the present research to affirm why or why not any given subject should or should not be regarded as a conspiracy theory. The president and members of his administration have already done so by simply referring to these issues in this fashion. In light of the charge, then, the circumstances underpinning them are secondary. The terms are defined by the charge itself. It is only in the interest of clarity and completeness that they have been addressed here at all. What is more significant, is what happened during that trip to Africa. There is no question, that for whatever reason, the Op/Ed piece in the New York Times by Joseph Wilson, which broke as the president was on his African trip, set off a chain of events that has continued ever since, and which shows no signs of abating. ${ }^{20}$

It has been pointed out that the summer of 2003 was already witness to growing speculation about the reasons given for invading Iraq. With the war just over three months old, serious questions were beginning to be raised about why the weapons had not yet been found. Statements from administration officials, on the contrary, were initially brimming with optimism. In his speech on March 17, 2003, just before the start of the invasion, President Bush declared, "Intelligence gathered by this and other governments leaves no doubt that the Iraq regime continues to possess and conceal some of the most lethal weapons ever devised."21 "We know where they are," said Secretary of Defence Donald Rumsfeld on March 30, with characteristic specificity. "They're in the area around Tikrit and Baghdad and east, west, south

\footnotetext{
${ }^{20}$ As of this writing, October 23, 2005, the results of the special prosecutor Patrick J. Fitzgerald's investigation are not yet known. Not surprisingly, it has been the subject of wild speculation in the mainstream news media, as well as by bloggers on the Internet.

${ }^{21}$ Office of the Press Secretary, President Says Saddam Hussein Must Leave Iraq Within 48 Hours, White House.gov, March 17, 2003. Accessed on March 18, 2003.
} 
and north somewhat."22 By May, however, the tone was already changing in public statements about the Iraqi weapons. "We never believed we would just tumble over weapons of mass destruction in that country," Rumsfeld was saying by May 4. He was joined by then National Security Advisor Condoleeza Rice saying on May 12 that U.S. officials never expected that "we were going to open garages and find" weapons of mass destruction. ${ }^{23}$ And then, with just over a week to go before the publication of Wilson's article, the Defence Secretary reassured that he "had reason, every reason, to believe that the intelligence that we were operating off was correct and that we will, in fact, find weapons or evidence of weapons programs that are conclusive. But that's just a matter of time .. It's now less than eight weeks since the end of major combat in Iraq and I believe that patience will prove to be a virtue." ${ }^{24}$

It would not take long for the White House to react to the claims made by Wilson. In the first direct charge that the intelligence had been twisted or exaggerated in the president's State of the Union address he began: "Did the Bush administration manipulate intelligence about Saddam Hussein's weapons programs to justify an invasion of Iraq? Based on my experience with the administration in the months leading up to the war, I have little choice but to conclude that some of the intelligence related to Iraq's nuclear weapons program was twisted to exaggerate the Iraqi threat." And so it was that administration officials would be thrown into a very gradual but widening investigation into its activities both before and after Wilson's story

\footnotetext{
${ }^{22}$ WMD Quotes Before \& After the Invasion, ActiveOpposition.com. Accessed on June 8, 2003.

23 ibid.

${ }^{24}$ Timeline of Official Quotes on Iraqi WMD, knoxnews.com. Accessed on February 7, 2004.
} 
appeared. At the crux of Wilson's case was his description of the structure of the consortiums which operated the mines in Niger. He pointed out that it would be exceedingly difficult for Niger to transfer uranium to Iraq under the existing structure. This was because Niger's uranium business consisted of only two mines, Somair and Cominak, and they are run by French, Spanish, Japanese, German, and Nigerien interests. "If the government wanted to remove uranium from a mine," he wrote, "it would have to notify the consortium, which in turn is strictly monitored by the International Atomic Energy Agency. Moreover," he continued, "because the two mines are closely regulated, quasi-governmental entities, selling uranium would require the approval of the minister of mines, the prime minister, and probably the president. In short, there's simply too much oversight over too small an industry for a sale to have transpired."

The reaction at the time by members of the administration was swift. On the front page of its July 8, 2003 edition, The Washington Post ${ }^{25}$ reported that "The Bush administration acknowledged for the first time yesterday that President Bush should not have alleged in his State of the Union address in January that Iraq had sought to buy uranium in Africa to reconstitute its nuclear weapons program." Interestingly however, the statement by the administration was not attributed to the article by Joseph Wilson. The Post went on to say that the"statement was prompted by publication of a British parliamentary commission report, which raised serious questions about the reliability of British intelligence that was cited by

\footnotetext{
${ }^{25}$ Walter Pincus, 'White House Backs Off Claim on Iraqi Buy', The Washington Post, July 8, 2003 [A01]. Accessed on July 8, 2003.
} 
Bush as part of his effort to convince Congress and the American people that Iraqi President Saddam Hussein's weapons of mass destruction program were [sic] a threat to U.S. security." Asked about the British report, the administration released a statement which, "after weeks of questions about the president's uranium-purchase assertion, effectively conceded that intelligence underlying the president's statement was wrong." The story went on to quote an unnamed senior administration official authorized by the White House. "Knowing all that we know now, the reference to Iraq's attempt to acquire uranium from Africa should not have been included in the State of the Union speech," the official said. The story goes on to describe how the statement itself "capped months of turmoil over the uranium episode during which senior officials have been forced to defend the president's remarks in the face of growing reports that they were based on faulty intelligence." The International Atomic Energy Agency had even informed the U.N. Security Council in March of 2003, before the start of the invasion, that the documents alleging the Iraqi efforts to buy the uranium from Niger had been forged. Even though the Bush administration did not dispute the IAEA's conclusion, it still launched the war later that month anyway. The story concluded, after briefly mentioning the role Wilson had in investigating the Niger claims, ${ }^{26}$ that according to one Bush administration official, "British and U.S. intelligence agencies got their Niger documents from the intelligence

\footnotetext{
${ }^{26}$ It is worth mention in passing that, not unlike many other conservative columnists, Ann Coulter predictably tarred Wilson by saying that another "high-profile John Kerry supporter was outed as a nutcase this week: Joseph C. Wilson IV, the Walter Mitty of conspiracy theorists. Wilson is the ne'er-do-well WASP embraced by the Democrats last year for calling Bush a liar." Coulter later refers to Wilson's wife as "a chair-warmer at the CIA who apparently wanted to get him out of the house." (Ann Coulter, Wilson Lied, Kids Died, townhall.com, July 15, 2004. Accessed on October 23, 2005.)
} 
service of one country that he refused to name, but that others have identified as Italy."27

But the problems for the Bush administration on this matter were only beginning. This was, in part, because the statement by the senior administration official that 'Knowing all that we know now, the reference to Iraq's attempt to acquire uranium from Africa should not have been included in the State of the Union speech,' was itself going to be proven untrue. It would later be revealed that a virtually identical passage had already been removed from an earlier speech, on October 7, 2002 in Cincinnati. In the vetting of the Cincinnati speech, ${ }^{28}$ the CIA refused to sign off on the claim. Furthermore, the CIA's refusal was based on suspicion of the very same British intelligence dossier later cited by the administration as the reason they were retracting the statement from the 2003 State of the Union address. The Washington Post ${ }^{29}$ wrote that "CIA Director George J. Tenet successfully intervened with White House officials to have a reference to Iraq seeking uranium from Niger removed from a presidential speech last October, three months before a less specific reference to the same intelligence appeared in the State of the Union address, according to senior administration officials." The story went on to describe how Tenet personally argued to deputy national security advisor Stephen Hadley, among others, that the allegation was not reliable because it relied on a single source, and that

\footnotetext{
${ }^{27}$ Even this part of the story has a very interesting history, after the Nigerien embassy in Rome was broken into in December 2001. A few valuables were taken, along with letterhead and embassy stamps that officials warned at the time, might be used to create forgeries.

${ }^{28}$ It was in this speech that Bush said: "Facing clear evidence of peril, we cannot wait for final proof - the smoking gun - that could come in the form of a mushroom cloud."

${ }^{29}$ Walter Pincus and Mike Allen, 'CIA Got Uranium Reference Cut in Oct.: Why Bush Cited it in Jan. Is Unclear', The Washington Post, July 13, 2003 [A01]. Accessed on July 13, 2003.
} 
the CIA had serious doubts about the accuracy of the documents upon which the claims were based. The documents in question turned out to have been forged.

"The new disclosure," the article went on, "suggests how eager the White House was in January to make Iraq's nuclear program a part of its case against Saddam Hussein even in the face of earlier objections by its own CIA director. It also appears to raise questions about the administration's explanation of how the faulty allegations were included in the State of the Union speech.” Journalists Pincus and Allen raised the question as to why Tenet had failed to intervene in January to prevent the questionable intelligence claim from appearing in the State of the Union speech, a speech which is much more symbolic than the previous one in October had been. They suggest that this underlay Tenet's decision to make a statement, issued two days earlier, that "[He was] responsible for the approval process in my agency."

All of this was about to greet the president as he returned from his trip to Africa. The Post reported in the same article that "Bush left Africa yesterday to return to Washington from a five-day trip overshadowed by the intelligence blunder." When asked if he considered the matter over, the president replied that he did. Press secretary Ari Fleischer told reporters "the president has moved on. And I think, frankly, much of the country has moved on, as well." ${ }^{, 30}$

\footnotetext{
${ }^{30}$ This bit of wishful thinking might have actually come true, but for another story which was to break the very next day after this Washington Post article appeared. July 14, 2003 was the day that a column by Robert Novak appeared which outed the name of Joseph Wilson's wife, Valerie Plame, as a covert CIA operative. Novak named two 'senior administration officials' as his sources. It smacked of retribution against Wilson from the start, and, after a formal request by the CIA, would eventually lead to the investigation by special prosecutor Patrick J. Fitzgerald. Fitzgerald, it should be noted, only took over the investigation from then Attorney General John Ashcroft, after Ashcroft recused himself from leading the investigation, citing conflict of interest concerns. Karl Rove, the
} 
Pincus and Allen noted the lingering suspicions that the circumstances regarding the claim had created, saying that "it is clear from the new disclosure about Tenet's intervention last October that the controversy continues to boil, and as new facts emerge a different picture is being presented than the administration has given to date." After summarizing some of the specifics related to the alleged attempts by Iraq to purchase the uranium, they cited administration sources who said

White House officials, particularly those in the office of Vice President Cheney, insisted on including Hussein's quest for a nuclear weapon as a prominent part of their public case for war in Iraq. Cheney had made the potential threat of Hussein having a nuclear weapon a central theme of his August 2002 speeches that began the public buildup toward war with Baghdad.

Later, after citing President Bush's expression of faith in Tenet from Abuja, Nigeria, they wrote that it "remains unclear who specifically wanted the information inserted in the State of the Union speech, or why repeated concerns about the allegations were ignored." Despite all of these concerns, senior Bush aides did not feel this represented a communication problem within the White House. "I'm sure there will have to be some retracing of steps, and that's what's happening,' White House communications director Dan Bartlett said. 'The mechanical process, we think is fine. Will more people now give more, tighter scrutiny going forward? Of course."

Bartlett's comments, as well as Tenet's apparent mea culpa provide one last point of contention to consider before moving on to other more general themes. It is raised by a press

president's chief political advisor, was not initially a formal focus of the investigation, but had worked on a previous political campaign for Ashcroft. Colleagues of Ashcroft at the Department of Justice suggested that, in any eventuality Rove should become a focus, Ashcroft would be in a conflict. 
briefing ${ }^{31}$ by both Dan Bartlett and Stephen Hadley on July 22, 2003. It is notable for a couple of reasons. The first is that between them, they take full responsibility for the inclusion of the 16 words in the State of the Union address no less than four separate times. The second is that they reference conspiracy theory while doing so.

"For the groundrules [sic] for this session today," Bartlett began, "both myself, as well as Steve Hadley will be on the record to discuss today's update to Friday's briefing." Bartlett then embarks on a long and detailed explanation about the drafting process the State of the Union speech underwent, paying particular heed to the number of draft revisions it received. There is no need to spend a great deal of time elaborating on the intricacies of Hadley and Bartlett's shell-game with the Washington press corp (and it clearly is one when reading the entire transcript), nor is there much to be gained from dwelling too much on the significance (or not) of their PR-driven apologia. ${ }^{32}$ What is worthwhile, is using the citation of conspiracy theory

\footnotetext{
${ }^{31}$ Office of the Press Secretary, Press Briefing on Iraq WMD and SOTU Speech, White House.gov, July 22, 2003. Accessed on October 11, 2005.

${ }^{32}$ STEPHEN HADLEY: "Now, the sentence that was uttered by President Bush about Iraqi efforts to acquire uranium was factually accurate. That was true when it issued, and it is true now. The British government -the statement said, the British government has learned that Saddam Hussein recently sought significant quantities of uranium from Africa [...] And the President had every reason to believe that the text of the State of the Union presented to him was sound. But the fact is that [...] I should have recalled at the time of the State of the Union speech that there was controversy associated with the uranium issue [...] I should have either asked that they -- the 16 words given to that subject be stricken, or I should have alerted DCI Tenet. And had I done so, this would have avoided the whole current controversy.
}

And in my current position, I am the senior most official within the NSC staff, directly responsible for the substantive review and clearance of presidential speeches [...] And it is now clear to me that $I$ failed in that responsibility in connection with the inclusion of these 16 words in the speech that he gave on the 28th of January. The National Security Advisor also wants, Condi wants it clearly understood that she feels a personal responsibility for not recognizing the potential problem presented by those 16 words. And we both agree that in permitting the inclusion of those words, the high standards that the President sets with his speeches were not met." 
by Dan Bartlett as another jumping off point into the real world tensions and issues behind it.

As part of his opening comments, Bartlett stated:

There is a conspiracy theory out there that there was some protracted negotiation, or that this was information that was in a clandestine way being forced into the speech by various factions of the administration. It's simply nonsense. This information was provided through the normal process, and in this case, the motivation behind citing the source was to make the speech in the broader sense more credible by, in a series of claims, to give public sourcing, to give the knowledge of how we knew this information to the American people and to the world.

It is difficult to know precisely what conspiracy theory Bartlett is referring to, since he does not specify, other than that it relates to the ways that information was gathered and sourced. It is possible, if not likely, that this is a reference to the many stories circulating at the time that Vice President Dick Cheney had made unprecedented trips to CIA headquarters in Langley,

DAN BARTLETT: "She's traveling today. That's why she's not here."

STEPHEN HADLEY: "That's why, yes."

QUESTION: "So you're saying mea culpa, it's not George Tenet's fault, as was indicated last week?"

DAN BARTLETT: "Well, we said, indicated that last what George Tenet has said and what we have given information here is that the process failed. He acknowledged the process on his end, and the fact-checking that he did on his end did not work properly. And as Steve Hadley has talked about here today, is that based on the information that was shared with him at the time, that it should have been remembered and flagged in our process. So the point is, is that - "

QUESTION: "So you're saying both processes failed?"

STEPHEN HADLEY: "This is a situation where a number of people had an opportunity to avoid the problem. And those opportunities were not taken advantage of. And what we needed to make clear today is that based on what we now know, we had opportunities here to avoid this problem. We didn't take them."

[A Few Questions and Clarifications Later]

QUESTION: "So the CIA tried to wave you off and the memos had slipped everyone's memory and, therefore, you put it in, even though had you seen those memos or remembered them, you would not have put it in?"

DAN BARTLETT: Yes. That's it. They tried -- they did wave us off and it did come out of the Cincinnati speech. So it was in a different speech. 
Virginia. The Guardian carried a story ${ }^{33}$ a few days earlier that had hit on many of these same themes. The story came the day after CIA director George Tenet gave secret testimony to the Senate on the Niger uranium affair, which for Borger, only represented one symptom of a much larger breakdown in the U.S. intelligence apparatus which helped take America to war. Where he writes that the failure of the CIA and FBI to prevent the 9/11 attacks was the result of internal institutional weaknesses, the implications of the Niger fiasco were far more damaging. It was already clear at the time of Borger's article that the White House was in for some difficulties. It was "the White House," he observed, "which stands accused of politicising and contaminating its own source of intelligence."

One of the central points of focus in this scenario was what Borger refers to as "a shadow agency of Pentagon analysts" called the Office of Special Plans. It was set up by defence secretary Donald Rumsfeld to effectively compete with the CIA and the Defence Intelligence Agency (DIA) by second-guessing standard intelligence reporting procedures. Borger records that it operated "under the patronage of hardline conservatives in the top rungs of the administration, the Pentagon and at the White House, including Vice-President Dick Cheney." He notes that though Tenet had officially taken responsibility for the unsubstantiated claim made by the president in the State of the Union address, he had also suggested that his agency was under pressure to justify a war which had already been decided on by the administration. At the forefront of these efforts, the article continues, was Vice-President Dick Cheney. It was $22,2004$.

\footnotetext{
${ }^{33}$ Julian Borger, 'The Spies Who Pushed for War', The Guardian, July 17, 2003. Accessed on February
} 
Cheney, he writes, that

was at the shadow network's sharp end. He made several trips to the CIA in Langley, Virginia, to demand a more "forward-leaning" interpretation of the threat posed by Saddam. When he was not there to make his influence felt, his chief of staff, Lewis "Scooter" Libby, was. Such hands-on involvement in the processing of intelligence data was unprecedented for a vice-president in recent times, and it put pressure on CIA officials to come up with the appropriate results.

Furthermore, the day-to-day operations were run by a former navy officer and ex-aide to Cheney named William Luti, who in turn answered to undersecretary of Defence for policy, Douglas Feith. The article continues that under pressure from hawks such as Cheney, intelligence report officers in the CIA's directorate of operations, who would normally sift through reports from agents around the world and filter out unsubstantiated information, became very reluctant to omit anything, even when it was clearly far-fetched. This included countless tips from the Iraqi National Congress, as well as other Iraqi opposition groups, whose information normally would have been received with much more skepticism by the CIA and the State Department. ${ }^{34}$ Though there is a lot more information in Borger's piece that is very interesting, it was by no means the only story of the sort that Dan Bartlett may have been referring to. But in closing, Borger makes it clear that the OSP absorbed all of this intelligence, rumour, and outright falsehoods, and channelled it directly to the White House. The principal readership for this information was Cheney, Libby, and Condoleezza Rice's then deputy, Stephen Hadley. Some of this information was then leaked to the press, or used to

\footnotetext{
${ }^{34}$ It is worth noting that Ahmad Chalabi was one of these individuals, and was himself a key source for a number of articles in the New York Times touting Hussein's weapons capabilities. A majority of these stories were penned by Judith Miller, who was later to spend 85 days in jail for refusing to discuss her sources in the CIA leak investigation by special prosecutor Patrick Fitzgerald. Eventually it was revealed that her source was I. Lewis Libby. Previous to Miller's jailing and still reeling from the Jayson Blair debacle, the New York Times issued a public statement that it regretted not being more stringent about the claims it printed regarding Saddam's non-existent weapons of mass destruction.
} 
prod the CIA and State Department to follow-up and investigate the OSP leads.

Another article from the Telegraph ${ }^{35}$ helps to rekindle the mood of unrest which has accompanied the on-going disclosures regarding the handling of intelligence previous to the invasion of Iraq. It recounts the creation of an unofficial 'Iraqi intelligence cell' in the summer of 2002 which circumvented the CIA and secretly briefed the White House on links between Saddam Hussein and al-Qaeda. As part of testimony released in a supplementary annex of the Senate intelligence committee's review of the intelligence leading to war in Iraq, which was written by three leading Democratic senators, it was alleged that the cell, headed by Douglas Feith, undermined the credibility of CIA judgements about Iraq's alleged al-Qaeda links within the highest levels of the Bush administration. "The cell appears to have been set up by $\mathrm{Mr}$ Feith as an adjunct to the Office of Special Plans," the story runs, "a Pentagon intelligencegathering operation established in the wake of 9/11 with the authority of Paul Wolfowitz. It's focus quickly became the al-Qa'eda-Saddam link." On occasion, and without informing then DCI Tenet, the group gave briefings to the White House which ran counter to the CIA analysis. The article cites an unnamed Democrat official saying that "Tenet fell on his sword, even though it's clear that he was placed under tremendous pressure to come up with the 'right' intelligence product for the administration on Iraq." It goes on to say that testimony to the committee on Feith, the third highest ranking civilian at the Department of Defence and a leading 'neo-con' hawk, "shows just what kind of pressure was being exerted. And when that

\footnotetext{
${ }^{35}$ Julian Coman, 'Fury Over Pentagon Cell that Briefed White House on Iraq's 'Imaginary' al-Qaeda Links', The Telegraph, July 12, 2004. Accessed on July 11, 2004.
} 
didn't work, the Pentagon was just coming up with its own answers and feeding them to the White House. And on al-Qa'eda they got it all wrong."

The Telegraph article adds the voice of a senior Pentagon advisor, who confirmed that Feith was being targeted by senators. The senators were unhappy, the advisor said, that the administration had so far escaped censure for how it used intelligence. "There are senators who are clearly gunning for Feith now," the advisor said. "This is turning into a classic conspiracy investigation. They want to get Feith and see if, through Feith, they can go up the ladder to even bigger fish." Other Pentagon officials who appeared before the Senate committee "testified that Mr Feith and others believed that the CIA was not sufficiently aggressive in its investigation of links between Saddam and al-Qa'eda. During the summer of 2002, administration hardliners believed that evidence of a connection between Iraq and the terrorist organization would provide a clinching argument for war." They revealed that after a cautious June 2002 report by the CIA entitled 'Iraq and al-Qa'eda: A Murky Relationship' Feith passed on a written assessment to secretary of defence Rumsfeld that it should be read "for content only - and CIA's interpretation should be ignored." In a briefing to Rumsfeld's deputy, Paul Wolfowitz, Feith's cell provided a "stinging condemnation of the CIA's intelligence techniques." In yet another incident, the cell worked to postpone publication of a CIA assessment of Iraq's alleged links to terrorism by raising numerous objections to the final draft at CIA headquarters. One specifically was that they "insisted that more should be made of an alleged meeting between the September 11 hijacker Mohammed Atta and an Iraqi official in Prague in April 2001." The CIA had judged that the reports were not credible, an 
assessment that was later upheld by the Senate committee report upon which Coman's story was based. More remarkable still, is that the report indicated that on September 16, 2002, two days before the CIA was to release the report that had initially been postponed, Feith's cell went directly to the White House to give an alternative briefing to deputy National Security Advisor Stephen Hadley, and Vice-President Dick Cheney. The briefing reiterated a list of "fundamental problems" with the intelligence gathering methods of the CIA, and also provided a detailed description of the purported meeting in Prague between Atta and an Iraqi agent. Coman's article concludes by pointing out that it was the following week when senior Bush officials made their confident statements regarding a link between Saddam and al-Qaeda. George Tenet would not learn of this secret briefing until March of 2004.

A more recent example from the New York Times, ${ }^{36}$ highlights this same period of time covered by Bartlett's charge of conspiracy theory, and marks the ongoing shift in public awareness and opinion of the claims which underpinned the case for war. "In 2002," the article begins, "at a crucial juncture on the path to war, senior members of the Bush administration gave a series of speeches and interviews in which they asserted that Saddam Hussein was rebuilding his weapons program." It goes on to summarize a few instances of high-level members of the administration making such claims which are worth recounting briefly. In a speech to war veterans in August of that same year, for example, Cheney remarked that Hussein could have an atomic bomb "fairly soon." The following month he asserted to an

\footnotetext{
${ }^{36}$ David Barstow, 'Skewed Intelligence Data in March to War in Iraq', The New York Times, October 3, 2004. Accessed on October 2, 2004.
} 
audience of Wyoming Republicans that the United States had "irrefutable proof" that thousands of high-strength aluminum tubes were set to become centrifuges for the processing of uranium. The tubes became one of the showpieces of the administrations case against Iraq, as National Security Advisor Condoleezza Rice made sure to attest on CNN, September 8, 2002. She claimed, just in advance of the first anniversary of the attacks, that the tubes were "only really suited for nuclear weapons programs." She then added her voice to the warning that "We don't want the smoking gun to be a mushroom cloud." However, the Times piece points out that at the time she was making comments like this, she had already been made aware that "the government's foremost nuclear experts had concluded that the tubes were most likely not for nuclear weapons at all, an examination by The New York Times [had] found." The paper quoted a senior administration official who said, "She was aware of the differences of opinion." Though there were also intelligence analysts who did believe the tubes were suitable for weapons production, senior administration officials "sometimes overstated even the most dire intelligence assessments of the tubes, yet minimized or rejected the strong doubts of their own experts. They worried privately that the nuclear case was weak, but expressed sober certitude in public."

Administration officials responded to questions at the time by emphasizing two points. The first was that "they had relied on the repeated assurances of George J. Tenet, then director of central intelligence, that the tubes were in fact for centrifuges. Second they noted that the intelligence community, including the Energy Department, largely agreed that Mr. Hussein had revived his nuclear program." The story states that it was not known if the president had been 
notified about the questions which had been raised about the tubes, but through spokesman Sean McCormack said these judgements "sometimes require members of the intelligence community to make tough assessments about competing interpretations of facts." Tenet, on the other hand, who declined to be interviewed for the story, issued a statement instead. In it, he said he "made it clear" to the White House "that the case for a possible nuclear program in Iraq was weaker than that for chemical and biological weapons." On the specific subject of the tubes, Tenet said "alternative views were shared" as part of the drafting of a new National Intelligence Estimate in late September 2002.

Tenet's claims echo earlier reports in the mainstream press which anonymously cited numerous intelligence analysts who were frustrated by the Bush administration's use of available intelligence. In another New York Times piece, ${ }^{37}$ for example, many of them expressed serious concerns about how the intelligence had been used to justify the war, but who were unwilling to speak out publicly. This NYT article in particular, followed the disclosure by Mohamed ElBaradei, head of the International Atomic Energy Agency, that the part of the administration case for an Iraqi attempt to purchase uranium from Niger had been based, in part, on forged documents. The analysts in Risen's story "had felt pressured to make their intelligence reports on Iraq conform to Bush administration policies." For a few months prior to this, a few of them had been privately expressing concerns to colleagues and certain congressional officials that the pressure had been geared toward shoring up links between Saddam Hussein and al-

\footnotetext{
${ }^{37}$ James Risen, 'C.I.A. Aides Feel Pressure in Preparing Iraqi Reports', The New York Times, March 23, 2003. Accessed on March 23, 2003.
} 
Qaeda, saying that their reports had received "unusually intense scrutiny from senior policy makers within the Bush administration. One government official quoted by Risen who had spoken with the C.I.A. analysts about the issue said that the forgery "heightened people's feelings that they were being embarrassed by the way Iraqi intelligence has been handled." Intelligence officials stated that the forged documents had not been created by the C.I.A., and that C.I.A. officials had always been wary of them. Some had even expressed that they had considered leaving the agency, though none at the time had told C.I.A. management that they were resigning in protest over the use of Iraqi intelligence. At the State Department, on the other hand, three foreign service officers had already resigned in protest over President Bush's policies. While one of the intelligence officials added that the analysts had not been pressured to change the substance of their reports, he allowed that the environment could be interpreted by some as being pressure-filled. "I'm sure it does come across as a pressured environment for analysts," the official said. "I think there is a sense of being overworked, a sense among analysts that they have already answered the same questions. But if you talk to analysts, they understand why people are asking, and why policy makers aren't accepting a report at face value." However, another official said that many veteran analysts were comparing the climate at the C.I.A. during this period as being similar to that of the $1980 \mathrm{~s}$, when many complained of being "under pressure from the Reagan administration to take a harder line on intelligence reports relating to the Soviet Union." This pressure had resulted in the analysts becoming "more circumspect in expressing their analytical views in the intelligence reports they produced" and acting more like reports officers rather than intelligence analysts. 
Despite the heavy emphasis on anonymous sources that news stories like Risen's rely upon, not all individuals insisted on anonymity, though even these were also sometimes reluctant to speak out publicly. One of these is Karen Kwiatkowski, who had a first-hand view ${ }^{38}$ of the operation of the Office of Special Plans from within the Pentagon. As a lieutenant colonel and twenty-year veteran in the U.S. Air Force, she had served as a communications officer in the field, and in acquisition programs, and had been a speech writer for the National Security Agency director. She had also done stints on the Headquarters Air Force and Office of the Secretary of Defence staffs for African affairs. In her words, a career which had started in 1978 with a four-year ROTC scholarship, "ended with 10 months of duty in a strange new country, observing up close and personal a process of decision making for a war not sanctioned by the Constitution we had all sworn to uphold."

In the spring of 2002, she writes that she was a cynical but willing staff officer with just over a year left on a three-year assignment at the office of the secretary of defence, undersecretary for policy, sub-Saharan Africa. With a reference to the Hollywood film 'Sixth Sense', she relates the intense fascination and fright she felt while watching what was going on around her. "While the people were very much alive," she says, "I saw a dead philosophy - Cold War anticommunism and neo-imperialism - walking the corridors of the Pentagon. It wore the clothing of counterterrorism and spoke the language of a holy war between good and evil."' But that evil was not only restricted to the more familiar form "articulated by Islamic clerics and

\footnotetext{
${ }^{38}$ Karen Kwiatkowski, 'The New Pentagon Papers', Salon.com, March 10, 2004. Accessed on March 29, 2004.
} 
radicals." It took another form, too. There were the enemies within, or "anyone who dared voice any skepticism about their grand plans, including Secretary of State Colin Powell and Gen. Anthony Zinni." A long first-person quote helps to capture the flavour of her very long article. There is much detail in Kwiatkowski's article which cannot be fully developed here, but which corroborates the anonymous accounts earlier, and provides both names and duties of the individuals involved in the preparation of the administration's case for war. ${ }^{39}$

From May 2002 until February of 2003, I observed firsthand the formation of the Pentagon's Office of Special Plans and watched the latter stages of the neoconservative capture of the policyintelligence nexus in the run-up to the invasion of Iraq. This seizure of the reins of U.S. Middle East policy was directly visible to many of us working in the Near East South Asia [NESA] policy office, and yet there seemed to be little any of us could do about it.

I saw a narrow and deeply flawed policy favored by some executive appointees in the Pentagon used to manipulate and pressurize the traditional relationship between policymakers in the Pentagon and U.S. intelligence agencies.

I witnessed neoconservative agenda bearers within the OSP usurp measured and carefully considered assessments, and through suppression and distortion of intelligence analysis promulgate what were in fact falsehoods to both the Congress and the executive office of the president.

While this commandeering of a narrow segment of both intelligence production and American foreign policy matched closely with the well-published desires of the neoconservative wing of the Republican Party, many of us in the Pentagon, conservatives and liberals alike, felt that this agenda, whatever its flaws or merits, had never been openly presented to the American people. Instead, the public story line was a fear-peddling and confusing set of messages, designed to take Congress and the country to a war of executive choice, a war based on false pretenses, and a war

\footnotetext{
${ }^{39}$ It should be noted that the Senate Select Committee on Intelligence Report on pre-War Intelligence, also referred to earlier, has dismissed her allegations as baseless (Report on the U.S. Intelligence Community's Prewar Intelligence Assessments on Iraq, July 7, 2004; pp. 282-283). She is not referred to by name in the report, but is instead described as 'Former Office of the Secretary of Defense (OSD) Desk Officer'. The report states: "(U) Committee staff contacted a former desk officer in the Office of the Deputy Under Secretary of Defense for Special Plans and NESA who had come to the Committee's attention through press accounts of the desk officer's experiences. The section of the report pertaining to her testimony ends: "She had no direct knowledge to support any claims that intelligence analysts were pressured and much of what she said is contradicted by information from other interviews and intelligence reporting."
} 
one year later Americans do not really understand. That is why I have gone public with my

account.

Again, there is little to be gained in a project like this by going beyond Kwiatkowski's opening statements. What is perhaps most interesting to note, along with the apparent 'fit' it shares with the other anonymous accounts, is that her brief tenure in the position she describes covers the very same time frame which oversaw the formation of the White House Iraq Group in the summer of 2002, the "marketing" comment subsequently made by Andrew Card, the beginning of the public campaign waged through the news media which insinuated a connection between Iraq and al-Qaeda, the growing public interest in allegations of intelligence tampering in the wake of Bush's 2003 SOTU address, and ends right before the beginning of the invasion at a time when public opinion polls were showing a staggering percentage of Americans believed that a direct connection existed between Saddam and al-Qaeda. ${ }^{40}$ She also raises another interesting possibility for the unspecified conspiracy theory referred earlier to by Dan Bartlett, around the assembly and use of intelligence for the Iraq war. She writes that in trying to understand the neo-conservative world view and grasp what she saw happening around her at the Pentagon, she wondered what could explain the rush to war and the disregard of real

\footnotetext{
${ }^{40}$ For example, a CNN/Time poll conducted in February 2003 and reported March 11, 2003, indicated that "76 percent of those surveyed felt that Saddam provides assistance to al-Qaeda. Another poll released in February asked, 'Was Saddam Hussein personally involved in the September 11 attacks?' Although it is a claim the Bush administration has never made and for which there is no evidence, 72 percent said it was either very or somewhat likely." (Bruce Morton, 'Selling an Iraq-al Qaeda Connection: Some Critics Blame TV News for Making Baghdad New Enemy', CNN.com, March 11, 2003. Accessed on October 29, 2005). There were, of course, many different polls around this period that contained the same or similar numbers. A PEW Research Center/Council on Foreign Relations survey found two-thirds believed that "UN weapons inspectors had 'found proof that Iraq is trying to hide weapons of mass destruction.' Neither Hans Blix nor Mohamed ElBaradei ever said they found proof of this." Another interesting one is from a Knight Ridder/Princeton Research poll that found " $44 \%$ of respondents said they thought 'most' or 'some' of the Sept. 11, 2001, hijackers were Iraqi citizens. Only 17\% of those polled offered the correct answer: none." (Ari Berman, 'Polls Suggest Media Failure in Pre-War Coverage', Editor and Publisher, March 26, 2003. Accessed on October 29, 2005).
} 
intelligence. She notes that as a group, neo-cons are fairly easy to study, since there are only a few of them, and the tend to work together both inside and outside of government. As a recent example of this, she points to the now famous open letter to Bill Clinton in 1998 by members of the Project for the New American Century (PNAC). PNAC is a neo-conservative think tank set up during the Clinton years that advocated many things, but key among them was a much stronger and aggressive foreign policy with regard to Iraq. The letter is worth summarizing briefly. ${ }^{41}$ It is dated January 26,1998 , and is written in advance of Clinton's SOTU address that year. "We are writing you because we are convinced that current American policy toward Iraq is not succeeding," the letter begins, "and that we may soon face a threat in the Middle East more serious than any we have known since the end of the Cold War." It stresses that the SOTU speech presents him with an opportunity to chart a new course with regard to meeting that threat, and urges him to seize that opportunity. "That strategy should aim, above all, at the removal of Saddam Hussein's regime from power. We stand ready to offer our full support in this difficult but necessary endeavor."

The letter goes on to suggest that the 1998 policy of 'containment' has been steadily eroding over the previous few months, and that they can no longer depend on partners in the first Gulf War coalition to continue to uphold the sanctions. "Our ability to ensure that Saddam Hussein is not producing weapons of mass destruction, therefore, has substantially diminished." With the ending of weapons inspections after Saddam threw them out, they continue that "in the not-

\footnotetext{
${ }^{41}$ Project for the New American Century, 'Open Letter to the Honorable William J. Clinton', Project for the New American Century.org, January 26, 1998. Accessed on October 29, 2005.
} 
too-distant future we will be unable to determine with any reasonable level of confidence whether Iraq does or does not possess such weapons." Such uncertainty can only lead to bigger problems in the future, the authors argue, and can only work to increase the instability of the entire Middle East. The letter warns that if "we continue along the present course" that the safety of American troops in the region could not be assured and that "our friends and allies like Israel and the moderate Arab states, and a significant portion of the world's supply of oil will all be put at hazard." Considering the magnitude of the threat that the letter envisions, they consider the [then] current policy to be "dangerously inadequate." They go on to suggest that the "only acceptable strategy is one that eliminates the possibility that Iraq will be able to use or threaten to use weapons of mass destruction. In the near term, this means a willingness to undertake military action as diplomacy is clearly failing. In the long term, it means removing Saddam Hussein and his regime from power. That now needs to become the aim of American Foreign policy."

The letter ends by urging Clinton to articulate this policy, and to turn his administration's attention toward "implementing a strategy for removing Saddam's regime from power." The letter then states that they are fully aware of the dangers and difficulties in implementing this policy, but that they believe they are far outweighed by the dangers in not doing so. "We believe the U.S. has the authority under existing UN resolutions to take the necessary steps, including military steps, to protect our vital interests in the Gulf. In any case, American policy cannot continue to be crippled by a misguided insistence on unanimity in the UN Security Council." It concludes by reiterating the need to act decisively, and warns that in accepting "a 
course of weakness and drift, we put our interests and our future at risk." What makes this letter even more worth the extended attention, apart from how it maps out the general thrust of the post-9/11 invasion of Iraq, are all the individuals who signed this open letter and presently hold (or held) key positions within the administration. ${ }^{42}$

Considering the text cited here, it is no surprise the group has won the sometimes apoplectic attention of conspiracy theorists. ${ }^{43}$ There is no need to spend more than great deal of time examining them, except as a general indication what conspiracy theories involving the group tend to look like. One of them ${ }^{44}$ boldly announces a " $9 / 11$ Checkmate" and goes on to say that some things they will address "are so disturbing that they are almost impossible to believe. That is why, in the 9/11 enigma, less is more. Until these questions are answered there is no need to establish more doubt. What we have here is solid undisputed evidence that we were never told the truth." One of the first conspiracy theories on the web site involving PNAC and 9/11 (and there are literally dozens of others), does not even get the name of the organization

\footnotetext{
${ }^{42}$ These include, but is not limited to, Richard Armitage (Deputy Secretary of State; 2001-2005), William J. Bennett (Radio Host; made the comment that if "you wanted to reduce crime ... if that were your sole purpose, you could abort every black baby in this country, and your crime rate would go down" [September 28, 2005]), John Bolton (U.S. Ambassador to the United Nations), Zalmay Khalilzad (U.S. Ambassador to Iraq), William Kristol (editor of The Weekly Standard, and co-founder of the Project for the New American Century), Richard Perle (former Assistant Secretary of Defence under President Reagan, member of the Defense Policy Board Advisory Committee;1987-2004, and Chairman of that Board; 2001-2003 under President George W. Bush), Donald Rumsfeld (Secretary of Defense), Paul Wolfowitz (former Deputy Secretary of Defense, and current president of the World Bank), and James Woolsey (former Director of Central Intelligence; 1993-1995).

${ }^{43}$ A Google search for "Conspiracy + Project for the New American Century" as only a very general indication, produced 3360000 hits (October 29, 2005). A search for "Conspiracy + Project for the New American Century + September 11" produced 1750000 hits (October 30, 2005).

44، 9/11 Conspiracy 'Theory' or is it Reasonable Suspicion Based on Evidence”, tvnewslies.org. Accessed on October 30, 2005.
} 
correct. ${ }^{45}$ It does point out, however, that even rookie detectives "will tell you that motive and means are the keys to identifying suspects in a crime. The self-proclaimed goals of the Project for a New American Century (PNAC) clearly establish a more realistic and plausible motive to create a 'new Pearl Harbor' than can be attributed to any Islamic extremist. The reference to a "new Pearl Harbor"' is perhaps the lynch-pin in the frequent citation of the group by conspiracy theorists. It comes from page 50 of a position paper published by PNAC on its web site called "Rebuilding America's Defences: Strategy, Forces and Resources for a New Century" ${ }^{46}$ Section Five of the report, from which the 'new Pearl Harbor' quote comes from, is titled 'Creating Tomorrow's Dominant Force', and it begins by suggesting that to "preserve American military preeminence in the coming decades, the Department of Defence must move more aggressively to experiment with new technologies and operational concepts, and seek to exploit the emerging revolution in military affairs." Over the course of mapping out a very long and involved rationale for revamping American Foreign Policy objectives, it begins to conclude that some of the steps taken would need to be drastic. "A transformation strategy that solely pursued capabilities for projecting force from the United States, for example, [...] would be at odds with larger American policy goals and would trouble American allies," the paper observes. "Further, the process of transformation, even if it brings revolutionary change, is likely to be a long one, absent some catastrophic and catalyzing event - like a new Pearl Harbor." This sentence alone, when coupled with the involvement of individuals such as Dick

\footnotetext{
${ }^{45}$ They refer to it as 'The Project for $\boldsymbol{a}$ New American Century'. It is a common error, however, in the mainstream press as well. I have even made this error.

${ }^{46}$ The paper includes a list of contributors at the end which includes I. Lewis Libby, Paul Wolfowitz, and William Kristol, among many others.
} 
Cheney, Jeb Bush, and many others with PNAC, has constituted something of a 'smoking gun', and that it was just this sort of "catastrophic and cataylzing event" which was 'allowed to happen' on $9 / 11$.

Returning to the conspiracy theory though, the tvnewslies web site goes on to say that "for the neocons in PNAC, 9/11 was a dream come true. Their dormant agenda now had an excuse for being implemented." The smoking gun allegations becomes stronger for groups like this when they suggest, as part of a "reality check", that " $800+$ pages of the Patriot Act were written before 9/11. So were plans to invade both Afghanistan and Iraq. But PNAC needed 9/11 to take place. They wanted 9/11 to take place. They wrote about 9/11 (their new Pearl Harbor) taking place. What makes you think they had absolutely nothing to do with 9/11 taking place." A sentence which follows only slightly further down the page, which is bolded for emphasis, runs: "PNAC is at the crux of every geopolitical event taking place today in this nation."

One more quick example will suffice. ${ }^{47}$ "Until recently few Americans knew the curious details of the 1997 plan $^{48}$ to inject an American military presence into the Persian Gulf," it begins. "The 'Project for a New American Century' the admitted brainchild of Dick Cheney, Donald Rumsfeld, and Paul Wolfowitz ${ }^{49}$ amongst others; remained absent from the 2000

\footnotetext{
${ }^{47}$ Tom Johannsen, 'Whitewashing the Project for a New American Century: "If you can't Beat it Feature it" - Part 1', Prisonplanet.com. Accessed on October 30, 2005.

${ }^{48}$ This is a reference to the 1997 open letter to Bill Clinton mentioned earlier.

${ }^{49}$ As has already been pointed out, this is incorrect. William Kristol and Robert Kagen are the co-founders of PNAC. All those mentioned here are connected or have contributed to the organization.
} 
Presidential debates and the eyes of the American public." It goes on to describe a Ted Koppel 'Nightline' story on ABC. According to the article, “Ted Koppel, a master of the Hegelian dialect technique (sic) "problem-reaction-solution,"' outlined a number of ways viewers could watch the upcoming story. Koppel describes a couple of extreme examples of conspiratorial rhetoric from Glasgow's 'Sunday Herald' and the 'Moscow Times', and introduces the PNAC example as something of a middle ground. "Take away the somewhat hyperbolic references to conspiracy, however," Koppel says, "and you're left with a story that has the additional advantage of being true." One might think that such a statement from Koppel, on one of the original 'Big Three' networks during prime time, would please a conspiracy theorist like Johannsen; but this was not the case. Johannsen points out that Koppel would later employ his own "hyperbolic statement" to further "comfort and distract his viewers" by saying "Hardly a conspiracy, the proposal was out there for anyone to see." Johannsen, who is already irate by this point, decries this “'journalistic' technique [which] slams the door on a multitude of facts that are quite pertinent. Facts that Mr. Koppel suggests should not be considered germane to the subject at hand. Facts to be discarded by simple omission primarily because they are 'conspiracy theories' even if they are true." If none of this seems to make much sense, then the point here is already being made. Johannsen desperately wants to see PNAC as evidence of the great, unseen conspiracy. He needs his smoking gun. It seems that Koppel's reluctance to refer to PNAC as a "Conspiracy", and instead, simply as a natural part of mundane reality, is part of the problem for conspiracy theorists like Johannsen. On the contrary, not unlike his misunderstanding of 'the Hegelian dialect', there nonetheless exists a dialectical window through which we might see the very same thing in a completely different way. 


\section{Conspiracy/Theory ${ }^{50}$}

It is fitting that there would be a demonstrable paradox right within Johannsen's words. The paradox is that as much as they yearn for confirmation of a vast and sinister conspiracy, they almost perfectly describe the original impetus for this entire study. One of the bigger differences, though, is that the present study is concerned with beliefs in vast conspiracies which do not and could not exist, rather than proving the existence of vast conspiracies to people who do not believe them. It is the difference between examination and vindication. There is a shared interest in the mechanisms by which 'facts can sometimes be discarded by simple omission primarily because they are "conspiracy theories"'. But, the dialectical opposition posed by this thesis would be, that the belief in vast conspiracies is already much more powerful than any conspiracy ever could be, and not in the way archetypal conspiracy theorists might think. As imagined solutions to complex realities that they themselves fail to explain, conspiracy theories work most immediately to uphold and reinforce the very tensions which gave rise to them in the first place. What makes conspiracy theories interesting to study, then, has very little to do with what they purport to explain. And what Johannsen fails to see is that in his own insistence on seeing PNAC as evidence of a sinister global conspiracy, he does much more to de-legitimate its significance than does Ted Koppel's willingness to take it seriously on prime time television. The objection he raises, in other words, is the very thing which keeps his own perspective marginal. The Project for the New American Century may be significant, but not because it constitutes evidence of a conspiracy. Rather, it is partly because of the conspiratorial suspicion aroused by groups like this, that people like Dan

\footnotetext{
${ }^{50} \mathrm{I}$ am borrowing this clever section title from Peter Knight, op. cit., p. 1, (2000).
} 
Bartlett are able to so easily dismiss questions and criticism of administration policy as 'conspiracy theory'.

There are a number of examples from mainstream news media over the same period which help to demonstrate this dynamic. Among other things, it provides a short yet handy overview of how the charge itself was an inextricable part of the coverage of the invasion of Iraq. Maybe one good example to start with, considering how the previous chapter began, is an interview with Laurie Mylroie by the conservative Front Page Magazine. ${ }^{51}$ She is introduced as one of the foremost scholars on Iraq and Saddam Hussein. About her book 'Study of Revenge: Saddam Hussein's Unfinished War Against America', Glazov writes that Dr. Mylroie “provided substantial evidence implicating Saddam's involvement in four terrorist attacks: the 1993 World Trade Center Bombing; the 1995 bombing in Riyadh, Saudi Arabia, the 1996 attack on the Khobar Towers in Saudi Arabia, and the 1998 bombings of two African embassies." The interview begins with Dr. Mylroie being warmly welcomed, and thanked for taking the time to be interviewed. He begins immediately by pointing out that Mylroie had "recently become the target of some pretty nasty attacks from the Left. Peter Bergen and David Corn, for instance, have really gone after you - and it is obviously for the evidence you unearthed regarding Saddam's terror links." The question continues that it "appears the Left simply cannot forgive you for what they see as the intellectual justification you helped provide for the U.S. liberation of Iraq. These attacks are quite personally vicious and engulfed with 23,2005 .

\footnotetext{
${ }^{51}$ Jamie Glazov, 'Saddam and 9/11', FrontPageMagazine.com, January 8, 2004. Accessed on September
} 
some delusional conspiratorial thinking. Could you talk about this and what you think these attacks signify?" Mylroie replies that "it's par for the course, particularly these days, when political discourse can be unusually ugly." She goes on to state that the $9 / 11$ attacks represent the "greatest intelligence failure since Pearl Harbor" and that Bill Clinton and his top advisors are most culpable in her view, "and I say that as someone who was Clinton's adviser on Iraq in the 1992 campaign."

Another interesting example comes from Oliver North, and another conservative web mag, Townhall. ${ }^{52}$ In an article titled simply 'Conspiracy Theories', North begins that it is "hard to say exactly when the Democrats decisively left the reservation, for the parallel universe that exists only in their own imaginations." He states that in that world, Bill Clinton was only impeached because Republicans wanted to overturn the election; Al Gore would be president if Jeb Bush did not steal the election in 2000; and Osama bin Laden is a CIA operative who conducted the 9/11 attacks to help George Bush end civil liberties in the United States. "This litany of conspiracy theories barely scratches the surface of the paranoid mentality that currently infects American liberals," he writes. "Liberals have always loved conspiracy theories because raising the specter of foul play and dirty tricks is an easy and convenient justification for ignoring their own political and policy failures." He then proceeds to list a few of his favourites, including the "Reagan Pact with Iran" to undermine Jimmy Carter, the made for television movie "The Reagans" (which, he makes sure to point out, stars "Barbra 2004

${ }^{52}$ Oliver North, 'Conspiracy Theories', Townhall.com, January 2, 2004. Accessed on September 23, 
Streisand's husband as Ronald Reagan"), and of course, the JFK assassination with Oliver Stone's treatment garnering special mention. He concludes that the "Democrats' fondness of conspiracy theories has crossed the line into rooting for the other team - all out of spite over President Bush's leadership in the war on terror [...] With Howard Dean leading their ticket, the Democrats are on track to have a 2004 convention that resembles an episode of the Twilight Zone."

The subject of oil was an easy target for right-wing ridicule along these lines. One prominent example came while another actress, Janeane Garofalo, appeared on CNN as a guest host of the now-defunct 'Crossfire' program..$^{53}$ "Another round of looniness from left-wing activist/actress Janeane Garofalo [...] she contended that the war in Iraq "was an attempt at a corporate takeover. This was about oil. It wasn't about human rights."' The page goes on to supply some "highlights of Garofalo's rants during the 'Political Alert' segment at the top of the August 20 Crossfire". These included her reaction to a Tucker Carlson read-through about the bombing by terrorists at the hotel where U.N. workers had been staying. A comment on the attacks, cited by Carlson, from Democratic senator Bob Graham affixing some of the blame for the attacks on the president for what he called the misguided foray into Iraq, Carlson concluded that it was revolting. Garofalo suggested that Graham was "partially right. I blame the president. I blame the media cheerleaders, I blame the pseudo patriots. Iraq was not the threat." Carlson protested that it was the terrorists who did it. Garofalo replied "You just did

\footnotetext{
${ }^{53}$ Brent Baker, 'GAROFALO ON BUSH: "It Is... a Conspiracy of the $43^{\text {rd }}$ Reich"', FreeRepublic.com, August 21, 2003. Accessed on September 6, 2003.
} 
a whole read-through. The lie that brought us into war was that Iraq was a threat to us. Well, now it is a threat. Now it is a terrorist hotbed. The fiction is now reality. And now we have to deal with it. It was an attempt at a corporate takeover. This was about oil. It wasn't about human rights. It's not about human rights." After she agreed that terrorists had just murdered UN peacekeepers, Carlson added "And you're blaming the President, the media and corporations?"

"I blame the occupation that the terrorists are resisting," she said.

Carlson, arms waving wildly laughed "Come on home, Janeane. You're out there." He later mocked, "It's a conspiracy Janeane. I agree with that. We're powerless, not really a democracy [...] It's like Apollo 13. There was no moon landing. That's tomorrow's show!"

Again, there is very little to be gained by illuminating the obvious. Leftist war criticism being derided as 'conspiracy theory' by the right is no more surprising than the reality of some of the wild conspiracy theories already pointed to in this thesis. They are crazy. They are out of this world. And yet all of them reinforce the normalcy of the positions they presume to attack. The coopting and wielding of the charge to dismiss an opponents point of view, as in the examples just noted, though hardly a brilliant rhetorical strategy, is without question effective.

All of this, though, would seem to need to rise to another level of analysis once the case study conducted here is taken into account. There is no question either that the subject of the past chapter has to be considered apart from the garden variety conspiracy theory. It is perhaps more than a little telling, that even after everything which has been written here, it still gives 
one pause to consider pointing out information now known about Bush administration plans for Iraq in the months before 9/11. Ron Suskind's book with former Treasury Secretary Paul O'Neill, for one, amply shows that a concern with Iraq and its oil was, literally, one of the new administration's first orders of business. On January 30, 2001, according to O'Neill who was there, President Bush held his first meeting with the principals of his National Security Council. O'Neill noted that the briefs circulated in advance of the meeting had been thin on details. The designated topic was to be Mideast Policy, and the discussion quickly turned to the Israeli-Palestinian situation. "We're going to correct the imbalances of the previous administration on the Mideast conflict," Bush declared. "We're going to tilt it back towards Israel. And we're going to be consistent. Clinton overreached, and it all fell apart. That's why we're in trouble. If the two sides don't want peace, there's no way we can force them."

The president went on to relate a short story of the first and only time he had met Ariel Sharon. It had been in a military helicopter flying over the Palestinian camps. "Looked real bad down there. I don't see much we can do over there at this point," Bush said. "I think it's time to pull out of that situation." Colin Powell suggested this would be inadvisable, considering the historical roots of all the trouble there. "The consequences of that could be dire," he said, “especially for the Palestinians." In O'Neill's account, Bush shrugged. "Maybe that's the best way to get things back in balance." The reply seemed to startle Powell. "Sometimes a show of strength by one side can really clarify things," Bush added. With that he turned to his National Security Advisor, Condoleezza Rice. "So, Condi, what are we going to talk about today? What's on the agenda?" Her reply: "How Iraq is destabilizing the region, Mr. 
President." Her feeling was that Iraq might be the key to reshaping the entire region. She then introduced CIA director George Tenet to give a briefing on the latest intelligence on Iraq. ${ }^{54}$ The specifics of the ensuing discussion are not important here, but the point has been made. To emphasize this point, a few other examples are worth some attention.

The next meeting for the NSC came two days later on February 1. It included a presentation by Defence Secretary Donald Rumsfeld to examine policy questions on how to proceed on Iraq. Before long, Rumsfeld had launched into assessments on the broader U.S. goal of getting rid of Hussein, and replacing his regime with a more friendly government receptive to U.S. and Western allies. "Imagine what the region would look like without Saddam and with a regime that's aligned with U.S. interests," he said. "It would change everything in the region and beyond it. It would demonstrate what U.S. policy is all about." He then proceeded to talk in general terms about post-Saddam Iraq, the Kurds, the oil fields, rebuilding the Iraqi economy, and freeing the Iraqi people. Early on then, it became clear to O'Neill that a battle was brewing between moderates like Powell and his staff at the State Department, and the "hard-liners like Rumsfeld, Cheney, and Wolfowitz, who were already planning the next war in Iraq and the shape of a post-Saddam country." Documents were already being prepared by the Defence Intelligence Agency, Rumsfeld's intelligence arm, which mapped Iraqi oil fields and areas of exploration. It listed companies which might be interested in participation. One document in particular was called 'Foreign Suitors for Iraqi Oilfield Contracts' and listed companies from over thirty countries

\footnotetext{
${ }^{54}$ Ron Suskind, op. cit.; pp. 71-72.
} 
- including France, Germany, Russia, and the United Kingdom - their specialties, bidding histories, and in some cases their particular areas of interest. An attached document [mapped] Iraq with markings for "supergiant oilfield," "other oilfield," and "earmarked for production sharing," while demarking the largely undeveloped southwest of the country into nine 'blocks' to designate areas for future exploration. The desire to "dissuade" countries from engaging in "asymmetrical challenges" to the United States - as Rumsfeld said in his January articualtion of the demonstative value of a preemptive attack - matched with plans for how the world's second largest oil reserve might be divided among the world's contractors made for an irresistible combination, O’Neill later said.

So it was clear already by February, that the talk was about logistics, not about why, but about how and how quickly. ${ }^{55}$ It was with more than a little dis-ease that O'Neill and Powell, along with other NSC figures, saw the president's campaign rhetoric about noninterventionism, being humble abroad, and not engaging in nation-building, unfold in precisely the opposite direction. As early as March, 2001 “'[a]ctual plans, to O’Neill’s astonishment, were already being discussed to take over Iraq and occupy it - complete with dispossession of oil fields, peacekeeping forces, and war crimes tribunals - carrying forward an unspoken doctrine of preemptive war." 56

Furthermore, as is now known, Suskind's book with Paul O'Neill would not be the only one written by a high-level administration insider. Richard Clarke's 'Against All Enemies' would echo many of the same points of view with regard to the pre-9/11 machinations on Iraq. Clarke writes that former

Treasury Secretary Paul O'Neill has written that the Administration planned early on to eliminate Saddam Hussein. From everything I saw and heard, he is right. The Bush administration reply to

\footnotetext{
${ }^{55}$ ibid., p. 96.

${ }^{56}$ ibid., p. 129.
} 
O'Neill was something like: Of course we were. Clinton signed a law making regime change in Iraq the American policy. That's true too, but neither the Congress nor Clinton had in mind regime change at the point of an American gun, a U.S. invasion of Iraq. ${ }^{57}$

Indeed, Clarke was to have his own rude awakening after the 9/11 attacks did happen. He recounts a meeting in the very early morning hours of September 12, 2001. Returning to the West Wing after a brief break to shower and change, Clarke had expected to enter into a round of meetings about possible future attacks, vulnerabilities, and short term solutions to both of these. "Instead," he writes, "I walked into a series of discussions about Iraq." He continues that he could hardly believe that they were even talking about anything else but getting alQaeda. But then it dawned on him why this was not to be. "I realized with almost a sharp physical pain that Rumsfeld and Wolfowitz were going to try to take advantage of this national tragedy to promote their agenda about Iraq. Since the beginning of the administration, indeed well before, they had been pressing for a war with Iraq." He then recounts a flashback he had, to hearing Wolfowitz talk about the very same thing the previous April, after the administration finally had its first deputy-secretary level meeting on terrorism. At that meeting, Clarke had urged action on al-Qaeda, only to hear Wolfowitz harken back to 1993 and the attack on the World Trade Center, saying that 'al-Qaeda could not have done that alone and must have had help from Iraq'. Wolfowitz had said even then, that the focus on al-Qaeda was wrong, and that they must go after Iraq-sponsored terrorism. Clarke recalled that Wolfowitz "had rejected my assertion and the CIA's that there had been no Iraqi-sponsored terrorism against the United

\footnotetext{
${ }^{57}$ Richard A. Clarke, Against All Enemies: Inside America's War on Terror, Free Press, New York, N.Y., 2004; p. 268.
} 
States since 1993. Now that line of thinking was coming back." 58

By that afternoon, Wednesday September 12, Defence Secretary Rumsfeld was already talking about broadening the scope of the response and "getting Iraq." Clarke reports relief at hearing Secretary of State Colin Powell push back and insist that the focus be kept on al-Qaeda. Glad to have some support, Clarke turned to both Powell and his deputy, Richard Armitage saying, "I thought I was missing something here. Having just been attacked by al Qaeda, for us now to go bombing Iraq in response would be like our invading Mexico after the Japanese attacked us at Pearl Harbor." Powell just shook his head. "It's not over yet." This proved to be true later that same day, as Secretary Rumsfeld was complaining that there were no decent targets to bomb in Afghanistan, and suggested they consider bombing Iraq, which had better targets. “At first I thought Rumsfeld was joking," Clarke says. "But he was serious and the President did not reject out of hand the idea of attacking Iraq. Instead, he noted that what we needed to do with Iraq was to change the government, not just hit it with more cruise missiles, as Rumsfeld had implied."59

None of this means that the Bush administration was involved in some sort of vast and sinister conspiracy, and it certainly does not mean that they had foreknowledge of the attacks, and allowed them to happen in order for cause to go into Iraq. But that is one of the things that the charge of conspiracy theory does very well. It conflates and confuses reality with

$$
\begin{aligned}
& { }^{58} \text { ibid., p. } 30 . \\
& { }^{59} \text { ibid., p. } 31 .
\end{aligned}
$$


representation, politics with paranoia, history with mystery, and truth with absolute fiction. But what the information provided by Clarke and O'Neill does reveal, is how sophisticated and carefully constructed the media relations campaign regarding the shift of focus to Iraq actually was, not to mention how successful it was, if public opinion polls reflecting a belief in Iraqi involvement are a meaningful indication. ${ }^{60}$ And, it is at this point undeniable that "conspiracy theory' was employed by the administration as a public relations tool. It is at this point, too, that the selection criterion for the instances of the charge underpinning this chapter will be revealed as being the White House web site. The charge appears on White House web site on eleven separate occasions between George W. Bush's inauguration and October 11, 2005 when the search of the site was conducted. The search was for "any text $=$ conspiracy" and the hundreds of hits that returned were pared down to the specific references to "conspiracy theory', 'conspiracy theories', or 'conspiracy theorist', etc.

This act of delimitation was thought to be most appropriate to the writing of the current chapter. It was felt that if there was anything to the thesis being explored, then this should be an effective strategy. This is because if conspiracy theories are a carnivalesque form of communication which work to reinforce dominant discourses at the same time they act to undermine them, then the administration's own use of the term should point directly to its own

${ }^{60}$ By December 31, 2005, these numbers had fallen significantly, but were still surprisingly high. A nationwide Harris Survey reported in Editor and Publisher (December 29, 2005) stated that more than four years after the $9 / 11$ attacks " $22 \%$ of adults believe that Saddam Hussein "helped plan and support the hijackers who attacked the United States on September 11."' It goes on to say that "nearly one in four (24\%) of all adults wrongly believe that 'several of the hijackers who attacked the United States on September 11 were Iraqis." Furthermore, $26 \%$ of adults believe that Iraq "had weapons of mass destruction when the U.S. invaded" and " $41 \%$ believe that Saddam Hussein had strong links to Al Qaeda” [Editor and Publisher Staff, 'Harris Survey: Many Americans Still Think Saddam Was Behind 9/11', Editor and Publisher, December 29, 2005. Accessed on December 29, 2005]. 
self-perceived points of weakness. Not unlike the creation of patrician counter-festivals in earlier centuries, meant to combat and undermine the more popular carnivals of the people, the charge of conspiracy theory, when wielded by the powerful, only acts to strengthen the resolve of those it is trying to undermine.

This will be addressed much more fully in the conclusions, but for now, a few examples from the popular press on this point will serve as a way to close out the chapter. New York Times columnist Paul Krugman, ${ }^{61}$ writing after Suskind's book hit the shelves and Paul O'Neill appeared on CBS's '60 Minutes' program, pointed out that suddenly, people were saying terrible things about George Bush. "They say his officials weren't sincere about pledges to balance the budget. They say that planning for an invasion of Iraq began seven months before $9 / 11$, that there was never any good evidence that Iraq was a threat and that the war actually undermined the fight against terrorism." Krugman says right away that he was not among those who celebrated the appointment of Paul O'Neill to the Treasury, and could not understand why he had not quit such a clearly dishonest administration if he was as principled as his friends had described him to be. "But now he's showing the courage I missed back then, by giving us an invaluable, scathing insider's picture of the Bush administration." After describing some of the more interesting revelations in the book, Krugman says that it remains to be seen "whether this book will open the eyes of those who think that anyone who criticizes the tax cuts is a wild-eyed leftist, and that anyone who says the administration hyped the threat 2004.

\footnotetext{
${ }^{61}$ Paul Krugman, 'The Awful Truth', The New York Times, January 13, 2004. Accessed on January 13,
} 
from Iraq is a conspiracy theorist."

He points out that the credentials of the administration's critics just keep getting better and better. "How can Howard Dean's assertion that the capture of Saddam hasn't made us safer be dismissed as bizarre," he asks, "when a report published by the Army War College says that the war in Iraq was a 'detour' that undermined the fight against terror? How can charges by Wesley Clark and others that the administration was looking for an excuse to invade Iraq be dismissed as paranoid in light of Mr. O'Neill's revelations?" After pointing out that administration officials had since attacked Mr. O'Neill's character, they hadn't refuted any of his facts. They had, however, "already opened an investigation into how a picture of a possibly classified document appeared during Mr.O'Neill's TV interview. This alacrity stands in sharp contrast with the evident lack of concern when a senior administration official, so far unknown, blew the cover of a C.I.A. operative ${ }^{62}$ because her husband had revealed some politically inconvenient facts."

In another Op-Ed piece ${ }^{63}$ Krugman writes that the "Bush administration, which baffled the world when it used an attack by Islamic fundamentalists to justify the overthrow of a brutal but secular regime, and which has been utterly ruthless in its political exploitation of $9 / 11$, must

\footnotetext{
${ }^{62}$ What the CIA Leak Investigation should signal, is the value of all these questions. As serious as the alleged infraction no doubt actually is, it has little bearing on the present study, except for what it reveals about how much the administration had at stake in their pre-war claims. No one in the administration, after all, dismissed Joseph Wilson, Richard Clarke, or Paul O'Neill as conspiracy theorists.

${ }^{63}$ Paul Krugman, 'Weak on Terror', The New York Times, March 16, 2004. Accessed on March 16, 2004.
} 
be very, very afraid." Following in the wake of the "stunning upset victory" by José Luis Rodríquez Zapatero in Spain, Krugman points out that polls in the United States were indicating that a reputation for being tough on terror was perhaps the only remaining political strength that George Bush had left. After invoking 9/11 to support an unrelated war, that reputation was based on image, and not reality. He notes the considerable reluctance Bush had shown to seriously pursue the terrorists who had actually attacked America, much less their backers in Pakistan and Saudi Arabia. It was a reluctance that went back to his first months in office when his inner circle tried so hard to prevent a serious investigation of 9/11. After striking back at the Taliban in Afghanistan, his failure to commit sufficient troops allowed Osama bin Laden to escape. "After that," Krugman writes, "the administration appeared to lose interest in Al Qaeda; by the summer of 2002, bin Laden's name had disappeared from Mr. Bush's speeches. It was all Saddam, all the time."

Krugman notes that this was much more than simply a rhetorical switch. Resources were diverted and pulled off a hunt for bin Laden, who had attacked America, to prepare for the overthrow of Saddam, who had not. But this did much more than simply give al-Qaeda a breather, the administration effectively ran interference for Saudi Arabia (redacting 27 pages involving the Saudis from its almost 900 page report on the terrorist attacks ${ }^{64}$ ) and Pakistan

${ }^{64}$ Josh Meyer, 'Saudi Government Provided Aid to 9/11 Hijackers, Sources Say', Los Angeles Times, August 2, 2003. Accessed on August 2, 2003. The story begins that the " 27 classified pages of a congressional report about Sept. 11 depict a Saudi government that not only provided significant money and aid to the suicide hijackers but also allowed potentially hundreds of millions of dollars to flow to Al Qaeda and other terrorist groups through suspect charities and other fronts, according to sources familiar with the document. One U.S. official who has read the classified section said that it describes 'very direct, very specific links' between Saudi officials, two of the San Diego-based hijackers and other potential co-conspirators "that cannot be passed off as rogue, isolated or coincidental."” 
(which actively engaged in nuclear proliferation through the A.Q. Khan network, before President Pervez Musharraf pardoned Khan). "Some of the administration's actions have been so strange," he observes, "that those who reported them were initially accused of being nutty conspiracy theorists."

And so, it has come full circle. It has come back to the original conspiracy theory which would lead to the blind pursuit of Saddam Hussein, and the sixteen words that would begin to unravel it. As Hofstadter noted, "in his extravagant passion for facts the paranoid occasionally manufactures them." The case study here is a demonstration of precisely this dynamic. As was the case in Hofstadter's time, it is the leap of faith that is always made at some critical point in the assembly and presentation of the facts that is of real interest. Nothing has changed, save for the public opinion of President George W. Bush at the present time. As he stood before the United Nations General Assembly, all that time ago, President Bush implored us all to "never tolerate outrageous conspiracy theories concerning the attacks of September the 11th; malicious lies that attempt to shift the blame away from the terrorists, themselves, away from the guilty." If recent approval ratings are any indication, the American people are finally beginning to take him at his word. 


\section{Chapter Seven - Legitimating the Looney Left}

In keeping with the themes of the case study which, in part, demonstrated the very distortions which can occur once 'reality' is viewed and interpreted through the 'mediating plane of appearances' comprised by forms like the conspiracy theory, the present chapter will do something different. It will devote attention to some of the very economic realities obscured by and lost within the charge of conspiracy theory. ${ }^{1}$ The dialectical process at play within conspiracy theories likewise requires that just such a shift in focus be conducted as a routine part of any investigation which seeks to understand them this way. It is, after all, the grasping of opposites in their unity which drives the dialectic in any case. As such, a study like this which did not provide an accounting of some of the current crises facing the somewhat ephemeral (but still important) notion of the 'global political economy', would itself be guilty of one-sidedness. It would be incapable of staking any claims on understanding the significance of conspiracy theories to infinitely more complicated systems of meaning. Paradoxically then, one of the clearest ways of approaching such an understanding is through the very perspective which facilitates and gives rise to the charge in the first place. The debatable extent to which Marxism itself might be considered a version of conspiracy theory stands as a handy demonstration of an earlier point, which held that 'what is socially peripheral is often symbolically central'. The recurring theme of 'looney left-wing conspiracy theories' which was highlighted in different ways in the case study, is remarkably consistent, and so positions itself as

\footnotetext{
${ }^{1}$ It should be noted that this may be said to parallel Frederic Jameson's notion of the "poor person's cognitive mapping", specifically as addressed by Timothy Melley and Fran Mason in Peter Knight (ed.) Conspiracy Nation: The Politics of Paranoia in Postwar America (New York University Press, 2002). See also Knight's own development of the concept in Conspiracy Culture: From Kennedy to the X-Files (Routledge, 2000), and by Mark Fenster in Conspiracy Theories: Secrecy and Power in American Culture (University of Minnesota Press, 1999).
} 
one of these peripheral forms which is nonetheless symbolically central. One of the aspects that makes this approach interesting, is the extent to which the warning flags raised by Marxist perspectives should so closely parallel the current crises emerging within the global economy. Of singular importance here, is that the voices marshaled in support of sounding the alarms in this way do not come from the left at all.

The work of David Harvey provides one handy way into an understanding of the real tensions that Marxist thinkers have struggled to reconcile with their own utopian strivings. One of the things that makes Harvey so interesting is the geographical orientation he brings to the task. Eschewing the formalist pretensions of so many other approaches (even Marxism in some important ways), he notes the glaring omissions they make with regard to the geographic underpinnings of the very things they are trying to study. As we shall see, it is attention to the 'uneven geographical development' of global capital which both hinders teleological academic perspectives which otherwise ignore this uneven development, while it nonetheless provides a literal ground for the 'big questions' that figure their way in to localized expression. This is an important aspect to consider in a study which seeks to understand conspiracy theories in precisely the opposite direction. They are localized expressions which struggle to explain vastly complicated circumstances in terms of a vast global or supraregional conspiracy which does not, and could not, exist. Harvey's approach is helpful in recognizing the impracticality of uniformly adhering to any one 'solution' to all the world's ills, to the point of stating outright that this, too, is impossible to achieve. Likewise, the belief in sinister global conspiracies is equally impractical. But both of these impracticalities are by no means useless. It is to this observation that attention will now be turned. 
Considering the central role that various forms of political, economic, or religious frictions can play in the formation of conspiracy theories, Harvey holds that "crises are inevitable under capitalism no matter what measures are taken to mitigate them. The tension between growth and technological progress is just too powerful to be contained within the confines of the circulation of capital." He continues to say, however, that it is open to human ingenuity and political action to effect and alter the timing, spatial extent, and the forms through which each of these crises manifest themselves. In an analysis which is much too involved to fully develop here, Harvey nonetheless proceeds to examine these options in great detail. What makes this essay by Harvey particularly interesting, is the almost staggering prescience from the vantage point of Reagan-era 1985. So while it is not possible to develop more than a few of Harvey's ideas at this time, key among them is his contention that it is also "open to human ingenuity and political action to convert crises into cataclysmic, though traumatic, moments in human progress, rather than letting them dissolve into barbarism, testimony to the frailty and futility of all enlightened human aspirations. To seize the moment of crisis as the opportunity for creative revolutionary change, however, requires deep understanding of how crises form and unfold.",2

One of the questions to which Harvey turns his attention is whether or not these 'dilemmas of capitalism' can be resolved through geographical expansion or restructuring. Given the modern state of globalized production arrangements described so well by Naomi Klein, ${ }^{3}$ Harvey's consideration

\footnotetext{
${ }^{2}$ David Harvey, 'The Geopolitics of Capitalism' [1985], in Spaces of Capital: Towards a Critical Geography, Routledge, New York, N.Y., 2001; p. 316.

${ }^{3}$ Naomi Klein, No Logo: Taking Aim at the Brand Bullies, Random House, Toronto, ON., 2000.
} 
of what he calls the "spatial fix" may provide a good basis for understanding them. He asks, in short, is there a 'spatial fix' to the internal contradictions of capitalism? He points out that the export of surpluses of labor power and capital does appear to be an easy enough way to avoid currency devaluation, and that there are all kinds of possibilities to stave off crises through geographical shifts and restructurings. The end result, he avers to conclude, is that these crises themselves become more global in scope. At the same time, geopolitical conflict becomes "part and parcel of the processes of crisis formation and resolution." 4

Harvey freely admits that this conclusion is fraught with many difficulties. He feels this is partly because the issues of space and geography have been the "sadly neglected stepchild in all social theory." Further, he states that incorporating a perspective on geography and space has a "numbing effect upon the central propositions of any corpus of social theory." One longer quotation will suffice here to summarize Harvey's point.

Microeconomists working with a theory of perfect competition encounter spatial monopolies, macroeconomists find as many economies as there are central banks and a peculiar flux of exchange relations between them, and Marxists looking to class relations find neighbourhoods, communities, regions and nations. Marx, Marshall, Weber, and Durkheim all have this in common: they prioritize time and history over space and geography and, where they treat of the latter at all, tend to view them unproblematically as the stable context or site for historical action. ${ }^{5}$

After some extended attention to the finer points of how this oversight might be reconciled, Harvey returns to his central concern with the spatial fix and how they may be an effective means of staving

\footnotetext{
${ }^{4}$ David Harvey, op. cit., p. 324 [emphases in original].

${ }^{5}$ ibid., pp. 324-325.
} 
off capitalist crises, especially when combined with temporal displacements. "It is rather as if," Harvey writes, "having sought to annihilate space with time, capitalism buys time for itself out of the space it conquers." He continues to acknowledge that crises cannot be avoided in the long run, he concedes "the possibility that the long run might be very long." But this long run must be punctuated by what he had referred to elsewhere as intense 'switching crises', or cataclysmic moments which reshape the whole geography of capital accumulation. They are moments where regional class alliances and rigid spatial structures are thrown into disarray. They even "undermine the power of state formations and reconstitute them all in a new geographic configuration that can better accommodate the powerful expansionary, conflictual and technological dynamic of a restless, shifting capital flow." He goes on to say that the question remains, as to what happens if the "spatial fix' is stymied, and the debts incurred by the temporal displacement fall due ${ }^{6}$

Harvey writes that the theory of overaccumulation-devaluation lurks beneath capital's façade of technological progress and market rationality, and reveals the intense destructive power at its core. In the course of a crisis, massive quantities of capital are devalued and destroyed, likewise for labor, as capitalists liquidate and cannibalize each other in a "war of all against all" that is the ultimate hallmark of a capitalist mode of production." He explains that what Marx nowhere anticipates, but that Lenin emphasized, is that this process is converted into economic, political, and military struggles between nation states. In staging the problem in this fashion, Harvey states that we have now constructed a more general proposition. With the unavoidable processes of crisis formation, the search for a spatial fix amounts to an attempt to convert "the threat of devaluation into a struggle

\footnotetext{
${ }^{6}$ ibid., p. 338.
} 
between unstable regional alliances over who is to bear the brunt of the crisis." In other words, it is more or less a move to stick someone else with the tab.

Faced with the prospect of splintering into a thousand warring pieces, a regional alliance may consolidate itself and turn its destructive tendencies towards the outside. The export of unemployment, inflation and the idle productive capacity become the stakes in an ugly game. Trade wars, dumping, tariffs and quotas, restrictions on capital flow and foreign exchange, interest-rate wars, immigration policies, colonial conquest, the subjugation and domination of tributary economies, the forced reorganization of the territorial division of labor within economic (even corporate) empires, and, finally, the physical destruction and forced devaluation achieved through military confrontation and war, can all be caught up as part and parcel of the processes of crisis formation and resolution. The search for a 'spatial fix' takes a viciously competitive and perhaps even violent turn. ${ }^{7}$

Again, writing in 1985, under the conditions he spends much time describing, Harvey says we can but look back nervously to the economic and diplomatic history of the 1930s and ask the question 'could it happen again?', and if so, 'how and why?' He notes how rapidly during that time geopolitical and economic alignments shifted, and that there had been many telltale signs of fragility in the 1920s. For example, there was hyperinflation in Germany, high unemployment in Britain, and what Harvey calls "speculative bombast in the US". He writes that if the strong expansionary dynamic of overaccumulation continued in the fashion he described, then a grim choice would seem to exist between depression and possible revolution at home, and military confrontation abroad, which Harvey describes as "the ultimate form of 'spatial fix'." As an example, Harvey points to the fact that it was the geographical unevenness of destruction in World War II that opened up "new spaces in the postwar period for the absorption of surplus US capital under the aegis of that benevolent 'spatial fix' known as the Marshall Plan."

\footnotetext{
${ }^{7}$ ibid., pp. 338-339.
} 
But the inner transformations of the 1930 s paled in comparison, and even faded into insignificance with the dramatic geopolitical and institutional changes that arose out of the calamity of WWII. At the behest of the United States, an array of supranational institutions, such as the World Bank and the International Monetary Fund (which were effectively under American control), and a favorable international monetary agreement, made the U.S. the world's de facto banker. Harvey writes that all of this was set in order to try and prevent "the emergence of rival power blocs within the capitalist world and to facilitate the internationalization of (mainly US) capital under conditions of fairly restricted geographical mobility of labor power. Co-optation and repression, at home and abroad, to keep the free world free for the circulation of capital, became the dominant political theme." Though Harvey does not specifically mention McCarthyism here (and I would have included it at this point in any case), he does add, just a couple of lines later, an interesting rejoinder. "And, of course," he writes, "the Soviet threat and anti-communism became the central ideological tool to ensure the solidarity of potentially competitive regional class alliances. To the degree that this ideology needed a material base, the geopolitical confrontation of the Soviet Union and the communist bloc became central to the survival of capitalism irrespective of Soviet policies or action." In other words, conspiracy theories about 'Communism' and the 'Red Menace' were directly involved, not in threatening capital interests, but in strengthening them. It is a clear historical demonstration of the paradoxical logic of conspiracy theory that this thesis has tried to explore.

Harvey concludes his long chapter by stating outright that he believes the theoretical argument he

\footnotetext{
${ }^{8}$ ibid., pp. 342-343 (emphasis added).
} 
has set out is crucially important to understanding the then-present plight that were the Reagan years. ${ }^{9}$ Harvey does say one very interesting thing in his 'requiem for a conclusion' which is deserving of special mention. "If I am correct," he writes, "and I hasten to add that I hope I am grossly in error and that history or others will quickly prove me so to be, then the perpetuation of capitalism in the twentieth century has been purchased at the cost of the death, havoc and destruction wreaked in two world wars." Harvey goes on, but what is important to note here is how significant it is that he expresses the wish to be wrong.

The point of positioning Harvey as a paradoxical way into understanding some of the neoconservative perspectives described earlier is merely to show what it is the paranoid style of the extreme right-wing finds so threatening. In short, these tensions partly arise out of the divergent perspectives on the very same processes, one which valorizes them while the other criticizes them. In fact, and in keeping with the descriptive tone maintained throughout these pages, each needs the other in order to exist themselves. While there is no need to re-describe the complicated dialectical relations between these opposites, conservative and liberal, the observation simply needs to be made that the upper hand gained by the political right anytime the left is dismissed as a wild conspiracy theory, is only reinforced by the most strenuous of efforts to show how this is not the case. For now, it is enough to preface the next section with this idea, while highlighting what might be described as the next looming crisis of capital along the lines of which Harvey has just described. Of key importance, though, is attention to a very simple twist on that theme; the criticism to be summarized

\footnotetext{
${ }^{9}$ It is worth remembering that many of the same principle figures, policies, and political philosophies, have also reasserted themselves during the current administration of George W. Bush.
} 
below does not come from the left at all.

\section{Conspiracy Theory and Capitalist Crises}

Without going into great deal of detail on the specifics of these various crises, a few notable trends are worth mentioning. The International Monetary Fund, as one example, declared in a 2004 report that the current United States deficit, in terms of percentage of G.D.P., was a threat to the global economy. "In nearly 60 pages of carefully worded analysis," the New York Times article began, "the report sounded a loud alarm about the shaky fiscal foundation of the United States, questioning the wisdom of the Bush administration's tax cuts and warning that large budget deficits posed 'significant risks' not just for the United States but for the rest of the world." The report went on to warn that U.S. financial obligations to the rest of the world could equal 40 percent of its total economy within a few years. This represents "an unprecedented level of external debt for a large industrial country" which could have a dramatic effect on the value of the U.S. dollar as well as international exchange rates. The equally unprecedented borrowing by the U.S. could also push up global interest rates and slow down global investment and economic growth. "Higher borrowing costs abroad would mean that the adverse effects of U.S. fiscal deficits would spill over into global investment and output," the report said.

The New York Times story states that White House officials have dismissed the report as alarmist, pointing out that President Bush had already vowed to reduce the budget deficit by half over the next

\footnotetext{
${ }^{10}$ Elizabeth Becker and Edmund L. Andrews, 'I.M.F. Report Says U.S. Deficits Threaten World Economy', The New York Times, January 7, 2004. Accessed on January 8, 2004.
} 
five years. Administration officials also made clear that they were not worried about the relative decline in value of the American dollar versus the euro, which had at that point lost almost one-fifth of its value against the euro over the previous 18 months, and was continuing to hit new lows. The Times piece conceded that the I.M.F. has criticized the United States for its budget and trade deficits over the past few years, but that the 2004 report "was unusually lengthy and pointed." The story also noted that the report reflected the views of its authors, and not the institution itself, whose major shareholder happens to be the United States. "But," the story added, "the fund officials also seemed intent on getting American attention." Charles Collins, the deputy director of the I.M.F.'s Western Hemisphere Department and one of the report's principal authors, said that they were "trying to contribute to persuading public opinion that this is an important issue that has to be dealt with." But Fund officials warned that the long-term fiscal outlook was very grim, and predicted that the underfinancing of Social Security and Medicare would lead to shortages of $\$ 47$ trillion dollars over the coming decades. It is a figure which represents a staggering 500 percent of the current gross domestic product over the same period. Other economists, however, point out that the carrying of heavy deficits is hardly anything new, and that the underlying economic conditions in the United States continued to be robust. "Is the U.S. fiscal position unique? Probably not," said Kermit Schoenholtz, a chief economist at Citigroup Global Markets, noting that Japan's budget deficit is even higher than that of the United States, and that those of France and Germany were also rapidly climbing. On the question of the dollar's relative value against the euro, many economists predicted that the dollar would continue to decline for quite some time, and that this itself would help to boost American industry by making American products cheaper in countries whose currency was gaining strength. "In the short term, it is probably helping the United States," said Robert Hormats, the vice 
chair of Goldman Sachs International.

Another report from the Chicago Tribune ${ }^{11}$ echoes many of these same concerns. Though it begins by pointing out that the fiscal outlook for 2005 was shaping up to be a pretty good year on the surface, digging a little deeper showed that there was plenty to be worried about. "For an increasing number of economists and investors, the generally rosy short-term outlook has an ugly underbelly - the massive U.S. trade and budget deficits." Oneal suggests that the most obvious sign of the lingering discomfort is the continued drop in the U.S. dollar. Though he writes that this has been a boon for exporters such as Caterpillar Inc. and John Deere, it signaled a warning from global investors to U.S. policymakers that there was only so much living beyond one's means that they would tolerate. A chief economist for Lehman Brothers of New York, Ethan Harris, helped to put the rosy picture into perspective. "The economy looks wonderful on the surface. The problem is, these imbalances are so big they just can't be ignored ... The markets are zeroing in on it." In a nutshell, the U.S. is spending more than it earns each year, and then must borrow from the rest of the world to make up the difference.

At the level of individual consumers, the voracious appetites for new goods have driven up imports while draining savings to historic lows. With interest rates so low, consumers have bought not only new houses, but have piled up personal debts on items such as fancy cars and designer products. On the other side of the ledger, though, foreign demand for American goods has dropped off, and this

${ }^{11}$ Michael Oneal, 'Deficits a Growing Danger: How long will global investors finance U.S. spending?', Chicago Tribune, January 2, 2005. Accessed on January 2, 2005. 
expands the trade deficit with the rest of the world. This was all fine during the boom years of the 1990s when foreigners were also willing to invest privately and heavily in American stock and bond markets, which had the effect of allowing the U.S. to boost consumption and investment at the same time. But this trend has waned in the past few years, with private foreign investment trailing off and most foreign government investment going towards the growing U.S. deficit burgeoning under the Bush tax cuts and the war on terror.

This has all been possible, the Tribune report continues, partly because countries such as China and Japan have continued to buy up U.S. treasury bonds at relatively low rates in order to keep the dollar from falling against their own currencies. After all, both of these countries are heavily reliant on the exports they produce, as well as on the U.S. market to continue buying them. A falling dollar makes their products more expensive to buy, and so explains why they have been so willing to keep propping up the American dollar. But this process cannot go on forever. Even the outgoing Federal Reserve Chairman, Alan Greenspan, said in November of 2004 that "Given the size of the U.S. current account deficit, a diminished appetite for adding to dollar balances must occur at some point." Translated, this means that China, Japan, and other foreign investors could not keep funding American spending, and that eventually something would have to give.

A report in Forbes Magazine ${ }^{12}$ was even more blunt. Ackman begins by reminding the reader how powerful the Fed chairman Greenspan has been, adding that even the White House has had to offer its critiques of him off the record "for fear of roiling the markets or upsetting the chairman's Elvis-

\footnotetext{
${ }^{12}$ Dan Ackman, 'World on Brink of Ruin', Forbes.com, January 7, 2005. Accessed online January 7, 2005.
} 
in-Vegas-like following. So when the chief economist of one of the world's most prestigious banks calls Greenspan a bum, that's a big deal. And yesterday it happened." That economist was Stephen Roach of Morgan Stanley \& Co.. Morgan Stanley is one of the most powerful investment banks and one of the world's 50 largest companies. Writing in an issue of Foreign Policy, Roach said that Greenspan had "driven the world to the economic brink." When he steps down, Roach continued, he would be leaving behind a record foreign deficit and a generation of Americans with little savings and a massive debt. Too many Americans are far too dependent upon the values of their assets, especially their homes, Roach says, rather than on income-based savings. The foreign debt held by other countries, especially in Asia, permits continued low interest rates and entices Americans further into debt.

However, even Roach backed off the "economic brink" line when interviewed by Forbes. "That's a little extreme," he said, and he did admit that the U.S. had prospered under Greenspan's tenure. But, he did not shy away from the stiff jabs he took at Greenspan in his article for Foreign Policy. "This is no way to run the global economy," Roach said, adding that so far the Fed had bucked the odds, but that the longer the situation continued, the greater the chance it would spell danger for the United States and the world. He says that Greenspan's monetary policy does deserve some praise for the boom of the 1990s, but that Bill Clinton's fiscal policies and other factors were equally responsible. And, Greenspan may even deserve credit for softening the recession which followed the stock market meltdown (a reference to the Asian financial crisis of 1997-98), but that his cure might result in "bigger problems down the road" with "the biggest bubble of all: residential property." Roach even questioned Greenspan's political independence. Though stopping short of 
calling him a partisan Republican, he does fault him for being a "cheerleader for policies such as tax cuts...that could make the endgame all the more treacherous."

An Associated Press ${ }^{13}$ article from a couple of weeks later would demonstrate how serious all of these issues are with respect to the importance of the American dollar to the global economy. At a standing room only session at the 2005 World Economic Forum in Davos, Switzerland, Fan Gang, the director of the National Economic Research Institute at the China Reform Foundation, said that China had lost faith in the stability of the U.S. dollar in favor of a more flexible basket of currencies. He went on to say that the issue was not whether China should devalue the yuan, but "to limit it from the U.S. dollar." As the world's fastest-growing economy, Fan was careful to stress that the Chinese government was under no pressure to revalue its currency. Critics have charged that the yuan is undervalued, making China's exports cheaper overseas, and giving it an unfair advantage in the manufacturing sector. Because of this, Beijing has been under pressure from its trading partners, not the least of which is the United States, to relax its controls on its currency. At the time the Associated Press article was released, China's exchange rate policy restricted the value of the yuan to about 8.28 yuan to one American dollar.

"The U.S. dollar is no longer - in our opinion is no longer - (seen) as a stable currency, and it is devaluating all the time, and that's putting troubles all the time," Fan said, speaking in English. "So the real issue is how to change the regime from a U.S. dollar pegging ... to a more manageable ...

\footnotetext{
${ }^{13}$ Edith M. Lederer, 'China Has Lost Faith in Stability of U.S. Dollar, Top Chinese Economist Says at World Forum', Associated Press, January 26, 2005. Accessed online January 27, 2005.
} 
reference ... say Euros, yen, dollars - those kind of more diversified systems. If you do this, in the beginning you have some kind of initial shock," Fan added. "You have to deal with some devaluation pressures." Fan's comments followed the posting of a new low for the dollar the previous month, which, Lederer writes, "has been falling against other major currencies on concerns about the ever-growing U.S. trade and budget deficits." China's economic modernization began over a decade ago, and Fan stressed that his country's economic development is a long-term process that will take decades, and maybe a century to achieve. China is clearly taking a long-term view. With some historical echoes of its own, the Associated Press story notes that since China's economic modernization began, " 120 million rural laborers have moved into cities, but that another 200-300 million more would have to do the same to spur development. “The income disparity is huge," Fan said, "and income disparity will stay with us for a long time, as long as those 200 to 300 million rural laborers stay in the countryside." William Parrett, the chief executive of Deloitte Touche Tohmatsu, said to the same panel that the Chinese were making great progress in becoming global giants, all led by state-owned companies. "It's probably at least 10 years before the objective of the government of 50 of the largest 500 companies in the world being Chinese" is achieved, he said.

But it isn't just the Chinese that are betting against the American dollar. Bill Gates, the world's richest man, is also doing the same thing. A Bloomberg release ${ }^{14}$ begins that "Bill Gates, the world's richest person with a net worth of $\$ 46.6$ billion, is betting against the U.S. dollar. 'I'm short the dollar', Gates, chairman of Microsoft Corp., told Charlie Rose in an interview late yesterday at the

\footnotetext{
${ }^{14}$ James Herling and Simon Clark, 'Bill Gates, World's Richest Man, Bets Against Dollar', Bloomberg.com, January 29, 2005. Accessed online January 30, 2005.
} 
World Economic Forum in Davos, Switzerland. 'The ol' dollar, it's gonna go down."' The story goes on to relate Gates' own concerns about the very same issues discussed above, saying the fact "that widening U.S. budget and trade deficits are undermining the dollar was echoed in Davos by policymakers including the European Central Bank President Jean-Claude Trichet and German Chancellor Gerhard Schroeder." The story points out that the dollar "fell 21 percent against a basket of six major currencies from the start of 2002 to the end of last year. The trade deficit swelled to a record $\$ 609.3$ billion last year and total U.S. government debt rose 8.7 percent to $\$ 7.62$ trillion in the past 12 months. 'It's a bit scary,' Gates said. 'We're in uncharted territory when the world's reserve currency has so much outstanding debt.", The story goes on to reaffirm that "U.S. President George W. Bush is pledging to clamp down on spending to halve the budget deficit $-\$ 427$ billion in the 12 months through Sept. 30 - during his second term." According to German Deputy Finance Minister Caio Koch-Weser, the U.S. budget shortfall is "the No. 1 risk, disregarding geopolitical risks" to the global economy. He then urged President Bush to present some "credible" plan for getting the deficit under control. Yu Yongding, a Chinese central bank advisor said at the same conference that the U.S. government should do more to tackle its own deficit. And, it should also ease pressure on China to loosen the restrictions mentioned earlier with regard to the yuan's ties to the dollar. "'The U.S. should take the lead in putting its own house in order', Yu said. 'It's the root cause' of global imbalances. 'China will make its contribution, but the world should not put disproportionate pressure' on the country."

A few other examples on this point give closing voice to still other ideas from other countries. The 
New York Times ${ }^{15}$ reported that as the dollar tumbled, markets "grew concerned about the likely impact of South Korea's plan to diversify its reserves out of U.S. assets, pushing the currency below key technical support levels. South Korea's central bank, which holds a large chunk of U.S. Treasuries, said on Monday it planned to spread its reserves, which are the world's fourth largest, among a variety of currencies." The story continues that the dollar " is under pressure. This started early in the Far East, with news of South Korea's plan to change reserve ratios,' said Andrew Busch, global FX strategist, capital markets, with Harris Nesbitt in Chicago. 'It comes on the heels of Russia saying the same thing. This has fueled speculation that Japan may do the same. That basically hit us and it ignited the euro to rally and continue to put it to new highs' against the dollar, Busch said."

MacLean's magazine ${ }^{16}$ asks if America is going broke. It begins by citing David Walker, the comptroller general of the United States. What this means is that he is the head auditor for the most powerful government in the world. It states that Walker is desperate to get a message out. It is that the "United States of America's public finances are a shambles. They're getting rapidly worse. And if something isn't done soon to solve the country's intractable budget problems, the world will face an economic shakeup unlike anything ever seen before." The story continues with its own interesting analogy.

Seated in his wood-panelled (sic) office in downtown Washington, Walker measures his words, trying

${ }^{15}$ Reuters, 'Dollar Sinks, SKorea Reserve Shift Weighs', New York Times, February 22, 2005. Accessed online February 22, 2005.

${ }^{16}$ Steve Maich, 'Is America Going Broke?: Record deficits, colossal debt and no clear plan for digging itself out. If the U.S. sinks, it will take Canada down with it.', MacLean's, March 2, 2005. Accessed online March $3,2005$. 
to walk the fine line between raising an alarm and fostering panic. He cringes when he hears prominent economists warning about a financial 'Armageddon,' but he makes no bones about the fact that the situation is dire. 'I don't like using words that are overly inflammatory,' he says, leaning forward in his chair. 'At the same time, I think it is critically important that the American people, as well as their elected representatives, get a better understanding of just how serious our situation is.'

Lawrence Kotlikoff is cited in the same story as providing a bleak summary of the situation for an article in Fortune magazine. "The U.S. government is effectively bankrupt," he wrote, and proceeded to outline a range of choices to help close the gap. It included hiking income taxes by 78 percent, slashing Medicare and Social Security benefits by half, or eliminating all other discretionary spending. "That is America's menu of pain," he said. Josh Bivens, an economist with the nonpartisan Economic Policy Institute in Washington D.C., does not quibble with Kotlikoff's numbers. "You've got all the ingredients for a pretty spectacular crash that a country as rich as the U.S. should just never be even close to flirting with. Another six or seven years along this path and I think we'll really be flirting with it. It's rather insane." But it is not just workers in the U.S. that need to be concerned. The consequences could effect literally millions of workers in Canada, the U.K., Japan, Germany, and elsewhere. "If suddenly Americans were unable to buy those goods from those countries, the countries would have to very quickly figure out how to keep their people employed," Bivens explained. "If a country as big as the U.S. gets sick, everybody's gonna get sick."

Warren Buffett ${ }^{17}$ also launched a withering attack on the US trade deficit, describing Americans as "rich spending junkies" who could turn the United States into a nation of "sharecroppers." In his

\footnotetext{
${ }^{17}$ Simon Bowers, 'Buffett Attacks American Spending Junkies', The Guardian, March 7, 2005. Accessed online March 7, 2005.
} 
annual letter to investors in the fund he has managed for the past 30 years, Berkshire Hathaway, he painted "a bleak picture of a future US in which ownership and wealth had continued to move overseas, leaving the economy in thrall to foreign investors and faced with financial turmoil and political unrest. Buffett, too, was betting against the U.S. dollar in terms of the growing trade deficit, which he warned may be approaching crisis point. "Without policy changes, currency markets could even become disorderly and generate spillover effects, both political and financial," Buffett warned. "Such a scenario is a far from remote possibility that policymakers should be considering now," though he conceded that policymakers' bent "is to lean towards not so benign neglect."

Bank of Canada governor, David Dodge ${ }^{18}$ has said much the same thing, chiding the Americans for their borrow-and-spendthrift ways, and suggesting that they are a threat to world economic stability. He also criticized countries such as China for rigging their currencies to boost exports and build up larger and larger foreign-exchange reserves. He said this was creating a lopsided world where Asian savings were financing U.S. spending. The CBC story states that Dodge's comments "echo those of many economists who have watched the United States evolve from the world's greatest creditor nation to the greatest debtor as Americans saved less, consumed more and imported more. China, meanwhile, took over much of the world's consumer goods manufacturing and used its export earnings to soak up vast amounts of U.S. debt.” Bush administration supporters have tended to argue, the article continues, that the three U.S. deficits, - international trade, current account, and federal budget - "do not matter to a superpower that prints the world's most widely used money." 31,2005

\footnotetext{
${ }^{18}$ CBC News, 'U.S. Living Beyond Means, Dodge Warns', CBC.ca, May 30, 2005. Accessed online May
} 
But Dodge, too, argues that this cannot go on forever. "At some point, they will have to be resolved. Why? For one thing, a country's external indebtedness cannot keep growing indefinitely as a share of its GDP. Eventually, investors will begin to balk at increasing their exposure to that country, even if it is a reserve-currency country, such as the United States."

This doom and gloom scenario has had a direct effect on the Bush administration's economic team. Academic economists do not want to go anywhere near it. The New York Times ${ }^{19}$ reports that though it is no secret hurricanes and wars have swamped the Bush team's economic agenda, "one fact has gone largely unnoticed: much of Washington's expert economic team has disappeared." For example, the chairmanship of the Council of Economic Advisors will soon be vacant, and two spots on the board of the Federal Reserve that had recently been filled by academic economists already are. Furthermore, there is "no assistant secretary of the Treasury for tax policy, and the director's chair at the Congressional Budget Office, currently occupied by Douglas J. Holtz-Eakin, will soon be empty too." Altman points out that the White House and Congress need as many as five top-level academic economists and it is not clear where they are going to come from. "Bush's reputation in at least the academic community is about as low as you can imagine," said William A. Niskanen, who was a member of the council for Ronald Reagan's first term current chairman of the libertarian research group, the Cato Institute. "A lot of people would not be willing to give up a good tenured position for a position in the White House."

\footnotetext{
${ }^{19}$ Daniel Altman, 'Help Wanted: Academic Economists, Pro-Bush', The New York Times, November 27 , 2005. Accessed online November 27, 2005.
} 


\section{Euro vs. U.S. Dollar}

If there is one other aspect that could even further impact and seriously undermine American economic dominance, it would be a shift to the euro as the currency of choice for oil transactions on the world market. With the dollar falling against the euro in a series of successive new lows, even the OPEC nations have been mulling a shift to the euro as the favored currency. For example, a Globe and $\mathrm{Mail}^{20}$ piece reported that OPEC "is considering a move away from using the U.S. dollar - and to the euro - to set its price targets for crude oil, the highest-profile manifestation of the debilitating effect of depreciation on the greenback's standing as the currency of international commerce." Several OPEC members were seeking talks on using the euro, as well as the dollar. “There are countries that are proposing this," said Rafael Ramirez, Venezuela's oil minister, "It's out there, under discussion." While he would not specify which countries were pushing the proposal, much of the impetus was believed to be from Persian Gulf producers. Many of these countries have seen their purchasing power in Europe falling along with the U.S. dollar. One Canadian analyst, Wilf Gobert, vice-chairman of Peters and Co. Ltd., said that any move to water down the use of the American dollar as the oil currency would have an enormous symbolic impact. "On a symbolic level, I think it's huge, not only for what it says about the U.S. dollar, but also the implied change to the nature of energy trading worldwide in the future."

Even more than being a blow to the dollar's symbolic prestige, Gobert said that a move by OPEC to even partly price in euros would ensure that any further depreciation in the U.S. dollar boosts oil

\footnotetext{
${ }^{20}$ Patrick Brethour, 'OPEC Mulls Move to Euro for Pricing Crude Oil', The Globe and Mail, January 12 , 2004. Accessed online January 15, 2004.
} 
prices. In other words, any country - not just the United States - using the U.S. dollar for pricing would see the cost of the commodity rise as that currency fell. Even though OPEC has yet to make any such formal break with the U.S. dollar, "its refusal to boost output has already offloaded much of the cost of the dollar's depreciation on to the American economy. Gobert said that the [then] current price of oil of $\$ 32$ a barrel would have been much lower if it had not been for the decline in the value of the dollar over the previous 24 months. Using the exchange rates between the dollar and the euro of two years earlier, crude would be selling at $\$ 22$ a barrel instead, he said. But Gobert did say that he believes it unlikely that OPEC would opt for a formal split with the dollar, although OPEC's musings about adoption of the euro are a signal of the rising value and influence of the currency among commodity traders and analysts.

However, it is not just OPEC countries that have started to talk about this sort of shift. A story in the Moscow Times ${ }^{21}$ quoted Russian President Vladimir Putin as considering the very same thing. In a move that "could have far-reaching repercussions for the global balance of power - potentially hurting the U.S. dollar and economy and providing a massive boost to the euro zone," Putin said that "We do not rule out that it is possible." Speaking at a joint news conference with German Chancellor Gerhard Schroeder, he continued to say that such a move "would be interesting for our European partners." Putin went on to say that such a decision "does not depend solely on us. We do not want to hurt prices on the market." For Youssef Ibrahim, managing director of the Strategic Energy Investment Group in Dubai, and a member of the Council on Foreign Relations, Putin's

\footnotetext{
${ }^{21}$ Catherine Belton, 'Putin: Why Not Price Oil in Euros?', The Moscow Times, October 10, 2003. Accessed online October 13, 2003.
} 
statement was very significant. "Putin's putting a big card on the table," he said. "In the context of what is happening worldwide, this statement is very important." The article points out that Putin's comments came amidst a "protracted drive by the EU" to attract more countries' currency reserves and trade into euros. It is a deliberate bid to "chip away at U.S. hegemony over the global economy and money supply." As the second largest oil exporter, for Russia to begin trading oil in euros could set off a chain reaction among other oil producers already thinking about such a switch. It would also substantially boost the euro's steadily growing share of global currency reserves.

Belton writes that while this could provide a huge boon to the euro zone, it could be potentially catastrophic for the United States. She explains that under the current circumstances, the dollarbased oil trade gives the United States "carte blanche to print dollars without sparking inflation - to fund huge expenses on wars, military build-ups, and consumer spending, as well as cut taxes and run up huge trade deficits." She goes on to say that almost two-thirds of the world's currency reserves are kept in dollars. This means that countries which import oil pay for that oil in dollars, and exporters keep their own reserves in the currency they are paid in. Since these dollars can subsequently be reinvested back into the American economy as well, it amounts to an interest-free loan with zero currency risk. A shift to the euro for a major oil exporter like Russia would throw a wrench in to the works, and would likely further devalue the U.S. dollar against the euro, making oil purchases with the U.S. dollar that much more expensive, and the euro just that much more attractive. 


\section{'Things Related and Not'22}

There was another country that did much more than consider a shift to the euro; it actually made the jump. That country was Iraq, and it happened in 2000. At the time, the move was described by economists as a foolhardy blunder that was going to cost Iraq millions. But they were not laughing for long, once the euro began to rally against the dollar. In a November 2000 article for Radio Free Europe, ${ }^{23}$ Charles Recknagel took a look at what was at stake for Iraq in what was described as a rebuke of Washington's hard-line on economic sanctions against it.

"Iraq is going ahead with its plans to stop using the U.S. dollar in its oil business in spite of warnings the move makes no financial sense. Baghdad this week insisted on and received UN approval to sell oil through the oil-for-food program for euros only after 6 November. Iraq had threatened to suspend all oil exports - about 5 percent of the world's total - if the body turned down the request." The story continues to describe the repeated cautions that Iraq's departure from the dollar standard of the oil industry would cost it millions in currency conversion fees. UN officials stated that Iraq would have to lower the cost of its crude by about 10 cents a barrel in order to compensate buyers for the additional costs. Further to this, the UN warned that Iraq would make far less interest on its oil revenues, which were being held in a UN-monitored escrow account in New York. Complicating matters even more, was that Baghdad would be keeping those accounts in dollars for the time being, meaning that the oil-for-food program would have to maintain two accounts - one in euros, and one

\footnotetext{
${ }^{22}$ David Martin, 'Plans for Iraq Attack Began on 9/11', CBSnews.com, September 4, 2002. Accessed on November 5, 2005.

${ }^{23}$ Charles Recknagel, 'Iraq: Baghdad Moves to Euro', Radio Free Europe, November 1, 2000. Accessed on September 29, 2005.
} 
in dollars.

"With Iraq now set to begin oil transactions in euros as early as next week," Recknagel writes, "President Saddam Hussein has clearly made up his mind that banning the dollar is worth flying in the face of financial logic. The euro reached record lows last week as it traded at 82 cents to the dollar, down 30 percent since its launch in January last year. Currency traders say they do not expect a rebound soon." Recknagel reports that many analysts were scrambling to find where Bagdad sees the payoff. One in particular, Pierre Shammas, a Middle East expert for the Cyprus-based Arab Press Service, called the move emotional, and that it was impossible to understand on economic grounds. "As long as the euro goes down, you don't switch to a currency that goes down in value while the dollar goes up in value. Saddam has not spelled out his plan in detail. These are politicians talking. They are not experts, they are not central bankers, they are not even oil men." Shammas speculated that the move made sense to Saddam as a way of trying to consolidate the divide he saw in world opinion about the economic sanctions on his country. One camp was led by the U.S. and the U.K., both outside the euro zone, which wanted to maintain strict controls on Iraq until it proved that it had no more weapons of mass destruction. The other was comprised of eurousing France - along with China and Russia - all who favored the lessening of sanctions on humanitarian grounds while still looking to pursue disarmament. Hussein saw France and Italy as sympathetic, and it appeared that he was motivated to encourage ties to states like them by embracing the euro.

But Saddam was hedging his bets. The escrow account held in connection with the UN sanctions 
at the New York branch of the French back BNP Paribas totaled about $\$ 10$ billion (U.S.) dollars. Hussein decided not to convert the escrow account, which some analysts felt at the time might have helped the struggling currency. "The untouched $\$ 10$ billion are equivalent to several European bank interventions to prop up the currency and such a large conversion might have helped bolster investor confidence in it." Shammas noted that in deciding to move to the euro, Baghdad was dusting off an Iranian strategy, proposed the previous year, which was shelved once the euro plunged against the dollar. He said that the appeal of the idea of switching to the euro for Iran and Iraq was that, if several major oil producers did it, "they could create a stampede from the dollar which would weaken Washington." He then suggested that another possible candidate for changing over to the euro would be Venezuela's Hugo Chavez, whose relations with Washington had already turned rocky by this point. Recknagel concludes that for now "no big stampede to the euro is on the horizon - except in Baghdad. And that leaves Saddam once again charting a highly individual course that guarantees he keeps other capitals guessing what his next move will be."

One of those moves, would be the eventual conversion of Iraq's $\$ 10$ billion fund to euros. It would also, predictably, provoke some writers to talk of the "real reason" that the United States became so determined to attack Iraq. "Although completely suppressed in the US media, the answer to the Iraq enigma is simple yet shocking," writes William R. Clark for The Guardian ${ }^{24}$ in Australia. Just in advance of the invasion of Iraq, Clark continued that the "upcoming war in Iraq is mostly about how the US ruling class and the Bush oligarchy view hydrocarbons at the geo-strategic level, and the

\footnotetext{
${ }^{24}$ William R. Clark, 'Battle of the Currencies - The Real Reasons for the War on Iraq', The Guardian (Australia), February 26, 2003. Accessed online December 5, 2005.
} 
overarching macroeconomic threats to the US dollar from the euro." Already, Clark himself has adopted the rhetorical affectations of a conspiracy theorist, as he continues that the "Real Reason for this upcoming war is this administration's goal of preventing further OPEC momentum towards the euro as an oil transaction currency standard. In order to pre-empt OPEC they need to gain geostrategic control of Iraq along with its second largest proven oil reserves." Clark's story, replete with quotations from an "astute and anonymous friend", goes on to say that the "Federal Reserves's greatest nightmare is that OPEC will switch its international transactions from a dollar standard to a euro standard. Iraq actually made this switch in Nov. 2000 (when the euro was worth around 80 cents), and has actually made off like a bandit considering the dollar's steady depreciation against the euro." Given the questionable merits of the source, the inclusion here is useful for how closely the admittedly compelling simplicity of Clark's perspective nonetheless echoes a standard conspiracy theory. It highlights once again, however, how questions about the nature of geo-political intentions very quickly devolve into what may or may not actually be conspiracy theories. Clark's article does not pass the test on this count.

Another that might, though, comes from the BBC's Greg Palast in a joint investigation with Harper's Magazine. ${ }^{25}$ In it, he begins that "conspiracy nuts believe the Bush administration had a secret plan to control Iraq's oil. In fact, there were TWO plans. In a joint investigation with BBC Television Newsnight, Harper's Magazine has uncovered a hidden battle over Iraq's oil. It began right after Mr.

\footnotetext{
${ }^{25}$ Greg Palast, 'Secret US Plans for Iraq's Oil', BBC, March 17, 2005. Accessed online September 21, 2005. See also, Greg Palast, 'OPEC and the Economic Conquest of Iraq: Why Iraq Still Sells its Oil a la Cartel Twilight of the neocon gods', Harper's Magazine, October 24, 2005. Accessed online December 9, 2005, and Greg Palast, 'Baghdad Coup D'Etat for Big Oil', Harper's Magazine, March 25, 2005. Accessed online March 29 , 2005.
} 
Bush took office - with a previously unreported plot to invade Iraq."

The two plans that are described in detail by Palast, based on interviews with principle actors in the State Department as well as information contained in lengthy reports, conflicted with each other and set off a hidden policy war. On one side of the debate were executives from major American oil companies and U.S. State Department "pragmatists"; on the other, were neo-conservatives at the Pentagon. It would be a debate that would be won handily by big oil, but not at all in a fashion that conspiracy theorists might imagine. "The latest plan," Palast writes, "obtained by [the BBC's] Newsnight from the US State Department was, we learned, drafted with the help of American oil industry consultants." The planning began "within weeks" of Bush's first taking office in 2001. In a series of secret meetings in California, Washington, and the Middle East, an Iraqi-born oil industry consultant, Falah Aljibury, who says he took part in them, described a State Department plan for a forced coup d'etat. ${ }^{26}$ Aljibury also said that he personally interviewed potential successors to Saddam at the behest of the Bush administration.

But this industry favored plan was pushed aside by another one drafted just before the invasion of Iraq in 2003 by neo-conservatives within the administration. It called for the sell off of all Iraqi oil fields, and a boosting of production well beyond OPEC quotas, in order to destroy it. One of the “intellectual godfathers" of this strategy was Ariel Cohen of the Heritage Foundation. In September

\footnotetext{
${ }^{26}$ It is important to simply note that, according to Palast, the State Department denied the existence of this report for months. Palast writes: "For months, the State Department officially denied the existence of this 323-page plan for Iraq's oil, but when I identified the document's title from my sources and threatened legal action, I was able to obtain the complete report, dated December 2003 and entitled 'Options for Developing a Long Term Sustainable Iraqi Oil Industry.",
} 
of 2002, Cohen and Gerald P. O'Driscoll, Jr. published a post-invasion plan, The Road to Economic Prosperity for a Post-Saddam Iraq, which put forward the idea of using Iraqi oil to smash OPEC. Palast writes that Cohen had explained to him

how such an extraordinary geopolitical feat might be accomplished. OPEC maintains high oil prices by suppressing production through a quota system effectively imposed on each member by Saudi Arabia, which reigns by dint of its overwhelming reserves. The Saudis, to maintain their control on pricing, must keep a lid on production from other members - particularly Iraq, which has the second greatest proven reserves. [Though Saddam had adhered to OPEC quotas] Cohen reasoned that if Iraq's fields were broken up and sold off, a dozen competing operators would quickly crank up production from their individual patches to the maximum possible, swiftly raising Iraq's total output to 6 million barrels a day. This extra crude would flood world petroleum markets, OPEC would devolve into mass cheating and overproduction, oil prices would fall over a cliff, and Saudi Arabia - both economically and politically - would fall to its knees.

Palast goes on to describe how by February of 2003, with the invasion looming, Cohen's position had been "enshrined as official policy, in the form of a hundred page blueprint for the occupied nation titled 'Moving the Iraqi Economy from Recovery to Sustainable Growth."' It was a plan which was favored by such administration hawks as Defense Secretary Donald Rumsfeld and his then deputy, Paul Wolfowitz, along with current Deputy National Security Advisor (and former IranContra figure) Elliott Abrams. After the advance into Baghdad, anyone who was skeptical of the neocon plan was swept aside. Key among them was the short-lived Coalition Provisional Authority head, General Jay Garner, who Palast reports received a phone call from Donald Rumsfeld on the night he arrived in Baghdad to tell him he would be dismissed. When Palast later met with Garner in March of 2004, he was told by him that he had resisted the planned sell-off of Iraqi assets, especially oil. "That's just one fight you don't have to take on right now," Garner said. "You don't want to end the day with more enemies than you started with." 
According to Robert Ebel, who was an Energy and CIA oil analyst, the sell off had been given the go ahead at another secret meeting in London, which Ebel attended at the request of the State Department. In fact, Aljibury, who had been Ronald Reagan's and George H.W. Bush's backchannel conduit to Saddam, claims it was the plans to sell off Iraq's oil which helped to instigate the insurgency there. Pushed by the US-installed Iraqi Governing Council in early 2003, the plan was used by insurgents as evidence that they would be losing their country and their resources to "a bunch of wealthy billionaires who want to take you over and make your life miserable," Aljibury said. "We saw an increase in the bombing of oil facilities, pipelines, built on the premise that privatisation is coming."

But it would not take long before this plan would hit a major snag. It came in the form of Philip Carroll, the former CEO of Royal Dutch/Shell, American division. It was Carroll who took control of Iraq's oil production for the U.S. government one month after the invasion. He told occupation chief L. Paul Bremer when he took over from General Jay Garner in May 2003 that there "was to be no privatization of Iraqi oil resources or facilities while I was involved." Carroll's position was balanced on the other side of the ledger by Ariel Cohen of the neo-conservative Heritage Foundation. Cohen felt that an opportunity had been missed as a result to privatize Iraqi oil fields. He told Newsnight that he had advocated the plan as a means to help the U.S. defeat OPEC, and that he felt they should have gone ahead with a decision he called a "no-brainer". Palast records that Carroll hit back by saying, "I would agree with that statement. To privatize would be a no-brainer. It would only be thought about by someone with no brain." 
The new plans, Palast continues, which were obtained by Newsnight and Harper's Magazine under the U.S. Freedom of Information Act, called for the creation of a state-owned oil company. The plan was completed in January of 2004 by Amy Jaffe of the James Baker Institute at Rice University in Texas. Jaffe stated that the oil industry prefers a state control arrangement over a sell-off, saying that oil companies are not comfortable with any plan that would undermine OPEC, and the current high price of oil. 'I' $m$ not sure that if I' $m$ the chair of an American oil company, and you put me on a lie detector test," Jaffe added, "I would say high oil prices are bad for me or my company." Philip Carroll agrees. "Many neo conservatives are people who have certain ideological beliefs about markets, about democracy, about this, that and the other. International oil companies, without exception, are very pragmatic commercial organizations," Carroll said. "They don't have a theology." 


\section{Chapter Eight - Conclusion: 'Remember, remember the fifth of November'}

Oil companies may not have a theology, but many conspiracies, whether real or imagined, most certainly do. Guy Fawkes and his Catholic plot to blow up the British Houses of Parliament four centuries ago demonstrates this every bit as clearly as the 9/11 attacks do. One of the things these events have in common, was their perpetrators' belief that something sinister was happening to their country, something they felt had to be stopped. God would pardon their souls for the courageous acts they performed in His name. But the carnival tradition which has kept the memory of Guy Fawkes alive in the U.K. on 'Bonfire Night' for the past four hundred years may be starting to fade. It is being gently nudged aside, perhaps not so ironically, by yet another carnival tradition with a distinctly foreign cachet. David Cannadine, ${ }^{1}$ writing on the eve of the $400^{\text {th }}$ anniversary of the Gunpowder Plot for the BBC, bemoans the waning of the tradition he grew up with, for another he only first encountered as a graduate student in the United States during the 1970s. It was Halloween.

Writing about the unusually high number of anniversary celebrations which fell in 2005 , he notes that January marked 40 years since the death of Winston Churchill, and the summer months witnessed many commemorations of the $60^{\text {th }}$ anniversary of the end of World War Two. But Cannadine remarks that as "commemoration moves from the realm of remembrance to the province of history, the numbers tend to get rounder, and it's centenaries or multiple centenaries that are

\footnotetext{
${ }^{1}$ David Cannadine, 'Halloween v Guy Fawkes Day', BBC News, November 4, 2005. Accessed on November 6, 2005.
} 
usually marked." He continues to point out that a period of a couple of weeks would cover two of those: “the $200^{\text {th }}$ anniversary of the Battle of Trafalgar on 21 October, marking Nelson's great naval triumph in 1805; and the $400^{\text {th }}$ anniversary of Guy Fawkes' abortive attempt to blow up the Houses of Parliament on 5 November 1605." He writes that it is hard to imagine two events more different from each other, both in terms of what happened, and who was at the center of them. Nelson was and remains a national hero, while Fawkes is a national villain. But Fawkes, like Nelson, was a professional fighting man. The difference is that while Nelson attracts visitors to the British naval Museum, Fawkes "has been greeted with collective boos and catcalls ever since. No wonder he is burned in effigy every year."

Cannadine says that it is not easy to get a sense of the scale of carnage that would have resulted had the Gunpowder Plot been successful. This is because on the day of the opening of parliament, "almost the entire elite of the nation would have been there: king, lords and commons, and all the senior officers of the church, military and the state. If all of them had gone up in smoke and flames, virtually the whole of the nation's establishment would have been taken out." But since the conspiracy was detected in advance, it was a failure. "Put in the Bush-and-Blair language of our own day, the foiling of the Gunpowder Plot was thus an outstandingly successful pre-emptive strike against what would now be described as the forces of organized, fanatical, religiously-motivated terrorism." Its celebration is an expression of national identity that shares with the Battle of Trafalgar, a common Catholic enemy. Celebrating both is an affirmation of Protestant patriotism, which gives pause to British Catholics even today. 
"But Catholics take heart: for these days, Bonfire Night is not the event it was when I was young," he writes. "I can vividly remember that for me 5 November meant street-corner guys in rickety prams; roasted potatoes and chestnuts; and my father in our back garden lighting the blue touch paper on rockets, roman candles and catherine wheels, and then retiring." Today, the family bonfires are much less popular, and that even the once-large civic displays have dwindled "because of the increasingly intrusive health and safety regulations." Though Halloween barely existed when he was growing up, it has moved into a more prominent position in the customs and practices of British children over the past decades. Though he acknowledges that the tradition traces its origins to Celtic and medieval times in the British Isles, "in its present-day guise, we associated it with America, with kids dressing up in spooky and lurid costumes, who then go trick or treating..." He points out that Halloween has always been big business in America, but that it has only very recently become so in the U.K., "where it's now much easier for shops and supermarkets to sell pointed hats in garish colours than fireworks."

Though 'Guy Fawkes' and 'Bonfire Night' have been around much longer in the U.K. than the memories of Nelson and the Battle of Trafalgar, Cannadine suggests that the prospects do not look good for them once the $400^{\text {th }}$ anniversary has passed. "Britain is not the Protestant nation it was when I was young: it is now a multi-faith society. And the Americanised Halloween is sweeping all before it - a vivid reminder of just how powerfully American culture and consumerism can be transported across the Atlantic." But here, Cannadine feels may be a chance for Britons to rally around a symbol that is their own, and resist the grab-bag of American influence. He concludes by saying that "here, perhaps, is an opportunity for the revival of 5 November. For those who wish to 
protest at the ever increasing Americanisation of our world might take up Bonfire Night as their cause. Guy Fawkes may have been a bad Briton, but in some ways he was a good European, and from there it's only a step to pulling faces at Uncle Sam."

It is interesting that David Cannadine would posit a form of symbolic British rebellion like Guy Fawkes as a model of resistance to American economic and cultural hegemony in the current political circumstances. On one level, it is a wholly understandable lament for one's past. On another, it represents a broader recognition of a newer resistive stab at global economic and cultural dominance. And while this is interesting enough on its own, it becomes even more so still in those particular cases where conspiratorial and/or religious tensions become materially-infused with currency itself. The 'Gunpowder Plot' represents one of these cases. To commemorate the $400^{\text {th }}$ anniversary of the foiled Catholic conspiracy, the British minted a 2 pound coin with the words from a refrain familiar to 'Bonfire Night' stamped into the outer edge of the coin. They are: "Remember, remember the fifth of November".

In this chapter I begin by revisiting the key themes that have been addressed in this thesis, as well as describing what they add to an understanding of the subject at hand. This will be done in order to set the stage for a more detailed look at some of the ways that a focus on simple conspiracy theories might be seen as a productive means of unlocking and localizing geographically specific critiques of a global system which is impossible to understand all at once. Not at all unlike a study of humor which sought to trace out regional specificity against a broader collective whole which is much too big to see all at once, it is one of the contentions of this thesis that a focus on conspiracy 
theory should be no less mysterious. To put it plainly again, there is nothing necessarily 'conspiratorial' about conspiracy theories. One of the more important questions this thesis has tried to address is what to do with them analytically.

In this thesis I have tried to position and employ the conspiracy theory as a useful and integral optic on the dialectics of representation and reality. Key to this effort was a conception of the conspiracy theory which is at once theoretically consistent, and yet versatile enough to be applied in any number of different political circumstances. Using conspiracy theories about the $9 / 11$ attacks and the invasion of Iraq as a case study demonstrated that such a model does indeed help to assemble widely divergent sets of historical circumstances and political practices. In the thesis, this took the form of a narrative which illuminated the originating frictions at play within conspiracy theories without falling victim to their obvious limits as causal explanations for material reality. At the same time however, it was also demonstrated that conspiracy theories can act as material forces in history, even though they themselves have no material basis in reality at all. As illusions which haunt the corridors of history, conspiracy theories evoke and represent real fear nonetheless. It was this, among other things, that rendered the lowly conspiracy theory a worthwhile subject of higher learning.

In this thesis I have argued that conspiracy theories, being an immanent feature of human experience, constitute micro-perspectives on macro-phenomena which fail to grasp their own inadequacies as explanations. They do so, however, from dialectically dependant viewpoints hinged on the exercise of power. On one side of the coin, they represent the contradictions between teleological world 
views, such as those inscribed within monotheistic religions for example (or Marxism for that matter), and the chaotically random circumstances out of which those religions evolved in the first place. They offer imagined solutions to the real world complexities which underpin the very circumstances they subsequently seek to describe. On the other side of the coin, the forms through which they attempt to grapple with these infinitely complex circumstances, renders them, in some cases, similar to carnival practices. In challenging dominant institutional arrangements and definitions of reality, they simultaneously reinforce their own marginality through the very act of doing so. It is this necessarily marginal status in relation to dominant ideas and practices which likens them to the carnival. On the other hand, it is important to remember that without these dominant ideas and practices, the carnival versions would not exist themselves. Put another way, there is no history of the carnival other than that which is transgressively indifferent to prevailing social norms. Likewise, there is no such thing as a conspiracy theory without some form of political might against which it is defined through its own expression.

A necessary starting point for any wide-ranging analysis of the $9 / 11$ attacks from the point of view of conspiracy theory is the broad history of conspiratorial suspicion inherent to the American political experience. Towards this end, Hofstadter's description of the paranoid style in American politics traces its history not only to the foundation of the Constitutional United States, but even further still, to the very circumstances which underscored the decision by Pilgrims to leave the European continent for the New World. Ironically perhaps, European conspiracy theories about Freemasonry and Illuminism, as only two examples, would make the trip to the New World as well, and would become self-styled impediments to the foundation of a new and godly society which 
would otherwise be able to flourish. Many other examples were pointed to as well, and included the Catholic church, which was viewed at the time in different ways as a plot against American values. In what was described as the 'pornography of the Puritan', anti-Catholicism demonized its practitioners with accusations of all manner of sexual indiscretion. In doing so, it worked to uphold Puritan values at the very same time it gave voice to forbidden Puritan longings. It was noted that it could hardly be a coincidence that the spectre of the carnival echoed in the suspicion of Jesuits, who were said to prowl the countryside as 'puppet show men, dancing masters, peddlers of images, and barrel organ players.'

Intellectuals were also targeted with conspiratorial suspicions. The Godly merits of the Calvinist or Protestant ethic was, in short order, counterposed with the twin perils of communism and socialism. The politics of dispossession associated with such fears was a motivating influence in the rise of the 'new right' which would awaken in the U.S. during the McCarthy era. The rise of modern mass media moved the alleged conspirators out of the Vatican and the shadowy recesses of masonic lodges, and into the mainstream institutional frameworks of 'New Deal' presidencies and the Supreme Court. It quickly became apparent that there was a relationship between capital expansion, religious beliefs, and the conspiratorial rhetoric which bubbled out of the fissures left in their wake.

As a point of comparison, the British colonial experience in both Africa and India demonstrated a similar coalition of Christian capital with conspiratorial explanations for the impediments to 'progress' over history. In Africa, the well-intentioned Victorian missionary zeal ran up against the 'backward' sophistication of the Dark Continent. With 'culture' becoming the new battle-front of 
imperial expansion, Christianization was envisaged as the necessary precondition for such a largescale transformation. Salvation of the African heathen and deliverance from the evils of their suffering life over-rode any concern for the dangers which inhered in Evangelical battles with deadly disease, machete-wielding bushmen, and hungry lions.

The situation in India, though much more complicated in terms of regional and religious politics, would nonetheless eventually display a rather similar interrelationship. Europeans had shared a much more extended and profitable history with India, one which had been marked with mutual admiration and even respect. The East India Company, as just one example, had maintained a steady balance of trade upon which commerce was paramount. In fact, legislation existed at the time which had expressly forbidden any attempts to Christianize or otherwise tinker with this sometimes delicate balance between Western and Eastern philosophies. In the interest of protecting trade, the East India Company was able to even restrict the entry of missionaries into the country. All of this would be thrown into disarray in 1813, however, when the company's charter came up for renewal and British Evangelicals seized the opportunity to try and ease the company's restrictive control over missionary activity in India. In what remains today a strikingly clear demonstration of the role that religious interventionism can play in upsetting an otherwise lucrative and long-standing commercial enterprise, the "moral darkness" of the Indian people would become the new British Evangelical cause célèbre. Various cultural practices such as female infanticide and the burning of a widow on the husband's funeral pyre struck the Evangelical as ungodly and barbaric, which they may in fact be. Simmering tensions like these, however, would slowly escalate into the Indian Mutiny of 1857, in part sparked by rumors of the use of fat from sacred cows or profane pigs on rifle cartridges. 
It was suggested that religious extremism was not at all unlike conspiracy theory itself, save for who is imagined to be in control. Even when working from Cubitt's schematic definition of conspiracy theories, the parallels to fundamentalist religious beliefs are striking. Despite whether or not God really does work in mysterious ways, or acts to help those who help themselves, one key difference was said to be that religious beliefs are predicated on faith, while conspiracy theories are driven by its dialectical opposite, suspicion. In both cases, the presence of what might be called 'socialist themes' was shown to be remarkably consistent. Whether or not religion can be understood as an opiate of the masses, it may be symptomatic, along with conspiracy theory, of more earthly contradictions. In being so, it draws special attention to those instances, such as the aftermath of the 9/11 attacks, where the boundaries between them begin to fall away.

All of this draws attention to the ways that political realities such as these are practiced and represented symbolically over history. As we have seen, there is a rich history of carnival which can be very useful as a conceptual tool to try and understand vastly more complicated political practices. The reciprocal parody of desire in status relations is ever present within carnival forms, though they, in spirit, refuse to understand each other. It was suggested that this might make the study of conspiracy theories an interesting template for various kinds of social and political analysis.

A handy analytical distinction will serve as a useful example at this point. Either the administration of George W. Bush fell for a groundless conspiracy theory regarding Saddam Hussein, or they really did try to perpetrate the biggest global conspiracy of the modern era. There is obviously no point in trying to take either of these illustrative extremes seriously, except to point out that in either case 
it was a miserable failure. What it does do, though, is simultaneously demonstrate the illusory power of conspiracy theories while illustrating why a global conspiracy could never succeed in the fashion imagined by conspiracy theorists. Vast conspiracy theories of global domination crumble under the weight of their own declaration. At the same time, as the $9 / 11$ attacks certainly prove, that does not mean that conspiracy theories can be ignored either. On the contrary, conspiracy theories are material forces in the unfolding of history, and so, are a factor in how it comes to be understood and remembered.

At this point, the carnival became a means of trying to untangle the various contradictory logics competing for dominance, entanglements which come in many forms. To the extent that conspiracy theories represent one of these, the suggestion was made that they are not that much unlike older carnival practices, which have always existed in different forms under different names. To this end, the centuries-long tradition of 'Guy Fawkes Day' served as an invaluable instance of a carnival tradition which commemorates the foiling of a Catholic plot to blow up the British Houses of Parliament, at the same time it celebrates there was even a plot at all. It actively connects the existence of a real conspiracy with the spirit of rebellion which pre-exists priests and kings. The fate of Guy Fawkes signals a cue to the carnival generally as an indication of the sometimes tenuous arrangements by which power has maintained itself historically. The debatable extent to which carnivals can truly be considered a 'licenced' form of transgression was seen to be secondary to the more immediate tensions between 'high' and 'low' forms, between repugnance and fascination, that always co-exist symbolically within carnival forms. Furthermore, the understandings of each are always reciprocally dependent on the other. The 'low', for example, is always a symbolic 
component of what it means to be 'high'.

As Bakhtin noted, it was the relational nature of high/low binarism in carnival festivity, its inversion of and ambivalent dependance upon official culture, which gives it a fundamental place within culture. It was concluded that the act of symbolic inversion and transgression was of utmost importance in any attempts to adopt the idea of carnival as an analytic category. From here, it was a short step to considering the conspiracy theory as an act of transgression, and the conspiracy theorist as one of society's marginal figures, or deviants. At any rate, it was the idea that the classificatory body of culture is always double and is always structured in relation to its inverse, which was key to understanding conspiracy theories as a carnivalesque form. They represent one instance of the 'taboo-laden overlap between high and low discourse', and become an analytically powerful tool in the study of ideological repertoires and cultural practices. They also return to the somatic symbol of the conspiracy theorist as the site of transgression in any attempt to control them. Taken together, these dynamics were shown to be 'intrinsic to the dialectics of social classification', and considering the theoretical parameters of the present study, this seguéd nicely into a more closely focused consideration of dialectics, ideology, and the hegemonic terrain over which conspiracy theories find their traction.

An important aspect in the turn to dialectics as a way of developing a more broadly-based understanding of conspiracy theories, was said to be their dialectical relation to conspiracy itself. In a nutshell, it was shown that the political and historical reality of conspiracy is as much a predicating influence on the formation of conspiracy theories, as conspiracy theories are a negation 
of political and historical reality. As a carnivalesque form, conspiracy theories invert accepted definitions of history and reality. It is this feature of conspiracy theories which draws them towards the dialectic as a means of incorporating them into a general study of power. It is not necessary to revisit the specific ways that Marxist writing has grappled with dialectics, except to say the dialectic between conspiracy and conspiracy theory was illustrative of the dialectic as a process of reason. This is because it is a process of reason which is predicated on the grasping of opposites in their unity, or of seeing the positive in the negative. The 'partial insight' on reality through the optic of the unreal in the form of conspiracy theory was held to be particularly important in this regard.

On turning to the concept of ideology, the question was raised of the extent to which conspiracy theories might be described as manifestations of ideological conflict. In drawing out a rather detailed set of perspectives on the general concept of ideology, particular attention was given to what John Thompson called Marx's latent conception of ideology. By this, Thompson meant to highlight the ways that Marx seemed to be trying to describe something which was vaguely ideological, without actually describing it as such. Perhaps the most famous example of this type of description was from Marx's 'The Eighteenth Brumaire of Louis Bonaparte,' where he described the 'tradition of all dead generations [weighing] like a nightmare on the brains of the living.' What characterized this "latent conception" of ideology most clearly for Thompson, was his use of terms such as 'illusions', 'ghosts', 'spirits', and 'fixed ideas' instead of the word ideology. It bears recalling Thompson's caveat in referring to this as Marx's latent conception of ideology. It was that this can only be done with the acknowledgment that it refers to a range of social phenomena which Marx described, but did not name. In Thompson's words, these were "phenomena which he perceptively and 
disconcertingly portrayed in his analyses but which, at the level of theory, he did not subsume under a discrete conceptual label."

\section{Conspiracy Theory and the Materiality of Meaning}

It was the engagement of questions like these at the level of language that made the work of Vološinov so useful. His discussion of the sign as a material embodiment of lived reality which is infused with ideological significance, was a handy way towards a consideration of the conspiracy theorist itself as a semiotic entity. Part and parcel with Vološinov's contribution, was his contention that signs never simply exist as a part of reality, but that they always reflect or refract another one. They can distort reality, or be truthful to it. They can perceive it from one point of view, or from another. As such, for Vološinov, where signs are present, ideology is as well. While the meaning of these signs can derive from any number of different realms, such as science, religion, or art, for example, each of them fosters its own distinctive orientation towards reality and performs a different or unique function within the unity of social life. Eschewing a position which would elevate the study of signs upwards to some sort of transcendental plane, nor downwards towards the pre-social abyss of psycho-biology, Vološinov contends that its real place is in the social material of signs made by man. It is this sort of orientation towards the study of the sign which emphasizes their social 'position' between organized individuals. It also draws particular attention to the fact that no cultural sign exists in isolation. On the contrary, they exist not only in their own specific 'realms', but also in between evolution. For example, the recent debate about 'intelligent design' derives its significance from the competing factions of science and religion by signaling their incompatibility. In this way, Vološinov's problematizing of tensions like these works to establish an ideological 
framework for thinking about the ruptures which exist between them.

The carnival becomes one site of analysis where tensions like these are articulated symbolically. ${ }^{2}$ This view of carnival as an epistemological category becomes particularly useful for a discussion of conspiracy theory. This is because the predicating tensions between 'high' and 'low' forms within the carnival are automatically factored into a discussion of both the conspiracy theorist as political figure, and conspiracy theory as political discourse. Hierarchies of meaning such as this are only reinforced in popular entertainments (each of which come with their own meandering historical ties to earlier carnival forms). In Hollywood film, for example, the heroes are often understood to be so because of their abilities to see and uncover vast and sinister conspiracies. The widespread and longrunning public interest in stories like these then, simultaneously reproduces the trope of impossibly large and complex conspiratorial narratives, while valorizing fictive attempts to uncover and disrupt them. Vološinov helped to draw attention to the fact that signs derive their meanings from their social milieu, and so the role of Hollywood films in reaffirming narrative understandings like this was said to be an important aspect to this representational matrix. They all play supporting roles in casting the conspiracy theorist as an ideological construct.

All of this highlighted how broadly focused a concern with ideology and ideological forms needs to be in order to try and understand them properly. They do not exist in isolation, and so only exist at

\footnotetext{
${ }^{2}$ Even the example cited is a handy demonstration of the same dynamic. 'Intelligent design' mediates the antithetical poles of 'evolution' and 'creation'. It reconciles the religiously inclined to the reality of the fossil record, while upholding a faith in the divine will behind its existence. In doing so, though, it signals a willful limitation on understanding the relative eternities of time and space that science tries to explain.
} 
all because of much larger systems and practices. It is the tendency of these larger systems and practices to reproduce and reinforce signs and symbols conducive to their own continuation. For some, a focus on hegemony in this fashion itself constitutes a version of conspiracy theory. Though it is difficult to know where to begin critiquing a position such as this, it must be conceded that in some hands, it may amount to little more than that. ${ }^{3}$ One key distinction on this point needs to be drawn, and that is between notions of hegemony which would view it as some sort of 'state' to be achieved and then protected, versus a more productive view which understands it as a process which more-or-less spontaneously protects itself. Interestingly, one way to explain the concept of hegemony is to counterpose it with the idea of conspiracy.

Speaking too generally, the work of Antonio Gramsci was in part concerned with trying to explain why it was that the 'revolution' predicted by Marx had failed to happen. Key to Gramsci's understanding was the acknowledgment that despite an active civil society where individuals were free to dispute and challenge dominant institutional arrangements, and that they routinely did so in different ways, these dominant arrangements tended to be upheld regardless. In critical studies of communication, the same kinds of questions sometimes take a slightly different tack. A hegemonic orientation to the study of representation in mass media may pose questions as to why it is, despite the abilities of audiences and actors to resist and challenge dominant ideas and representations, that

\footnotetext{
${ }^{3}$ The work of Noam Chomsky would seem to fall into this category. Chomsky's use of the term in his recent book "Hegemony or Survival" suggests precisely this interpretation of the concept. For one, he does not define hegemony, but instead casts it (without irony) as an American impediment to basic human survival. He concludes by saying that "One can discern two trajectories in current history: One aiming toward hegemony, acting rationally within a lunatic doctrinal framework as it threatens survival; the other dedicated to the belief that another world is possible, ..." (Hegemony or Survival: America's Quest for Global Dominance, Henry Holt and Company, 2004, New York, N.Y.; p. 236).
} 
these dominant ideas and representations tend to be upheld nonetheless. Commercial mass media are vastly complex and open systems. A mechanism to 'control' them is non-existent, and would be impossible to achieve in any case. When confronting the cyclical dominance of ideological themes in commercial mass media, whatever they happen to be, it bears remembering that there $i s$ simply no conspiracy. Since there is no conspiracy, the question then becomes, how do we deal with the observation that dominant ideas and perspectives tend to reproduce themselves regardless? We know that they do, and, that there is no conspiracy in place to ensure this, so how does it happen? In this scenario, conspiracy theory is the straw man. ${ }^{4}$ At the same time, hegemonic systems are partially maintained through the materiality of conspiracy theories, and the various ways they intersect with political practice.

Set against an understanding like this, a study of the conspiracy theory within that representational system becomes a very interesting one indeed. As we have already seen, the charge of conspiracy theory is a powerful framing device. This is not only true in the cases where it actually is warranted, but is perhaps especially so in those cases where it is not. The difficulty, in some cases, is telling the difference. In trying to draw distinctions along these lines, one risks stepping on to a slippery slope. The risk is to be seen as either defending conspiracy theories tout court, or defending oneself to such an extent that it somehow validates the charge. It was this sort of conundrum that constituted one of my original interests in this topic as a serious subject of study. When commercial news

\footnotetext{
${ }^{4}$ My thanks to the late Lynne Hissey, whose explanation to me along these lines (and a long time ago as an undergraduate) helped form the basis of my understanding of the concept ever since. It was in no small way the beginnings of my thinking on this very topic. Any misgivings about the explanation here say more of my own faulty memory than it does Lynne's exemplary skills as a teacher.
} 
media, for example, report critique as conspiracy theory, or political opposition is dismissed as such, how does one necessarily know? This rather unproductive question, however, leads to others. How is this uncertainty itself a functional aspect of a larger system of meaning? How is it that meaning and reality are influenced by the non-reality of conspiracy theory, or are they? While never forgetting that there is such a thing as crackpot conspiracy theories, why are they so pervasive? What do they represent? Why is it that different forms of power always seem to be at the center? How might this be a point of entry for academic work?

The list, of course, could go on. There should be no suggestion here that some of these questions do not already have easy answers. They are intended only to reflect an overall 'arch' of interest which would lead to the present attempt to understand the more difficult ones. There is very little to be surprised about when an event such as the $9 / 11$ attacks comes to be the focus of conspiratorial suspicion. Colossally disruptive or unexpected events will always trigger efforts to try and make sense of them, and some of those will invariably come in the form of conspiracy theories. This aspect to the formation of conspiracy theories is straight-forward enough.

What becomes more difficult is teasing out those circumstances where conspiracy theories themselves become the motive forces behind real world action. It is altogether too easy to dismiss the grandiosity of the claims made by conspiracy theories, and forget about the seeds of realism they sow. If there is one lesson which has been learned in the preceding pages, it is that for this very reason, conspiracy theories cannot be dismissed. On the contrary, it is the tendency to flippantly disregard them as serious objects of study which, in part, makes them even more important to pay 
attention to.

It is in the attempt to see conspiracy theories as a unique form of mediated communication which led to a study of the carnival as a model for trying to understand them this way. A carnival focus simultaneously captures both the frivolous nature of the play-element of conspiracy theories, and the more serious political, economic, and military ramifications they either grow out of, or leave in their wake. ${ }^{5}$ As is the case in the study of the historical carnival in European history, real tensions simmered beneath the surface, and violent clashes often broke out as a result. This led to concerted efforts by political authorities to try and stamp out the unruly carnival of the people. It is in the relatively few but various forms of carnival proper which survive into the present day where we see glimpses of the unbridled will of the masses. It speaks, symbolically, in a voice which transcends time, history, culture, and religious or political affiliation. It also raises another question, one that Stallybrass and White ask themselves; where does this revolutionary spirit go as the bonfires of carnival are slowly stamped out of European history?

There is at least one common denominator across these different aspects of experience, one the carnival helps us to see. It is the fear which registers itself in the form of political or religious resistance to cultural practices and historical movements which evolve over time. That these fears should so often be based in religious or political doctrine is hardly surprising. After all, both of these systems, especially in the abstract, tend to work best when the prevailing order is maintained.

\footnotetext{
${ }^{5}$ Mark Fenster [op. cit., pp. 199-219] includes a chapter length consideration of the play-element of conspiracy theories which is a worthwhile extension on this theme.
} 
Though it is admittedly easy to make sweeping generalizations about religious and political practices, it is still difficult to ignore the conservative tendencies of both. Similarly, conservative tendencies would not exist, were it not for the ever-present crush of forces pushing against them. Conservative and liberal positions, then, stand in their own dialectical relationship to each other. And while competing conservative and liberal perspectives are themselves vastly numerous, the dynamic between them is remarkably consistent. It is also this central tension which the carnival helps to illustrate more clearly. On that basis, it becomes useful to explore that central tension between these competing conservative and liberal tendencies in the explosion of conspiracy theories about the 9/11 attacks and the invasion of Iraq.

\section{Philosophy in a Time of Terror ${ }^{6}$}

Giovanna Borradori begins her comparative interviews with Habermas and Derrida by asking whether discussion of the $9 / 11$ attacks and global terrorism need to reach back to include a critical reassessment of the political ideals of the Enlightenment. The thesis of her book is that it does. Though her direct engagement with both Jürgen Habermas and Jacques Derrida is interesting and worthwhile, it will not be developed here. What is important to do at this point is consider some of the ways that Borradori frames this issue, and how it provides an appropriate way to assemble and unify the broader themes under study in this dissertation.

Borradori positions the role of the philosopher as one of key importance to examining the juridical

\footnotetext{
${ }^{6}$ Giovanna Borradori, Philosophy in a Time of Terror: Dialogues with Jürgen Habermas and Jacques Derrida, University of Chicago Press, Chicago, Il., 2003.
} 
and political structuring of international law and various other multilateral institutions. She points out that in the battle against terrorism, there are no preset rules, no clear distinction between legal and illegal moves, and so little basis for deciding what the best move might be. She aims to try and establish an understanding of the role of philosophy in light of the 9/11 attacks as "a single historical event of worldwide significance." Borradori suggests that if global terrorism is the opening trauma of the new millennium, "philosophy may yet be unaware of the extent of its involvement with it."”

Aristotle famously declared that since philosophy deals with universal principles and history, that 'even poetry is more philosophical than history'. Borradori points out that since, in Aristotle's view, history did not conform to universal principles, it remained opaque to the Western tradition of philosophical thinking until the middle of the eighteenth century. At that time, both the French and American revolutions showed that the present may actually hold the possibility for a radical break from the past. Borradori claims that it was only then that philosophy began to ponder whether or not it might have an intrinsic moral and social responsibility, and so should develop a more active relationship with history. "Despite his conservative disposition," she writes by way of example, "Kant admired the revolutionary spirit for having given individuals a sense of their own independence in the face of authority, including the authority of the past. For Kant and other Enlightenment philosophers it became clear that the self-affirmation of reason has a historical impact, for only reason can indicate how to reshape the present into a better future." However, she goes on to say that despite this, reason remained for them "a mental faculty with which every individual is endowed simply by belonging to the human species and whose force is entirely

\footnotetext{
${ }^{7}$ ibid., p. 2.
} 
independent of the contingencies of history."

It would not be until one generation later that Hegel would take the important step in narrowing the distance between philosophy and history by declaring that reason itself was bound up with history. For Hegel, she continues, reason is not simply some sort of abstract mental faculty with which all humans come equipped. Instead, it grows out of the ways that individuals understand themselves as part of a community. ${ }^{9}$ If the ability to think at all is shaped by time and culture, then "only the study of history can disclose our nature and place in the world." Since from Hegel's perspective reason is history dependent, the Aristotelian dictum needs to be reversed to read that, apart from philosophy, nothing is more philosophical than history.

This distinction itself has a direct implication for the very meaning of "freedom", a term which has itself enjoyed a renaissance of sorts since the $9 / 11$ attacks. Borradori draws attention to this distinction because it is important to understand that if reason is conceived of as 'preceding history', then there is room to consider the possibility that 'rational agents' can see themselves as somehow independent or autonomous from it. According to this model, individual choices result from 'unique will' and 'singular needs'. In the mid-nineteenth century, "the liberalist tradition developed this sense of individual autonomy into a notion of negative freedom, according to which I am free when

${ }^{8}$ ibid., p. 3.

${ }^{9}$ Benedict Anderson's Imagined Communities (1983) provides a useful way of thinking about this from the point of view of conspiracy theory. Though the focus of Anderson's study is nationalism, the parallels are clear enough. 
I am left alone, not interfered with, and able to do as I please. ${ }^{10 "}$ She goes on to note that Hegel's response ${ }^{11}$ to this position

as well as those who followed Hegel, including Marx and Freud, was that this was an illusory conception, for it does not probe beneath the surface and ask why individuals make the choices they do. Since these choices are limited by one's own access to all kinds of resources - economic, cultural, educational, psychological, religious, technological - the idea that people can be left alone to make their own choices without interference from others does not make them free; on the contrary, it leaves them at the mercy of the dominant forces of their time."12

The belief that there is nothing more philosophical than history implies an observation that real freedom begins by realizing that individual choices are always formed out of a constant negotiation with external forces. "Freedom," she writes, "is thus measured by the degree to which we become able to gain control over these forces, which would otherwise control us." She goes on to say that this renders it incumbent upon philosophy to make some sort of contribution to the public discussion of $9 / 11$. This is because the event itself has emerged in such a way as to profoundly impact our understandings of the world and of ourselves.

\footnotetext{
${ }^{10}$ [footnote from original citation] "John Stuart Mill's treatise On Liberty is a manifesto of the principle of negative freedom. 'The object of this Essay is to assert one very simple principle ... that the sole end for which mankind are warranted, individually or collectively, in interfering with the liberty of any of their number, is selfprotection. That the only purpose for which power can be rightfully exercised over any member of the civilized community, against his will, is to prevent harm to others. His own good, either physical or moral, is not a sufficient warrant.' John Stuart Mill, On Liberty (Norton, 1975), p. 48."

${ }^{11}$ In what may simply be a case of faulty wording, Borradori seems to suggest that Hegel responded to a mid-nineteenth century liberalist tradition. Though she provides no dates, it must be noted that Hegel died in 1831 . Marx died 52 years later in 1883.

${ }^{12}$ The unproblematic way that Borradori equates Hegel's response to that of Marx should be noted in light of the discussion on this point in Chapter Three.
} 


\section{9/11 and the Neoconservative Agenda}

It is not surprising that since the $9 / 11$ attacks, there have indeed emerged a number of competing positions on their significance to world history. Differing philosophical orientations to the response to $9 / 11$ have in some ways underpinned the present study. One of the common denominators, at this point, is the central component of fear to these matrices of meaning. Shadia Drury ${ }^{13}$ writes on the philosophical roots of the modern American fear of liberalism. Her book goes into more detail than will be possible to address here, but she does highlight a number of important threads with strong connections to this study. It is important to note, though, that unlike Borradori, Drury's book was written well before the 9/11 attacks occurred, originally released in 1997. Any resonance her book now holds is amplified somewhat by the chain of events the attacks have set into motion. Focused primarily on the work of Leo Strauss, she sets out to situate his philosophical thought not only within the canon of thinkers such as Plato, Aristophanes, Aristotle, Machiavelli, Hobbes, Locke, and others, but also to trace out its influence on the American political system through his work as a professor of political science at the University of Chicago. An overview such as this is important to include because of the parallels which exist between his teachings, the policy positions taken up by some of his students in the Reagan years onward, and the influence they have since had in building the modern neoconservative movement.

Strauss $\{1899-1973\}$ was a German-Jewish philosopher who, like many others in his cohort, fled Germany when the Nazis came to power. Key to his approach to philosophy was a self-gratifying conceit upon which he based his belief that philosophers must be secretive and esoteric in order to

\footnotetext{
${ }^{13}$ Shadia B. Drury, Leo Strauss and the American Right, St. Martin's Press, New York, N.Y., 1999.
} 
be effective. He believed that only a select few were fit to receive it. Though a fear of persecution or ostracization was no doubt a component in this mix, more immediate was his contention that the truth was not necessarily the best thing for a society, but was instead dangerous or even destructive to it. That this should be his position while writing from within one of the freest of societies imaginable, goes a long way towards explaining his inherent aversion to liberalism.

Strauss' impact on North American academia is nothing to sniff at, and Drury cites the historian Gordon S. Wood as describing it as "the largest academic movement in the twentieth century." It is an influence which is not limited to political philosophy, but extends into literary criticism, religious studies, American history, classics, intellectual history, and American constitutional law. The list of prominent names associated with his thinking is long, and includes authors such as Allan Bloom, Daniel Bell, and Irving Kristol. Influential American political figures who pay a debt of gratitude to Strauss include some names which are already familiar. These are Paul Wolfowitz, Alan Keyes, Robert Bork (whose nomination to the Supreme Court by George H.W. Bush was blocked by a Democratic senate majority), Supreme Court Justice Clarence Thomas, William Bennett, and PNAC co-founder William Kristol. He has been so influential that the New York Times called Strauss 'the godfather of the Republican party's 1994 Contract with America.' ${ }^{15}$

The roots of Strauss' hostility to liberalism, and liberal democracy in particular, go back to the

\footnotetext{
${ }^{14}$ Gordon S. Wood, The Fundamentalists and the Constitution, New York Review of Books, (February 1988), pp. 33-40; cited in Drury, op. cit., 1999, p. 2.

${ }^{15}$ Richard Bernstein, 'A Very Unlikely Villain (or Hero)', New York Times, January 29, 1995, p. E4; cited in Drury, op. cit., p. 3.
} 
Weimar Republic in Germany following WWI. Though the historical details are interesting, it is enough to quickly point out how it was that people like Strauss understood the connection between the Weimar and the rise of German fascism. With no liberal traditions to fall back on in German history, Drury writes that the Weimar Republic was doomed from the start. It was the target of attacks from all sides. Conservative nationalists, such as Hitler's party, preferred the monarchical and bureaucratic model of the Kaiser-reich, and felt that the parliamentary system was inherently divisive. This perceived fragmentation would prove to be an obstacle, the logic ran, to necessary social changes in the national interest, and dictatorship was the only solution. The communists, on the other hand, preferred a dictatorship of the proletariat, and saw the parliamentary system as a relic of bourgeois interests. Against these fears, both of these groups made strong electoral gains, but by 1932, it was Hitler's National Socialists who had won the most seats in the Reichstag. As noted earlier in the footnoted reference to the Reichstag fire, by 1933, Hitler became the chancellor and leader of the majority party. Within a year after that, he had abolished all state power and brought German life under Nazi control. ${ }^{16}$

As a student of Plato, who described democracy as the second worse form of government which inevitably led to tyranny, Strauss saw his experiences in Germany in this light. Not unlike Theodor Adorno and many other German intellectuals, who felt that America was the replication of the Nazi system without the brutality of the police, Strauss' position was not unique. Drury notes, for example, that Adorno marveled at "the extent, sagacity, subtlety, and near invisibility of the American style of domination." Drury also cites a disturbing essay by Hiram Caton which praises

\footnotetext{
${ }^{16}$ pp. 4-5.
} 
Strauss for understanding how American liberalism is the re-creation of the "spineless liberalism of Weimar" which in America created a moral vacuum where eugenics was gaining the upper hand. It was the result of a

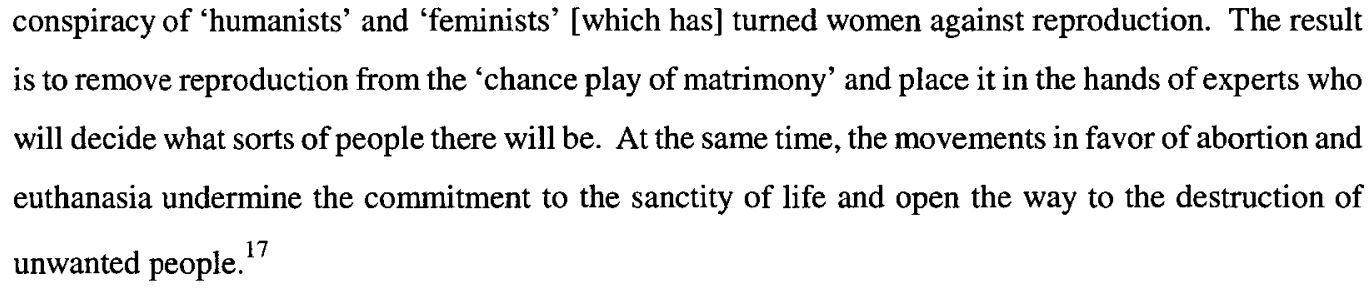

But more than this simple association between American liberal democracy and the Weimar, Strauss' critique emphasized the effect that liberalism had on eroding religious faith, which he felt to be an essential factor in any viable political order. Though he was grateful to the United States for giving him shelter, he still wanted to critique it, albeit secretly. It is to this end that his critique of 'modernity' was itself a veiled critique of America. Drury, however, notes one rare example where Strauss expressed his views more candidly. It came at a Jewish-Protestant Colloquium sponsored by the Divinity School of the University of Chicago. Drury reports that all of the participants at the conference agreed that a revival of religious faith was needed to remedy the anomie and alienation that derived from secular society. Still, there was no intention to impose their religion on others, something that would be un-American and would violate the Constitutional provision that "Congress shall make no law respecting an establishment of religion, or prohibiting the free exercise thereof." Their solution, then, was to revive a diversity of religious faiths which would co-exist with mutual tolerance and respect.

\footnotetext{
${ }^{17}$ p. 6.
} 
Though Strauss shared their concerns with regard to the rootlessness borne of liberalism, he dissented on the point that religious pluralism could ever function because it seemed illogical to him. His argument against religious pluralism ran along the lines that since every religion represented a particular revelation of truth, that it was bound to run into conflict with other versions of truth. In light of conflicts like this, he felt that it was impossible for any one religious faith to tolerate another and still remain true to itself. As a Jew, he felt that it was impossible for him to respect Christianity, especially when considering the historical slaughter of Jews by Christians, not only in the distant past, but right up into the $20^{\text {th }}$ century. This made the demise of religion not only likely, but unavoidable, and gave way to nihilism, or the belief in nothing.

Strauss was convinced that the persecution of Jews by the Nazis had everything to do with the demise of biblical religion and the rise of nihilism. In fact, he was convinced that liberalism bred nihilism. From his point of view, nihilism was the achievement of 'modernity'. The turn to reason which was unleashed by the Enlightenment led to the situation where religious faith could not survive scrutiny by it. It was reason that destroyed faith. In destroying biblical morality, the Nazis had broken through the veil of illusion which had protected the Western society from a descent into barbarism. For Strauss and his followers, liberalism leads people to reject the notion of one single and indisputable reality. It is a stance which conflicts with "the Straussian conviction that society requires unwavering faith and unflinching devotion. And even though the result is zealotry and fanaticism, Strauss does not flinch from it, for zealotry and fanaticism are preferable to nihilism and skepticism, because the latter weaken society, while the former strengthen it."18

${ }^{18}$ pp. 8-9. 
Drury concedes, rightly, that one "would have expected that the horrors of the Hitler regime would have had a profound effect on a German Jew." However, she also points out that one "would have expected such a man to embrace liberalism with open arms. After all, liberalism had its roots in the European experience of religious persecution." As an example, Drury points out that in England, the rise of a Catholic monarch to the throne, Queen Mary I (later known as "Bloody Mary") in 1553 required that Protestants declare their allegiance to Rome. Those who refused were burned at the stake. When Queen Elizabeth I came to the throne and re-established her father's Church of England, Catholics were not allowed to declare their allegiance this way, and were forced to conform to the Church of England. Elizabeth I reigned from 1558 to $1603 .{ }^{19}$ It is worth remembering at this point that it was precisely these religious tensions which led to the Gunpowder Plot and the attempt to kill her successor, James I in 1605.

The quarrel Strauss had with liberalism was not that he thought it could not work, but that he was afraid it might. He repudiated secular politics, equality, human rights, and individual freedoms. This was because he felt that secular politics were the very thing which led to nihilism, equality led to mediocrity, and individual freedom to licentiousness. Instead, he advocated a hierarchical social order steeped in religiosity which would emphasize civic virtue and fanatical commitment. Within the standard conservative view, the social fabric is seen as a delicate weaving together of hundreds of years of cumulative wisdom that is precious and worthy of preserving. It was partly this accumulation of civilized traditions which distinguished man from beast. But Strauss felt differently, and represented a new form of conservatism. He did not see tradition as the repository for the

\footnotetext{
${ }^{19}$ pp. $9-10$.
} 
wisdom of the ages. In keeping with his penchant for self-flattery, he felt that tradition was the conscious creation of philosopher/lawgiver/prophets, or what Nietzsche had called 'Supermen'. These were the great men whose wisdom was exactly what was needed in their times. They had the gift of understanding which they were willing and able to bestow "in the form of some glorious myth, noble lie, or pious fraud." Where classic conservatives might laud the mysterious origins of tradition, new conservatives realized that every tradition begins somewhere, even though it is still useful to perpetuate the mystery of origins. ${ }^{20}$

One of the troubles with liberal society, according to Strauss, is that it had dispensed with the noble lie, or the pious fraud. It tries to establish a society based on secular considerations which exist for the benefit of all. Abiding by the rules of that society acts to the mutual benefit of its members, and promotes liberty and order. But this is where it goes wrong, according to Strauss. He felt that there was an unbridgeable gulf between the interests of society, and the interests of individuals. Spanning this divide required the camouflage of lies and deception, for which religion served as the perfect vehicle. Human beings, by nature, were selfish and uncooperative, and required the belief in a punishing god who rewards the just. Since it was impossible to establish the proof of such a god by means of reason or philosophy, what was needed was "something grand enough to capture the human imagination, something magnificent and majestic, something splendid and sublime, such as Judaism, Christianity, or Islam." Drury notes that Marx had seen religion as the "opium of the

\footnotetext{
${ }^{20}$ It is interesting to ponder any role that conspiracy theories may play in this symbolically evolutionary process of mystification.
} 
people', and that Strauss does not disagree. It was just that Strauss felt people needed their opium. ${ }^{21}$

It was the ascendency of ill-conceived ideas in the West which evolved out of the Enlightenment which Strauss believed led to a break with ancient wisdom. To him, the holocaust was the logical outcome of Enlightenment rationality. The task, then, was to turn the tide by producing the right kind of intellectuals to reverse the trend. Strauss, in part owing to his position as a professor at the University of Chicago, was in a position to graduate more than one hundred doctoral students in political philosophy to this end. But he recognized that intellectuals could not be effective unless they had the ear of those in power.

This opportunity would present itself with the presidency of Ronald Reagan. The role Strauss envisioned for his American disciples was to amplify the remnant echoes of this ancient wisdom in order to gently and imperceptibly tip the balance away from the advancement of modernity. Since this was, in Drury's words, “ a supremely un-American activity, it is a very dangerous proposition and must therefore be undertaken with utmost care, not to mention secrecy. It requires great tact and a multiplicity of resourceful strategies, for it is nothing short of a counterrevolution." Books like Allan Bloom's The Closing of the American Mind, a best-seller which popularized Strauss' ideas, might be seen as a stark betrayal of this teaching, but for the fact that it is itself somewhat ambiguous and unclear. ${ }^{22}$

$$
\begin{aligned}
& { }^{21} \text { pp. } 11-12 . \\
& { }^{22} \text { pp. } 14-15 .
\end{aligned}
$$




\section{Leo Strauss and the Religious Right}

Drury writes that Strauss gave his students a totally extravagant faith in the abilities of right-thinking elites to divine the will of the people. One only need turn to history to study its most useful lesson that nothing could be more effective in this regard than the influence of religion. The work of Irving Kristol, as a Strauss-inspired neoconservative, has been useful in spreading Strauss' view of the value of religious enthusiasm for cutting at the roots of America's troubles. Seemingly blind to what Drury refers to as the "immoderate nature of groups such as the Moral Majority of Jerry Falwell or the Christian Coalition of Pat Robertson and Ralph Reed," Kristol has encouraged the Republican party to embrace the religious right.

Drury is careful to point out that religion can often exert a wholesome influence on human conduct. This is not being disputed here. She goes on to say that it may, in some cases, even present a measure of protection against tyranny and the abuse of power by people so committed to moral life they prefer to risk their own than go along with things they know to be wrong. But the other case is also true. Religion can also turn the corner towards militancy and intolerance. "Religious groups are not always satisfied with the religious freedom that liberal society affords them," she writes. "They are not content to gather together, worship, sing, play, and educate their children as they see fit. They are interested in imposing their vision of private morality on the rest of society. What they want is not freedom of religion, but conformity to their religious views." As has already been seen, this is not a problem limited to American Christianity, much less recent history.

Still, it would be hard to dispute the fact that the current mood is one which tends towards militancy. 
Pat Robertson and his Christian Coalition provide a rather handy example, and though Drury notes this herself, he would have to be included here regardless in light of some of the recent comments he has made with respect to the fate of Venezuelan President Hugo Chavez, the 'godless' decision to vote against the teaching of 'intelligent design' in Dover, Pennsylvania, and the 'will of God' in smiting Israeli Prime Minister Ariel Sharon. Along with Robertson's protégé, Ralph Reed, the "leadership school" of the Christian Coalition put a strong emphasis on the political process, and the "modern art of quick communication - phone, fax, and modem. These leaders are trained to mobilize their troops into rapid response networks intended to 'blitz' or bombard congressmen with the values of the coalition."

Even at the time of Drury's writing, there was no doubt that the Christian Coalition held a great deal of sway within the Republican party, as she notes that in the 1994 election "it may well have provided the margin for as many as half of the Republicans' 52-seat gain in the House of Representatives." Drury points out that with its 1.6 million active supporters and $\$ 25$ million annual budget, the Christian Coalition held virtual veto power over the Republican nomination for president in 1996. She cites William Lacy, chief strategist for Bob Dole's campaign that year as saying that the Republican candidate needs the support of the Christian right to win either the nomination or the general election. ${ }^{23}$ Ralph Reed did as much as his predecessors in the leadership of the Christian Coalition, Pat Robertson and Jerry Falwell, to push the agenda of the Christian right. This includes instituting school prayer, "recriminalizing abortion, stripping known homosexuals of their civil rights, teaching creationism in the schools, and censoring libraries and the press." Given

23 'The Gospel According to Ralph', Time, May 8, 1995; pp. 18-27, cited in Drury, ibid., p. 20. 
this apparent influence in the political process, it makes sense that politicians would want to court the religious right in their political campaigns.

It makes less sense, Drury goes on, as to why Jewish intellectuals such as the Kristols would be so quick to defend individuals such as Pat Robertson, whose own anti-Semitism is well known. For example, in his own book The New World Order, Robertson provides an account of world history, including both World Wars and the Nazi holocaust, that imagines it as a conspiracy of Jews, Freemasons, and international bankers. It should be duly noted, however, that whatever influence the religious right may have in the Republican party, Robertson himself failed to win the party nomination in 1988. Regardless, the Jewish conservatives weaned on Strauss share with their Christian counterparts a belief that religion is the necessary cement for a strong society, and also share a mutual disdain for their common enemy - liberalism. ${ }^{24}$

As was stated earlier, though, the evangelical Christian right in the United States is not content to 'live and let live', nor do they intend to 'leave judgement to heaven'. When this drive is coupled with real political power the resulting mix, though not a 'conspiracy', does much to encourage and inflame the 'paranoid style in American politics' which marked the beginnings of this study. That the 'paranoid style' dovetails so nicely here with the teachings of Leo Strauss, with his emphasis on the secretive, and even duplicitous, nature of effective leadership, merely has to be pointed out. The vast, unseen enemy that lurks around every corner and threatens the very fabric of American life, works very well as a means to draw together a fortified and outward looking community in order to

${ }^{24}$ pp. 19-21. 
fight it. If that struggle requires the 'noble lie', or the 'pious fraud' in order to be successful, then so be it. It also helps to enhance an understanding of how liberal ideas come to be framed, at times, as a common enemy to be feared and defended against. And it is hardly surprising that the fear of these liberal perspectives and programs could come to be understood as insidious conspiracies against an otherwise virtuous way of life. The same, of course, holds true of the opposite. It is not difficult to see how the absence of liberal perspectives and programs, for those who could benefit from them, might also be expressed as conspiracy theories. Race, class, gender, and religious tensions can only amplify the more fundamental divergence between conservative and liberal viewpoints.

Drury continues that the 'new right' in America emerged as a reaction to the New Deal, and became a political force after WWII. This was contrasted with the old right, which consisted primarily of conservative Southerners and Confederates who wished to hold on to the old South and the culture of slavery which made it prosperous. The new right became "disenchanted with social welfare liberalism and harkened back to laissez-faire economics." The new right is a grouping which can itself be split in to two camps, as it refers to both libertarians and neoconservatives, both of which advocate economic liberalism. The difference, she continues, is that libertarians are consistent liberals, and neoconservatives are not. Libertarians advocate minimal state intervention, not only in the economy, but in social life as well. In Drury's words, "they mean to keep government out of our pocketbooks as well as out of our bedrooms." In contrast,

neoconservatism combines capitalist economics with conservative social policies. It aims to keep the government out of the economy, but not out of the bedrooms, the schools, the arts, publishing, and broadcasting. Neoconservatism is the real challenge to the reigning liberal ethos. It is the dominant form 
that the new right assumes in America, and it is the most powerful ideological force within the Republican party.

It was this kind of ideological force that was given a huge shot in the arm on September $11^{\text {th }}, 2001$. The boogeyman of liberalism has been repeatedly invoked since $9 / 11$ by the religious and political right in the United States to help consolidate the movement towards an illusory conservative Christian homeland. This focus on 'ways of seeing' has a significance unto itself, one which the study of conspiracy theories brings to the fore, and which already has deep roots in the warring canons of philosophical thought.

\section{Conspiracy and the Logic of Capital}

Vincent $\mathrm{Mosco}^{25}$ relates the tale of an age-old myth which will help to close out this dissertation. It is a myth which deals with the 'Secret of Life', and involves the Norse god Thor. It seems that Thor liked to descend from Valhalla from time to time, cavorting with mere mortals for the sheer sport of it. On one such visit, he tangled with a local strongman named Sven, who managed to catch Thor in a submission: a painful headlock. Before long, it became clear that there was no way out, and Thor began the ungodly task of negotiating the terms of his release. "What would it take for you to release me?" Thor asked.

At first, Sven would have none of it, and responded only by tightening his already firm hold. But after some thought, Sven realized he might be able to turn this even more to his advantage. What 2004; pp. 9-10.

${ }^{25}$ Vincent Mosco, The Digital Sublime: Myth, Power, and Cyberspace, MIT Press, Cambridge, Mass., 
would it take to release Thor? Before long, he had it. "Tell me the Secret of Life," Sven demanded.

Thor groaned under the weight of the request, and protested, until Sven sunk the choke even deeper. Seeing that Sven was not going to relent, Thor came up with a counter-offer. "I'll tell you the secret of life, but on one condition." Sven laughed in reply. They both knew that Thor was in no position to set terms, but the offer was tempting, as Thor knew it would be. And so it came: "Pluck out one of your eyes."

Sven laughed again, and suggested the lack of circulation to his brain was affecting his judgement. Thor admonished Sven not to press his luck, and reminded him that though he was in mortal form now, he was still a god. "Now think about it," Thor reasoned. "You receive something no mortal has ever possessed, something that people far smarter than you, and after far more sacrifice, have failed to acquire. Most would give both eyes for such a gift. All I ask for is one of yours."

Even though an eye was indeed a high price to pay, Sven became enamoured of the idea he alone could know something no other person in human history had ever known. After much back and forth, the temptation become too much, and Sven agreed to pluck out an eye in return for the secret of life. In a fit of determination, he reached into his left eye, and tore it out with a scream that all could hear.

"Here, Thor, my eye for life's secret." Released from Sven's grasp, Thor took the eye, and spoke. "You have earned your reward, dear Sven. Now for the secret of life. It is painfully simple: 
See vigilantly, with both eyes."

The myth is a good one for illuminating one of the central tensions in this thesis: between that which is believed, and that which can be known. It also echoes the allure of conspiracy theory rather closely, in its promise to reveal a singular secret, and provides a parallel lesson on the high cost of trying to attain them. At the same time, it speaks to the sublime promise of life which religion portends to deliver unto the faithful. The role and power of myth to inform and fulfill human experience in this way can be seen very clearly. It is itself yet another area of study which will not be developed, but which in a very real sense, has already pervaded the thesis to this point in any case. What makes the myth of Sven and his deal with Thor useful here, is the simple observation that it operates just as well as a cautionary tale for religion, as it does for conspiracy theory. What differentiates them is the operative logic behind each.

In The Battle for God, ${ }^{26}$ Karen Armstrong takes up the old scholarly interest in the division between mythos and logos in the 'sense-making' histories of mankind. In the ancient world, both of them were regarded as essential, and complementary, ways of establishing truth. Myth was regarded as primary, and was concerned with that which was timeless and constant in experience. It looked to the origins of life, the foundations of culture, and to matters of the mind. It was not concerned with practical matters, but instead, was concerned with meaning. "Unless we find some significance in our lives," Armstrong writes, "we mortal men and women fall very easily into despair." These mythological tales were not meant to be taken literally, and were more like an ancient form of

\footnotetext{
${ }^{26}$ Karen Armstrong, The Battle for God, Ballantine Books, 2001; pp. xv-xxi.
} 
psychology. When heroes descended into the underworld (or into this one), did battle with monsters, and struggled through labyrinths, they were bringing to light that which is inaccessible to rational investigation, but which still has a profound effect on experience and behavior.

The insights which myth provided, then, were more intuitive, and held more in common with inspirations of art, music, or poetry. Myth only became reality once it was "embodied in cult, rituals and ceremonies which worked aesthetically upon worshipers, evoking within them a sense of sacred significance and enabling them to apprehend the deeper currents of experience." In fact, Armstrong points out that myth and cult are so deeply entwined that it remains a matter of scholarly debate as to which came first, the mythical narratives, or the rituals attached to them. ${ }^{27}$

She notes that in the premodern world, people had a very different view of history. They were less concerned with what had actually happened in a given event, and more concerned with what it meant. Historic events were not unique occurrences, but external manifestations of timeless realities. History always repeats itself, and it is in this cyclical observation that myth is able to carry itself forward. Whether or not the Exodus from Egypt actually happened exactly the way that it is recorded in the Bible, or, whether one demands scientific evidence that it did, all of this is to mistake the purpose of the story. This is because it confuses mythos with logos. ${ }^{28}$

Logos was the rational, pragmatic, and scientific side of mankind that helped them to function well

\footnotetext{
${ }^{27}$ ibid., p. xvi.

${ }^{28}$ ibid.
} 
in the material world. It strove to relate in an exacting fashion to external realities, and appealed for efficiency in an otherwise mundane world. In contrast to myth, logos is expressly practical. It seeks control over our environment, discovery, and new beginnings. In the premodern world, both mythos and logos were regarded as indispensible. "Each would be impoverished without the other. Yet the two were essentially distinct, and it was held to be dangerous to confuse mythical and rational discourse. They had separate jobs to do." Armstrong offers as an example the work of Pope Urban II in summoning the First Crusade in 1095. His plan belonged to the realm of logos. He wanted the knights of Europe to stop fighting each other, something which was tearing the fabric of Western Christendom apart, and to expend their energies instead by extending the power of his Church into the Middle East. But when the military expedition became bogged down with biblical lore and apocalyptic fantasies, the results were catastrophic. When logos prevailed, there were victories in battle, and prosperous colonies in the Middle East. However, when "Crusaders started making a mythical or mystical vision the basis of their policies, they were usually defeated and committed terrible atrocities."29

Logos, of course, has its limitations too. It could not comfort human sorrow, and could make no sense of tragedy. A scientist could work wonders of efficiency in the material world, but could not explain the meaning of life. That was to remain the preserve of cult and myth. ${ }^{30}$

The 9/11 attacks, among many other things, represent just such a contest between mythos and logos.

\footnotetext{
${ }^{29}$ ibid., pp. xvi-xvii.

${ }^{30}$ ibid., p. xvii.
} 
They were a mythical salvo against the logic of empire and the spread of global capital. From bin Laden's own words, we have already seen this to be true. But they also harken much more than just a simple clash of fundamentalisms. It marks a return of sorts to the crises wrought by the eighteenth century Enlightenment, when the people of Europe and America "had achieved such astonishing success in science and technology that they began to think that logos was the only means to truth and began to discount mythos as false and superstitious." As is reflected in the views noted earlier, the new world which was created out of that transition has changed the experience of religion in the modern world, with more and more people regarding scientific rationalism alone as truth. Fundamentalists respond by trying to turn their mythos into logos, and the confusion this creates, as the $9 / 11$ attacks and their aftermath certainly demonstrate, only leads to more problems. ${ }^{31}$

The extended consideration of the revival of the religious right in the current American political scene is not in the least coincidental. But neither is it a result of the 9/11 attacks. The attacks, not to mention the response they were calculated to draw out, are emblematic of the more widely felt existential crisis Armstrong points to in her introduction to The Battle for God. Though the attacks, in a strict sense, did not start anything, they remain now as an echo of a much older battle to make sense of, and impose order on, the entire world. Not at all unlike the ways that scholars may turn to myth as a way of understanding the symbolic repertoires of meaning in earlier times, conspiracy theories can be considered in ways which demonstrate the many continuities they hold with these earlier forms.

\footnotetext{
${ }^{31}$ ibid.
} 
In the case of American history, it is as simple as looking at the underlying frictions which led to its formation to see very quickly how much this is the case. It has been noted at length that the writing of the American Constitution was founded upon Enlightenment principles. The founding fathers were all too aware of the problems that arose once political and ecclesiastical power became one and the same. The separation of Church and State was much more than a handy catch-phrase. It was of utmost importance to the operation of good government. The extent to which religious and political persecution went hand in hand, when and wherever they were allowed to get that close, was not lost on those who sought to create a new country founded on the principles of liberty and equality. Provisions against this sort of 'adulterous union' that such a pairing produced, flew into the face of those for whom those 'values' led inevitably to licentiousness and moral decay.

These fears continue to play themselves out today, as President Bush moves to make Supreme Court appointments that will likely turn back many of the freedoms and liberties the Constitution was originally enshrined to protect. That there is already a whole history of conspiracy theories about the American Constitution which happen to be consistent with the paranoid style in American politics is clearly no coincidence. As a figure who embodies the paranoid rhetoric that soared to new heights after 9/11, George W. Bush has presided over a return to the primordial tensions circa 1776. The United Nations is another target of conspiratorial suspicion from the enlightened confines of paranoid thinking. Quite apart from being flagrantly disregarded anyway in the unilateral invasion of Iraq, it represents something of a long-standing 'obstacle' to American military power which 'needs to be' vanquished in the name of the very Constitution the paranoid style already holds suspect. Social Security, a 'relic' of the New Deal according to this point of view, joins a whole host 
of other "socialist" trends which undermine and otherwise detract from the "virtue' of those for whom God himself has blessed with material success.

If there is a silver lining in any of this, it is that George W. Bush is perhaps the least popular American president of the modern era, including Richard Nixon. And in the eyes of world opinion, he is the swaggering epitome of the 'ugly American.' It becomes interesting then to counterpose this relative unpopularity with the unprecedentedly brash and irresponsible foreign and fiscal policies. As insignificant a man in terms of popularity and world wide respect, he will leave a legacy which is paradoxically much more substantial. As much as this dissertation has been concerned with recording and attempting to critique his presidency, as it relates to his decisions and their consequences following $9 / 11$, this should in no way overemphasize his relatively negligible role in the execution of the attacks, despite the many conspiracy theories to the contrary. In fact, one of the things this study shows, is that the charge itself helped to buoy his public approval ratings at the very time these disastrous decisions were being made. Now, this may or may not be a coincidence; but what this study also shows is that the charge was actively deployed, from within the well-oiled Bush public relations machine, as a rather effective means of dissembling criticism.

Nor should this study unduly predicate the influence of any religious minority to a political system specifically designed to resist it. Despite the 'rabid response times' for films such as Mel Gibson's "The Passion of the Christ" and the more recent "The Chronicles of Narnia: The Lion, the Witch, and the Wardrobe," Hollywood shows no signs of selling out if the public response to "Brokeback Mountain" is any indication of popular sensibilities. As was the case in our earlier look at popular 
film in the McCarthy era, the recent "Goodnight, and Good Luck" was also quite well received. There is to be no doubt that Hollywood is already responding in kind.

And so it is in the spirit of these rather obvious examples that one must really think about what it means to contemplate the relations between conspiracy and capital. If the judicial oversight in recent years of companies such as Enron is any indication there is, at the very least, a blushing fascination between them. What is worth recalling at this point, is Weber's feeling that it was just this sort of restraint which made capitalism so successful as a social system. If this is so, then it seems there is a relation between conspiracy and capital which may in some way hinge on the concept of logic itself.

Logic is a very complex topic in the history of philosophical thought. It is, however, only the logic of the dialectic which need occupy the spotlight in the closing act. Much is made in the mythos of religion and conspiracy theory about the divine or duplicitous designs at play behind the scenes. For example, in the sphere of religion, God is angry at the world, so he sends tragedies such as 9/11 and Hurricane Katrina to signal his displeasure. That an all-seeing and all-powerful God would need to perform such colossal deeds in shadow play at once demonstrates the problems one runs into once mythos and logos are used interchangeably. But it also steps across into a belief set which gives rise to conspiracy theories, and the mystical and ubiquitous power conspirators are alleged to enjoy. Where they diverge in terms of origin and intention, they share a foundational 'cause/effect' logic which makes perfect sense in the directed ordering of the human world, but which falls apart within the dialectical logic of reality and representation. Rather than seeing religion and conspiracy theory 
in terms of 'cause' and 'effect', religion and conspiracy theory might be more accurately understood as an effect of their own cause. They create their own worlds in ways which allow them to exist at all.

Though there is no way to properly characterize all religious struggle in one handy little anecdote, it is still worth noting that nothing less than the fiat currency of global capital is also infused with its own tensions in this regard. Considering the well-documented history of American conspiratorial suspicion, it is not at all surprising that the imagery on the American dollar has itself also been the subject of conspiracy theories. Knight (ed.) $)^{32}$ points out that the unique and esoteric symbolism on the American dollar bill has long been a subject of debate and speculation for conspiracy theorists. Many who have studied this symbolism have drawn connections between it and a number of different secret or occult groups, including the Masons. For them, the incorporation of occult or Masonic symbolism into the Great Seal of the United States of America constitutes evidence that these secret societies are not only still controlling the United States right up into the present day, but are also trying to rule the world. A brief closing look at the history behind some of this symbolism is useful for what it demonstrates of the continuities which exist with the past in this regard.

After the signing of the Declaration of Independence, a decision was taken by the Second Continental Congress that a seal should be designed to mark the founding of the new nation. Several years and committees later, the design was finally approved in June of 1782. The committee which selected the Great Seal included some familiar names. These were Benjamin Franklin, John Adams,

\footnotetext{
${ }^{32}$ Knight (ed.), op. cit., pp. 226-227.
} 
and Thomas Jefferson. Significantly, Franklin and Adams, not to mention many of the founding fathers (including George Washington himself) were Masons. It would seem only natural then that the symbolism of the Great Seal would in some ways reflect the Masonic brotherhood.

The front of the seal, which appears on the right hand side of the American dollar bill, depicts an eagle which is holding and olive branch as well as arrows. Though the eagle has been a traditional symbol of American liberty for many generations, there has been speculation that the eagle on the seal was supposed to be a phoenix. The phoenix is significant, because it signifies rebirth, and has roots in the time of ancient Egyptians. It also happens to be an important symbol in the ceremonies and mythology of Freemasonry. It signifies the initiation and rebirth into the Masonic brotherhood, as well being born into a new form of wisdom. It is also the symbol of the thirty-third degree of Masonry, which is the highest level within the Scottish Rite of Masonry that members can attain. In occult circles, it is also associated with the mythical lost civilization of Atlantis.

The connection of the eagle image on the Seal to the mythical phoenix is not without some merit. Earlier versions of the Great Seal feature a bird with a long, narrow neck, and a tuft of feathers on the back of the head. Conspiracy theorists are quick to point out that these earlier depictions bear no resemblance to a bald eagle, and more closely resembles the traditional description of the phoenix. The presence of the phoenix from this perspective, then, was meant to imply that the United States would become a 'new Atlantis' guided by Masons. The plumage on this phoenix/eagle hybrid has also garnered suspicious attention. The bird has thirty-two feathers on the right wing, and thirty-three on the left, another reference to the highest level of Scottish Rite Masonry. The tail 
feathers, of which there are nine, are thought to represent the nine levels of York Rite Masonry. The scroll in the mouth of the phoenix/eagle carries the inscription "E Pluribus Unum" which translates as "From Many to One". Ordinarily, this is taken to be a reference to the uniting of the original thirteen colonies, and has also been said to reference monotheism. Conspiracy theorists, of course, see a double meaning in these words. They see it as a reference to the unity of the Masonic brotherhood, and as an indication of their intentions to bring the entire world under the control of one secret organization. In order to downplay the Masonic imagery in the eyes of the public, the eagle gradually replaced the phoenix in subsequent renditions of the Great Seal, but the tuft of feathers is still visible on the back of the eagle's head.

The other side of the Great Seal, which appears on the left side on the back of the dollar, has been considered to be even more controversial. The center of the seal is a pyramid without a capstone. Above it, also in a triangle, is the "All Seeing Eye of God," which floats above the pyramid emitting rays of light. The unfinished pyramid is itself of great significance in the symbolism of Masonry. This is because the pyramid without a top represents the loss of ancient wisdom and the connection to God. When a member attains the rank of Master Mason, they themselves become the capstone, and hence, a link to the divine. The pyramid also signifies the release of the Israelites from slavery in Egypt, and so is viewed as a symbol of freedom. On the base of the pyramid is the date 1776 in Roman numerals, the year American independence was declared. But there is a double meaning here too, for those inclined to seek them out. As noted at the beginning, it is also the year that the Illuminati was formed in Bavaria by Adam Weishaupt. A couple of other inscriptions on the back of the seal further fan the embers of conspiracy thinking. "Annuit Coeptis" translates as "He Favors 
Our Undertakings" and the other, "Novus Ordo Seclorum" as "New Order of the Ages". For conspiracy theorists, this is offered as proof of the existence of the "New World Order". It is described as a network of secret societies and organizations, each with cross-membership, which is working to create one world government under the control of a few powerful elites.

The number thirteen also has a recurring presence in many different ways on the seal. With its obvious ties to the occult, the number thirteen is seen by some as very significant. The cloud above the eagle's head contains thirteen stars. The olive branch in one of the eagle's talons has thirteen leaves, and there are thirteen arrows in the other one. The shield has thirteen stripes, and the pyramid, including the "All Seeing Eye”, has thirteen levels. Both 'E Pluribus Unum' and 'Annuit Coeptis' contain thirteen letters each. Despite the obvious references to the original thirteen colonies, this has done little to quell suspicious minds.

On the front of the bill, and unconnected to the Great Seal, are some other symbols which are also significant to Masonic initiation rituals. The seal of the United States Treasury contains the Scales of Justice, a key, and a square. All of this plays a role in fostering agreement among conspiracy theorists that Freemasons and New World Order conspirators control the leading financial institutions in the world. They further agree that the conspirators are using these institutions to exert their will on the masses, and take the presence of the symbolism on the bill as proof of this. More conventional historians, however, take a different view. Though they do agree there are without question elements of Masonic imagery in the Great Seal, they state that these elements were used, intentionally or not, because of their familiarity to its creators. 
It may be simple coincidence that Jews, as the first monotheistic religion, have historically remained at the center of so many different conspiracy theories over millennial history. It is certainly not surprising that events such as those which took place in New York and Washington would be looked at simultaneously as a strike against Zionist Christians and Jews, as well as evidence of their nefarious complicities. Whatever the debates on issues like these, there is no question that the belief in conspiracy theories is often tied up with monetary considerations, even though conspiracy and capital themselves form a pair dialectical opposites. Capital is beckoned by conspiracy as surely as its viability as a global system of exchange requires that it be avoided. What is sometimes lost between conservative and liberal positions on its operation, and which comes to be mediated by conspiracy theories, is that these networks of exchange are at their most vibrant when they are accessible to the mass, and become crippled when limited to the few.
\end{abstract}

There is also little debate that amid and behind all of the charges and counter-charges of conspiratorial intrigue, the fallout from the attacks is a towering demonstration of the problems that arise once real world action is dressed up in the garish rhetoric of apocalyticism and 'God's plan'. It is a willful confusion of mythical meaning with logical practice which the myths of history have long warned against. The myth of Sven and his deal with Thor led to the anguished realization that he already had the secret of life before it was sacrificed in selfish pursuit. It is worth taking note of the irony that the American dollar bill, as a symbolic common denominator of global capitalism, also sees with only one eye. As such, it usefully obscures real world attention from the looming financial crisis which al-Qaida is now gleefully and openly exploiting. And yet, it also does 
something else. It obstructs and interferes with the very understanding and cooperation which has always been required whenever such challenges have presented themselves in the past. Despite the symbolic blows to global economic and military power the mythos of $9 / 11$ will always represent, it remains to be seen whether the logos of lived reality prevails when it is only ever 'In God We Trust'. 


\section{Bibliography}

60 Minutes; 'Woodward Shares War Secrets', CBS.com, April 18, 2004.

9/11 Conspiracy 'Theory' or is it Reasonable Suspicion Based on Evidence, tvnewslies.org.

Ackman, Dan; 'World on Brink of Ruin', Forbes.com, January 7, 2005.

Allen, Gary; None Dare Call it Conspiracy, Concord Press: Seal Beach, Ca., 1971.

Alterman, Eric; When Presidents Lie: A History of Official Deception and its Consequences, Viking: New York, N.Y., 2004.

Althusser, Louis; \& Balibar, Étienne; Reading Capital, Verso: New York, N.Y., 1999.

Altman, Daniel; 'Help Wanted: Academic Economists, Pro-Bush', The New York Times, November 27, 2005.

Ali, Tariq; The Clash of Fundamentalisms: Crusades, Jihads and Modernity, Verso: New York, N.Y., 2002.

Anderson, Benedict; Imagined Communities: Reflections on the Origins and Spread of Nationalism, Verso Books: New York, N.Y., 1991 (orig. 1983).

Anderson, Perry; 'The Antimonies of Antonio Gramsci', New Left Review, \#100, Nov. 1976 - Jan. 1977.

Andrew, Christopher; 'Intelligence Analysis Needs to Look Backwards Before Looking Forward', History and Policy, Date unknown.

Andrew, Christopher; 'Why Lessons of the Past Can Help Fight Terror of the Future', The Scotsman, July 10, 2004.

Armstrong, Karen; Islam: A Short History, Random House: Toronto, ON., 2002

Armstrong, Karen; The Battle for God, Random House: Toronto, ON., 2000.

Armstrong, Karen; A History of God: The 4000 Year Quest of Judaism, Christianity, and Islam, Ballantine Books: New York, N.Y., 1994.

Aslan, Reza; No god but God: The Origins, Evolution, and Future of Islam, Random House: New York, N.Y., 2006. 
Associated Press, 'Bin Laden Tape Aired', The Globe and Mail, January 4, 2004.

Author Unknown; 'US is "battling Satan" says general', BBC.com, October 17, 2003.

Author Unknown; 'Conspiracy Theories: Saddam's Tanning and the Boys are Gambling', smh.com.au, July 25, 2003.

Author Unknown; 'Falwell Apologizes to gays, feminists, lesbians', CNN, September $14,2001$.

Babcock, Barbara (ed.); The Reversible World: Symbolic Inversion in Art and Society, Cornell University Press: Ithaca, N.Y., 1978.

Baker, Brent; 'GAROFALO ON BUSH: "It Is... a Conspiracy of the $43^{\text {rd }}$ Reich"', FreeRepublic.com, August 21, 2003.

Bakhtin, Mikhail M; Rabelais and His World, Indiana University Press: Indianapolis, Ind., 1984.

Barbour, Benjamin R.; Jihad vs. McWorld: Terrorism's Challenge to Democracy, Ballantine Books: New York, N.Y., 2001.

Barstow, David; 'Skewed Intelligence Data in March to War in Iraq', The New York Times, October 3, 2004.

Barthes, Roland; Mythologies (Trans. by Anne Lavers), Hill and Wang: New York, N.Y., 1995.

Baudrillard, Jean; The Spirit of Terrorism (Trans. by Chris Turner), Verso: New York, N.Y., 2002.

Baudrillard, Jean; Simulations (Trans. by Paul Foss, Paul Patton, and Philip Beitchman), Semiotext(e): New York, N.Y., 1983.

Beaud, Michel; A History of Capitalism: 1500-2000, Monthly Review Press: New York, N.Y., 2001.

Becker, Elizabeth; \& Andrews, Edmund L.; 'I.M.F. Report Says U.S. Deficits Threaten World Economy', The New York Times, January 7, 2004.

Belton, Catherine; 'Putin: Why Not Price Oil in Euros?', The Moscow Times, October 10, 2003.

Bennis, Phyllis; Before and After: U.S. Foreign Policy and the War on Terrorism, Olive Branch Press: New York, N.Y., 2003. 
Bergen, Peter; 'Laurie Mylroie: The Neocons' Favorite Conspiracy Theorist', Washington Monthly; December 2003.

Berman, Ari; 'Polls Suggest Media Failure in Pre-War Coverage', Editor and Publisher, March 26, 2003.

Berman, Marshall; All That is Solid Melts into Air: The Experience of Modernity, Penguin Books: New York, N.Y., 1988.

Blum, William; Killing Hope: U.S. Military and C.I.A. Interventions Since World War II, Common Courage Press: Monroe, ME., 2004.

Blumenthal, Max; 'The Avenging Angel of the Religious Right', Salon; January 6, 2004.

Booth, Ken; \& Dunne, Tim (eds.); Worlds in Collision: Terror and the Future of Global Order, Palgrave Macmillan: New York, N.Y., 2002.

Borger, Julian; 'The Spies Who Pushed for War', The Guardian, July 17, 2003.

Borger, Julian; 'Staff Cry Poetic Injustice as Singing Ashcroft Introduces Patriot Games', The Guardian, March 4, 2002.

Borradori, Giovanna; Philosophy in a Time of Terror: Dialogues with Jürgen Habermas and Jacques Derrida, University of Chicago Press: Chicago, Ill., 2003.

Bottomore, Tom (ed.); A Dictionary of Marxist Thought, Harvard: Cambridge, Mass., 1983.

Bourke, John; 'Bush Conspiracy Theories', Pravda, November 24, 2003.

Bowers, Simon; 'Buffett Attacks American Spending Junkies', The Guardian, March 7, 2005.

Brethour, Patrick; 'OPEC Mulls Move to Euro for Pricing Crude Oil', The Globe and Mail, January 12, 2004.

Broderick, J.; The Economic Morals of the Jesuits: An Answer to H.H. Robertson, Oxford University Press: Oxford, U.K., 1934.

Campbell, Joseph; Primitive Mythology: The Masks of God, Penguin: New York, N.Y., 1991.

Cannadine, David; 'Halloween v Guy Fawkes Day', BBC, November 4, 2005.

CBC News; 'U.S. Living Beyond Means, Dodge Warns', CBC.ca, May 30, 2005. 
Chomsky, Noam; Hegemony or Survival: America's Quest for Global Dominance, Henry Holt and Company: New York, N.Y., 2004.

Chomsky, Noam; 9-11, Seven Stories Press: New York, N.Y., 2001.

Chomsky, Noam; Media Control: The Spectacular Achievements of Propaganda, Seven Stories Press: New York, N.Y., 1997.

Clark, William R.; 'Battle of the Currencies - The Real Reasons for the War on Iraq', The Guardian (Australia), February 26, 2003.

Clarke, Richard A.; Against All Enemies: Inside America's War on Terror, Free Press: New York, N.Y., 2004.

Clarkson, Frederick; 'On Ten Commandments Bill, Religious Right has it Wrong', The Christian Science Monitor, April 21, 2004.

CNN Wire, 'Union: Nigerian Police Kill 10', CNN.com, July 7, 2003.

Cockburn, Alexander; \& St. Clair, Jeffrey (eds.); The Politics of Anti-Semitism, AK Press: Oakland, Ca., 2003.

Cohn, Norman; Cosmos, Chaos, and the World to Come: The Ancient Roots of Apocalyptic Faith, Yale University Press: New Haven, Conn., 1993.

Cohn, Norman; The Pursuit of the Millennium: Revolutionary Millenarians and Mystical Anarchists in the Middle Ages, Temple Smith: London, U.K., 1970 (Orig. 1957).

Cohn, Norman; Warrant for Genocide: The Myth of the Jewish World-Conspiracy and the Protocols of the Elders of Zion, Eyre \& Spottiswoode: London, U.K., 1967.

Coll, Steve; Ghost Wars: The Secret History of the CIA, Afghanistan, and Bin Laden, from the Soviet Invasion to September 10, 2001, Penguin Books: New York, N.Y., 2004.

Coman, Julian; 'Fury Over Pentagon Cell that Briefed White House on Iraq's 'Imaginary' al-Qaeda Links', The Telegraph, July 12, 2004.

Cooperman, Alan; 'DeLay Criticized for "Only Christian" Remarks', The Washington Post, April 20, 2002 [A05].

Coulter, Ann; 'Wilson Lied, Kids Died', townhall.com, July 15, 2004.

Crowley, David; \& Mitchell, David (eds.); Communication Theory Today, Stanford University Press: Stanford, Ca., 1994. 
Cubitt, Geoffrey, The Jesuit Myth: Conspiracy Theory and Politics in NineteenthCentury France, Clarendon Press: Oxford, U.K., 1993.

Davis, David Brion (ed.); The Fear of Conspiracy: Images of Un-American Subversion from the Revolution to the Present, Cornell University Press: Ithaca, New York, N.Y., 1971.

Dean, Jodi (ed.); Cultural Studies and Political Theory, Cornell University Press: Ithaca, New York, N.Y., 2000.

Dean, Jodi; Aliens in America: Conspiracy Cultures from Outerspace to Cyberspace, Cornell University Press: Ithaca, New York, N.Y., 1998.

DeLillo, Don; Libra, Viking: New York, N.Y., 1988.

Denning, Michael; The Cultural Front, Verso: New York, N.Y., 1998.

Diamond, Jared; Collapse: How Societies Chose to Fail or Succeed, Viking: New York, N.Y., 2005.

Diamond, Jared; Guns, Germs, and Steel: The Fates of Human Societies, Norton: New York, N.Y., 1999.

Domhoff, G. William; The Bohemian Grove and Other Retreats: A Study in RulingClass Cohesiveness, Harper and Row: New York, N.Y., 1974.

Domke, David; 'Bush, God, and the Media: How the president has used religion to control American politics', Mediatransparency.org, March 7, 2005.

Domke, David; \& Coe, Kevin; 'Bush Changes White House Rhetoric about God', Seattle Post-Intelligencer, January 19, 2005.

Downie, Gordon; Coke Machine Glow, Vintage Books: Toronto, ON., 2001.

Dreyfuss, Robert; 'Reverend Doomsday: According to Tim LaHaye, The Apocalypse is Now'; Rolling Stone, January 28, 2004.

Drury, Shadia B.; Leo Strauss and the American Right, St. Martin's Press: New York, N.Y., 1999.

Dyer-Witherford, Nick; Cyber-Marx: Cycles and Circuits of Struggle in HighTechnology Capitalism, University of Illinois Press: Urbana and Chicago, Ill., 1999.

Eco, Umberto; Foucault's Pendulum, Random House: Toronto, ON., 1988. 
Eagleton, Terry; The Illusions of Postmodernism, Blackwell Publishers: Malden, Mass., 1997.

Eagleton, Terry; Ideology: An Introduction, Verso: New York, N.Y., 1991.

Eagleton, Terry; Walter Benjamin or Towards a Revolutionary Criticism, Verso: London, U.K., 1981.

Editor and Publisher Staff; 'Harris Survey: Many Americans Still Think Saddam Was Behind 9/11', Editor and Publisher, December 29, 2005.

Engle, Matthew; 'Meet the New Zionists', The Guardian; October 28, 2002.

Femia, Joseph V.; Gramsci's Political Thought: Hegemony, Consciousness, and the Revolutionary Process, Oxford University Press, 1981.

Fenster, Mark; Conspiracy Theories: Secrecy and Power in American Culture, University of Minnesota Press: Minneapolis, Minn., 1999.

Ferguson, Niall; Colossus: The Rise and Fall of the American Empire, Penguin Books: New York, N.Y., 2004.

Ferguson, Niall; Empire: The Rise and Demise of the British World Order and the Lessons for Global Power, Basic Books: New York, N.Y., 2004.

Ferguson, Niall; The Cash Nexus: Money and Power in the Modern World, 1700-2000, Basic Books: New York, N.Y., 2001.

Fineman, Howard; 'Religion: Apocalyptic Politics', Newsweek; May 24, 2004.

Fisk, Robert; The Great War for Civilization: The Conquest of the Middle East, Fourth Estate: London, U.K., 2005.

Fiske, John; Understanding Popular Culture, Routledge; New York, N.Y., 1994.

Fiske, John; Reading the Popular, Unwin Hyman; Cambridge, Mass., 1989.

Fitrakis, Bob; 'Diebold. Electronic Voting, and the Vast Right-Wing Conspiracy', Common Dreams; September 3, 2005.

Foucault, Michel; Society Must be Defended: Lectures at the College de France 19751976, Picador: New York, N.Y., 2003.

Foucault, Michel; The Order of Things, Routledge: New York, N.Y., 2002. 
Foucault, Michel; Discipline and Punish: The Birth of the Prison, Vintage: New York, N.Y., 1995.

Foucault, Michel; Power/Knowledge: Selected Interviews \& Other Writings, 1972 1977 (ed. Colin Gordon), Pantheon; New York, N.Y., 1980.

Garnham, Nicholas; Emancipation, the Media, and Modernity: Arguments about the Media and Social Theory, Oxford University Press: New York, N.Y., 2000.

George, Liz; 'Is Oil Drawing Bush to Nigeria?', CNN.com, July 7, 2003.

Gitlin, Todd; 'Prime Time Ideology: The Hegemonic Process in Television Entertainment' in Television: The Critical View [5th ed.] (Horace Newcomb, ed.), Oxford University Press: New York, N.Y., 1994.

Gitlin, Todd; The Whole World is Watching: Mass Media in the Making and Unmaking of the New Left, University of California Press: Berkeley, Ca., 1980.

Glazov, Jamie; 'Saddam and 9/11', FrontPageMagazine.com, January 8, 2004.

Gluckman, Max; Custom and Conflict in Africa, Basil Blackwell: Oxford, U.K., 1973 (orig. 1956).

Gluckman, Max; Order and Rebellion in Tribal Africa: Collected Essays with an Autobiographical Introduction, Cohen \& West: London, U.K., 1963.

Goldberg, Robert Alan; Enemies Within: The Culture of Conspiracy in Modern America, Yale University Press: New Haven, Conn., 2001.

Goodman, Amy; 'President Bush Arrives in Nigeria Today', DemocracyNow.org, July $11,2003$.

Gramsci, Antonio (edited and trans. by Quinton Hoare \& Geoffrey Nowell Smith); Selections from the Prison Notebooks, International Publishers: New York, N.Y., 1999.

Gramsci, Antonio (edited by David Forgacs \& Geoffrey Nowell Smith, trans. by William BoelHower); Selections from Cultural Writings, Harvard University Press: Cambridge, Mass., 1985.

Grauman, Carl F.; \& Moscovici, Serge (eds.); Changing Conceptions of Conspiracy, Springer-Verlag: New York, N.Y., 1987.

Hall, Anthony J.; The American Empire and the Fourth World: The Bowl With One Spoon, Part One, McGill-Queens University Press: Ithaca, N.Y., 2003. 
Hallow, Ralph Z; 'DeLay to Offer Own Hill Agenda', The Washington Times; March 8, 2004.

Hardt, Michael; \& Negri, Antonio; Empire, Harvard University Press: Cambridge, Mass., 2000.

Harvey, David; Spaces of Capital: Towards a Critical Geography, Routledge: New York, N.Y., 2001.

Harvey, David; Spaces of Hope, University of California Press: Berkeley, Ca., 2000.

Harvey, David; The Condition of Postmodernity, Blackwell Publishers: Malden, Mass., 2000 (orig. 1990).

Hauerwas, Stanley; \& Lentricchia, Frank (eds.); Dissent from the Homeland: Essays after September 11, Duke University Press: Durham, N.C., 2002.

Herling, James; \& Clark, Simon; 'Bill Gates, World's Richest Man, Bets Against Dollar', Bloomberg.com, January 29, 2005.

Herman, Edward; 'The Media and the U.S. Political Economy' (pp. 77-93), in Questioning the Media: A Critical Introduction (eds. John Downing, Ali Mohammadi, \& Annabelle Sreberny-Mohammadi), Sage: Thousand Oaks, Ca., 1995.

Hofstadter, Richard; “The Paranoid Style," in The Paranoid Style in American Politics and Other Essays (pp. 3-40), Alfred A. Knopf: New York, N.Y., 1966.

Holliday, Stacey; 'Ron Reagan Disguised Pro-Cloning Message Behind Research Label, Says Dr, Janice Crouse', Concerned Women For America; July 28, 2004.

Holquist, Michael (ed.); The Dialogic Imagination: Four Essays by M.M. Bakhtin (Trans. by Caryl Emerson and Michael Holquist), University of Texas Press: Austin, Tx., 2004.

Holquist, Michael; Dialogism, Routledge: New York, N.Y., 2004.

Horkheimer, Max; \& Adorno, Theodor; The Dialectic of Enlightenment (ed. Gunzelin Schmid Noerr; trans. by Edmund Jephcott), Stanford University Press: Stanford, Ca., 2002.

Ince, John; 'America's Debt Time Bomb', Alternet.org, December 1, 2005.

Inter Press Service; 'Bush's Safari to Benefit U.S. Investors', AEGIS.com, July 9, 2003. 
Isermann, Ralf; '9/11 Conspiracy Theories Gain Ground', iafrica.com, September 8, 2003.

Ives, Peter; Gramsci's Politics of Language: Engaging the Bakhtin Circle and the Frankfurt School, University of Toronto Press: Toronto, ON., 2004.

Ives, Peter; Language \& Hegemony in Gramsci, Pluto Press: London, U.K.., 2004.

Jacobs, Jane; The Nature of Economies, Random House: Toronto, ON., 2000.

Jacoby, Mary; 'The Gospel According to Karl', Salon Magazine; July 6, 2004.

Jameson, Fredric; "Totality as Conspiracy", in The Geopolitical Aesthetic: Cinema and Space in the World System (pp.1-35), Indiana University Press: Bloomington, Indiana, 1992.

Jameson, Fredric; Postmodernism, or The Cultural Logic of Late Capitalism (pp. 1-54 \& 340-56), Duke University Press: Durham, North Carolina, 1991.

Johannsen, Tom; 'Whitewashing the Project for a New American Century: "If you can't Beat it Feature it" - Part 1', Prisonplanet.com.

Jordan, Lara Jakes; 'Rice Defends Bush's Katrina Response', San Francisco Gate Online; September 4, 2005.

Kahane, Howard; Logic and Philosophy (4th ed.), Wadsworth: Belmont, Ca., 1982.

Karim, Karim H.; Islamic Peril: Media and Global Violence, Black Rose Books: Montreal, P.Q., 2003.

Kean, Thomas (Chair); \& Hamilton, Lee (Vice-Chair); The 9/11 Report: The National Commission on Terrorist Attacks Upon the United States, St. Martin's Paperbacks: New York, N.Y., 2004.

Kellner, Douglas; Media Culture: Cultural Studies, Identity and Politics Between the Modern and the Postmodern, Routledge: New York, N.Y., 1995.

Kellner, Douglas; Television and the Crisis of Democracy, Westview: Boulder, Co., 1990.

Kingwell, Mark; Dreams of Millennium: Report from a Culture on the Brink, Viking: Toronto, ON., 1995.

Klare, Michael T.; Blood and Oil: The Dangers and Consequences of America's Growing Dependency on Imported Petroleum, Owl Books: New York, N.Y., 2004. 
Klein, Naomi; No Logo: Taking Aim at the Brand Bullies, Vintage Books: Toronto, ON., 2000.

Knight, Peter (ed.); Conspiracy Theories in American History: An Encyclopedia, ABCCLIO: Oxford, U.K., 2003.

Knight, Peter (ed.); Conspiracy Nation: The Politics of Paranoia in Postwar America, New York University Press, New York, N.Y., 2002.

Knight, Peter; Conspiracy Culture: From Kennedy to the X-Files, Routledge: New York, N.Y., 2000.

Krugman, Paul; 'Weak on Terror', The New York Times, March 16, 2004.

Krugman, Paul; 'The Awful Truth', The New York Times, January 13, 2004.

Kwiatkowski, Karen; 'The New Pentagon Papers', Salon.com, March 10, 2004.

Laclau, Ernesto; \& Mouffe, Chantal; Hegemony and Socialist Strategy, Verso; New York, N.Y., 2001.

Laclau, Ernesto; Butler, Judith; \& Zizek, Slavoj; Contingency, Hegemony, Universality, Verso; New York, N.Y., 2000.

Lohor, Josephine; Okocha, Chuks; Isiekwenagbu, Ify; 'Bush Arrives as Nigerian Oil Reserves Climb', This Day/All Africa Global Media, July 11, 2003.

Latour, Bruno; Pandora's Hope: Essays on the Reality of Science Studies, Harvard University Press: Cambridge, Mass., 1999.

Lawrence, Bruce (ed.); Messages to the World: The Statements of Osama bin Laden (trans. by James Howarth), Verso: New York, N.Y., 2005.

Lederer, Edith M.; 'China Has Lost Faith in Stability of U.S. Dollar, Top Chinese Economist Says at World Forum', Associated Press, January 26, 2005.

Lipsitz, George; Time Passages: Collective Memory and American Popular Culture, University of Minnesota Press: Minneapolis, Minn., 1990.

Lotringer, Sylvère (ed.); Foucault Live: Collected Interviews, Semiotext(e): New York, N.Y., 1996.

Lukács, Georg; History and Class Consciousness: Studies in Marxist Dialectics (trans. by Rodney Livingstone), MIT Press: Cambridge, Mass., 1971 (orig. 1968). 
McChesney, Robert W.; 'The Global Media Giants' (pp. 159 - 170), in Critical Studies in Media Commercialism (eds. Robin Andersen \& Lance Strate), Oxford: New York, N.Y., 2000.

McCullagh, Declan; 'There's Something About Gary', Wired; January 7, 1999.

McQuaig, Linda; It's the Crude, Dude: War, Big Oil, and the Fight for the Planet, Anchor Books: Canada, 2005.

Mackay, Charles; Extraordinary Popular Delusions \& the Madness of Crowds, Three Rivers Press: New York, N.Y., 1980.

MacMillan, Margaret; Paris 1919: Six Months that Changed the World, Random House: New York, N.Y., 2003.

Marlin, Randall; Propaganda \& the Ethics of Persuasion, Broadview Press: Toronto, ON., 2003.

Martin, David; 'Plans for Iraq Attack Began on 9/11', CBSnews.com, September 4, 2002.

Marx, Karl; The German Ideology, Prometheus Books: New York, N.Y., 1998.

Marx, Karl; \& Engels, Frederick; The Communist Manifesto, Verso: New York, N.Y., 1998.

Marx, Karl; Grundrisse, Penguin Books: New York, N.Y., 1993.

Marx, Karl; Capital: Volume 1, Penguin Books: New York, N.Y., 1990.

Mattleart, Armand; Mapping World Communications: War, Progress, Culture, University of Minnesota Press: Minneapolis, Minn., 1994.

Machiavelli, Niccolò; The Prince, Oxford University Press: New York, N.Y., 1998.

Maich, Steve; 'Is America Going Broke?: Record deficits, colossal debt and no clear plan for digging itself out. If the U.S. sinks, it will take Canada down with it.', MacLean's, March 2, 2005.

Meyer, Josh; 'Saudi Government Provided Aid to 9/11 Hijackers, Sources Say', The Los Angeles Times, August 2, 2003.

Monbiot, George; 'Their Beliefs are Bonkers, But They Are at the Heart of Power: US Christian Fundamentalists are Driving Bush's Middle East Policy', The Guardian; April 20, 2004. 
Morton, Bruce; 'Selling an Iraq-al Qaeda Connection: Some Critics Blame TV News for Making Baghdad New Enemy', CNN.com, March 11, 2003.

Mosco, Vincent; The Digital Sublime: Myth, Power and Cyberspace, MIT Press: Cambridge, Mass., 2004.

Mosco, Vincent; The Political Economy of Communication, Sage: Thousand Oaks, Ca., 1996.

Moyers, Bill; 'There is No Tomorrow', Minneapolis StarTribune; January 30, 2005.

Mulgan, G.J.; Communication and Control: Networks and the New Economics of Communication, Guilford: New York, N.Y., 1991.

Munck, Ronaldo; Marx@ 2000: Late Marxist Perspectives, Zed Books: New York, N.Y., 2000.

North, Oliver; 'Conspiracy Theories', Townhall.com, January 2, 2004.

Nyberg, David; The Unvarnished Truth: Truth Telling and Deceiving in Ordinary Life, University of Chicago Press: Chicago, Il., 1994.

Office of the Press Secretary, Press Briefing on Iraq WMD and SOTU Speech, White House.gov, July 22, 2003.

Office of the Press Secretary; President Bush Discusses Upcoming Africa Trip with Reporters, White House.gov, July 3, 2003.

Office of the Press Secretary; Press Briefing with Ari Fleischer, White House.gov, April 10, 2003.

Office of the Press Secretary, President Says Saddam Hussein Must Leave Iraq Within 48 Hours, White House.gov, March 17, 2003.

Office of the Press Secretary; President Delivers "State of the Union", White House.gov, January 28, 2003.

Ollman, Bertell; Dance of the Dialectic: Steps in Marx's Method: University of Illinois Press: Chicago, Ill., 2003.

Oneal, Michael; 'Deficits a Growing Danger: How long will global investors finance U.S. spending?', Chicago Tribune, January 2, 2005. 
Palast, Greg; 'OPEC and the Economic Conquest of Iraq: Why Iraq Still Sells its Oil a la Cartel - Twilight of the neocon gods', Harper's Magazine, October 24, 2005.

Palast, Greg; 'Baghdad Coup D'Etat for Big Oil', Harper's Magazine, March 25, 2005.

Palast, Greg; 'Secret US Plans for Iraq's Oil', BBC, March 17, 2005.

Panitch, Leo; \& Leys, Colin (eds.); The Empire Reloaded: Socialist Register 2005, Merlin Press: London, U.K., 2004.

Panitch, Leo; \& Leys, Colin (eds.); The New Imperial Challenge: Socialist Register 2004, Merlin Press: London, U.K., 2003.

Pappe, Ilan; A History of Modern Palestine: One Land, Two Peoples: Cambridge University Press, New York, N.Y., 2004.

Perlstein, Rick; 'The Jesus Landing Pad: Bush White House Checked with Rapture Christians Before Latest Israel Move', The Village Voice; May 18, 2004.

Popper, Karl; "Prediction and Prophecy in the Social Sciences," in Conjectures and Refutations (pp.336-46), Harper and Row: New York, N.Y., 1963.

Popper, Karl; "Towards a Rational Theory of Tradition," in Conjectures and Refutations (pp.120 - 135), Harper and Row: New York, N.Y., 1963.

Pincus, Walter; and Allen, Mike; 'CIA Got Uranium Reference Cut in Oct.: Why Bush Cited it in Jan. Is Unclear', The Washington Post, July 13, 2003 [A01].

Pincus, Walter; 'White House Backs Off Claim on Iraqi Buy', The Washington Post, July 8, 2003 [A01].

Pincus, Walter; 'Report Cast Doubt on Iraq-Al Qaeda Connection', The Washington Post, June 22, 2003 [A01].

Pincus, Walter; 'CIA Says it Cabled Key Data to White House', The Washington Post, June 13, 2003 [A16].

Pitt, William Rivers; 'George W. Christ', Truthout.org, May 05, 2003.

Project for the New American Century, 'Open Letter to the Honorable William J. Clinton', Project for the New American Century.org, January 26, 1998.

Ralston Saul, John; The Unconscious Civilization, Anansi Press: Toronto, ON., 1995. 
Report on the U.S. Intelligence Community's Prewar Intelligence Assessments on Iraq, July 7, 2004; pp. 282-283.

Recknagel, Charles; 'Iraq: Baghdad Moves to Euro', Radio Free Europe, November 1, 2000 .

Reuters, 'Dollar Sinks, SKorea Reserve Shift Weighs', The New York Times, February $22,2005$.

Reuters; 'Reuters Sees Touched Up Bodies of Saddam Sons', Reuters, July 25, 2003.

Rich, Frank; 'Never Forget What?', The New York Times, September 14, 2002.

Richey, Warren; 'Muslim Opinion Sees Conspiracy', Christian Science Monitor, November 6, 2001.

Risen, James; 'C.I.A. Aides Feel Pressure in Preparing Iraqi Reports', The New York Times, March 23, 2003.

Ritsch, Fritz; 'Of God, and Man, in the Oval Office', The Washington Post, March 2, 2003 [B03].

Roff, William R. (ed.); Islam and the Political Economy of Meaning: Comparative Studies of Muslim Discourse, Croom Helm: London, U.K., 1987.

Roth, Philip; The Plot Against America: A Novel, Houghton Mifflin: New York, N.Y., 2004.

SA Wire, 'Oil Tops Bush's Nigeria Visit', NEWS24.com, July 12, 2003.

Said, Edward; Culture and Resistance: Conversations with Edward Said, South End Press: Cambridge, MA., 2003.

Said, Edward; Orientalism, Vintage Books: New York, N.Y., 1994.

Said, Edward; Culture and Imperialism, Vintage Books: New York, N.Y., 1994.

Scalia, Antonin; 'God's Justice and Ours', First Things Journal of Religion, Culture, and Public Life, May, 2002.

Schiller, Herbert I.; Culture Inc.: The Corporate Takeover of Public Expression, Oxford University Press: Toronto, ON., 1989.

Sharabi, Hisham; Theory, Politics and the Arab World: Critical Responses, Routledge: New York, N.Y., 1990. 
Sharlet, Jeffrey; ‘Jesus Plus Nothing’, Harper's Magazine; March 2003.

Shermer, Michael; Why People Believe Weird Things, Owl Books: New York, N.Y., 2002 .

Signatories Listed in Text; 'Open Letter to George W. Bush', Project for the New American Century, September 20, 2001.

Showalter, Elaine; Hystories: Hysterical Epidemics and Modern Culture, Columbia University Press: New York, N.Y., 1997.

Solomon, Norman; \& Erlich, Reese; Target Iraq: What the News Media Didn't Tell You, Context Books: New York, N.Y., 2003.

Stallybrass, Peter; \& White, Allon; The Politics and Poetics of Transgression, Cornell University Press: Ithaca, N.Y., 1986.

Suskind, Ron; The Price of Loyalty: George W. Bush, the White House, and the Education of Paul O'Neill, Simon and Shuster Paperbacks: New York, N.Y., 2004.

Tawney, R. H.; Religion and the Rise of Capitalism: An Historical Study, John Murray: London, U.K., 1964.

Taylor, Gary; Cultural Selection: Why Some Achievements Survive the Test of Time-And Others Don't, Basic Books; New York, N.Y., 1996.

Thatcher Dowell, William; 'Made-in-America Wahhabism: The Christian right is our own brand of extremism', The Los Angeles Times, March 8, 2005.

Thompson, John B.; The Media and Modernity: A Social Theory of the Media, Stanford University Press: Stanford, Ca., 1995.

Thompson, John B.; Ideology and Modern Culture, Stanford University Press: Stanford, Ca., 1990.

Timeline of Official Quotes on Iraqi WMD; knoxnews.com. Accessed on February 7, 2004.

Vološinov, V.N.; Marxism and the Philosophy of Language (Trans. by Ladislav Matejka and I.R. Titunik), Harvard University Press: Cambridge, Mass., 1986.

Weber, Max; The Protestant Ethic and the Spirit of Capitalism (Trans. by Talcott Parsons), Charles Scribner's Sons: New York, N.Y., 1958. 
Williams, Raymond; Television: Technology and Cultural Form, Schocken Books: New York, N.Y., 1975.

Wilson, Joseph C.; 'What I Didn't Find in Africa', The New York Times, July 6, 2003.

WMD Quotes Before \& After the Invasion, ActiveOpposition.com. Accessed on June 8, 2003.

Woodward, Bob; Bush at War, Simon \& Schuster: New York, N.Y., 2003.

Yurica, Katherine; 'The Despoiling of America: How George W. Bush Became the Head of the New American Dominionist Church/State', The Yurica Report; February $11,2004$. 